\title{
Evaluation of High Temperature Gas-Cooled Reactor Physics Experiments as VHTR Benchmark Problems
}

prepared by

Nuclear Engineering Division

Argonne National Laboratory 


\section{About Argonne National Laboratory}

Argonne is managed by The University of Chicago for the U.S. Department of Energy under contract W-31-109-Eng-38. The Laboratory's main facility is outside Chicago, at 9700 South Cass Avenue, Argonne, Illinois 60439. For information about Argonne and its pioneering science and technology programs, see www.anl.gov.

\section{Availability of This Report}

This report is available, at no cost, at http://www.osti.gov/bridge. It is also available on paper to U.S. Department of Energy and its contractors, for a processing fee, from:

U.S. Department of Energy

Office of Scientific and Technical Information

P.O. Box 62

Oak Ridge, TN 37831-0062

phone (865) 576-8401

fax (865) 576-5728

reports@adonis.osti.gov

\section{Disclaimer}

This report was prepared as an account of work sponsored by an agency of the United States Government. Neither the United States Government nor any agency thereof, nor The University of Chicago, nor any of their employees or officers, makes any warranty, express or implied, or assumes any legal liability or responsibility for the accuracy, completeness, or usefulness of any information, apparatus, product, or process disclosed, or represents that its use would not infringe privately owned rights. Reference herein to any specific commercial product, process, or service by trade name, trademark, manufacturer, or otherwise, does not necessarily constitute or imply its endorsement, recommendation, or favoring by the United States Government or any agency thereof. The views and opinions of document authors expressed herein do not necessarily state or reflect those of the United States Government or any agency thereof, Argonne National Laboratory, or The University of Chicago. 


\section{Evaluation of High Temperature Gas-Cooled Reactor Physics Experiments as VHTR Benchmark Problems}

by

T.A. Taiwo, T.K. Kim, W.S. Yang, and H.S. Khalil

Nuclear Engineering Division, Argonne National Laboratory

W.K. Terry, J. Blair Briggs, and D.W. Nigg

Idaho National Laboratory

September 15, 2005
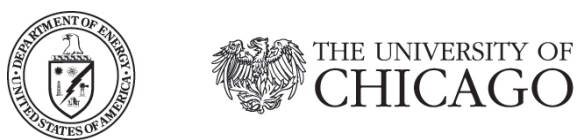

Argonne National Laboratory is managed by

The University of Chicago for the U.S. Department of Energy 


\section{Evaluation of High Temperature Gas-Cooled Reactor Physics Experiments as VHTR Benchmark Problems}

T. A. Taiwo, T. K. Kim, W. S. Yang, and H. S. Khalil

Nuclear Engineering Division 9700 South Cass Avenue

Argonne National Laboratory

Argonne, IL 60439

W. K. Terry, J. Blair Briggs, and D. W. Nigg

P. O. Box 1625

Idaho National Laboratory

Idaho Falls, ID 83415

September 15, 2005 
ANL-GenIV-059 


\section{Table of Contents}

- EXECUTIVE SUMMARY

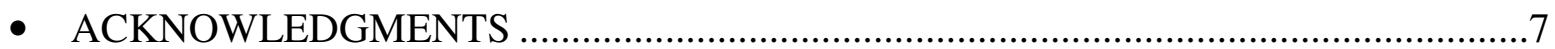

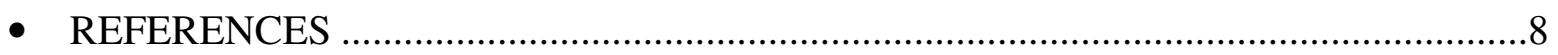

- EVALUATION OF THE COMPACT NUCLEAR POWER SOURCE (CNPS) CRITICAL EXPERIMENTS

- EVALUATION OF THE HIGH TEMPERATURE ENGINEERING TEST REACTOR (HTTR) START-UP EXPERIMENTS

- EVALUATION OF THE INITIAL CRITICAL CONFIGURATION OF THE HTR-10 PEBBLE-BED REACTOR 
ANL-GenIV-059 


\section{EXECUTIVE SUMMARY}

\section{Background}

The Very High Temperature Reactor (VHTR) is a leading candidate for the Next Generation Nuclear Plant (NGNP) because of its high temperature and passive safety design, and its potential for efficient electricity and hydrogen generation. The physics characteristics of this system is quite different from that of operating light-water-cooled reactors (LWRs) because of the use of (1) an annular core design, (2) solid graphite moderator, (3) higher enrichment of the uranium fuel, and (4) TRISO fuel particles. Consequently, a suite of core physics models and analysis tools different from those utilized for analyzing the LWRs are required for accurately representing the physics of the VHTR. These models have typically been based on Monte Carlo codes and associated libraries, or the deterministic code systems (lattice physics and whole-core analysis codes) that can accurately represent the core physics impacts of the coated fuel particles (CFPs), neutron streaming along channels (prismatic block-type) or at core top (pebble-type), and inner reflector-core interface in the annular VHTR core design. These models and analysis tools must be verified and validated to ensure their accuracy, quantify their prediction uncertainties and support their use in VHTR design, safety confirmation and licensing.

The verification and validation $(\mathrm{V} \& \mathrm{~V})$ of the code packages is typically done in two ways. The first, verification, is the assurance that the code actually performs as designed, i.e., it solves accurately the equations that represent the physical phenomena occurring in the systems. This step is typically accomplished by model and software inspection, and by comparing code solutions to analytical solutions for simple problems, or to solutions from previously verified and validated codes, or to solutions from higher fidelity codes. The second step of validation gives the assurance that the models employed can provide physically valid representations of the system characteristics and can be used to derive core parameters. This step is usually accomplished by comparing calculated results to experimental measurements or results of models that have already been validated against relevant measurements.

To implement and qualify the neutronics analysis tools for the NGNP/VHTR, the Gen IV program includes the following activities: 
- Nuclear data assessment by uncertainty and target accuracy studies.

- Survey of existing data and development of benchmark database for VHTR code validation and qualification.

- Assessment and development of analysis tools for lattice and whole-core physics calculations.

In FY 2004, ANL and INL examined information on several past and present experimental and prototypical facilities based on HTGR concepts that could potentially be used for the $\mathrm{V} \& \mathrm{~V}$ basis of codes employed in the design and analysis of the VHTR cores. A preliminary assessment of the applicability of the existing test data for benchmarking the pebble-bed and prismatic block-type cores was performed as part of that effort. The experiments assessed included [1]

- Pebble-bed type cores: ASTRA, AVR, CESAR II, GROG, HTR-10, HTR-PROTEUS, KAHTER, SAR, and THTR, and

- Prismatic block-type cores: CNPS, DRAGON, Fort St. Vrain, GGA HTGR criticals, HITREX-1, HTLTR, HTTR, MARIUS-IV, Peach Bottom HTGR, Peach Bottom Criticals, SHE, NESTOR/HECTOR, and VHTRC.

The FY 2004 preliminary evaluation revealed that the VHTR systems under development in the Gen IV program differ in significant ways from previous high-temperature reactors (e.g., thorium utilization, highly enriched fuel, BISO versus TRISO fuel, thermal efficiency, operating temperatures, etc). These differences limit the applicability and direct usefulness of some of the existing experimental data for NGNP core designs. Furthermore, it was acknowledged that for data produced on commercial basis or by foreign governments, availability of the data might be quite limited. An effort was made to identify experimental tests of the highest priority, recover the data for those cases, and then develop standard problems (benchmarks) that are of sufficient quality for use in the licensing of the VHTR analysis codes. A set of criteria was employed to judge the relevance of the different tests. These included, purpose of the previous experiment, geometry of core, fuel forms, core materials, physics parameters measured, measurement state, 
availability of design and uncertainty data, and applicability of data to V\&V. Based on these criteria, the experiments judged to be of the highest priorities are:

- ASTRA, AVR, HTR-10, HTR-PROTEUS for the pebble-bed cores and

- HTTR, VHTRC, and CNPS for the prismatic block-type cores.

Some attributes of these facilities and experimental tests are summarized in Table 1.

Table 1. High Priority Experiments of Potential Interest to VHTR Systems. [1]

\begin{tabular}{|l|l|l|l|l|l|l|}
\hline Facility & Geometry & Size & Fuel type & $\begin{array}{l}\text { Asymptotic } \\
\text { state or } \\
\text { zero-power } \\
\text { startup }\end{array}$ & $\begin{array}{l}\text { Availability of } \\
\text { data }\end{array}$ & Priority \\
\hline Pebble-Bed Reactor Type & $\begin{array}{l}\text { Annular, but } \\
\text { not } \\
\text { azimuthally } \\
\text { symmetric }\end{array}$ & Small & As desired & $\begin{array}{l}\text { Zero-power } \\
\text { startup }\end{array}$ & $\begin{array}{l}\text { Existing facility } \\
- \text { data can be } \\
\text { obtained }\end{array}$ & High \\
\hline AVR & Cylindrical & $\begin{array}{l}\text { Short; } \\
\text { radial } \\
\text { extent } \\
\text { appropriate }\end{array}$ & $\begin{array}{l}\text { Various; } \\
\text { some low- } \\
\text { Tnrichment } \\
\text { TRISO }\end{array}$ & Both & Uncertain & High \\
\hline HTR-10 & Cylindrical & Small & $\begin{array}{l}\text { Low- } \\
\text { enriched } \\
\text { TRISO }\end{array}$ & Both & $\begin{array}{l}\text { Existing facility } \\
\text {-data can be } \\
\text { obtained }\end{array}$ & High \\
\hline $\begin{array}{l}\text { HTR- } \\
\text { PROTEUS }\end{array}$ & Cylindrical & Small & $\begin{array}{l}\text { LEU } \\
\text { pebble-bed } \\
\text { fuel }\end{array}$ & Zero-power & $\begin{array}{l}\text { PSI and IAEA } \\
\text { would need to } \\
\text { be contacted }\end{array}$ & High \\
\hline Prismatic-Block Reactor Type & \multicolumn{5}{|l|}{} \\
\hline HTTR & $\begin{array}{l}\text { Cylindrical/ } \\
\text { Annular }\end{array}$ & Small & LEU & Both & $\begin{array}{l}\text { Existing facility } \\
\text {-data can be } \\
\text { obtained }\end{array}$ & High \\
\hline VHTRC & Hexagonal & Small & LEU & Zero & JAERI data & High \\
\hline CNPS & Cylindrical & Small & LEU & Zero & LANL data & High \\
\hline
\end{tabular}

In FY 2005, three of these cases have been further analyzed for purposes of creating a set of standard benchmark problems that could be used for validating codes and nuclear data; INL evaluated the available HTR-10 data, while ANL evaluated the CNPS and HTTR data. The results of these evaluations have been documented in laboratory reports and they have been collated into this single report. 


\section{Summary}

ANL conducted a technical evaluation of the CNPS and HTTR measurements; this included sensitivity studies to understand discrepancies in data or impact of modeling assumptions on the results. Due to insufficient data (particularly the uncertainties to be associated with the design data) these efforts did not progress to the stage of defining a standard benchmark following the structure that has been recently defined by the International Reactor Physics Experiments Preservation (IRPhEP) sub-group of the OECD/NEA. It is noted, however, that the models developed could be used for specifying numerical benchmarks based on the experiments. On the other hand INL concentrated on developing a standard benchmark for the HTR-10.

The conclusions from the ANL and INL evaluation activities are:

- CNPS: An evaluation of the Compact Nuclear Power Source (CNPS) experiments conducted at the Los Alamos National Laboratory (LANL) in the late 1980s has been done using information available in the open literature. The Monte Carlo results that were obtained for critical test configurations have been quite good with $\mathrm{k}_{\text {eff }}$ values within $0.5 \%$ of the critical value of unity. The material worths calculated in this study were found fairly close to the measurement values. The lack of information on design data uncertainties and the inconsistency in the design data from different sources make it difficult to quantify the uncertainty in the core integral parameters arising from data uncertainties. The evaluated configurations could however be useful as numerical benchmarks that are based on the currently available information.

- HTTR: An evaluation of the High Temperature Engineering Test Reactor (HTTR) start-up experiments has been performed using the data available in the open literature. Monte Carlo (MCNP) and deterministic models were developed and used for the analysis of the four critical configurations of the HTTR, which were attained along the path to full-core loading. The results obtained show a significant difference $(1.8 \% \Delta \mathrm{k} / \mathrm{k})$ between the core criticality calculated by the MCNP code and the experimental measurement; larger differences of about $2.3-3.4 \% \Delta \mathrm{k} / \mathrm{k}$ were found 
for the deterministic codes. These discrepancies are consistent with those reported during an HTTR experiment evaluation effort previously organized by the IAEA. The magnitudes of these differences are attributed to the incomplete specification of the HTTR core configuration (e.g., impurities and nitrogen in graphite, design data uncertainties, etc), uncertainties in nuclear data, and of approximations inherent in the code solution methods (primarily for the deterministic codes). Due to the incomplete data, it is not possible at this stage to state conclusively the major contributions to the discrepancies. It is recommended that the Gen IV program should continue to engage JAERI (Japan) and other international partners in order to obtain additional VHTR-related core physics experimental data.

- HTR-10: Using the COMBINE and PEBDAN codes for cross section generation and the PEBBED code for whole-core calculation, a baseline value of 1.03257 was calculated for the $\mathrm{k}_{\text {eff }}$ of the critical HTR-10 core in this evaluation. This baseline value is farther from unity (1.0) than one would expect. The PEBBED code has been validated extensively but its results are dependent on the quality of the cross sections supplied to it. Calculation of cross sections in graphite systems presents problems that need resolution. There are also other sources of uncertainty, such as the shape of the upper surface of the core, for which PEBBED assumes a planar upper core surface. The error introduced by this assumption has not yet been evaluated. A statistical combination of all sources of potential uncertainties in the benchmark result (assumed uncorrelated) yields an overall uncertainty of $0.54 \%$ in the $\mathrm{k}_{\text {eff }}$ of the HTR-10 critical core. This value was obtained by making consistently conservative assumptions on the variability of parameters on which $\mathrm{k}_{\text {eff }}$ may depend. The parameters that could have the largest effect are the boron densities, the graphite matrix density, the fuel loading, and the pebble diameter. It is unlikely that any of the boron densities and impurity level, on average, are as far from the nominal value as the tolerance range permits. Therefore, the initial criticality measurement in HTR-10 is judged to be an acceptable benchmark. However, a number of improvements have been identified during internal review of this evaluation. Many of these improvements will be made prior to formal submittal to the IRPhEP on September 30, 
2005. Additional improvements will be made prior to the IRPhEP Meeting in November as a result of continued internal review as well as IRPhEP external review. Furthermore, contact with key individuals at Tsinghua University in China has been reestablished with the hope of more complete information to follow in the coming months.

Based on the findings of this study, the need for new integral measurements cannot be ruled out. Cost effective approaches for creating high quality measurements will be pursued by ANL and INL in collaboration with other local and international organizations. 


\section{ACKNOWLEDGMENTS}

This joint ANL and INL work on the evaluation of high-temperature physics experiments was supported by the U.S. Department of Energy, Office of Nuclear Energy, Science and Technology (Design and evaluation Methods element of the Generation IV Program).

The following people contributed to either the evaluation or review of the experimental tests reported in this work: Soon-Sam Kim (INL), Sang-Ji Kim (ANL, a visiting scientist from KAERI (ROK)), Frank Szakaly (ANL, a 2004 summer intern from the Texas A\&M University), and Mark Paulson (ANL, a 2005 summer intern from the University of Wisconsin, Madison). Their efforts are greatly appreciated. 


\section{REFERENCES}

1. W. K. Terry, J. K. Jewell, J. Blair Briggs (INEEL), and T. A. Taiwo, W. S. Park, H. S. Khalil (ANL), "Preliminary Assessment of Existing Experimental Data for Validation of Reactor Physics Codes and Data for NGNP Design and Analysis," Gen IV Report, Argonne National Laboratory, September 15, 2004. 


\section{Evaluation of the Compact Nuclear Power Source (CNPS) Critical Experiments}

T. A. Taiwo, W. S. Yang, S. J. Kim, T. K. Kim, and Mark Paulson

Nuclear Engineering Division

9700 South Cass Avenue

Argonne National Laboratory

Argonne, IL 60439

September 14, 2005 


\section{Table of Contents}

Page

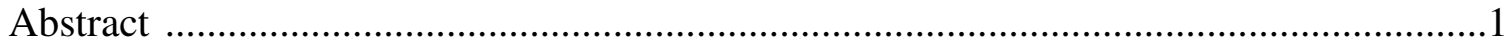

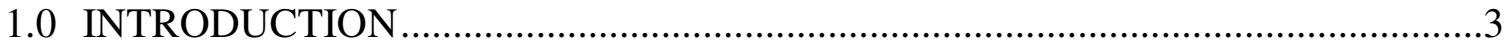

2.0 GENERAL CNPS REACTOR AND EXPERIMENT DESCRIPTIONS .................5

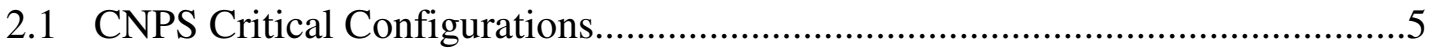

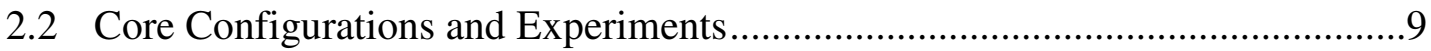

2.3 Comparison of CNPS Data from Various Sources .......................................14

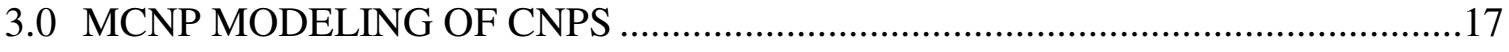

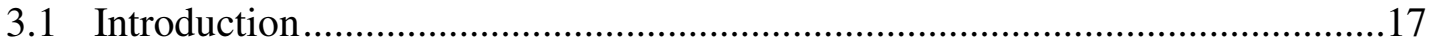

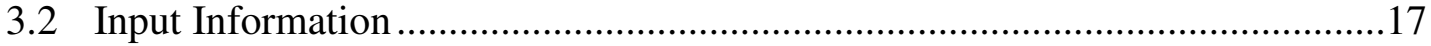

3.3 Impact of Number of Neutron Histories ......................................................... 18

3.4 Impact of Discrepancies in CNPS Design Data on Solutions..........................19

3.5 Control Rod Thimble Configuration.........................................................20

3.6 Control and Material Worths .....................................................................22

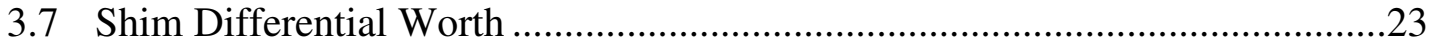

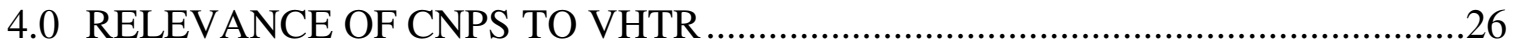

4.1 Double Heterogeneity Effect .......................................................................26

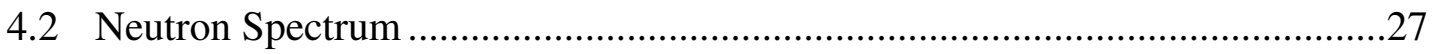

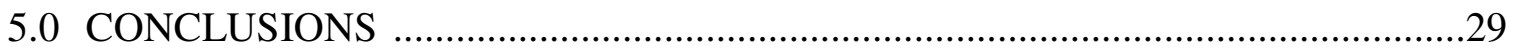

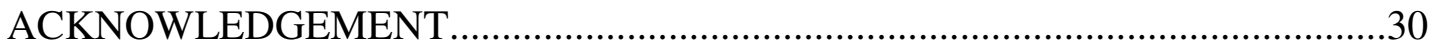

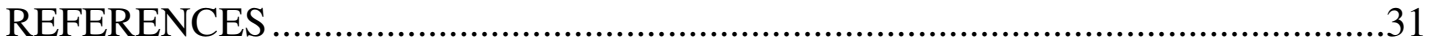

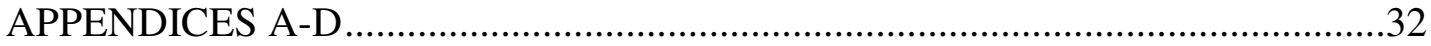




\section{List of Tables}

Page

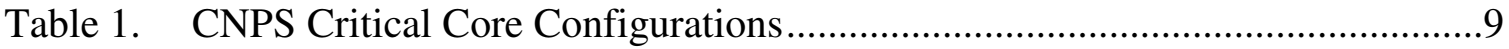

Table 2. MCNP Neutron History Effect on CNPS First Core Eigenvalue $\left(\mathrm{k}_{\mathrm{eff}}\right) \ldots \ldots \ldots . . .19$

Table 3. CNPS Core Eigenvalues using Values from Various Sources .......................20

Table 4. CNPS Configuration Sensitivities to Control Thimble Data ........................21

Table 5. Comparison of CNPS Design Element Worths .........................................22

Table 6. Eigenvalues of CNPS with Different Coated Fuel Particle Models ...............27 


\section{List of Figures}

Page

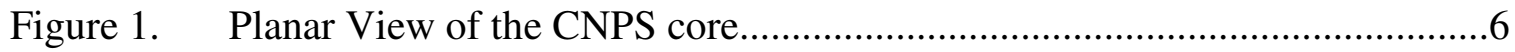

Figure 2. Vertical Cross Section of the CNPS Core................................................

Figure 3. First Critical Core Configuration .................................................. 10

Figure 4. 202 Fuel Channel Configuration....................................................... 11

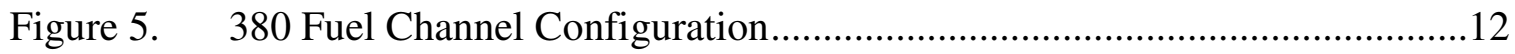

Figure 6. Full Critical Core Loading Configuration............................................13

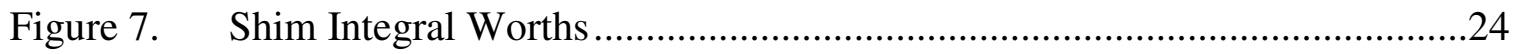

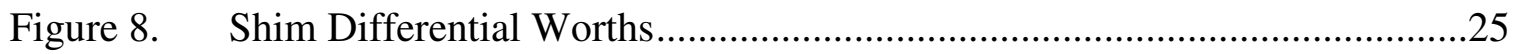

Figure 9. Neutron Spectra for the CNPS and Block-Type VHTR ..........................27 


\begin{abstract}
An evaluation of the Compact Nuclear Power Source (CNPS) experiments conducted at the Los Alamos National Laboratory (LANL) in the late 1980s has been done using information available in the open literature. The Monte Carlo results that were obtained for critical test configurations have been quite good with $k_{\text {eff }}$ values within $0.5 \%$ of the critical value of unity. The material worths calculated in this study were found fairly close to the measurement values. The lack of information on design data uncertainties and the inconsistency in the design data from different sources make it difficult to quantify the uncertainty in the core integral parameters arising from data uncertainties. The evaluated configurations could however be useful as numerical benchmarks that are based on the currently available information.
\end{abstract}




\section{INTRODUCTION}

The Compact Nuclear Power Source (CNPS) [1] was a small reactor system designed to provide power at sites where fuel costs and logistics make fossil-fuel-powered systems less attractive. In the 1980s, it was proposed that the system be used to provide power for the shortrange radar sites in the upgrade of the North Warning System. [1] The CNPS design used TRISO fuel particles and could produce $20 \mathrm{KWe}$ continuously for 20 years without refueling and be walk-away safe; the core had an inherently large negative temperature reactivity coefficient and relied on the stability of the TRISO fuel particle at the highest temperature achievable following a maximum credible accident. Due to the size and weight constraints, the CNPS was criticality limited and its ability to remain critical for the life of the core had to be verified, hence the original plans to conduct physics experiments at the Los Alamos National Laboratory (LANL). The CNPS project was cancelled after the fuel and graphite blocks had been delivered to LANL. A reduced critical experiments program was however undertaken to obtain integral data.

The available open information on physics experiments for the Compact Nuclear Power Source (CNPS) has been reviewed. The features of the CNPS make these experiments of interest to the Next Generation Nuclear Plant/Very High Temperature Reactor (NGNP/VHTR). The core used low-enriched (19.9\%) uranium graphite fuel in TRISO form, with a C/U-235 atomic ratio of 3000 (i.e., $\mathrm{C} / \mathrm{U} \sim 600$ ). The heterogeneous uranium graphite core was reflected using graphite. The core physics experiments for the CNPS included measurements of reactivity worths relative to void, of graphite, $\mathrm{BeO}$, depleted fuel, and polyethylene in 20 replacement holes. The worth of the safety rod was also determined using the rod-drop method. Other measurements included material and central control rod worths, shim differential worth, and limited temperature reactivity coefficient measurements using electrical radiant heaters. Measurement of the activation rate of ${ }^{235} \mathrm{U}$ in heat pipe channels was also performed.

Using the available data for the CNPS critical experiments has not been straightforward, as one could expect for an experiment that was conducted 20 years ago by another institution. Making the task difficult is the unavailability of the personnel that conducted the experiments at LANL. There are, however, a few publications by the same authors on the CNPS experiments that list design specifications, geometry and material composition, and experimental results. 
However, amongst the literature on the CNPS critical experiments, there are discrepancies on geometrical dimensions and material compositions. In order to generate a set of benchmark problems, the approach that has been taken is to evaluate the range of design data that are available in open literature. Using engineering judgment, the best set of data was used to derive a reference dataset. Then data deviations from this set were used in sensitivity studies performed to judge the impact of these uncertainties in design data on the results. Additionally, only Monte Carlo models have been used in this study. A NGNP/VHTR code package would use deterministic tools, particularly to expedite tradeoff and design studies, and hence it would be quite important to verify and validate these tools for use in NGNP analysis.

In Section 2, a description of the CNPS reactor is provided. A collection of the data used in this study is also given along with discussions on the differences between the data sources. The MCNP model used in this study is documented in Section 3. The results of the sensitivity studies and MCNP calculations are summarized in Section 4. Conclusions from the work are presented in Section 5. 


\section{GENERAL CNPS REACTOR AND EXPERIMENT DESCRIPTIONS}

The primary sources of data on the CNPS are Refs. 1 to 5, with most of the data obtained from Ref. 1. There is however no or limited information on data uncertainties. In Section 2.1 a description of the CNPS core is provided. Information on the configuration and experiments are provided in Section 2.2. The discrepancies that were found in the references are discussed in Section 2.3 .

\subsection{CNPS Critical Configurations}

The CNPS was designed to use a heterogeneous uranium graphite cylindrical core, depicted schematically in Figures 1 (planar view) and 2 (vertical view). The core height is $113 \mathrm{~cm}$ and the diameter is $120 \mathrm{~cm}$. The core is reflected both radially and axially with graphite. The thicknesses of the graphite reflectors were $39 \mathrm{~cm}$ (average) and $24 \mathrm{~cm}$ at the core top and bottom, respectively, and $20 \mathrm{~cm}$ radially. An average reflector thickness is provided for the top reflector, because a flat top is not used; the smallest thickness is $25 \mathrm{~cm}$ at the periphery, and largest thickness is $45 \mathrm{~cm}$ at the core center. [1] In the experimental setup, there is a $0.4 \mathrm{~cm}$ radial gap between the core and radial reflector (not visible in Figure 1). This gap, which would not have been in the actual reactor planned for deployment, was used as clearance for the movement of the core into the reflector and was necessary for the operation of the vertical critical assembly machine used at LANL. [1] The core and bottom reflector were supported by a $6 \mathrm{~cm}$ thick aluminum plate attached to a hydraulic ram. [1]

The active core consisted of 9 graphite segments (blocks), with penetrations (channels) for fuel pellets, control rods and heat pipes. There was a central cylindrical sector called the inner core and eight curved-trapezoidal outer core sectors. The core contained 492 fuel channels, 5 control rod channels, and 12 heat pipe channels. An extra 20 channels were also available near the core center. These extra channels were provided in the event that additional fuel was required to make the core critical by the addition of beryllium rods. (The radial locations of the 20 extra holes are provided in Appendix A.) Each fuel channel or extra channel had a diameter of 1.285 $\mathrm{cm}$. The control channels had a diameter of $3.494 \mathrm{~cm}$ and penetrated the upper reflector. The heat pipe channels had a diameter of $6.185 \mathrm{~cm}$ and penetrated the upper reflector (completely) and bottom reflector (by $3.175 \mathrm{~cm}$ ). [1] The requirement of ensuring a minimum web thickness 
between any two free surfaces made it difficult to maintain a constant fuel element pitch. To minimize this problem, the CNPS was designed with a 45 degree azimuthal symmetry. The coordinates of the channels (centers) in a 45 degree core sector were obtained from Ref. 1 and are summarized in Appendix A.

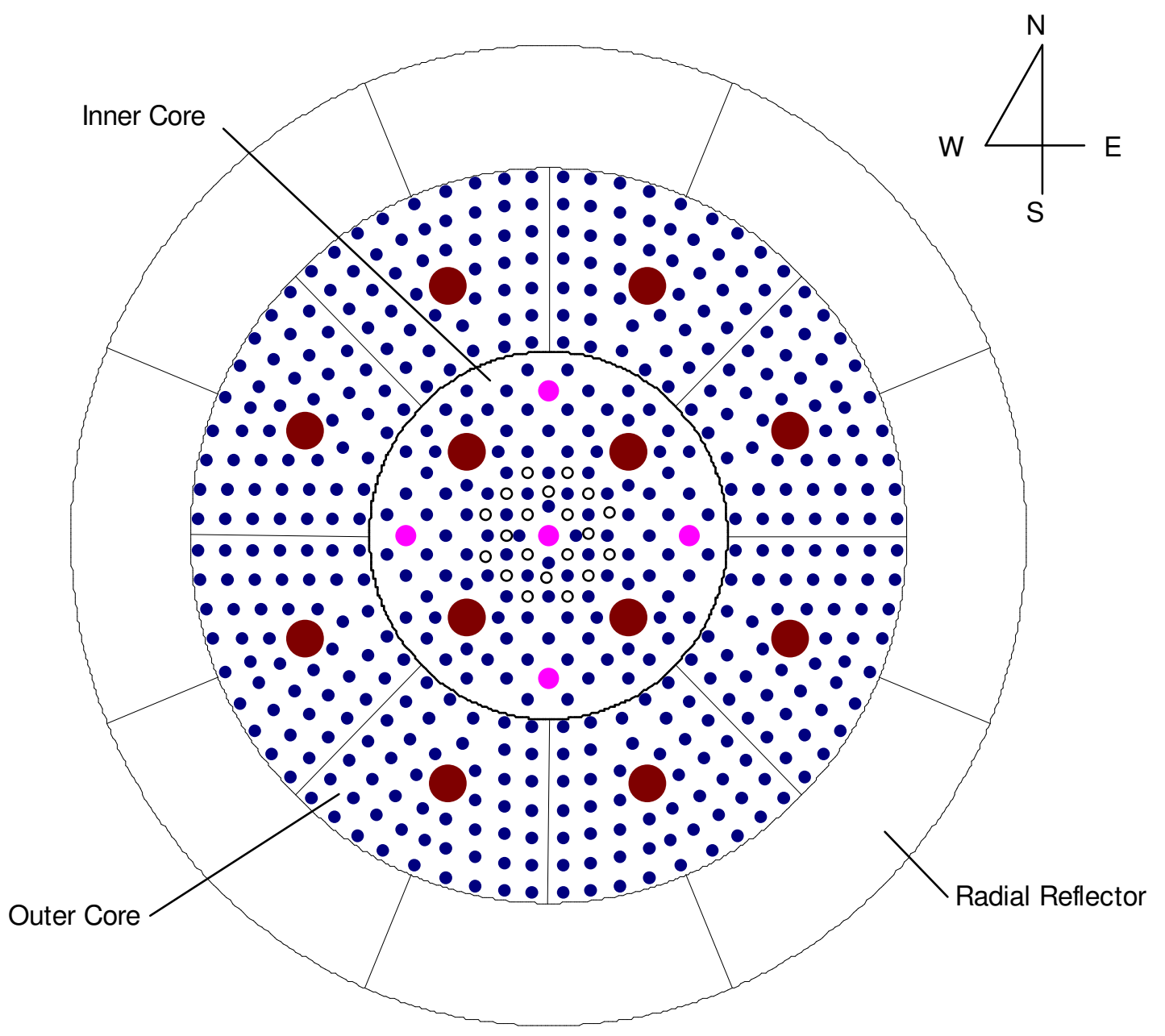

\begin{tabular}{ll|}
\hline - Fuel Channels (492) & - Control Rod Channels (5) \\
- Heat Pipes Channels (12) & o Extra Holes (20)
\end{tabular}

Figure 1. Planar View of the CNPS Core. 


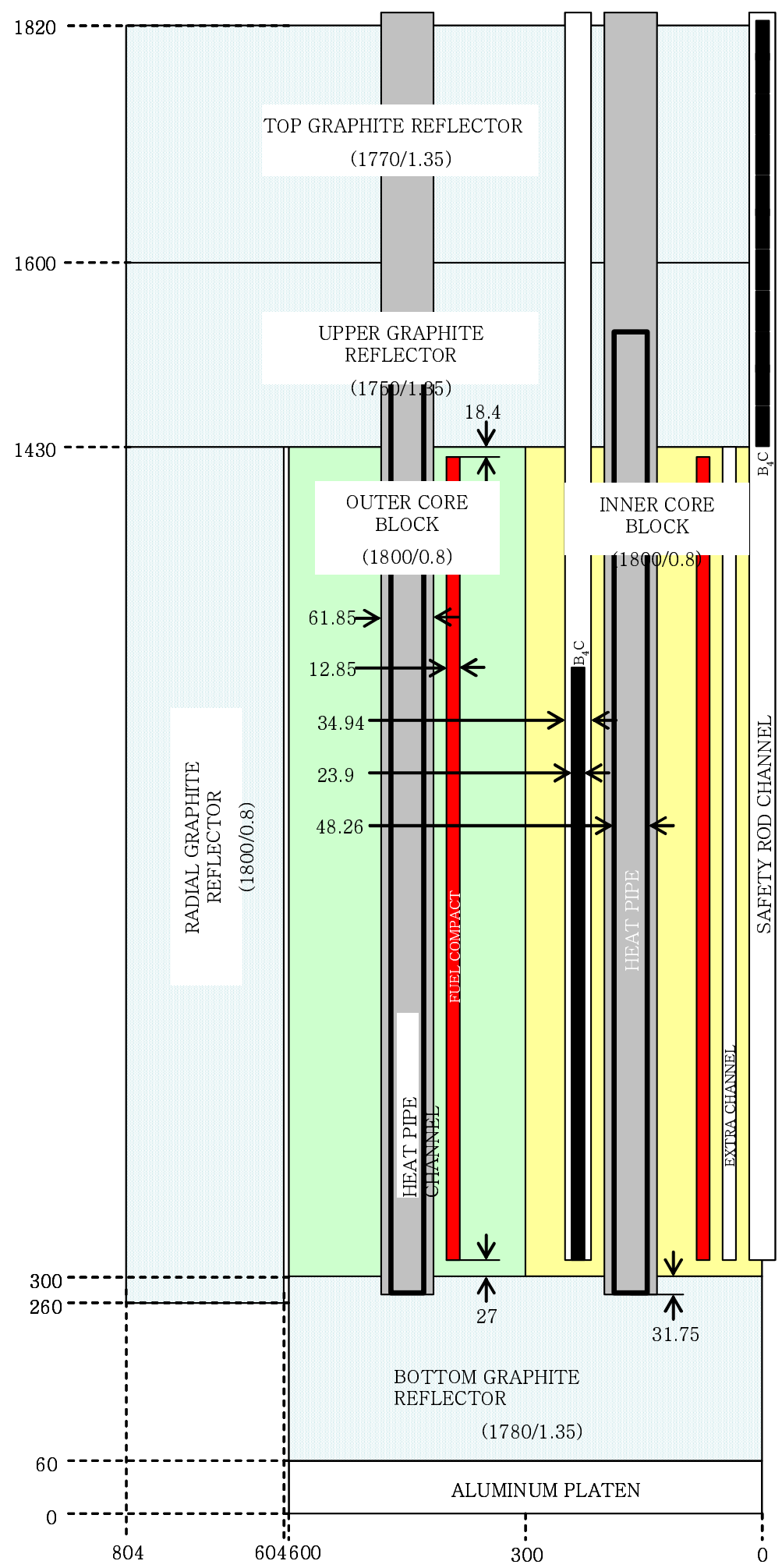

Figure 2. Vertical Cross Section of the CNPS Core. (The dimensions shown are in mm.) 
As aforementioned, the reactor was fueled with rodded compacts of TRISO fuel particles in a graphite material. This is similar to the fuel type that is being considered for the NGNP/VHTR. Information on the coated fuel particles (CFPs) and the compact composition are presented in Appendix B. Each fuel channel contained 22 fuel compacts. The equivalent boron impurity content in the compact was $5.2 \mathrm{ppm}$. The active core height was $108.46 \mathrm{~cm}$, which is less than the height of the core block $(113 \mathrm{~cm})$. The active core zone ranged from $2.7 \mathrm{~cm}$ above the bottom of the graphite core blocks. [1]

To simulate the heat pipes that would have been present if the CNPS was put into operation, two materials were tested. In separate configurations, pipes of type 316 stainless steel $(4.826 \mathrm{~cm}$ o.d., $0.368 \mathrm{~cm}$ wall thickness, and $123.7 \mathrm{~cm}$ long) and zirconium (4.826 cm o.d., $0.264 \mathrm{~cm}$ wall thickness, and $119.9 \mathrm{~cm}$ long) were fully inserted into the heat pipe channels. Although stainless steel is a stronger neutron absorber than the zirconium, it was being considered strongly for the demonstration reactor because testing of the zirconium indicated that there might be long-term problems with the wall integrity. [2] It was realized that the use of stainless steel would place additional uncertainty on the ability of the reactor to operate at power for 20 years without refueling.

The mockup for the CNPS control rods consisted of $\mathrm{B}_{4} \mathrm{C}$ cylindrical pellets $2.39 \mathrm{~cm}$ in diameter and $5.013 \mathrm{~cm}$ in length containing $7.44 \mathrm{~g}$ of ${ }^{10} \mathrm{~B}$ at 19.75 at.\% boron. These pellets were stacked in a control rod channel from the bottom of the active core up to various heights depending on the particular CNPS configuration. The CNPS critical experiment also used 22 cylinders of enriched $\mathrm{B}_{4} \mathrm{C}$, each containing $20.7 \mathrm{~g}$ of ${ }^{10} \mathrm{~B}$ at 54.88 at.\% boron for various CNPS configurations. [1] Additionally, the other control design element, called a shim rod, is a thin walled aluminum tube $163.3 \mathrm{~cm}$ long with an inner diameter of $1.257 \mathrm{~cm}$, packed with natural $\mathrm{B}_{4} \mathrm{C}$ at a density of $0.89 \mathrm{~g} / \mathrm{cm}$. This shim rod is inserted in the south control rod channel from the top of the CNPS reactor into an otherwise empty control channel. During the CNPS critical experiment, the central control rod was used as a safety rod. [1] 


\subsection{Core Configurations and Experiments}

Critical state measurements were conducted under the CNPS experimental program. Four of the simple critical loadings were described in Ref. 1 and these are summarized in Table 1. They included cores with loadings of 184 to 492 fuel channels, the latter being the fully-loaded core, and different axial positions of the shim rod. To simulate the heat pipe, both zirconium and stainless steel were utilized.

Table 1. CNPS Critical Core Configurations. [1]

\begin{tabular}{|c|c|c|c|}
\hline Fueled Channels & Simulated Heat Pipes & B $_{4}$ C Pellets & $\begin{array}{c}\text { Shim Rod } \\
\text { Position Above } \\
\text { Active Core (cm) }\end{array}$ \\
\hline 184 & 0 & 0 & 105.3 \\
\hline 202 & 11 zirconium & 0 & 36.6 \\
\hline 380 & 12 SS-316 & 21 in N* & 72.4 \\
\hline 492 & 12 SS-316 & 13 each W,N,E* & 60.4 \\
\hline
\end{tabular}

* Control rod channel position in Fig. 1; N - North, W - West, E - East.

\section{First Critical Core}

The first critical core was obtained when 184 fuel channels were loaded as shown in Figure 3. [1] In this configuration, the 20 replacement (extra) channels were filled with graphite rods, the shim and safety rods were out to their limits $(105.3 \mathrm{~cm}$ and $112.5 \mathrm{~cm}$ above the bottom of the active core, respectively), and all the other control and heat pipe channels were empty. [1] The loading (radially) were from the core center all the way out to include the second ring in the outer core, but with the exclusion of the four channels. Due to its clean nature, most of the core physics experiments were performed with this core configuration. These included:

- The worths of graphite, $\mathrm{BeO}$, depleted fuel, and polyethylene relative to void, were measured in the 20 replacement holes. [1]

- The safety rod worth was measured using the rod-drop method in which neutron detectors monitor count rates before a fast pneumatic insertion (drop) of the rod and either during the drop or after the drop. Measurements were taken using internal and external core detectors. [1] 
- Shim differential worth measurements were obtained with about 180 to 200 filled channels and the 20 extra channels loaded with miscellaneous materials. [1]

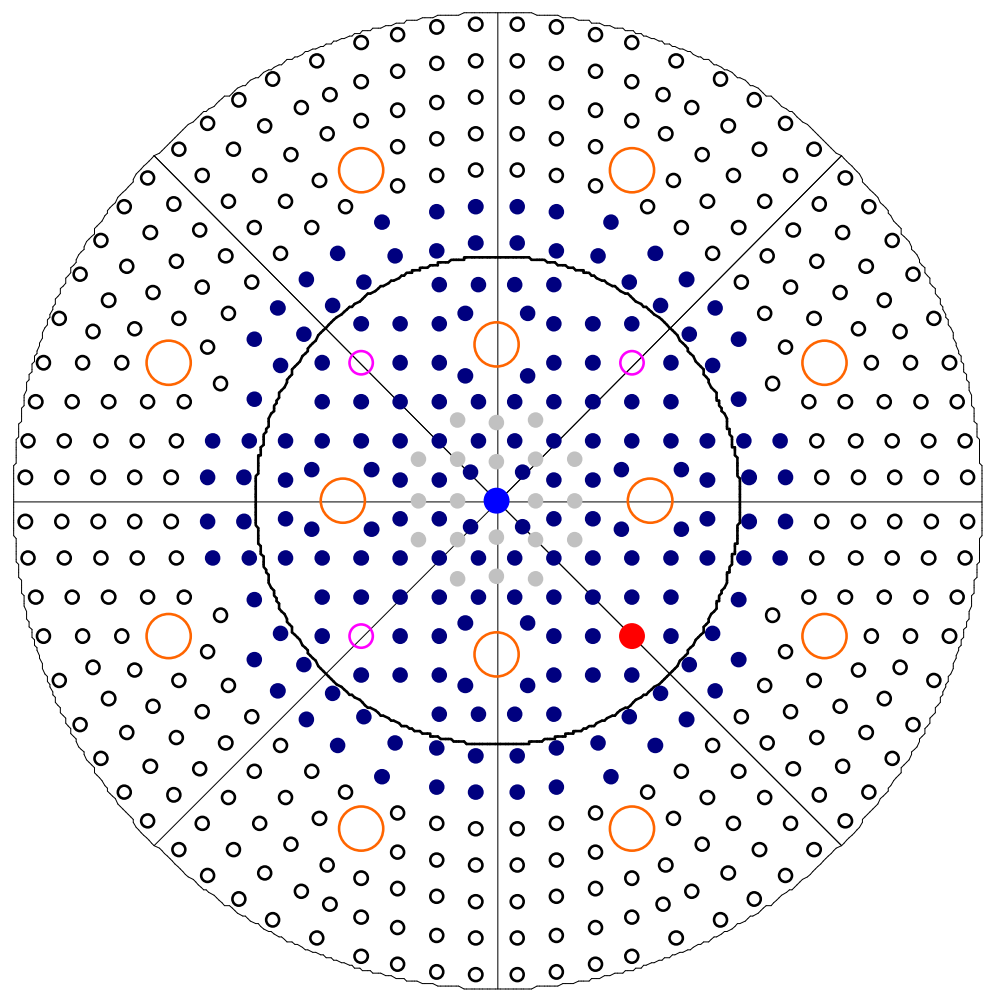
- Fuel Channels-184
o Control Rods-Empty
○ Heat Pipes-Empty
- Extra Holes-Graphite filled • Safety Rod-1125 above • Shim Rod-1053 above

\section{Figure 3. First Critical Core Configuration.}

\section{Other Configurations}

The three other configurations were obtained in stages. These included various loadings of zirconium and stainless steel tubes used to mock up the heat pipe walls, and various arrangements of mock up control rod configurations. As in the first core, the last three cores had graphite rods in the 20 replacement channels (i.e., extra hole locations). 
The second core was obtained by the addition of 11 zirconium heat pipes, which necessitated the increase in the core loading to 202 fuel channels. This loading extends from the core center to the second ring in the outer core and additional 14 channels in the third ring as shown in Figure 4. The empty heat pipe location was approximately the south-east (SE) position in the outer core. [1]

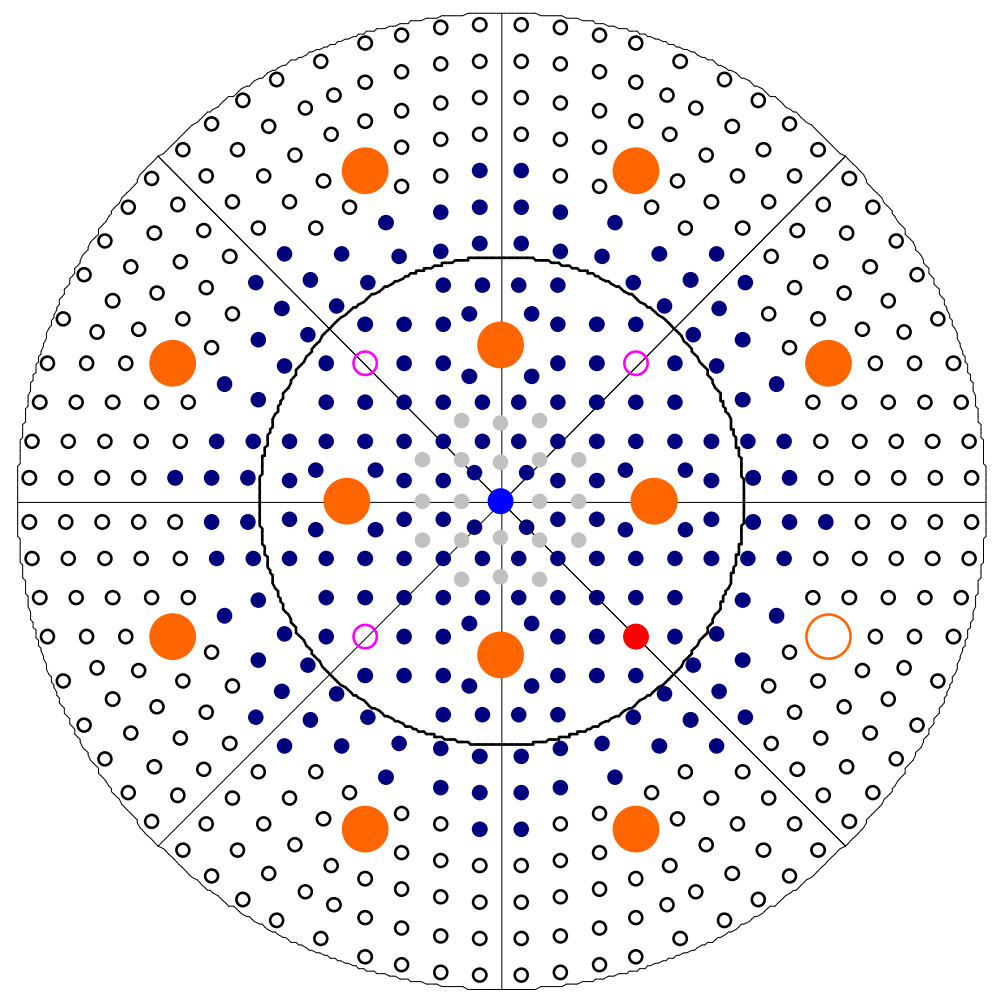

$\begin{array}{lll}\text { - Fuel Channels-202 } \quad \text { Control Rods-Empty } & \bullet \text { Heat Pipes-11 Zirconium } \\ \text { - Extra Holes-Graphite filled } \bullet \text { Safety Rod-1125 above } & \bullet \text { Shim Rod-366 above }\end{array}$
$\circ$ Heat Pipe-Empty

Figure 4. 202 Fuel Channel Configuration.

A relatively larger loading (380 channels) were required for the third core, because of the use of both 12 stainless steel simulated heat pipes and the loading of a stack of 21 natural $\mathrm{B}_{4} \mathrm{C}$ pellets to represent a fully inserted CNPS control rod. [1] This loading extends from the core 
center to the fifth ring in the outer core plus 32 channels in the sixth ring as shown in Figure 5. [1]

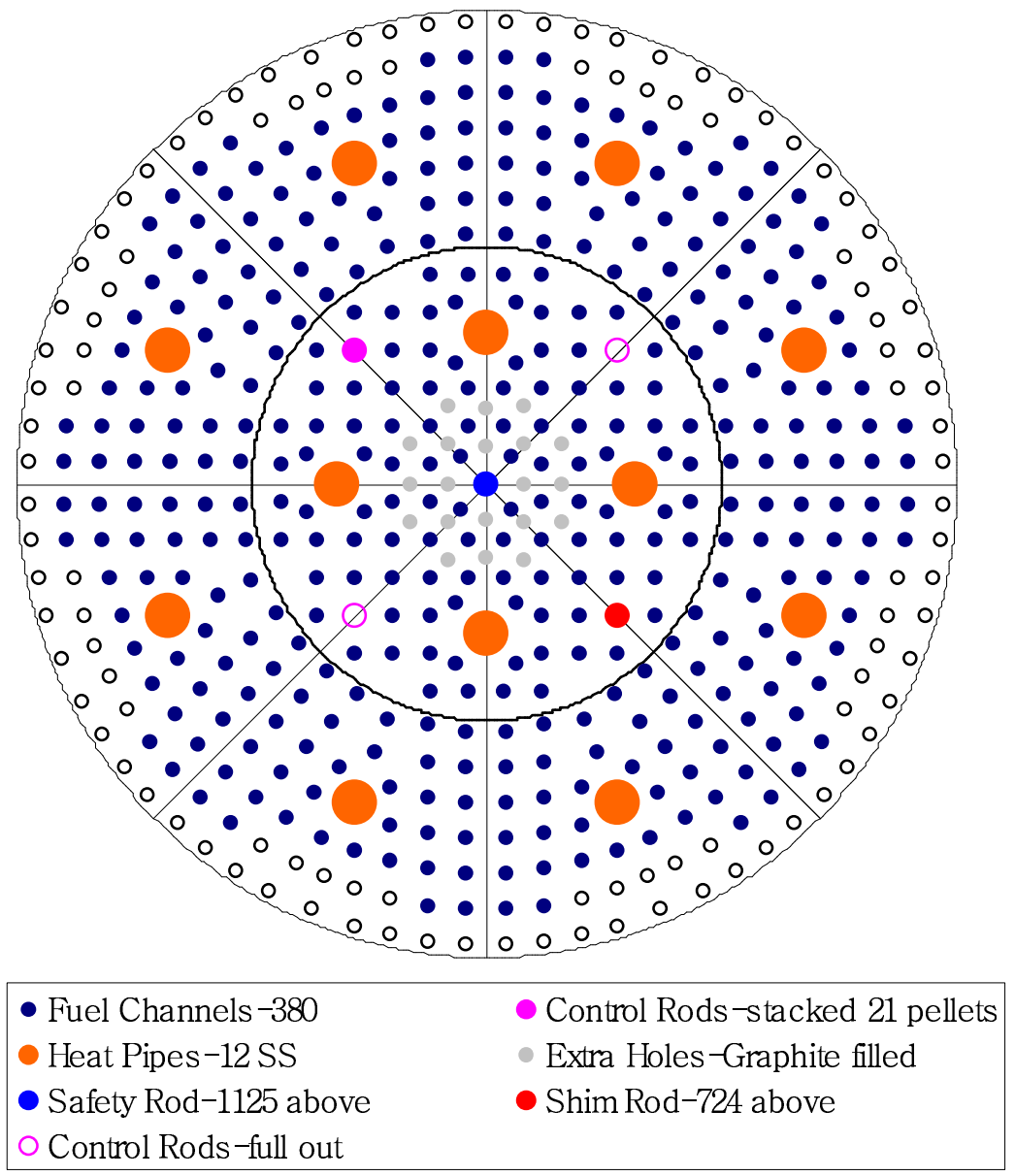

Figure 5. 380 Fuel Channel Configuration.

The full critical core loading (492 channels) was achieved with a combination of 12 stainless steel rods and the equivalent of 3 partially inserted (location in the core bottom) CNPS control rods as shown in Figure 6. Worth measurements were performed with this core configuration. [1] These include:

- Shim differential worth measurements by varying the number of $\mathrm{B}_{4} \mathrm{C}$ cylinders in the outer control channels. 


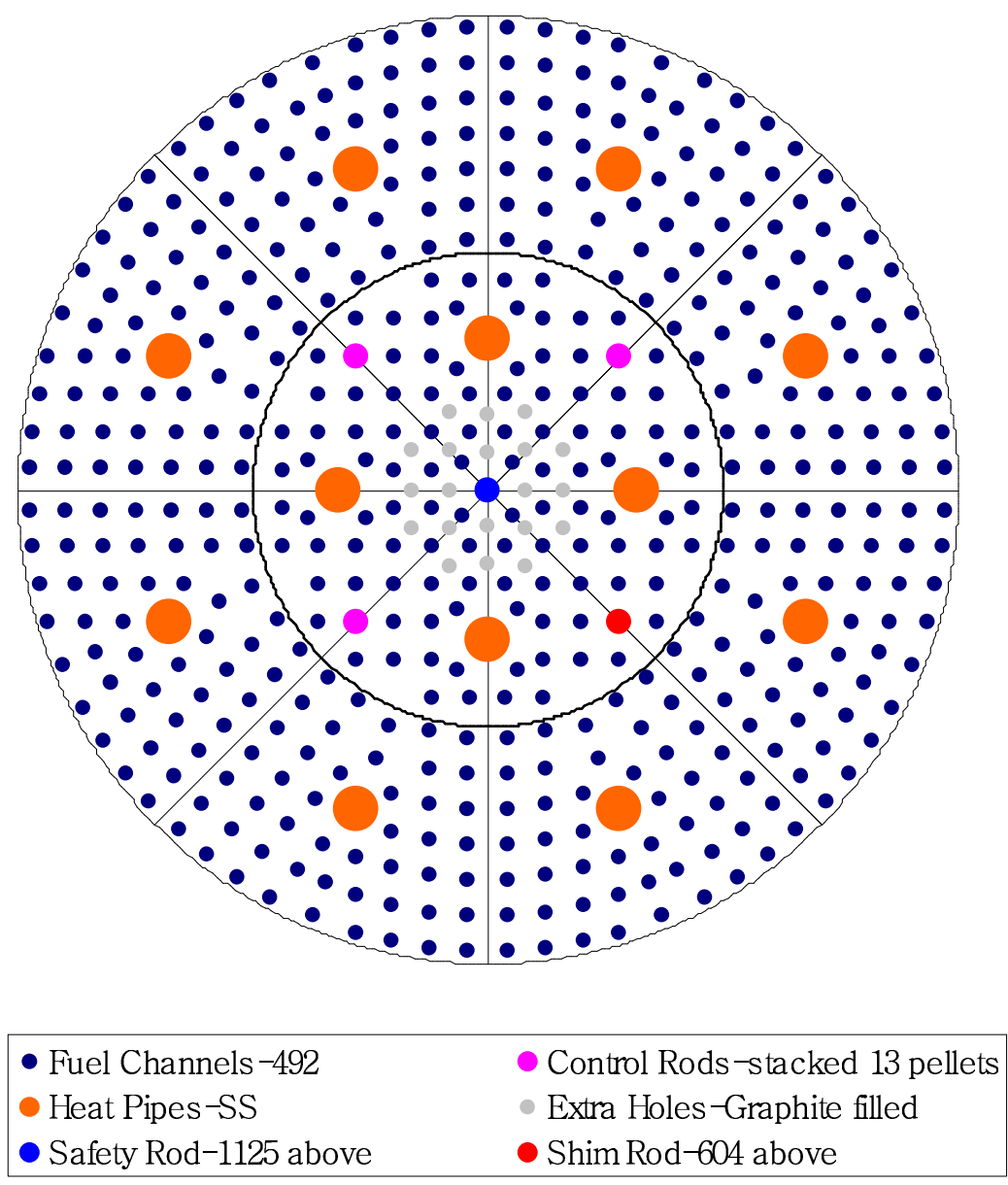

Figure 6. Full Critical Core Loading Configuration.

- Materials worths and central control rod worth measurements. The worth of the 54.88 at.\% enriched $\mathrm{B}_{4} \mathrm{C}$ rod was also measured.

- Temperature reactivity coefficient over a small range above the ambient room temperature (to less than $353 \mathrm{~K}$ ) to confirm the negative temperature reactivity coefficient. This was done using electrical radiant heaters (calrods) placed near the radial surface of the exposed core. The calrods and the core were enclosed radially by an aluminum foil shroud to increase the efficiency of the heating process. Eighteen thermocouples were used to sample the temperature distributions in the core (none in the radial reflector). [1] 
- Activity of foils placed in the outer surface of the heat pipes to confirm a uniform heat load to the stainless steel heat pipes (i.e., all pipes were designed to remove the same heat load).

\subsection{Comparison of CNPS Data from Various Sources}

\section{Fuel Packing Fraction in Graphite Matrix}

The initial Monte Carlo (MCNP) model developed for this study used a fuel packing fraction of 0.399. This value is based on the information provided in Table II of Ref.1, which gave a value for the "Packing fraction (by volume)". With this value of the packing fraction, the

${ }^{235} \mathrm{U}$ loading in a filled fuel channel was estimated to be $20.79 \mathrm{~g}$. However, another paper by the same authors reported, without including detailed geometry and composition data, that a filled fuel channel contained $29.25 \mathrm{~g}$ of ${ }^{235} \mathrm{U}$. [3] In order to resolve this inconsistency, Monte Carlo simulation of a CNPS core was performed using the detailed data in Ref. 1. The CNPS configuration containing 184 fueled channels was analyzed using the MCNP code with mostly ENDF/B-VI Release 6 library. For simplicity, homogenized fuel compacts were used rather than modeling fuel particles explicitly. The core eigenvalue determined with five million neutron histories was $0.9655 \pm 0.0004$. This result suggested that the detailed information in Ref. 1 includes unidentified errors, since the grain heterogeneity effect of the CNPS fuel reported by the GA Technology is only 200 to $300 \mathrm{pcm}$. There was therefore a need to confirm or find additional source of data from those contained in Ref. 1.

Following evaluation of additional data (Refs. 2-4), it was found that the value in Ref. 1 is open to misinterpretation because of the apparent misuse of the word packing fraction. Apparently the value in Ref. 1 referred to the packing fraction (volume fraction) of the graphite matrix in the compact. With a fuel packing fraction of 0.601 (instead of 0.399) and a $1.245 \mathrm{~cm}$ diameter fuel compact with $\mathrm{UC}_{0.3} \mathrm{O}_{1.7}$ kernels, the uranium mass per fuel channel reported in Ref. 3 (29.25 g) was obtained. A re-analysis of the CNPS critical core configuration gave a $k_{\text {eff }}$ value closer to unity. The information on the fuel compact was found in an LANL memorandum “Experimental Plan No. 215 - Delayed Critical Operation of CNPS Mock-up Assemblies,” [5] (see discussion below). 
The process of determining a correct core packing fraction for the CFP in the graphite matrix led to the finding of discrepancies between the data in the open literature for the CNPS design. These additional discrepancies were not as significant as that in the fuel packing fraction. Our solution to this issue is to collect a reference set of data, from which sensitivity calculations could be performed.

\section{Resolution of Other Discrepancies}

There are three reports in which data on the CNPS critical experiment are provided, including core configuration and experimental results; these are Ref. 1,2 and 3. Additionally, a report on the neutronic design studies for a small, long-lived nuclear heat source (Ref. 4), a preanalysis to the CNPS design, provides information on the TRISO fuel used in the CNPS. However, the information in Ref. 4, essentially corroborated those in Refs. 1 and 2.

The only other available literature on the CNPS is a packet of documents received at ANL from LANL, with the assistance of J. B. Briggs (INL). This packet included several LANL memoranda, a CNPS critical experiment plan, a draft report on the CNPS quality assurance program, and timetables for the CNPS project as well as budget summaries. The only pertinent information for the CNPS core is found under the title, "Experimental Plan No. 215 - Delayed Critical Operation of CNPS Mock-Up Assemblies, Q2-86-WP-67, January 23, 1986.” [5] This experimental plan includes fuel compact diameter and a reference design core layout for the CNPS that includes a control rod thimble. In no other CNPS literature is there reference to control rod thimbles. The reference design core layout lists control rod thimble outer diameter of $3.0 \mathrm{~cm}$ and thickness of $0.1 \mathrm{~cm}$ but no material information. It is reasonable to assume that there was some control rod thimble during the CNPS critical experiment and this is discussed further in the MCNP modeling section of this report (Section 3.5).

A complete comparison of the CNPS configuration values given in the first three references (designated Reports 1, 2 and 3) is shown in Appendix C. The shim position for various CNPS configuration differs in all three reports. The values for graphite densities and uranium enrichment of the fuel are not consistent between Reports 1 and 2. Report 3 generally agrees with Report 1 for those material and dimensional values that are listed. However, 
Report 3 gives the least amount of information of which the only difference is the below active core material thickness. The differences among the three reports are small enough that they could be attributed to round-off or human error in reporting. The significance of the CNPS literature differences is determined by MCNP modeling of each case for intra-comparison. The final set of data taken as reference in this study is summarized in Appendix B. 


\section{MCNP MODELING OF CNPS}

\subsection{Introduction}

The complexity of the CNPS core design dictated the use of a code that could accurately represent the intricate geometrical arrangements in the core, for the purpose of creating a reference solution against which more efficient model could be compared. For this reason, the Monte Carlo code, MCNP, was selected for the reference model. MCNP provides a continuous energy capability that also allows detailed representation of the specified geometry. One disadvantage of the method is the enormous computer resources (computational time) required to obtain satisfactory solution with decent accuracy. It is planned in subsequent work to develop more efficient deterministic models for the core modeling. All the full-core results presented in this section were done with the MCNP code.

As a starting point, an MCNP input deck was created for the CNPS configuration with 184 fueled channels, representing these channels and other constituents such as the core graphite moderator, all 20 extra channels filled with graphite moderator, all graphite reflectors, full Al support plate, void heat pipe channels, void empty fuel channels, and void control rod channels. The calculated final eigenvalue given by this initial CNPS configuration is $1.00314 \pm 0.00042$. This value is reasonable and was expected to decrease as the various CNPS design elements are added to the MCNP model.

\subsection{Input Information}

The material compositions were initially taken from Ref. 1, being the most complete and most recently published. Using the material composition information, number densities and atom percents for input into the MCNP deck were calculated in a spreadsheet. The resulting "reference" data can be found in Appendix B. When creating the material cards in MCNP, constituent elements were separated to include the most isotope cross sections available. For graphite, $S(\alpha, \beta)$ data at $300 \mathrm{~K}$ were used to account for the thermal neutron scattering by the solid graphite moderator. 
While the physical geometry of the CNPS configurations was modeled as accurately as possible there were a few assumptions made to simplify the MCNP input deck and speed up run time. The gap between the fuel compacts and fuel channel necessary for the physical loading of fuel was not modeled. Complete information was not provided in the references for this gap; none of the CNPS references listed a different fuel compact and fuel channel diameter. According to the fuel compact diameter found in the LANL memorandum "Experimental Plan No. 215," [5] the gap could have been $0.2 \mathrm{~cm}$. This assumption is likely to cause a small overprediction of core eigenvalues (since the gap could be a pathway for neutron streaming). Another assumption that was made is the Al cladding wall thickness of the shim rod. Although a thickness of $0.254 \mathrm{~cm}$ was assumed, $\mathrm{Al}$ has low cross sections for neutron interactions, making the relative significance of the cladding thickness extremely small.

The last significant assumption made was the spatial homogenization of the fuel rods in the MCNP input materials. This means that fuel grain heterogeneity was ignored, smearing the elemental contents of the TRISO fuel evenly throughout the fuel compact using volume weighting. Reference 1, quoting a General Atomics Technologies source, indicated the reactivity effect of the grain shielding to be on the order of 200 to $300 \mathrm{pcm}$. An evaluation of this effect was later made in this study (see Section 4).

\subsection{Impact of Number of Neutron Histories}

To ensure that the core $k_{\text {eff }}$ values that were obtained are of reasonable accuracy, a first study focused on the impact of the number of neutron histories on the value of this core integral parameter. The total number of MCNP neutron histories is the product of the nominal source size per cycles and the number of $\mathrm{k}_{\mathrm{eff}}$ cycle values. Additionally, the number of skipped $\mathrm{k}_{\mathrm{eff}}$ cycles affects the final $\mathrm{k}_{\mathrm{eff}}$ value. The input information of the neutron history is located under the kcode data card of the MCNP input structure. The final number of neutron histories to be employed is determined from a trade-off between run time and solution accuracy. Results have been obtained for different number of neutron histories and are summarized in Table 2.

For the same CNPS configuration, varying the neutron history options (in the range evaluated) did not change the final eigenvalue more than the solution uncertainty, but did 
increase the run time substantially. This is because the uncertainty of the MCNP solution is proportional to the inverse square root of histories run. It was determined that using five million neutron histories is enough to give sufficient accuracy in the $\mathrm{k}_{\mathrm{eff}}$ to the third decimal place. For all other MCNP simulations in this work, a neutron history of five million was used.

Table 2. MCNP Neutron History Effect on CNPS First Core Eigenvalue ( $\left.k_{\text {eff }}\right)$.

\begin{tabular}{|c|c|c|c|c|c|c|}
\hline \multicolumn{2}{|c|}{ Critical Configuration } & \multirow[b]{2}{*}{$\begin{array}{l}\text { MCNP Calculated } \\
\text { Value } k_{\text {eff }}\end{array}$} & \multicolumn{3}{|c|}{ Neutron History Options } & \multirow[b]{2}{*}{$\begin{array}{l}\text { Approx. } \\
\text { run time } \\
\text { (hr) }\end{array}$} \\
\hline $\begin{array}{c}\text { Fueled } \\
\text { Channels }\end{array}$ & $\begin{array}{l}\text { Shim Rod } \\
\text { Position } \\
\text { Above } \\
\text { Active } \\
\text { Core }(\mathrm{cm})\end{array}$ & & $\begin{array}{c}\text { Nom. } \\
\text { Source } \\
\text { Size Per } \\
\text { Cycle }\end{array}$ & $\begin{array}{c}\# \text { of } \\
\text { Skipped } \\
\text { Cycles }\end{array}$ & $\begin{array}{l}\text { \# of } k_{\text {eff }} \\
\text { cycle } \\
\text { values } \\
\text { stored }\end{array}$ & \\
\hline 184 & 105.3 & $1.00148 \pm 0.00030$ & 10000 & 5 & 1000 & 6 \\
\hline 184 & 105.3 & $1.00156 \pm 0.00043$ & 10000 & 10 & 500 & 3 \\
\hline 184 & 105.3 & $1.00147 \pm 0.00045$ & 10000 & 50 & 500 & 3 \\
\hline 184 & 105.3 & $1.00157 \pm 0.00042$ & 10000 & 5 & 500 & 3 \\
\hline 184 & 105.3 & $1.00166 \pm 0.00018$ & 50000 & 5 & 500 & 15 \\
\hline 184 & 106.0 & $1.00128 \pm 0.00043$ & 10000 & 5 & 500 & 3 \\
\hline 184 & 106.0 & $1.00166 \pm 0.00018$ & 50000 & 5 & 500 & 15 \\
\hline
\end{tabular}

\subsection{Impact of Discrepancies in CNPS Design Data on Solutions}

The impact of discrepancies in the material composition and geometry design data (from References 1 to 3 ) on the core $\mathrm{k}_{\mathrm{eff}}$ has been determined for "five" CNPS configurations: a simple no-shim 184-fueled channel case, and the four critical configurations. Results are summarized in Table 3 for the first two only. The results for the other cases have not been included in the table because they are still being verified. However, the observed trends are quite similar. The core $\mathrm{k}_{\mathrm{eff}}$ values (eigenvalues) obtained using data from each of References 1 to 3 (designated as Reports 1 to 3) are presented. Note that Report 3 did not list enough information to make a full MCNP model. The values listed in Report 1 match those from Report 3 best and were used to fill in the missing information for the MCNP model of Report 3. 
As expected the small difference $(0.3 \mathrm{~cm})$ in the starting axial position of the active core in Report 3 did not change the eigenvalue because of the thick bottom reflector. The eigenvalue of Report 3 model is statistically identical to that of Report 1 model.

The differences in results between Reports 1 and 2 are at most of the order of $100 \mathrm{pcm}$. Report 2 lists a slightly lower uranium enrichment and inner pyrolytic carbon layer density, which would have little overall effect in this MCNP model. Additionally, Report 2 lists a higher graphite moderator density and lower graphite reflector density compared to Report 1 . The shim positions of Report 2 are on average further in the core than from Report 1. This particular variation of graphite densities and shim rod position causes an increase in neutron absorption in the shim and changes the moderator-to-fuel ratio, resulting in a lower $k_{\text {eff. }}$.

Table 3. CNPS Core Eigenvalues using Values from Various Sources [1,2,3].

\begin{tabular}{|l|c|c|c|}
\hline \multirow{2}{*}{$\begin{array}{l}\text { CNPS configuration } \\
\text { as given in } \rightarrow\end{array}$} & \multicolumn{3}{|c|}{$\mathrm{k}_{\text {eff }}$ of MCNP Model } \\
\cline { 2 - 4 } & Report 1 & Report 2 & Report 3 \\
\hline $\begin{array}{l}\text { 184 Fueled Channels } \\
\text { NO Shim }\end{array}$ & $1.00314 \pm 0.00042$ & $1.00290 \pm 0.00043$ & $1.00310 \pm 0.00043$ \\
\hline $\begin{array}{l}\text { 184 Fueled } \\
\text { Configuration }\end{array}$ & $1.00148 \pm 0.00042$ & $1.00037 \pm 0.00042$ & - \\
\hline
\end{tabular}

\subsection{Control Rod Thimble Configuration}

As previously mentioned, the control rod thimble thickness was presented as $0.1 \mathrm{~cm}$ in a reference design but no material information was provided. To determine the effect of these control rod thimble on the CNPS core eigenvalues they were added to the MCNP model. The control rod thimbles were modeled using both SS-316 and Zr-2.5Nb, common thimble materials. It was observed that in the same CNPS report that mentioned the control rod thimble, other core dimensions, such as heat pipe radius, did not match values given in other CNPS reports. In order to compare eigenvalues and determine sensitivities of the control rod thimble, CNPS configurations using both of these materials at varying thicknesses were modeled. Table 4 is a summary of the results for the 184-fueled channel configuration and also lists the corresponding 
literature and the no thimble configuration eigenvalues. Similar calculations have been done for the other configurations. The results for these are still undergoing verification, but trends are similar to that for the 184-fuel channel configuration.

As expected stainless steel has a greater effect on the core eigenvalues than the zirconium alloy; stainless steel has a higher neutron absorption cross section than zirconium alloy. For all stainless steel control rod thimble configurations the core eigenvalue is below 1.0. The CNPS configurations using zirconium alloy, except for the case with a $0.2 \mathrm{~cm}$ thimble thickness, result in core eigenvalue slightly greater than 1.0. Also of note is the fact that the maximum difference in $\mathrm{k}_{\mathrm{eff}}$ for the zirconium alloy cases over the thickness range of 0.05 to $0.2 \mathrm{~cm}$ is of the order of $100 \mathrm{pcm}$, while a much larger difference $(\sim 2000 \mathrm{pcm})$ is observed for the stainless steel cases over the same variation in the thickness.

The addition of stainless steel or zirconium alloy control rod thimbles to the MCNP model of the CNPS did not result in exactly matching the core eigenvalues presented in the references for the CNPS experiment (also shown in Table 4). This does not mean that the current model is wrong however. The eigenvalues from this study (either the no thimble or zirconium alloy thimble cases) are quite close to those reported in the CNPS references and to experimental measurement $(\mathrm{C} / \mathrm{E}$ about 0 to $0.5 \%)$.

Table 4. CNPS Configuration Sensitivities to Control Thimble Data.

\begin{tabular}{|c|c|c|c|c|c|c|c|c|c|}
\hline $\begin{array}{l}\text { Fueled } \\
\text { Channels }\end{array}$ & $\begin{array}{l}\text { Simulated } \\
\text { Heat Pipes }\end{array}$ & $\mathrm{B}_{4} \mathrm{C}$ Pellets & $\begin{array}{l}\text { Shim Rod } \\
\text { Position } \\
\text { above Active } \\
\text { Core }(\mathrm{mm})\end{array}$ & $\begin{array}{l}\text { Thimble } \\
\text { Material }\end{array}$ & $\begin{array}{c}\text { Thimble } \\
\text { Thickness } \\
\text { (mm) }\end{array}$ & $\mathrm{k}_{\mathrm{eff}}$ & error \pm & Literature $\mathrm{k}_{\text {eff }}$ & $\begin{array}{c}\text { Without } \\
\text { Thimble } \\
k_{\text {eff }}\end{array}$ \\
\hline \multirow[t]{5}{*}{184} & 0 & 0 & 1053 & SS-316 & 0.25 & 0.99685 & 0.00041 & $0.993 \pm 0.003$ & 1.00148 \\
\hline & & & & & 0.5 & 0.99174 & 0.00040 & & \\
\hline & & & & & 1 & 0.98404 & 0.00043 & & \\
\hline & & & & & 1.5 & 0.97720 & 0.00041 & & \\
\hline & & & & & 2 & 0.97092 & 0.00042 & & \\
\hline \multirow[t]{4}{*}{184} & 0 & 0 & 1053 & $\mathrm{Zr}-2.5 \mathrm{Nb}$ & 0.5 & 1.00105 & 0.00042 & $0.993+0.003$ & 1.00148 \\
\hline & & & & & 1 & 1.00046 & 0.00041 & & \\
\hline & & & & & 1.5 & 1.00052 & 0.00043 & & \\
\hline & & & & & 2 & 0.99972 & 0.00043 & & \\
\hline
\end{tabular}




\subsection{Control and Material Worths}

The CNPS reports used as reference for this work provided values of various design element worths measured and calculated at the time using MCNP and in some cases deterministic models. This detailed information allows for the comparison between our current MCNP results and the CNPS study results. The CNPS design elements for which worth measurements were performed and that were modeled are: central rod worth in dollars of natural and enriched $\mathrm{B}_{4} \mathrm{C}$ for 184 and 492 fueled channels, stainless steel and zirconium alloy heat pipe worth in cents per kilogram separated into inner and outer core blocks for 184 fueled channels, and the worth in cents per kilogram of the 20-hole experimental channels filled with fuel and graphite. The modeling results and literature information are presented for comparison in Table 5 for the 184-fueled channel configuration. The worth is calculated relative to the voided state in the extra channels and the MCNP results used to calculate worth are shown in Appendix D.

The values reported in Table 5 are in either dollar or cent of reactivity. The conversion to these units was done in this work assuming a delayed neutron fraction (beta) value of 0.00737 .

Table 5. Comparison of CNPS Design Element Worths.

\begin{tabular}{|l|c|c|c|}
\hline & \multicolumn{2}{|c|}{ Literature Values } & \multirow{2}{*}{$\begin{array}{c}\text { Current MCNP } \\
\text { Calc. }\end{array}$} \\
\hline Central Rod Worth (\$), Natural $\mathrm{B}_{4} \mathrm{C}$ & Experiment [1] & $9.03 \pm 0.08$ \\
\hline 184 fueled channel & $8.2 \pm 0.7$ & $7.6 \pm 0.3$ & $9.51 \pm 0.08$ \\
\hline Replacement Worth $(\phi / \mathrm{kg})$ of 20 extra holes, 184 fueled channels \\
\hline Fuel & 10.8 & $11.4 \pm 0.4$ & $12.20 \pm 0.08$ \\
\hline Graphite & $3.3 \pm 5.4$ & $10.7 \pm 0.6$ & \\
\hline
\end{tabular}

The current MCNP modeling for the central rod over-predicted the worth. Conversely, for the other CNPS design elements, the current MCNP model either under-predicted or overpredicted the worths. In general the MCNP modeling results presented in Ref. 1 were closer to experiment values. It is however noted that those earlier MCNP calculations used a much smaller number of neutron histories $(50,000)$ [1] to reduce significantly the computational time. As a result, these earlier MCNP results show much higher uncertainties in the results. Overall, our 
current MCNP results are close to measurement values, though only in the case of the 20-hole replacement with graphite worth experiment is the results better than those presented in Ref. 1.

These results do not reveal any overall single bias in the MCNP benchmark modeling. Rather, it is likely that the uncertainty in the exact heat pipe material composition and modeling simplifications of geometry and fuel slightly skew the result obtained with our current model. The number of neutron histories used for the calculations might also be a source of error.

\subsection{Shim Differential Worth}

The shim differential rod worths for the CNPS "clean" core and fully-loaded core configurations were measured by the experimental team. The measurement results, in cents per centimeter, are presented graphically in Ref. 1. However, it was not described how these plots were generated. The numerical data used to generate the plots were not provided either, so only general information can be obtained from the graph; e.g., the shape of the shim differential worth curve is close to cosine. Note additionally that the exact configuration of the clean core was not provided in Ref. 1; it also referred to the use of an undefined "miscellaneous material" in the 20 extra channels.

We have however generated shim differential worth for the 184- and 492-fueled channel core configurations. These are referred to in the following paragraphs as the clean and fullyloaded cores, respectively. The first attempt to generate the shim differential worth curve was done by modeling with MCNP the shim at various positions in the CNPS core and comparing cases with $1.0 \mathrm{~cm}$ difference in position. This method did not produce meaningful results because the computational uncertainty of each core eigenvalue was larger than the difference between core eigenvalues corresponding to a $1.0 \mathrm{~cm}$ shim position difference.

Alternately, the core $\mathrm{k}_{\mathrm{eff}}$ obtained from the MCNP calculations were used to generate integral worth data for the two core configurations. These integral worth data were then fitted as a function of the shim position. The plots of the integral worth data and polynomial fits are displayed in Figure 7. The correlation coefficient $\left(\mathrm{R}^{2}\right)$ indicates the goodness of the fits. 


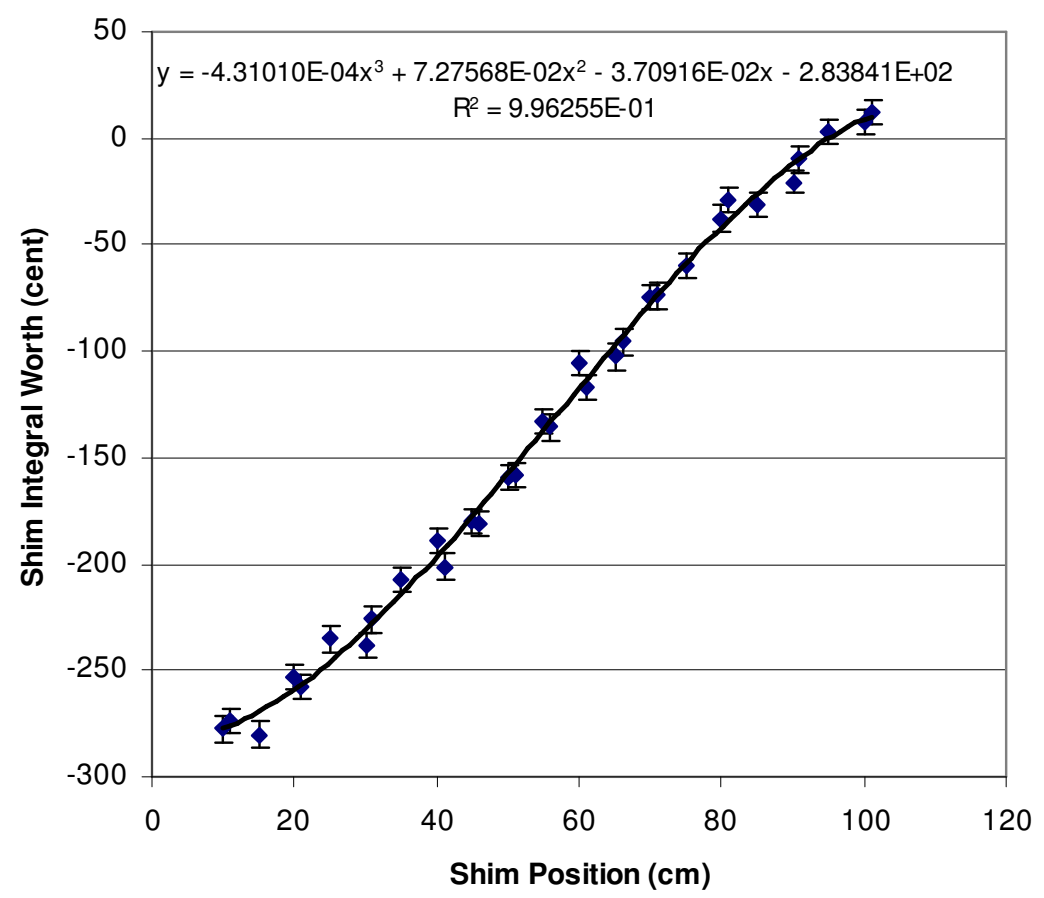

(A)

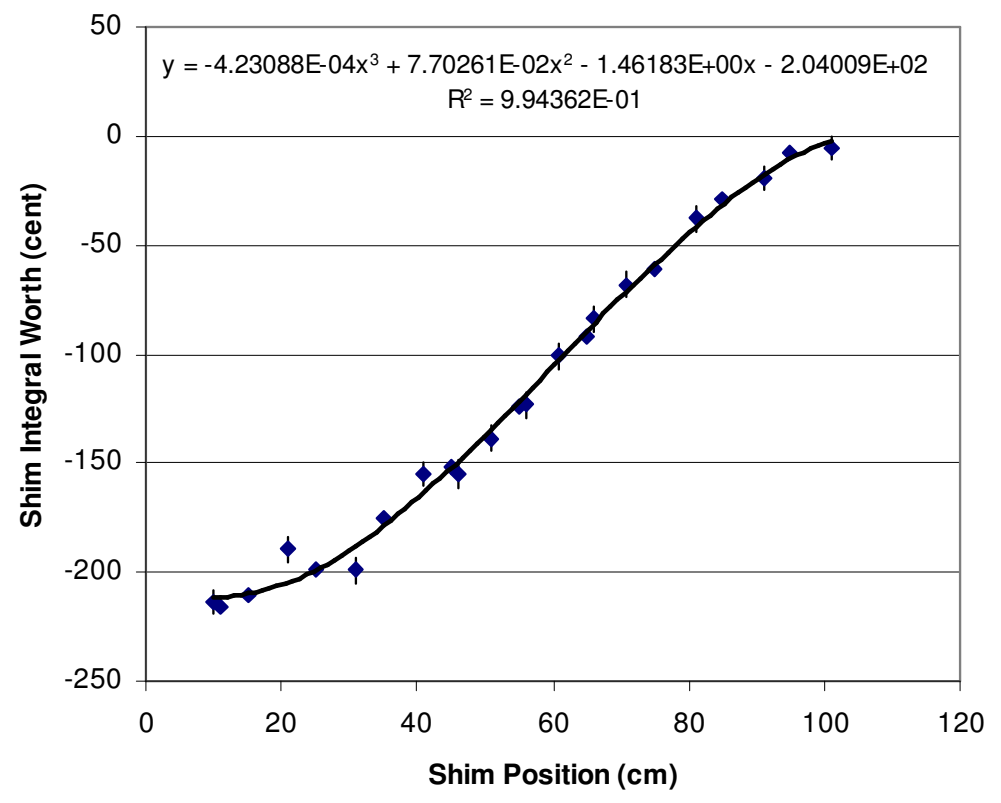

(B)

Figure 7. (A) Shim Integral Worths for 184-Fueled Configuration and (B) Shim Integral Worth for 492-fueld configuration. (Zero position corresponds to the bottom of the active core.) 


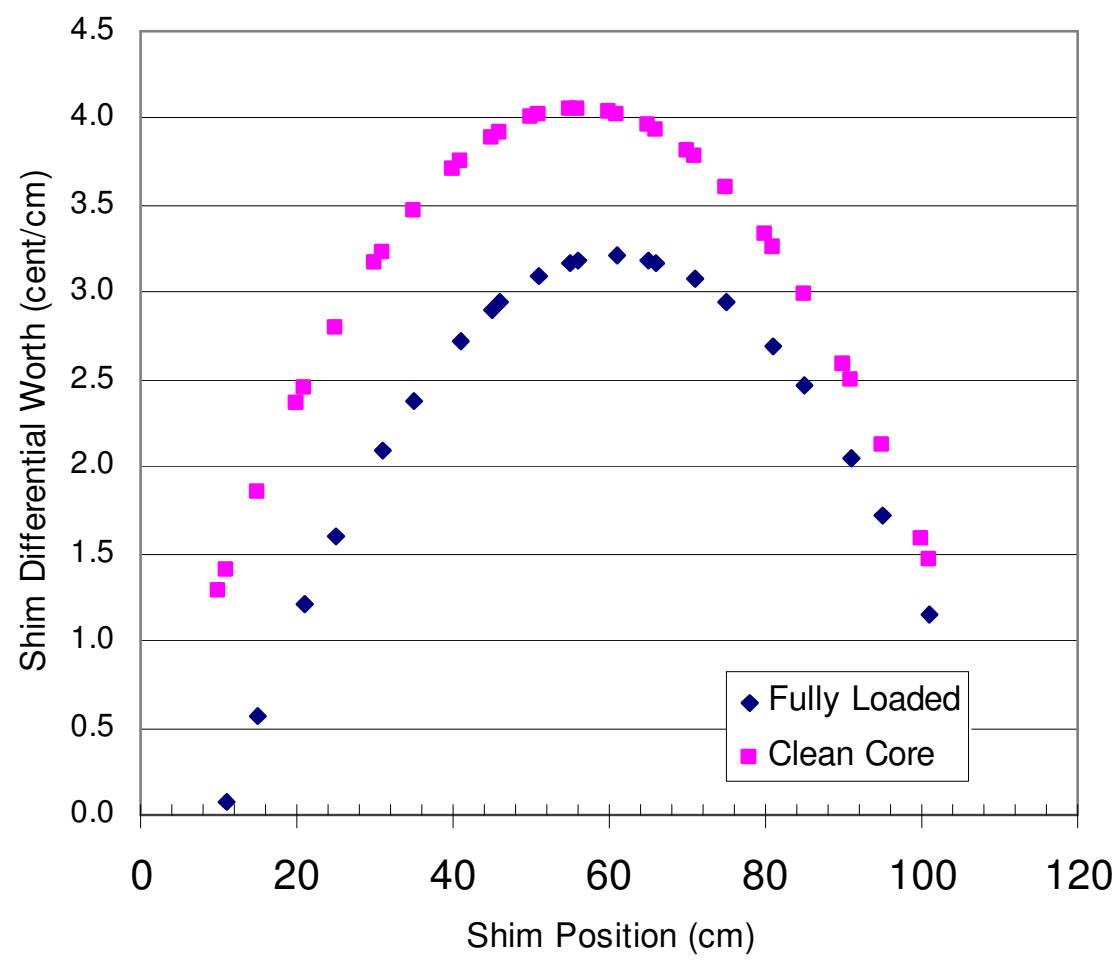

Figure 8. Shim Differential Worths for Clean (184-Fueled) and Full-Loaded (492-Fueled) Core Configurations.

The shim integral curves are then used for determining the shim differential worths by differentiating the curves at points along the core height. The differential worth curves that were obtained are displayed in Figure 8. For both core configurations the maximum shim differential worth agrees with the literature curve, approximately at 3.9 and $3.2 \phi / \mathrm{cm}$ for the clean and fullyloaded configurations respectively.

The other important trend is the asymmetry exhibited in the differential worth of the fully loaded configuration. The asymmetry is also seen in the shim differential curve presented in Ref. 1 for this case. This is because the fully loaded core is heavily poisoned in the lower half by the $\mathrm{B}_{4} \mathrm{C}$ absorber, which tilts the flux upward. [1] Even though calculated values of the shim differential worth do not match the available CNPS literature data, the distinct cosine shape and trends are apparent. 


\section{RELEVANCE OF CNPS TO VHTR}

Some core parameters for the CNPS have been calculated and compared to those for a prismatic block-type VHTR design that were developed in FY 2004. The VHTR used TRISO fuel with a uranium enrichment of $14 \%$ U-235. [6] Results of the comparisons are summarized in this section.

\subsection{Double Heterogeneity Effect}

The fuel packing fraction (coated fuel particle volume fraction in the compact) used for the VHTR design is between $0.20-0.25$, while that for the CNPS is 0.601 . This would suggest different physics behaviors of the cores. A first core parameter that was compared is the double heterogeneity effect of the fuel zone, which provides an indication of the impact of not explicitly treating the self-shielding of the CFPs. This parameter has typically been calculated as the reactivity difference of a calculation using a homogenized compact model and one using an explicit treatment of the CFPs. Calculation of this parameter has been previously done for the VHTR fuel element, and was found to be about $2300 \mathrm{pcm}$.

The MCNP results reported for the CNPS in Section 3 were performed using a homogenized model in which the coated fuel particles (CFPs) and the graphite matrix were smeared (homogenized) into a single compact composition using volume weighting. This was deemed appropriate for the current study, because the double heterogeneity effect was expected to be small due to the high packing fraction (0.601). A model that explicitly represents the CFPs was subsequently developed and used to evaluate the double heterogeneity effect of the CNPS. The 184 fueled-channel core was selected for the explicit CFP calculations. It was assumed that the shim rod is positioned at $105.3 \mathrm{~cm}$ and that the thimble material is $\mathrm{Zr}-2.5 \mathrm{Nb}$ with a thickness of $0.1 \mathrm{~cm}$. The body centered cubic $(\mathrm{BCC})$ regular lattice model was utilized to describe the individual coated fuel particles in the fuel compact. In the BCC model, the "cubic size" was adjusted to conserved the kernel mass. In the Monte Carlo calculations, five-million neutron histories were traced after 50,000 neutron histories were skipped.

Table 6 provides the $\mathrm{k}_{\mathrm{eff}}$ (eigenvalue) obtained from the MCNP4C calculations. Due to the double heterogeneity effect, the $k_{\text {eff }}$ value increases when the coated fuel particles were 
explicitly modeled. The double heterogeneity effect of the CNPS is only $174 \mathrm{pcm}$, compared to the 2300 pcm for the block-type VHTR fuel element. This lower value is due to the much higher CFP packing fraction in the CNPS fuel compact, which tends to minimize the impact of mispredicting the magnitude of the resonance self-shielding.

Table 6. Eigenvalues of CNPS with Different Coated Fuel Particle Models.

\begin{tabular}{|c|c|c|c|c|c|}
\hline $\begin{array}{c}\text { Fueled } \\
\text { Channels }\end{array}$ & $\begin{array}{c}\text { Shim } \\
\text { Position } \\
(\mathrm{cm})\end{array}$ & $\begin{array}{c}\text { Thimble } \\
\text { Material }\end{array}$ & $\begin{array}{c}\text { Thimble } \\
\text { Thickness } \\
(\mathrm{cm})\end{array}$ & $\begin{array}{c}\text { Coated fuel } \\
\text { particle model }\end{array}$ & $\mathrm{k}_{\mathrm{eff}}$ \\
\hline 184 & 105.3 & $\mathrm{Zr}-2.5 \mathrm{Nb}$ & 0.1 & Smeared & $1.00046 \pm 0.00041$ \\
\cline { 5 - 6 } & & & Explicit & $1.00220 \pm 0.00044$ \\
\hline
\end{tabular}

\subsection{Neutron Spectrum}

The neutron spectrum of the CNPS core has been compared to that of the VHTR fuel assembly. The spectrum plots are displayed in Figure 9.

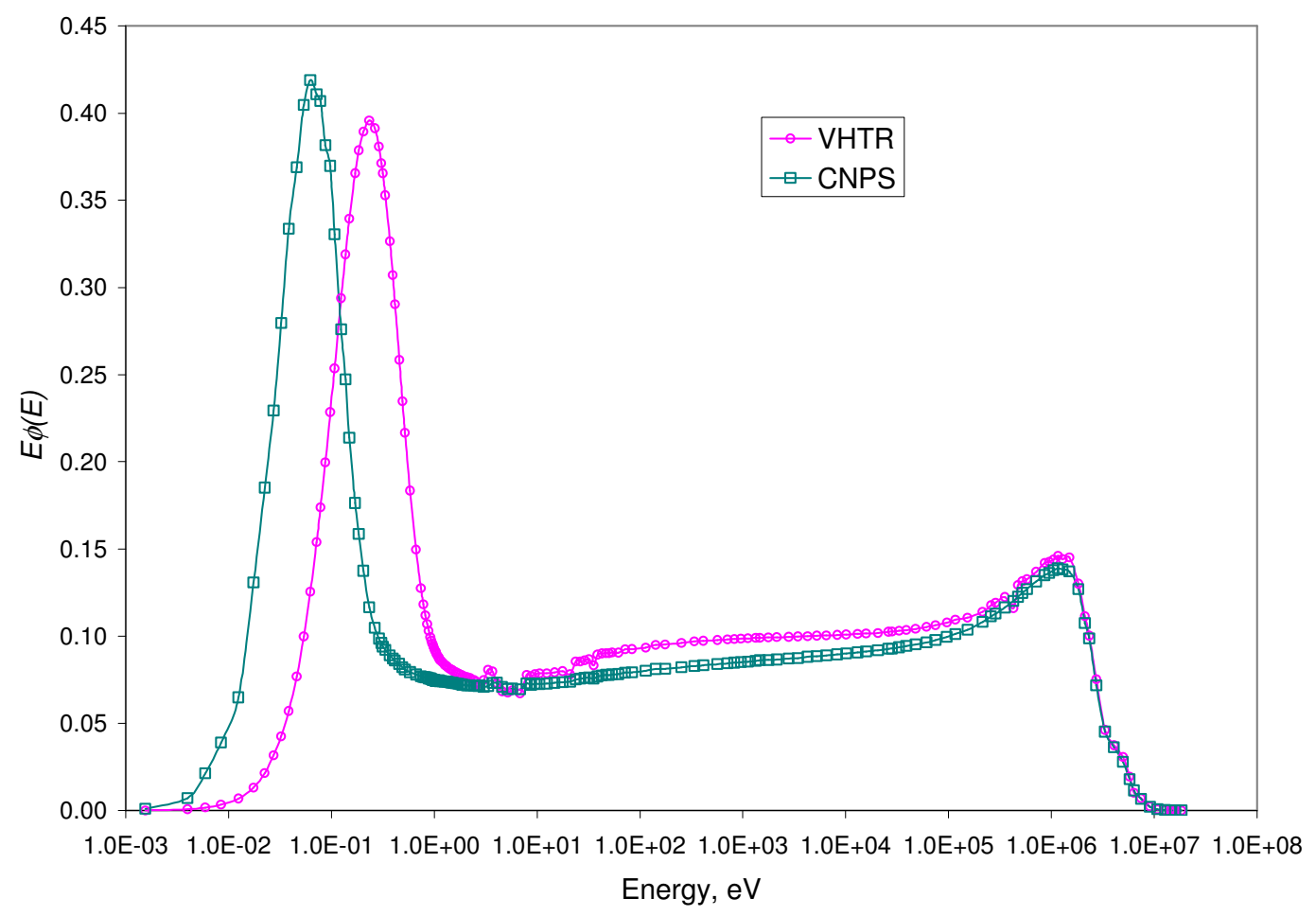

Figure 9. Neutron Spectra for the CNPS and Block-Type VHTR. 
The two spectra have quite similar shapes. The thermal fraction of the VHTR spectrum is however lower and its thermal peak is shifted to higher energy, relative to the CNPS spectrum, because the VHTR assembly has a significantly higher fuel-to-moderator ratio than CNPS core and its calculation was performed at operating temperature conditions; the CNPS calculation was for the cold state in which the experimental measurements were performed. These different spectra might result in different reactivity impacts (magnitude) for these resonances, and might account for the lower double heterogeneity effect observed for the CNPS (though the contributions to the double heterogeneity effect have not been evaluated in this study). 


\section{CONCLUSIONS}

An evaluation of the Compact Nuclear Power Source (CNPS) experiments conducted at the Los Alamos National Laboratory (LANL) in the late 1980s was done in this work using information available in the open literature. Even for the limited sources of information, there were inconsistency in specified values that were mostly attributed to numerical round-off and possible human-errors in recording data in the References. The variations in data did not produce large or unexpected differences in core eigenvalues. A major issue was the initial misinterpretation of the value given for the packing fraction of the fuel particles in the fuel compact. Subsequent analysis indicated that the fuel particle packing fraction is about 0.60 .

The Monte Carlo (MCNP) results that were obtained for critical test configurations have been quite good with $\mathrm{k}_{\text {eff }}$ values within $0.5 \%$ of the critical value of unity. The material worths calculated in this study were in general close to the measurement values and previous MCNP modeling presented in the CNPS literature. The MCNP calculations have provided useful information on the CNPS design. Sensitivity studies on the shim thimble showed that using zirconium alloy as the thimble material resulted in core $\mathrm{k}_{\mathrm{eff}}$ value that would be representative of a critical configuration. For this material, the variation of the thimble thickness from 0.05 to $0.2 \mathrm{~cm}$ had little impact (of order $100 \mathrm{pcm}$ ) on the core $\mathrm{k}_{\mathrm{eff}}$.

The lack of information on design data uncertainties and the inconsistency in the design data from different sources make it difficult to quantify the uncertainty in the core integral parameters arising from design data uncertainties. The evaluated configurations could however be useful as numerical benchmarks that are based on the currently available information. 


\section{ACKNOWLEDGMENTS}

This ANL work was supported by the U.S. Department of Energy, Office of Nuclear

Energy, Science and Technology (Generation IV Program) under Contract number W-31-109-Eng-38. 


\section{REFERENCES}

1. G. E. Hansen and T. G. Palmer, "Compact Nuclear Power Source Critical Experiments and Analysis," Nucl. Sci. Eng., 103, 237 (1989)

2. R. G. Palmer, "Postanalysis of the CNPS Critical Experiments," Proc. Int'l. Reactor Physics Conference, Jackson Hole, Wyo., 18 September 1988.

3. G. E. Hansen, J. H. Audas, E. R. Martin, R. A. Pederson, G. D. Spriggs, and R. H. White, "Critical Experiments in Support of the CNPS Programs," Proc. Int'l. Reactor Physics Conference, Jackson Hole, Wyo., 18 September 1988.

4. J. W. Durkee Jr. and G. E. Palmer, "Neutronic Design Studies for and Unattended, Low Power Reactor," Proceeding of the Topical Meeting on Reactor Physics and Safety, Saratoga Springs, NY, 17-19 September 1986.

5. "Experimental Plan No. 215 - Delayed Critical Operation of CNPS Mock-Up Assemblies, Q2-86-WP-67, January 23, 1986.” (LANL document.)

6. T. K. Kim, W. S. Yang, T. A. Taiwo, H. S. Khalil, "Equilibrium Cycle Analysis in Support of Fuel Specification for Next Generation Nuclear Power Plant," Proc. of ICAPP '05, Seoul, Korea, May 15-19, 2005. 


\section{Appendix A}

Table A.1 Fuel, Control Rod, Heat Pipe, and Extra Hole Channel Positions.

\begin{tabular}{|c|c|c|c|c|c|}
\hline \multicolumn{2}{|c|}{ Fuel Channel } & \multicolumn{2}{c|}{ Fuel Channel } & \multicolumn{2}{c|}{ Fuel Channel } \\
\hline $\mathrm{X}$ & $\mathrm{Y}$ & $\mathrm{X}$ & $\mathrm{Y}$ & $\mathrm{X}$ & $\mathrm{Y}$ \\
\hline \multicolumn{5}{|c|}{ Coordinate of Channels in the 45-deg Core Sector (mm) } \\
\hline 32.33 & 32.33 & 534.99 & 73.41 & 448.48 & 209.62 \\
71.63 & 23.88 & 580.34 & 73.41 & 498.89 & 206.64 \\
119.37 & 23.88 & 119.37 & 119.37 & 540.43 & 223.85 \\
153.59 & 37.40 & 167.12 & 119.37 & 303.85 & 267.59 \\
228.40 & 37.40 & 214.88 & 119.37 & 365.90 & 262.11 \\
262.62 & 23.88 & 300.14 & 124.32 & 425.07 & 253.75 \\
313.91 & 25.65 & 341.67 & 141.53 & 482.11 & 243.25 \\
359.06 & 25.65 & 386.32 & 121.16 & 335.87 & 299.62 \\
404.06 & 25.65 & 433.47 & 121.16 & 398.08 & 294.29 \\
449.36 & 25.65 & 479.99 & 121.16 & 457.77 & 286.45 \\
494.38 & 25.65 & 526.24 & 121.16 & 515.44 & 276.59 \\
539.39 & 25.65 & 572.28 & 121.16 & 367.00 & 331.46 \\
584.49 & 25.65 & 214.88 & 167.12 & 430.19 & 326.41 \\
71.63 & 71.63 & 268.48 & 164.68 & 490.32 & 319.01 \\
119.37 & 71.63 & 465.34 & 168.91 & 399.54 & 363.42 \\
167.12 & 71.63 & 512.91 & 168.91 & 462.25 & 358.48 \\
214.88 & 71.63 & 560.04 & 168.91 & 431.36 & 395.12 \\
262.62 & 71.63 & 239.42 & 203.84 & Control Rods \\
306.29 & 73.41 & 301.05 & 197.26 & 0.00 & 0.00 \\
352.35 & 73.41 & 358.84 & 187.51 & 167.12 & 167.12 \\
398.17 & 73.41 & 271.99 & 235.73 & Heat Pipes \\
444.06 & 73.41 & 333.44 & 229.65 & 191.00 & 0.00 \\
489.57 & 73.41 & 392.18 & 220.85 & 405.49 & 167.96 \\
\hline \multicolumn{7}{|c|}{ Coordinates of Extra Holes in the 90-deg Sector (mm) } \\
\hline 47.75 & 0.00 & 0.00 & 96.51 & 95.51 & 49.60 \\
0.00 & 47.75 & 47.75 & 49.60 & 47.75 & 97.40 \\
95.51 & 0.00 & & & \\
\hline
\end{tabular}




\section{Appendix B}

Table B.1 Description of the Fuel Compact [1,5]

\begin{tabular}{|l|c|c|c|}
\hline \multicolumn{1}{|c|}{ Component } & Thickness $(\mathrm{mm})$ & Density $\left(\mathrm{Kg} / \mathrm{m}^{3}\right)$ & Other \\
\hline Kernel & 0.5065 & 10620 & 0.3 \\
\hline C/U ratio & & & 0.199 \\
\hline O/U ratio & & & \\
\hline Enrichment (weight) & & 960 & \\
\hline Carbon buffer & 0.0790 & 1900 & \\
\hline Pyrolytic graphite & 0.0330 & 3210 & \\
\hline Silicon carbide & 0.0350 & 1870 & 0.601 \\
\hline Pyrolytic graphite & 0.0350 & 700 & \\
\hline Graphite matrix & & & \\
\hline $\begin{array}{l}\text { Fuel particle packing } \\
\text { fraction (by volume) }\end{array}$ & & & \\
\hline
\end{tabular}

Table B.2 Number Densities for Core Materials

Fuel Compact

Core Block

Aluminum Plate

Bottom Reflector

Upper Reflector
Number Density (Atoms/barn-cm)

$6.13572 \mathrm{E}-02$

$5.75967 \mathrm{E}-02$

$$
\mathrm{U}-235
$$

$\mathrm{U}-238$

C

O

$\mathrm{Si}$

B-10

B-11

9.02515E-02

C

B-10

B-11

6.02626E-02

Al-27

8.92488E-02

\section{C}

B-10

B-11

8.77446E-02

C

B-10
Atomic Fractions

Remarks

Smeared over fuel channel

9.24802E-03

3.67543E-02

7.87630E-01

7.82039E-02

8.81594E-02

8.98535E-07

3.65101E-06

9.99999E-01

2.91439E-07

1.18420E-06

$1.00000 \mathrm{E}+00$

9.99998E-01

4.91803E-07 1.35 ppm boron impurity

1.99834E-06

9.99998E-01

4.91803E-07 1.35 ppm boron impurity density $=1.78 \mathrm{~g} / \mathrm{cc}$

density $=1.75 \mathrm{~g} / \mathrm{cc}$ 


\begin{tabular}{|c|c|c|c|c|}
\hline & & B-11 & 1.99834E-06 & \\
\hline \multirow[t]{4}{*}{ Top Reflector } & 8.87474E-02 & & & density $=1.78 \mathrm{~g} / \mathrm{cc}$ \\
\hline & & C & $9.99998 \mathrm{E}-01$ & \\
\hline & & $B-10$ & 4.91803E-07 & $1.35 \mathrm{ppm}$ boron impurity \\
\hline & & B-11 & $1.99834 \mathrm{E}-06$ & \\
\hline \multirow[t]{4}{*}{ Radial Reflector } & $9.02515 \mathrm{E}-02$ & & & density $=1.80 \mathrm{~g} / \mathrm{cc}$ \\
\hline & & C & 9.99999E-01 & \\
\hline & & $B-10$ & $2.91439 \mathrm{E}-07$ & $0.8 \mathrm{ppm}$ boron impurity \\
\hline & & B-11 & $1.18420 \mathrm{E}-06$ & \\
\hline Graphite Rod in & $9.02515 \mathrm{E}-02$ & & & \\
\hline \multirow[t]{4}{*}{ Extra Channels } & 8.47202E-02 & & & Smeared over channel \\
\hline & & $\mathrm{C}$ & 9.99999E-01 & \\
\hline & & B-10 & $2.91439 \mathrm{E}-07$ & $0.8 \mathrm{ppm}$ boron impurity \\
\hline & & B-11 & $1.18420 \mathrm{E}-06$ & \\
\hline \multirow[t]{4}{*}{ B4C Shim } & 4.84999E-02 & & & B4C density $=0.89 \mathrm{~g} / \mathrm{cc}$ \\
\hline & & C & 2.00000E-01 & $19.9 \mathrm{a} / \mathrm{o} \mathrm{B}-10$ \\
\hline & & B-10 & $1.59200 \mathrm{E}-01$ & \\
\hline & & $B-11$ & $6.40800 \mathrm{E}-01$ & \\
\hline \multirow[t]{4}{*}{ Natural B4C Pellet } & $1.25928 \mathrm{E}-01$ & & & $\mathrm{~B}-10$ mass $=7.44 \mathrm{~g}$ \\
\hline & & $\mathrm{C}$ & 2.00000E-01 & 19.75 a/o B-10 \\
\hline & & $B-10$ & $1.58000 \mathrm{E}-01$ & \\
\hline & & $B-11$ & $6.42000 \mathrm{E}-01$ & \\
\hline \multirow[t]{4}{*}{$\begin{array}{l}\text { Enriched B4C } \\
\text { Pellet }\end{array}$} & $1.26088 \mathrm{E}-01$ & & & $\mathrm{~B}-10$ mass $=20.7 \mathrm{~g}$ \\
\hline & & C & $2.00000 \mathrm{E}-01$ & 54.88 a/o B-10 \\
\hline & & $B-10$ & 4.39040E-01 & \\
\hline & & B-11 & $3.60960 \mathrm{E}-01$ & \\
\hline \multirow[t]{11}{*}{ SS316 Heat Pipe } & 8.67142E-02 & & & density $=7.96 \mathrm{~g} / \mathrm{cc}$ \\
\hline & & C & 3.68085E-03 & $0.08 \mathrm{w} / \mathrm{o}$ \\
\hline & & $\mathrm{Mn}$ & 2.01180E-02 & $2 \mathrm{w} / 0$ \\
\hline & & $\mathrm{Si}$ & 1.47573E-02 & $0.75 \mathrm{w} / \mathrm{o}$ \\
\hline & & $\mathrm{Cr}$ & $1.80678 \mathrm{E}-01$ & 17 w/o \\
\hline & & $\mathrm{Ni}$ & 1.12985E-01 & $12 \mathrm{w} / 0$ \\
\hline & & Mo & $1.44002 \mathrm{E}-02$ & $2.5 \mathrm{w} / \mathrm{o}$ \\
\hline & & $P$ & 8.02873E-04 & $0.045 \mathrm{w} / \mathrm{o}$ \\
\hline & & $S$ & 5.17033E-04 & $0.03 \mathrm{w} / 0$ \\
\hline & & $\mathrm{N}$ & $3.94541 \mathrm{E}-03$ & $0.1 \mathrm{w} / \mathrm{o}$ \\
\hline & & $\mathrm{Fe}$ & $6.48115 \mathrm{E}-01$ & $65.495 \mathrm{w} / \mathrm{o}$ \\
\hline Zr Heat Pipe & 4.29823E-02 & & & density $=6.511 \mathrm{~g} / \mathrm{cc}$ \\
\hline
\end{tabular}




\section{Appendix C}

\section{Table C.1 Comparison of Design Specifications from Different Sources}

\section{Fuel Compact}

kernel

diameter $(\mathrm{mm})$

Reference 1 Reference 2 Reference 3

$\begin{array}{ll}\text { C buffer } & \begin{array}{l}\text { enrichment (weight) } \\ \text { thickness }(\mathrm{mm}) \\ \text { density }\left(\mathrm{kg} / \mathrm{m}^{3}\right) \\ \text { thickness }(\mathrm{mm}) \\ \text { PyC }\end{array} \\ \text { density }\left(\mathrm{kg} / \mathrm{m}^{3}\right) \\ \text { thickness }(\mathrm{mm}) \\ \text { PyC } & \begin{array}{l}\text { density }\left(\mathrm{kg} / \mathrm{m}^{3}\right) \\ \text { thickness }\left(\mathrm{mm}^{3}\right) \\ \text { density }\left(\mathrm{kg} / \mathrm{m}^{3}\right)\end{array} \\ \text { C matrix } & \text { density }\left(\mathrm{kg} / \mathrm{m}^{3}\right) \\ \text { Impurity } & \text { boron equivalent, ppm }\end{array}$

density $\left(\mathrm{kg} / \mathrm{m}^{3}\right)$

$\mathrm{C} / \mathrm{U}$ ratio

$\mathrm{O} / \mathrm{U}$ ratio

0.5065

10620

0.274

1.631

0.199

0.079

960

0.033

1900

0.035

3210

0.035

1870

700

5.2

Reference

Fuel Compact Atomic Ratio

$\mathrm{O} / \mathrm{U}$

NL

0.5065

$\mathrm{NL}$

10620

0.274

1.631

$0.1989^{*}$

0.079

960

0.033

$1870^{*}$

0.035

3210

0.035

1870

700

NL

$\mathrm{NL}$

$\mathrm{NL}$

0.199

NL

$\mathrm{NL}$

$\mathrm{NL}$

$\mathrm{NL}$

NL

NL

NL

NL

NL

NL

5.2

$\mathrm{Si} / \mathrm{U}$

NL

$\mathrm{NL}$

1.7

$\mathrm{C} / \mathrm{U}$

$\mathrm{NL}$

$\mathrm{NL}$

1.88

NL

17.34

\section{Fuel Channel}

hole diameter $(\mathrm{mm})$

height $(\mathrm{mm})$

active core height $(\mathrm{mm})$

bottom of active core $(\mathrm{mm})$

12.85

12.85

12.85

1100

1100

1084.6

1084.6

1100

27

27

$\mathrm{NL}$

fuel compacts

22

compact height $(\mathrm{mm})$

50

22

$30^{*}$

22

U235 mass (g)

$\mathrm{NL}$

50

NL

29.25

\section{Core Dimension}

$$
\text { height }(\mathrm{mm})
$$

diameter $(\mathrm{mm})$

1130

1130

1130

1200

1200

1200

\section{Graphite Density $\left(\mathrm{kg} / \mathrm{m}^{3}\right)$}

$$
\begin{aligned}
& \text { central core block } \\
& \text { outer core block } \\
& \text { radial reflector } \\
& \text { bottom reflector } \\
& \text { upper reflector } \\
& \text { top reflector }
\end{aligned}
$$

$\mathrm{NL}$

$\mathrm{NL}$

1780

1800

$\mathrm{NL}$

1750

$1750^{*}$

$\mathrm{NL}$

1770

1750

$\mathrm{NL}$

$1750^{*}$

$\mathrm{NL}$ 
Graphite Impurity (boron equivalent, ppm)

central core block

0.8

outer core block

0.8

radial reflector

0.8

bottom reflector

1.35

upper reflector

1.35

top reflector

1.35

$\begin{array}{ll}N L & N L \\ N L & N L \\ N L & N L \\ N L & N L \\ N L & N L \\ N L & N L\end{array}$

Shim Rod Position (mm above active core bottom)

184 fueled channels

$1053^{*}$

$1160^{*}$

1130 *

202 fueled channels

$366^{*}$

380 fueled channels

$724^{*}$

$346^{*}$

$\mathrm{NL}$

396 fueled channels

$\mathrm{NL}$

492 fueled channels

$604^{*}$

$702^{*}$

$\mathrm{NL}$

$\begin{array}{cc}\mathrm{NL} & 502 \\ 583^{*} & 774^{*}\end{array}$

\section{$\mathrm{B}_{4} \mathrm{C}$ Control Rod Compacts}

diameter $(\mathrm{mm})$

length $(\mathrm{mm})$

23.9

50.13

Natura ${ }^{10} \mathrm{~B}$ atomic percent

19.75

Enriched ${ }^{10} \mathrm{~B}$ atomic percent

54.88

12.57

1633

diameter $(\mathrm{mm})$

length ( $\mathrm{mm}$ )

19.9

${ }^{10} \mathrm{~B}$ atomic percent

NL-Not Listed density $\left(\mathrm{g} / \mathrm{cm}^{3}\right)$

0.89

$\begin{array}{ll}N L & N L \\ N L & N L \\ N L & N L \\ N L & N L\end{array}$

* Difference between references.

\section{References of CNPS Literature}

1. G. E. Hansen and T. G. Palmer, "Compact Nuclear Power Source Critical Experiments and Analysis," Nucl. Sci. Eng., 103, 237 (1989)

2. R. G. Palmer, "Postanalysis of the CNPS Critical Experiments," Proc. Int'l. Reactor Physics Conference, Jackson Hole, Wyo., 18 September 1988.

3. G. E. Hansen, J. H. Audas, E. R. Martin, R. A. Pederson, G. D. Spriggs, and R. H. White, "Critical Experiments in Support of the CNPS Programs," Proc. Int'l. Reactor Physics Conference, Jackson Hole, Wyo., 18 September 1988 


\section{Appendix D}

\section{Table D.1 Worth Results}

\begin{tabular}{|c|c|c|}
\hline 20-Hole & fuel & graphite \\
\hline & 0.6425 & 0.6425 \\
\hline & 108.46 & 108.46 \\
\hline & 140.66 & 140.66 \\
\hline & 1.9 & 1.8 \\
\hline & 267.25 & 253.18 \\
\hline
\end{tabular}

worths relative to void

$\beta=$

0.00737

Core Configuration

keff

without

Central Rod

184-fuled $\quad 0.99174$

replacement of 20-hole

184-fuel

fuel $\quad 0.99746$

graphite $\quad 0.99746$ error \pm

0.00040

$\rho$

$-0.00833$

0.00042

0.00042

\section{keff}

with

error \pm

$\rho$

0.93033

0.00043

$-0.07489$

$\Delta \rho$

0.06656

Worth (\$)

error \pm

\begin{tabular}{l|l}
9.03102 & 0.07969
\end{tabular}

$-0.00255$

$\begin{array}{lll}1.00120 & 0.00040 & 0.00120\end{array}$

$\begin{array}{lll}1.00201 & 0.00044 & 0.00201\end{array}$
0.00375
0.00455

$\begin{array}{ll}0.50815 & 0.07870 \\ 0.61770 & 0.08253\end{array}$
9.50689

12.19855 


\section{Evaluation of the High Temperature Engineering Test Reactor (HTTR) Start-up Experiments}

T. K. Kim, T. A. Taiwo, and Frank Szakaly

Nuclear Engineering Division

9700 South Cass Avenue Argonne National Laboratory

Argonne, IL 60439

September 12, 2005 


\section{Table of Contents}

Abstract .1

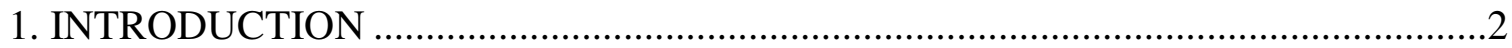

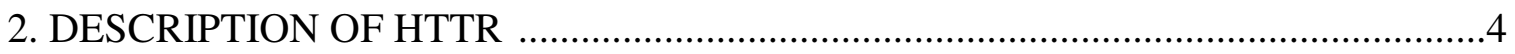

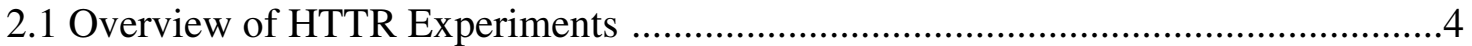

2.2 Description of HTTR Core Configuration .........................................................5

2.3 Fuel Loading Scheme and Fuel Block Designation ...........................................

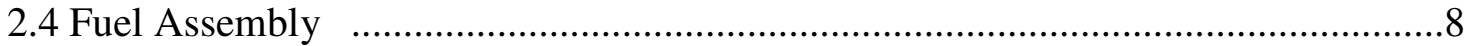

2.5 Burnable Poison Rods and Control Rods .........................................................11

2.6 Replaceable Reflector, Dummy, and Permanent Reflector Blocks .......................13

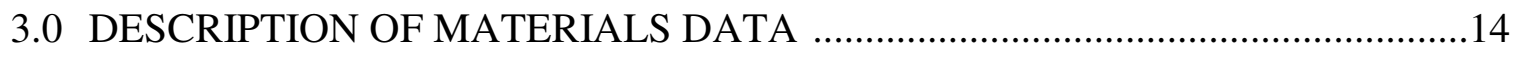

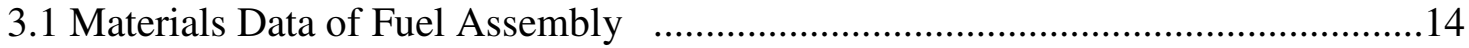

3.2 Materials Data of Reflector, Control Rods Guide and Dummy Blocks ................15

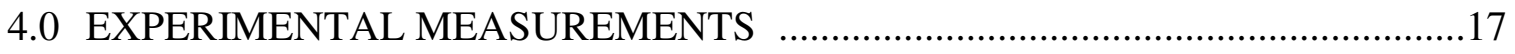

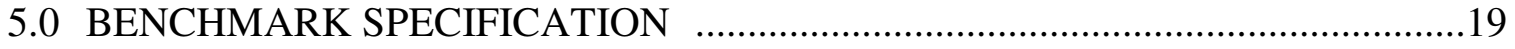

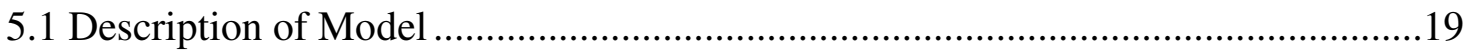

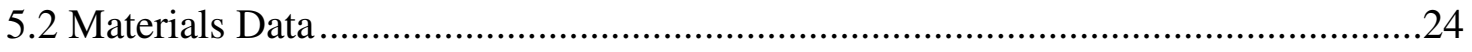

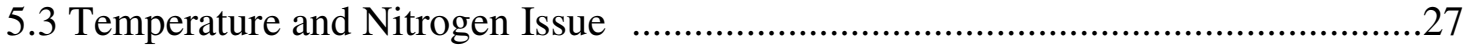

6.0 EVALUATION OF BENCHMARK SPECIFICATION …................................28

6.1 Reference Monte Carlo Calculations ................................................................28

6.1.1 Number of Columns Required for First Criticality....................................29

6.1.2 Position of Control Rods for Critical Configurations ..................................29

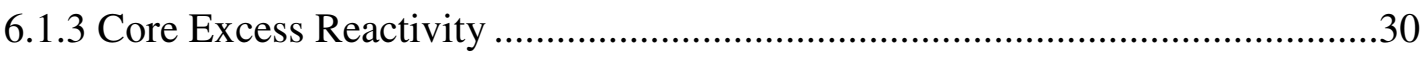

6.1.4 Comparison to Other Monte Carlo Results...................................................30 
6.1.5 Impact of Regular Lattice versus Random CFP Modeling ..............................31

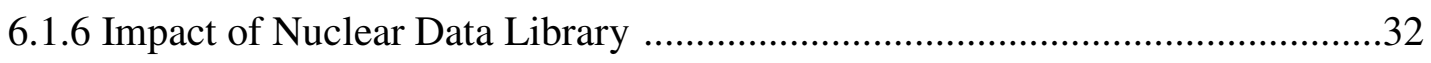

6.1.7 Impact of Homogeneous versus Heterogeneous Compact Modeling …….......33

6.1.8 Impact of Impurity on Core Criticality ............................................................33

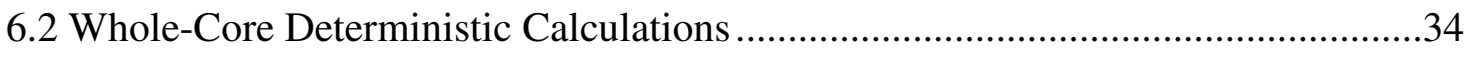

6.2.1 Descriptions of the DRAGON and DIF3D codes ............................................34

6.2.2 Lattice and Core Modeling ................................................................................

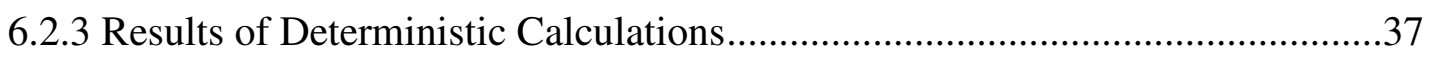

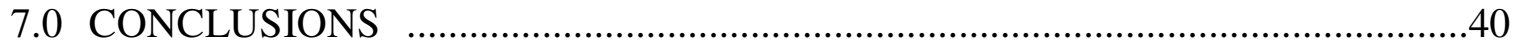

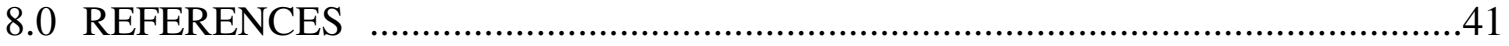




\section{List of Tables}

Table 2.1. Primary Design Parameters of HTTR ........................................................

Table 2.2. Configurations of Fuel Blocks in HTTR Core ...........................................11

Table 3.1. Materials Data of Fuel Compacts ...........................................................14

Table 3.2 Materials Data of Coated Fuel Particles ...................................................15

Table 3.3. Materials Data of Fuel Compacts ..........................................................16

Table 4.1. Measured Data in HTTR Start-up Core ......................................................18

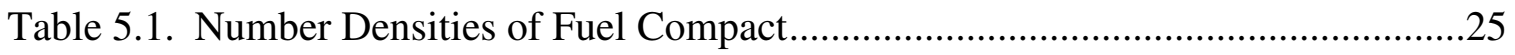

Table 5.2. Number Densities of Graphite Block and Control Rods .............................26

Table 5.3. Number Densities in Replaceable Reflector Blocks ....................................26

Table 5.4. Number Densities of Control Rods Guide Blocks ......................................26

Table 5.5. Number Densities of Dummy Blocks ....................................................26

Table 6.1. Comparison of Number of Columns for First Criticality .............................29

Table 6.2. Control Rods Positions at Critical Conditions .............................................30

Table 6.3. Eigenvalues of HTTR Core Calculations .................................................30

Table 6.4. Comparison of Monte Carlo Calculations for Full-Core Case ......................31

Table 6.5. Comparison of $\mathrm{k}_{\mathrm{eff}}$ Obtained with Different Libraries .................................32

Table 6.6. Eigenvalues of HTTR Core Calculations ...................................................33

Table 6.7. Comparison of HTTR and VHTR Fuel Parameters .......................................37

Table 6.8. Eigenvalue Comparison for Deterministic HTTR Core Calculations .............39 


\section{List of Figures}

Page

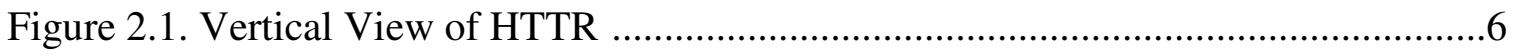

Figure 2.2. Horizontal View of HTTR and Fuel Column Loading Order ........................

Figure 2.3. Structure of Fuel Assembly ..................................................................

Figure 2.4. Graphite Blocks with 31 and 33 Fuel Holes.............................................10

Figure 2.5. Fuel Assembly Zones in HTTR Core .......................................................10

Figure 2.6. Axial Heterogeneity of Burnable Poison Rods ............................................12

Figure 2.7. Control Rods Guide Block from 1st to 5th Layers.......................................12

Figure 5.1. Core Layout for HTTR Benchmark Model ...............................................19

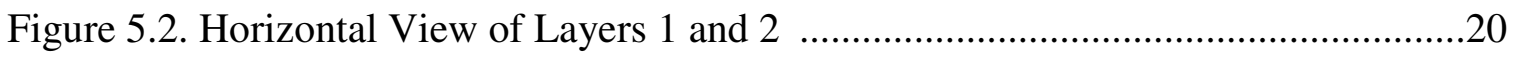

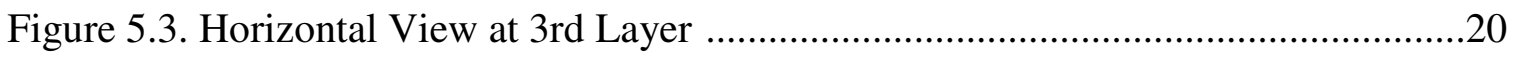

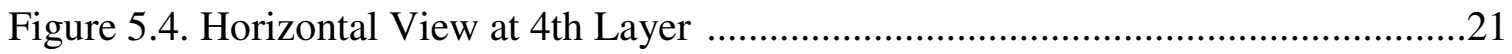

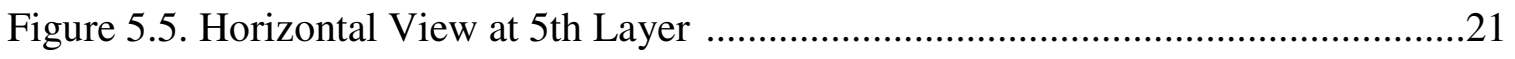

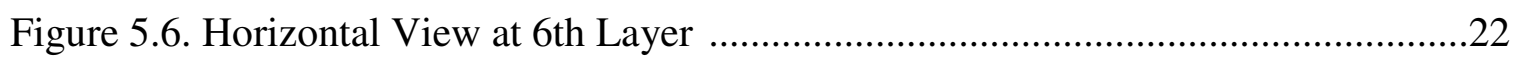

Figure 5.7. Horizontal View at 7th Layer ....................................................................22

Figure 5.8. Horizontal View at 8th Layer ............................................................23

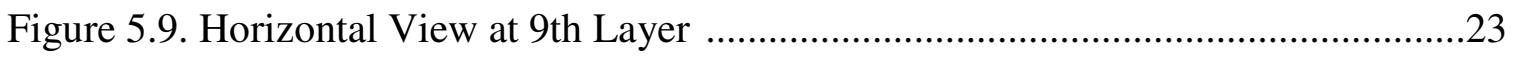

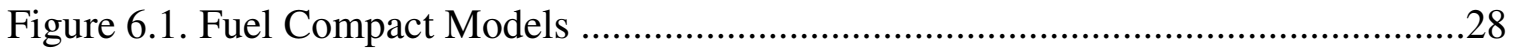

Figure 6.2. An Approximation Model for Generating Cross Sections of Control Rod

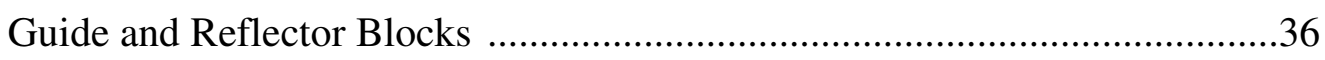

Figure 6.3. Block Models According to Axial BP Homogenization Approach ................37

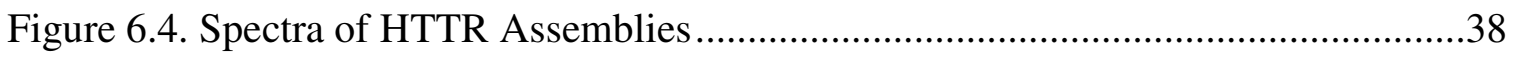




\begin{abstract}
An evaluation of the High Temperature Engineering Test Reactor (HTTR) start-up experiments has been performed using the data available in open literature. Monte Carlo (MCNP) and deterministic models were developed and used for the analysis of the four critical configurations of the HTTR, which were attained along the path to full-core loading. The results obtained show a significant difference $(1.8 \% \Delta \mathrm{k} / \mathrm{k})$ between the core criticality calculated by the MCNP code and the experimental measurement; larger differences of about $2.3-3.4 \% \Delta k / k$ were found for the deterministic codes. These discrepancies are consistent with those reported during an HTTR experiment evaluation effort previously arranged by the IAEA. The magnitudes of these differences are attributed to the incomplete specification of the HTTR core configuration (e.g., impurities and nitrogen in graphite, design data uncertainties, etc), uncertainties in nuclear data, and of approximations inherent in the code solution methods (primarily for the deterministic codes). Due to the incomplete data, it is not possible at this stage to state conclusively the major contributions to the discrepancies.
\end{abstract}




\section{INTRODUCTION}

To give assurance that reactor analysts will be using a code capable of generating results that are representative of the system being analyzed, it is imperative that the code be used to model basic experiments or mock-ups of the system. This so-called validation step is important in the licensing of a reactor system. The task is however not straightforward for advanced systems, e.g., the Very High Temperature Reactor (VHTR), for which no experimental or mockup facilities exists. This problem can be overcome initially by using representative and well documented numerical benchmarks to identify code limitations and needed improvements in code data and methodologies. Additionally, at a latter stage in the system life (e.g., at start-up), data would have to be generated to provide indications of the ability of the codes to represent accurately the system. Another approach that could be used in conjunction with those above would be to find existing representative experiments that could be used to evaluate the code performance for similar systems.

In FY 2004, a set of such existing experimental tests of potential relevance to VHTR (pebble-type and prismatic block-type) were identified by ANL and INL personnel. The experiments were ranked in order of relevance. One of the experiments given a high priority ranking is the High Temperature Engineering Test Reactor (HTTR) start-up test performed at JAERI (Japan) in the late 1990s. [1-3] This facility uses low enriched uranium fuel encased in TRISO fuel layers being considered for the VHTR. Additionally, the moderator and reflectors in the HTTR core are made of materials that are similar to those for the VHTR (graphite). Because of these attractions, the open literature information available on the HTTR start-up tests have been collected and used in an exercise designed to evaluate the performance of some of the Monte Carlo and deterministic tools available at ANL. The limitation in data is due to the fact that at the time of this effort no additional source of data (e.g., more detailed or proprietary data) was available to us. This report summarizes the results of the evaluation.

In Section 2, an overview of the HTTR experiments is presented along with a fairly detailed description of the core configurations and constituents. Material data for the various core constituents are presented in Section 3. Section 4 contains a description of the experimental 
measurements and values derived from the measurements. In Section 5, the models that were developed in this study are presented along with the number densities derived from the data provided in Section 3. The results of the evaluations that have been performed are summarized in Section 6. Section 7 contains the conclusions from this study. 


\section{DESCRIPTION OF HTTR}

\subsection{Overview of HTTR Experiments}

In the late 1980s, the Japan Atomic Energy Commission (JAEC) issued a revised report on the "Long Term Program for Development and Utilization of Nuclear Energy." The report stressed that Japan should proceed to develop more advanced reactor technologies in parallel with the upgrading of existing nuclear reactors. It was recognized in that program plan that though the High Temperature Gas cooled Reactor (HTGR) was not to be incorporated into the existing nuclear power plant systems there were benefits to be derived from its deployment, such as its inherent safety and its utilization for the production of high temperature heat, and should be pursued. [2] The JAEC also concluded that the demand for nuclear heat application (up to $\sim 1,000{ }^{\circ} \mathrm{C}$ ) is expected to become strong in the early part of the $21^{\text {st }}$ century. Within this program, the committee recommended the construction of a test reactor to test and study advanced HTGRs. The committee's report also stated that the maximum reactor coolant outlet temperature should be $950{ }^{\circ} \mathrm{C}$, which is the highest temperature attainable considering the current technology level. For irradiation test, a prismatic block type core structure was proposed, with a thermal power rating of $30 \mathrm{MW}$. Based on these suggestions, the Japan Atomic Energy Research Institute (JAERI) started building the High Temperature Engineering Test Reactor (HTTR) in 1992 and the first criticality was attained with an annular core type on November 10, 1998. [1-4]

The objectives of the HTTR program are to establish and upgrade the technological basis for the Advanced High Temperature Gas-cooled Reactors and to conduct various irradiation tests in support of innovative high-temperature basic research. The HTTR was designed to keep all specific safety features within the graphite blocks. The intermediate heat exchanger is equipped to supply high temperature helium, and the control system is designed to allow operation that simulates anticipated operational occurrences (AOO). The primary design requirement of the HTTR are $[2,5]$ : (1) coated fuel particles shall not fail during normal operation and AOO; to satisfy this requirement, the maximum fuel temperature shall not exceed $1600{ }^{\circ} \mathrm{C}$ for any AOO, (2) the reactor shall be shut-down safely and reliably during operation using the control system; 
furthermore, a reserved shutdown system (RSS) which is independent of the control system shall be provided, and (3) the residual heat after shutdown shall be removed safely, etc.

The primary design parameters of the HTTR are provided in Table 2.1. The thermal output of the HTTR is $30 \mathrm{MWt}$ and the coolant outlet temperature is designed to be $850{ }^{\circ} \mathrm{C}$ at the rated operation, but it is allowed to be $950{ }^{\circ} \mathrm{C}$ for high temperature test operating conditions. The design life of permanent structural components in the HTTR plant is 20 years with a load factor of $60 \%$ of full power operation. [1,2,4]

Table 2.1. Primary Design Parameters of HTTR [4]

\begin{tabular}{|l|c|c|}
\hline \multicolumn{1}{|c|}{ Design parameter } & Unit & Value \\
\hline Thermal power & $\mathrm{MWt}$ & 30 \\
Coolant outlet temperature & ${ }^{\circ} \mathrm{C}$ & $850\left(950^{\mathrm{a})}\right)$ \\
Coolant Inlet temperature & ${ }^{\circ} \mathrm{C}$ & 395 \\
Primary coolant pressure & $\mathrm{MPa}$ & 4 \\
Core structure & - & Graphite \\
Equivalent core diameter & $\mathrm{m}$ & 2.3 \\
Effective core height & $\mathrm{m}$ & 2.9 \\
Average power density & $\mathrm{W} / \mathrm{cm}^{3}$ & 2.5 \\
Fuel uranium enrichment & $\mathrm{wt} \%$ & $3.4-9.9$ \\
Cycle length & $\mathrm{EFPD}$ & 660 \\
Coolant material & - & Helium gas \\
Flow direction & - & Downward \\
Reflector thickness (top/radial/bottom) & $\mathrm{m}$ & $1.16 / 0.99 / 1.16$ \\
Number of fuel block & - & 150 \\
Number of fuel column & - & 30 \\
Number of pairs of control rods (in core/reflector) & - & $7 / 9$ \\
\hline
\end{tabular}

a) High temperature test condition

\subsection{Description of HTTR Core Configuration}

Figures 2.1 and 2.2 show the vertical and horizontal cross sections of the HTTR. The core consists of core components and reactor internals. They are arranged in the reactor pressure vessel, which is $13.2 \mathrm{~m}$ high and $5.5 \mathrm{~m}$ in diameter. The core components are prismatic hexagonal blocks $58 \mathrm{~cm}$ high and $36 \mathrm{~cm}$ wide across the flats. These include fuel element blocks, control rods guide blocks, replaceable reflector blocks, and irradiation blocks. There is a small gap $(2 \mathrm{~mm})$ between the hexagonal graphite blocks. The reactor internals consist of graphite and metallic core support structures and shielding blocks. 
The active core, which has a height of $2.9 \mathrm{~m}$ and an effective diameter of $2.3 \mathrm{~m}$, consists of 30 fuel columns and 7 control rods guide columns. One column is composed of 9 core components piled up axially. Each fuel column consists of 2 top reflectors, 5 fuel blocks, and 2 bottom reflector blocks. The replaceable reflector region adjacent to the active core consists of 9 control rod columns, 12 replaceable reflector columns, and 3 irradiation columns, which are surrounded by permanent reflector blocks.

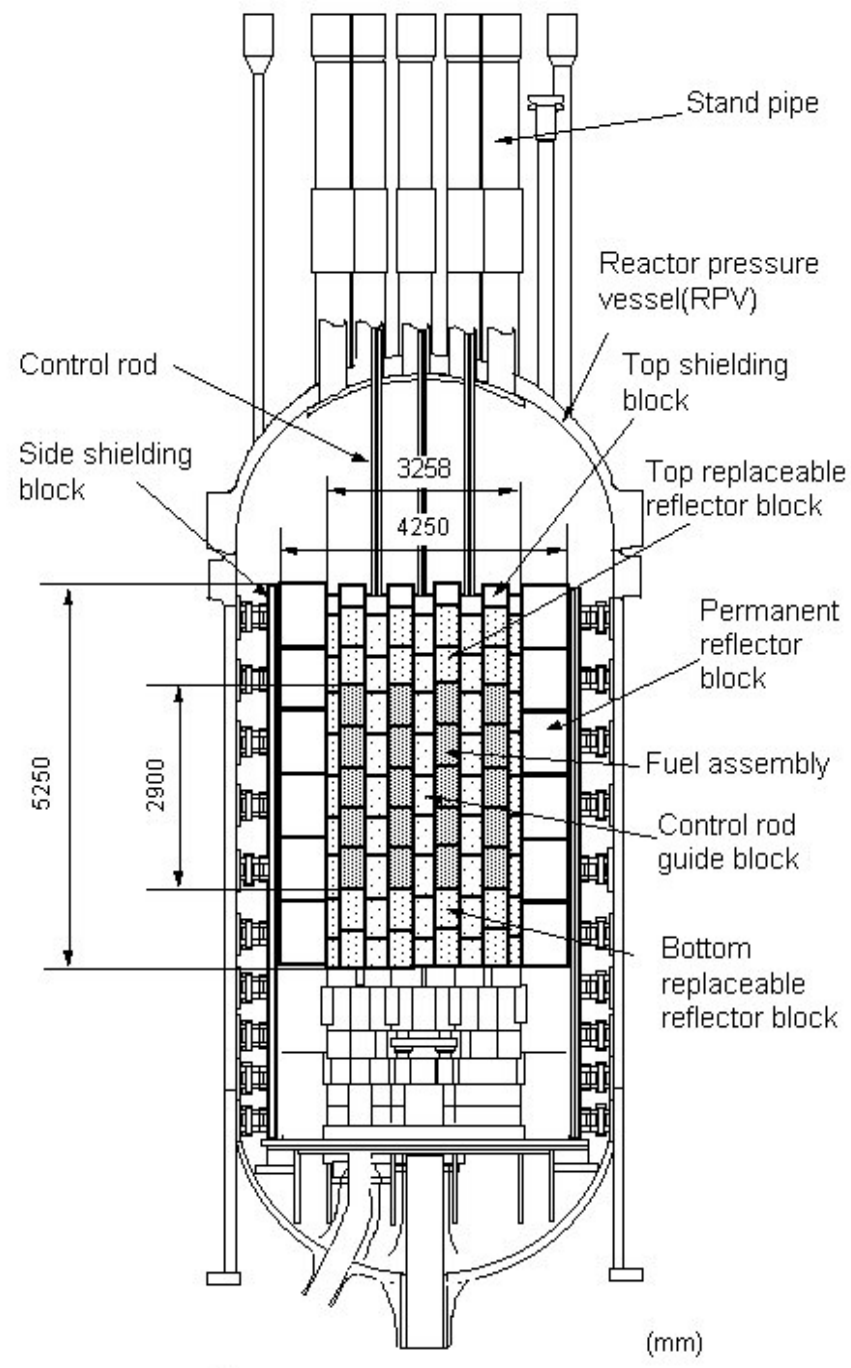

Figure 2.1. Vertical View of HTTR [4] 


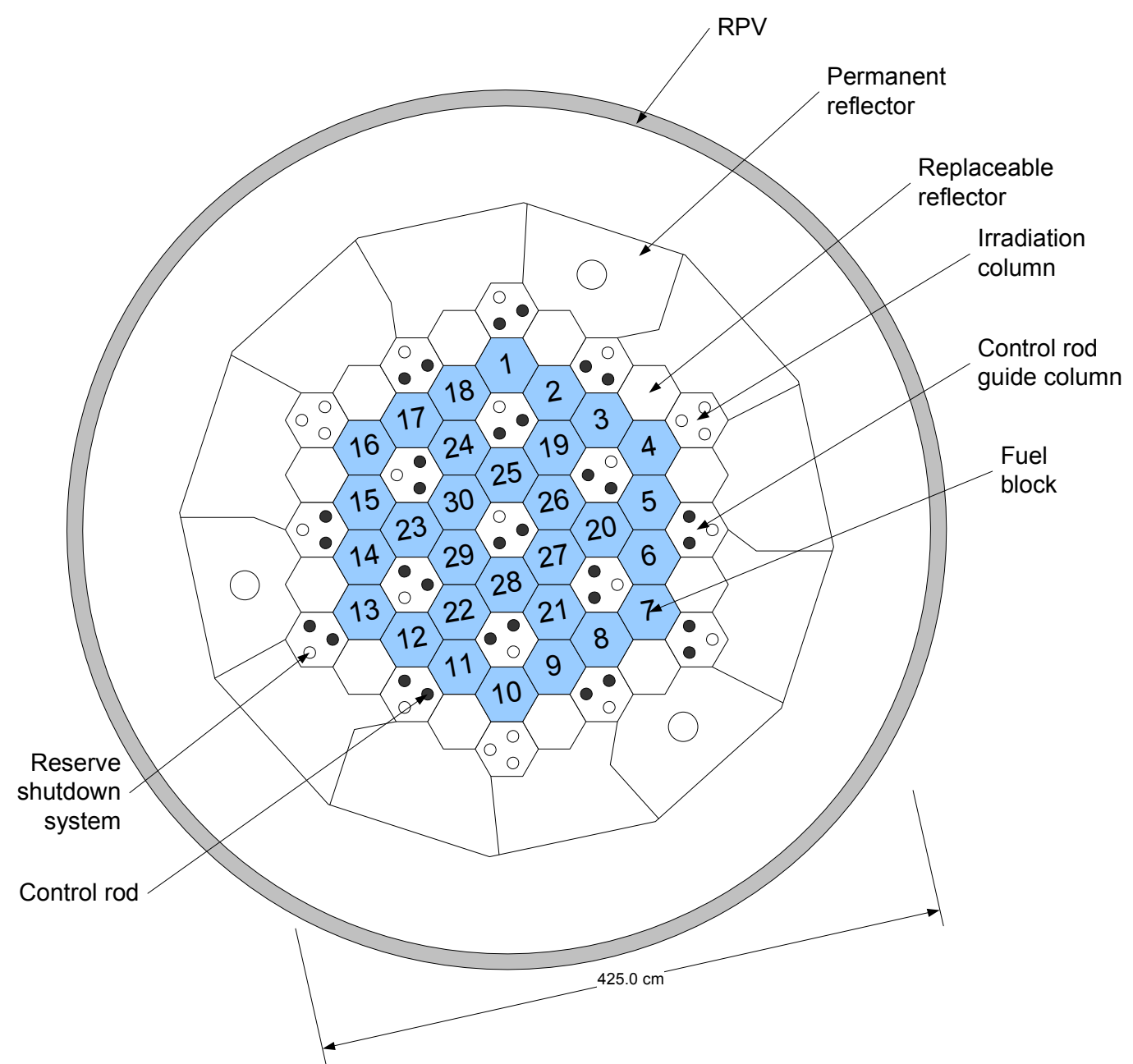

Figure 2.2. Horizontal View of HTTR and Fuel Column Loading Order [4]

\subsection{Fuel Loading Scheme and Fuel Block Designation}

An annular core is one of the promising core types for the future Very High Temperature Rector (VHTR) because of its high inherent safety characteristics following a loss of coolant accident. The decay heat removal is enhanced by introduction of the annular core because the heat transfer path will be shortened due to the relatively thin active core region. As a result, the fuel temperature in a loss of coolant accident can be maintained at less than the fuel temperature limit of $1600{ }^{\circ} \mathrm{C}$. Thus, an annular core was planned as the approach to the first critical core type of the HTTR. It was anticipated that the experimental data for the annular core would be useful for the validation of computation tools and models for large-scale annular type VHTR cores. 
Before fuel loading, the whole fuel region in the core is filled with dummy graphite blocks. The primary coolant system is filled with helium at normal atmospheric pressure and it is not in operation during fuel loading. [4] The core is at room temperature. To implement an annular core, the loading order of the fuel columns into the core was determined as shown in Figure 2.2; the fuels are loaded at first into the outermost rings of the active core and sequentially loaded into the core center. In experiments, the first critical core was obtained with 19 fuel columns [1] and all control rods fully withdrawn from the core. This means that the annular critical core was obtained by loading the fuel columns into the outermost core zone mostly. After the first criticality, subsequent core criticality was maintained by inserting control rods in the core. In the path to a full-core loading, two different annular cores were obtained in this experiment: a thin annular core with 18 fuel columns and a thick annular core with 24 fuel columns.

In this experiment, the position of a block in the core is distinguished by using the axial layer number and the radial column number. The axial layer numbers are counted from the top to the bottom of the core. For the radial column number, the column rings are alphabetically assigned from the core center, and the fuel blocks in the same ring are counted from the north in clockwise direction. For example, " $4 \mathrm{CO} 5$ " block means that the block is located at the $4^{\text {th }}$ layer from the top of the core, the $3^{\text {rd }}$ ring from the core center, and the $5^{\text {th }}$ block from the north in clockwise direction.

\subsection{Fuel Assembly}

Figure 2.3 shows the structure of the fuel assembly. A fuel assembly consists of fuel rods, burnable poison (BP) rods, and a fuel graphite block. The fuel rods are inserted into fuel holes of $4.1 \mathrm{~cm}$ diameter. The fuel rod is formed by the graphite sleeve (clad) containing 14 fuel compacts. The outer diameter of the graphite sleeve is $3.4 \mathrm{~cm}$. There is no separate hole for the coolant and the coolant flows between the fuel rods and fuel holes. The fuel compact consists of coated fuel particles (CFPs) and graphite matrix. The form is a hollows cylinder of $1.0 \mathrm{~cm}$ inner diameter, $2.6 \mathrm{~cm}$ outer diameter, and $3.9 \mathrm{~cm}$ in height. Each fuel compact contains about 13000 CFPs embedded in the graphite matrix (the total number of CFPs is dependent on the packing fraction). A CFP consists of a spherical fuel kernel of low enriched $\mathrm{UO}_{2}$ and the TRISO coating. 
From the center of the CFP, the materials of TRISO coating are a low-density porous Pyrolytic Carbon (PyC) buffer layer, a high density PyC layer, a silicon-carbide (SiC) layer, and an outer PyC layer.

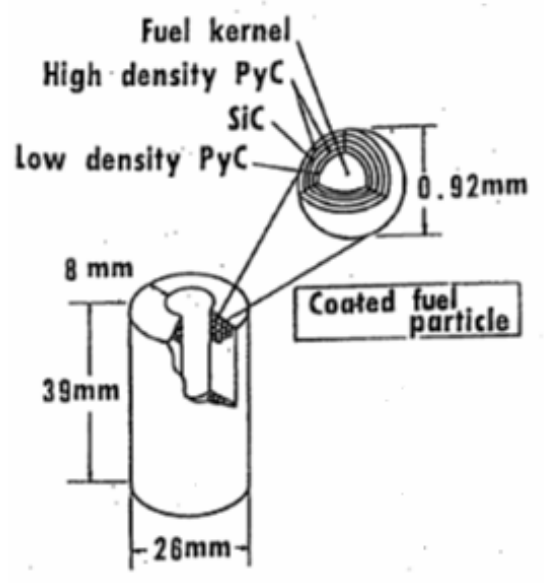

Fuel compact

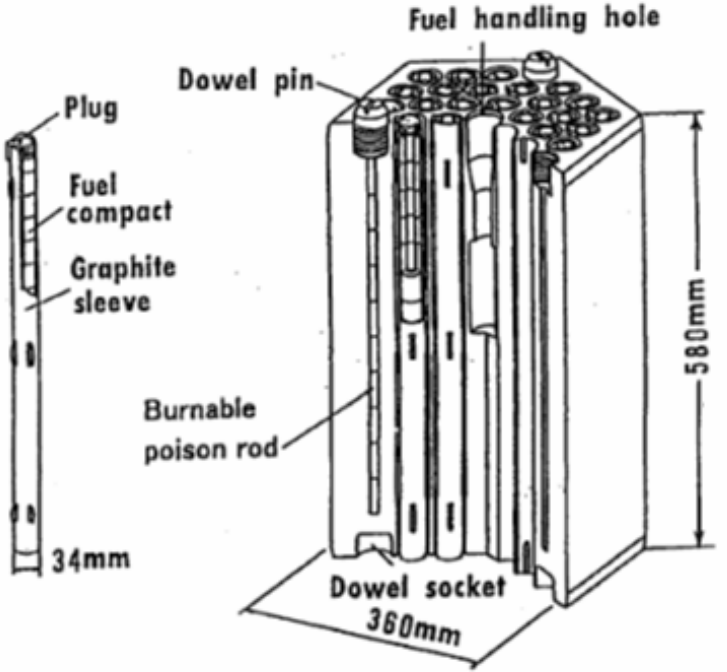

Fuel assembly

Figure 2.3. Structure of Fuel Assembly [4]

The HTTR has two types of fuel graphite blocks having 31 or 33 fuel rods (see Figure 2.4). Both graphite blocks have one fuel-handling hole and three holes for burnable poison (BP) rods; two of these holes are occupied by BPs and the other one is empty. In total, 12 different enriched uranium fuels and two different types of burnable poisons were used in the HTTR core (detailed information about BP are described in Section 2.5). The highest and lowest enrichments are $9.9 \%$ and $3.4 \%$, respectively. The active core region is divided into four zones as shown in Figure 2.5 and the configuration of the fuel blocks are provided in Table 2.2. Fuels of higherenriched uranium are placed in the upper and outer core regions, and fuel graphite blocks having 33 fuel rods are locate in zones 1 and 2. This loading scheme helps to reduce the maximum fuel temperature because a downward coolant flow direction is used in the HTTR. 

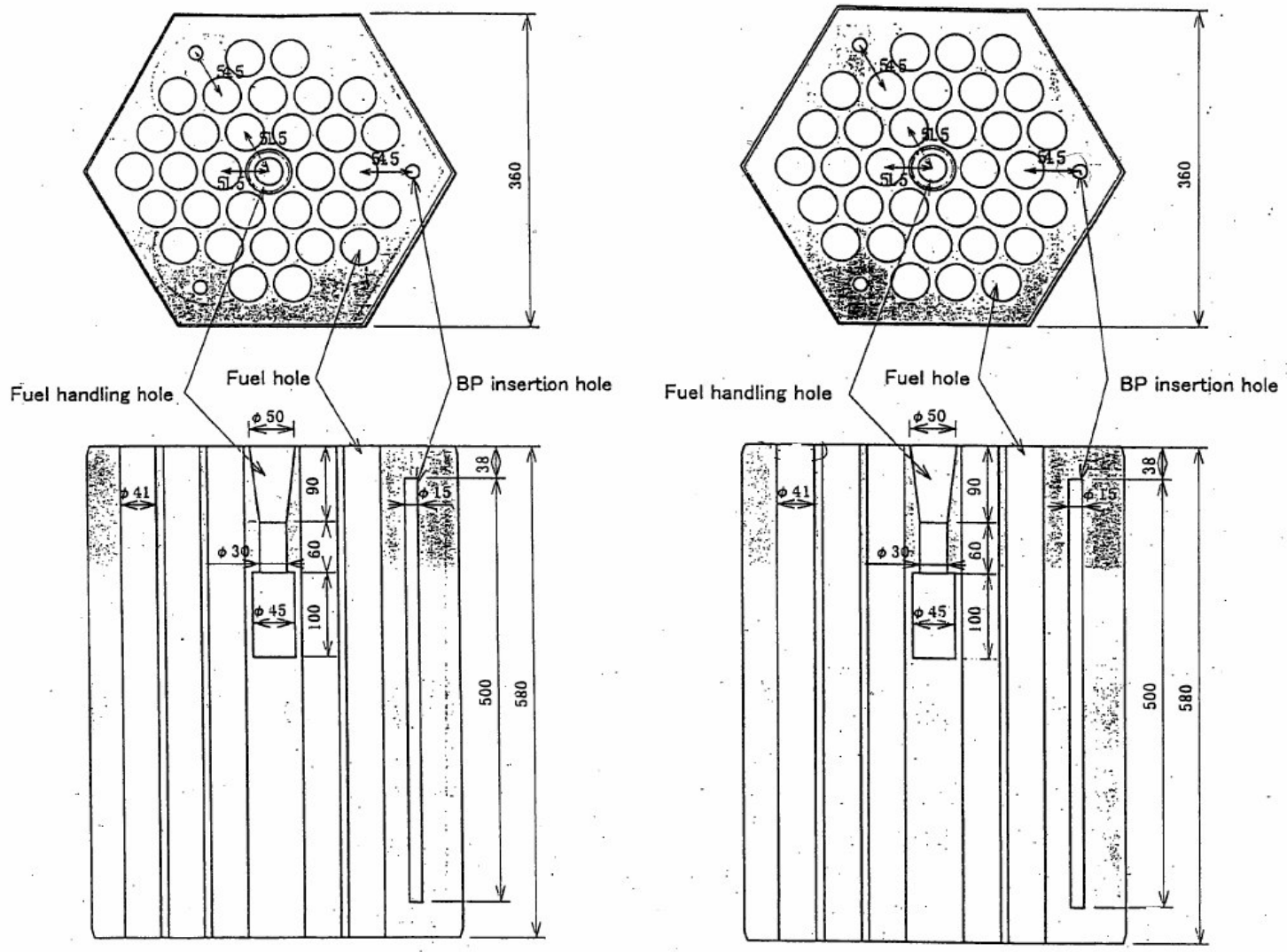

Figure 2.4. Graphite Blocks with 31 (left) and 33 (right) Fuel Holes [4]

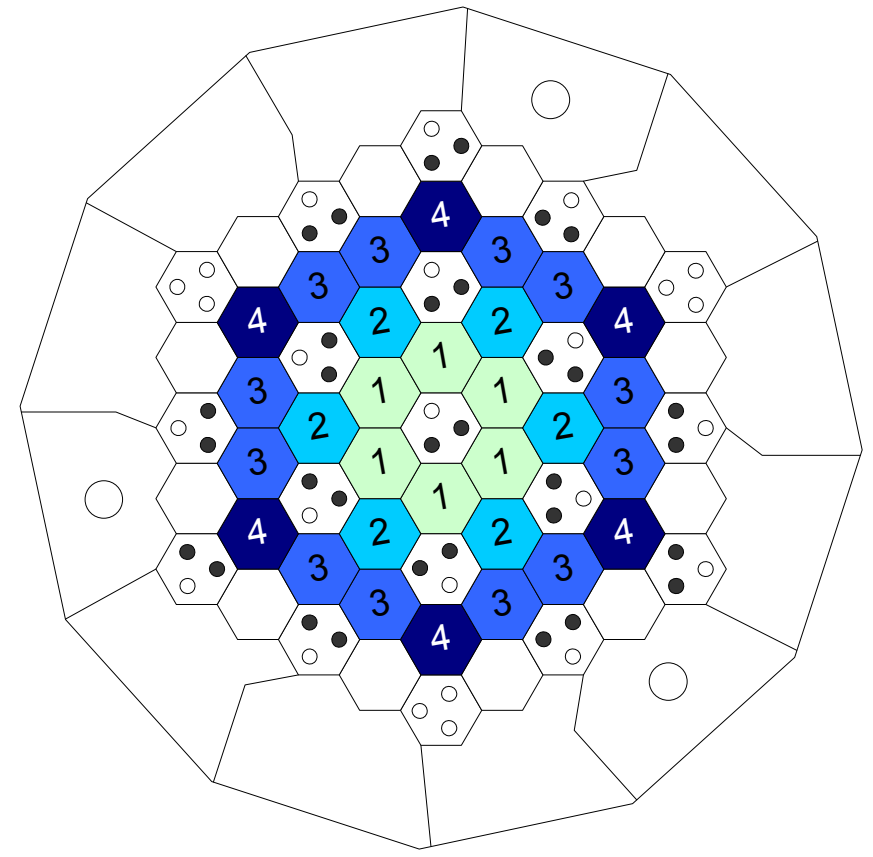

Figure 2.5. Fuel Assembly Zones in HTTR Core [4] 
Table 2.2. Configurations of Fuel Blocks in HTTR Core [4]

\begin{tabular}{|c|l|c|c|c|c|}
\hline \multirow{2}{*}{$\begin{array}{c}\text { Axial layer } \\
\text { number }\end{array}$} & \multicolumn{1}{|c|}{ Items } & \multicolumn{4}{|c|}{ Fuel zone number } \\
\cline { 2 - 5 } 3 & & 1 & 2 & 3 & 4 \\
\hline \multirow{3}{*}{3} & Uranium enrichment (\%) & 6.7 & 7.9 & 9.4 & 9.9 \\
& Number of fuel rods & 33 & 33 & 31 & 31 \\
& Burnable poison type & H-1 & H-1 & H-1 & H-1 \\
\hline \multirow{4}{*}{4} & Uranium enrichment (\%) & 5.2 & 6.3 & 7.2 & 7.9 \\
& Number of fuel rods & 33 & 33 & 31 & 31 \\
& Burnable poison type & H-II & H-II & H-II & H-II \\
\hline \multirow{3}{*}{5} & Uranium enrichment (\%) & 4.3 & 5.2 & 5.9 & 6.3 \\
& Number of fuel rods & 33 & 33 & 31 & 31 \\
& Burnable poison type & H-II & H-II & H-II & H-II \\
\hline \multirow{3}{*}{7} & Uranium enrichment (\%) & 3.4 & 3.9 & 4.3 & 4.6 \\
& Number of fuel rods & 33 & 33 & 31 & 31 \\
& Burnable poison type & H-1 & H-1 & H-1 & H-1 \\
\hline & Uranium enrichment (\%) & 3.4 & 3.9 & 4.3 & 4.6 \\
& Number of fuel rods & 33 & 33 & 31 & 31 \\
& Burnable poison type & H-1 & H-1 & H-1 & H-1 \\
\hline
\end{tabular}

a) Axial layer number from the top of the core.

\subsection{Burnable Poison Rods and Control Rods}

Burnable poison (BP) rods are inserted into two of the three BP holes of the fuel graphite block. The ends of the BP holes are plugged by dowel pins. The BP rods consist of two BP pellets and graphite disks with a diameter of $1.4 \mathrm{~cm}$ and height of $50.0 \mathrm{~cm}$. The 20 graphite disks, each of $0.5 \mathrm{~cm}$ thickness, are sandwiched between BP pellets (see Figure 2.6). Thus, total axial occupancies of the graphite disk and BP pellets in the BP hole are $10.0 \mathrm{~cm}$ and $40.0 \mathrm{~cm}$, respectively. The BP pellet contains boron-carbide $\left(\mathrm{B}_{4} \mathrm{C}\right)$ and carbon composite. Two types of BP pellets are utilized: H-I contains $2.22 \mathrm{wt} . \%$ natural boron and H-II contains $2.74 \mathrm{wt} . \%$ of the material.

There are 16 pairs of control rods: 7 in the active core and 9 in the replaceable reflector region. Figure 2.7 shows the control graphite block in the $1^{\text {st }}$ to $5^{\text {th }}$ layers. The control graphite block has three control rods guide holes, each of $12.3 \mathrm{~cm}$ diameter, and one fuel-handling hole: two holes are control rod insertion holes and the other hole is reserved for reactor shutdown system in case of an emergency. The control rod consists of 10 axial neutron absorber sections 
connected with metallic spine and support ring. Each section contains 5 sintered compacts of $\mathrm{B}_{4} \mathrm{C}$ and carbon composite as neutron absorber material in the annular space. The outer diameter of the control rod is $10.5 \mathrm{~cm}$.
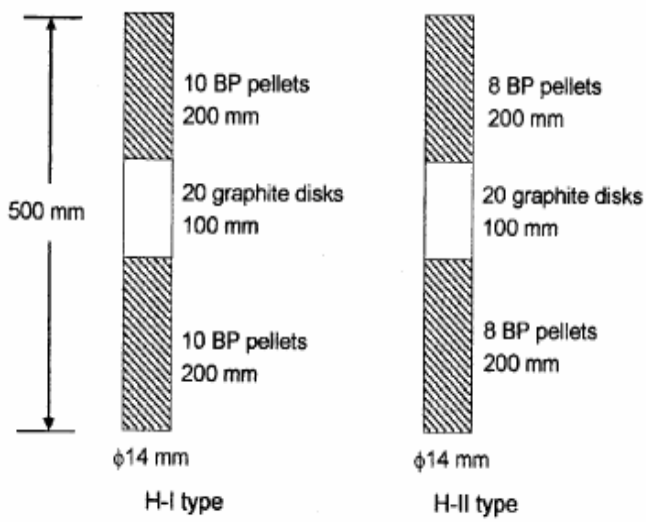

Figure 2.6. Axial Heterogeneity of Burnable Poison Rods [4]

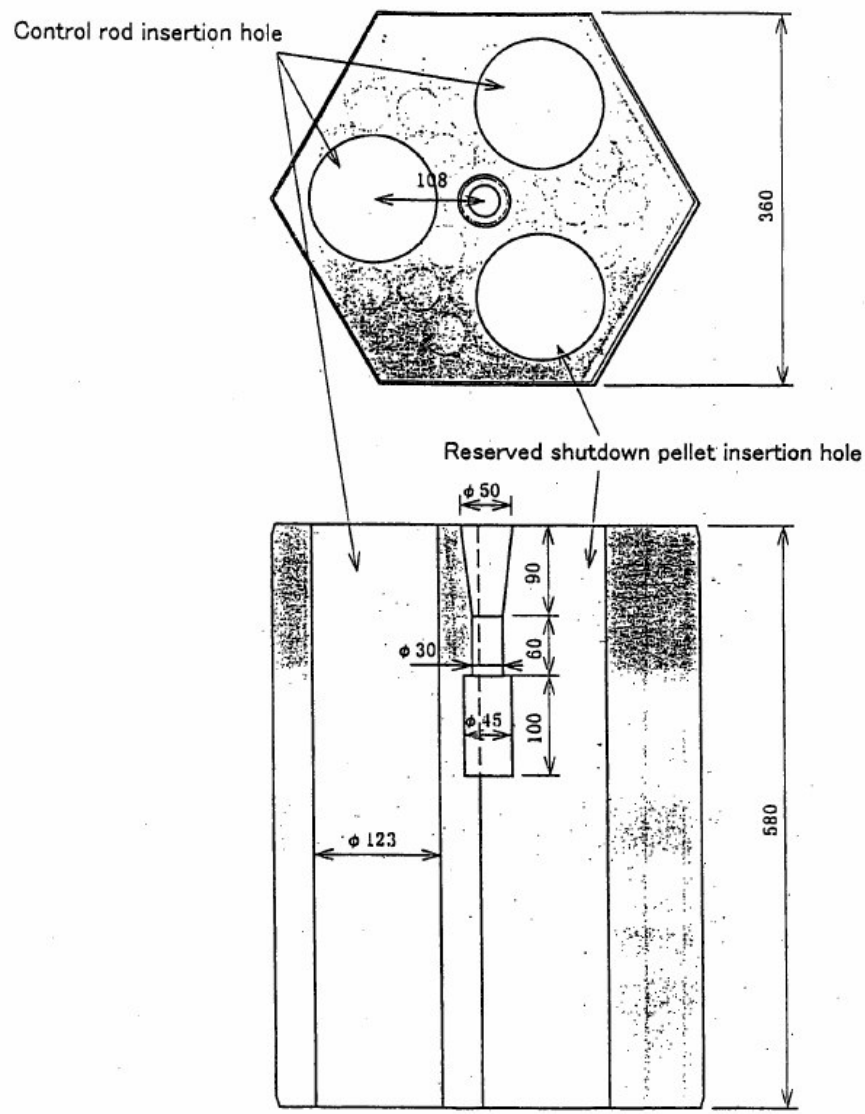

Figure 2.7. Control Rods Guide Block from $1^{\text {st }}$ to $5^{\text {th }}$ Layers [4] 
When the control rods are fully withdrawn, the upper limit of control rods is the upper face of the $1^{\text {st }}$ layer of fuel column except for columns E03, E05, E07, E09, E11, and E13. The control rods in these six columns have upper limit at $72.5 \mathrm{~cm}$ below from the upper face of the $1^{\text {st }}$ block. [4,5] In operating the reactor, three pairs of control rods in columns E01, E09 and E17 are fully withdrawn; it is noted that these control rods are located in the replaceable reflector region and the naming of the columns was explained in section 2.3.

\subsection{Replaceable Reflector, Dummy, and Permanent Reflector Blocks}

Top and bottom replaceable reflector blocks are placed above and below the fuel assemblies. Except for the $9^{\text {th }}$ layer reflector block, the number of coolant holes and their positions correspond to the fuel holes in the fuel block. However, the diameter of holes in the top and bottom reflector blocks is smaller than that of the fuel holes in the fuel block $(2.3 \mathrm{~cm}$ versus $4.1 \mathrm{~cm}$ ). The most bottom replaceable blocks (i.e., $9^{\text {th }}$ layer) have six large coolant holes of $5.4 \mathrm{~cm}$ diameter. The radial replaceable reflector blocks, which surround the active core, have the same external shape to the top and bottom replaceable reflectors, but have no coolant holes. Boron pins are installed into all replaceable blocks of the $9^{\text {th }}$ layer for neutron shielding.

The dummy blocks are initially loaded into the locations of the fuel columns before fuel loading. The external shape of the dummy blocks is identical to the fuel graphite blocks, but the dummy blocks contain higher impurity (i.e., boron in graphite) than that of the fuel blocks. In fully-loaded core, all dummy blocks are replaced with fuel assemblies.

The core is surrounded by 12 permanent reflector blocks whose form is a large polygonal graphite block (see Figure 2.2). The width of the across flats of the core including the permanent reflector blocks is $4.25 \mathrm{~m}$. The permanent reflector blocks have some holes for irradiation tests and neutron detection, and gaps: the void fraction is $0.7 \%$ due to the holes. Outside the permanent reflector blocks, there are side shielding blocks containing $\mathrm{B}_{4} \mathrm{C}$ and carbon composite. 


\section{DESCRIPTION OF MATERIALS DATA}

\subsection{Materials Data of Fuel Assembly}

The principal fuel assembly structural material is IG-110 graphite in the form of a right hexagonal prism having a density of $1.77 \mathrm{~g} / \mathrm{cm}^{3}$ with $0.40 \mathrm{ppm}$ natural boron equivalent impurity. [4] The material of the fuel sleeve (clad) is identical to the fuel graphite block, but the impurity is slightly lower than that of the fuel graphite block $(0.37 \mathrm{ppm}$ versus $0.40 \mathrm{ppm})$. A total of 12 different enriched uranium fuels are used in the HTTR core. Thus, the fuel compact and coated fuel particles are distinguished by the uranium enrichment. The material data of the fuel compact and coated fuel particles are provided in Tables 3.1 and 3.2.

There are two different burnable poisons ( $\mathrm{H}-1$ and $\mathrm{H}-\mathrm{II})$. The material of the $\mathrm{BP}$ is $\mathrm{B}_{4} \mathrm{C}$ and carbon composite and the densities of $\mathrm{H}-1$ and $\mathrm{H}-\mathrm{II}$ are $1.79 \mathrm{~g} / \mathrm{cm}^{3}$ and $1.83 \mathrm{~g} / \mathrm{cm}^{3}$, respectively. The natural boron weight percents of $\mathrm{H}-1$ and $\mathrm{H}-\mathrm{II}$ are $2.22 \%$ and $2.74 \%$, respectively. The graphite disk between the BP pellets has a density of $1.77 \mathrm{~g} / \mathrm{cm}^{3}$ with $0.37 \mathrm{ppm}$ of boron equivalent impurity.

Table 3.1. Materials Data of Fuel Compacts [4]

\begin{tabular}{|c|c|c|c|}
\hline Enrichment $(\%)$ & Packing fraction $(\%)$ & Density $\left(\mathrm{g} / \mathrm{cm}^{3}\right)$ & Impurity $(\mathrm{ppm})$ \\
\hline 3.4 & 29.6 & 1.697 & 0.95 \\
\hline 3.9 & 30.4 & 1.686 & 0.91 \\
\hline 4.3 & 30.5 & 1.686 & 0.90 \\
\hline 4.8 & 30.3 & 1.683 & 0.88 \\
\hline 5.2 & 30.5 & 1.690 & 0.90 \\
\hline 5.9 & 30.3 & 1.685 & 0.51 \\
\hline 6.3 & 29.9 & 1.683 & 0.54 \\
\hline 6.7 & 30.3 & 1.687 & 0.50 \\
\hline 7.2 & 30.8 & 1.682 & 0.85 \\
\hline 7.9 & 28.8 & 1.703 & 0.87 \\
\hline 9.4 & 29.8 & 1.686 & 0.89 \\
\hline 9.9 & 29.3 & 1.698 & 0.90 \\
\hline
\end{tabular}


Table 3.2. Materials Data of Coated Fuel Particles [4]

\begin{tabular}{|c|l|r|r|r|r|r|r|}
\hline \multicolumn{2}{|c|}{ Enrichment $(\%)$} & 3.4 & 3.9 & 4.3 & 4.8 & 5.2 & 5.9 \\
\hline \multirow{5}{*}{ Kernel } & Enrichment $(\%)$ & 3.301 & 3.864 & 4.290 & 4.794 & 5.162 & 5.914 \\
& Density $\left(\mathrm{g} / \mathrm{cm}^{3}\right)$ & 10.08 & 10.75 & 10.78 & 10.76 & 10.76 & 10.77 \\
& Diameter $(\mu \mathrm{m})$ & 609.0 & 594.4 & 593.6 & 594.9 & 591.8 & 592.4 \\
& Impurity $(\mathrm{ppm})$ & 0.92 & 0.89 & 0.92 & 0.94 & 1.24 & 0.96 \\
\hline \multirow{2}{*}{$1^{\text {st }}$ layer } & Density $\left(\mathrm{g} / \mathrm{cm}^{3}\right)$ & 1.158 & 1.091 & 1.112 & 1.110 & 1.118 & 1.112 \\
& Thickness $(\mu \mathrm{m})$ & 59.1 & 61.7 & 61.3 & 60.9 & 60.4 & 60.3 \\
\hline \multirow{2}{*}{$2^{\text {nd }}$ layer } & Density $\left(\mathrm{g} / \mathrm{cm}^{3}\right)$ & 1.873 & 1.879 & 1.905 & 1.907 & 1.893 & 1.909 \\
& Thickness $(\mu \mathrm{m})$ & 30.9 & 30.4 & 30.5 & 30.3 & 30.7 & 30.8 \\
\hline \multirow{2}{*}{$3^{\text {rd }}$ layer } & Density $\left(\mathrm{g} / \mathrm{cm}^{3}\right)$ & 3.206 & 3.207 & 3.206 & 3.205 & 3.205 & 3.204 \\
& Thickness $(\mu \mathrm{m})$ & 29.8 & 28.9 & 29.2 & 29.1 & 29.4 & 29.3 \\
\hline \multirow{2}{*}{$4^{\text {th }}$ layer } & Density $\left(\mathrm{g} / \mathrm{cm}^{3}\right)$ & 1.855 & 1.858 & 1.869 & 1.905 & 1.846 & 1.890 \\
& Thickness $(\mu \mathrm{m})$ & 46.4 & 45.7 & 46.2 & 45.2 & 45.7 & 45.9 \\
\hline \hline \multirow{2}{*}{ Enichment $(\%)$} & 6.3 & 6.7 & 7.2 & 7.9 & 9.4 & 9.9 \\
\hline \multirow{2}{*}{ Kernel } & Enrichment $(\%)$ & 6.254 & 6.681 & 7.189 & 7.820 & 9.358 & 9.810 \\
& Density $(\mathrm{g} / \mathrm{cm} 3)$ & 10.74 & 10.73 & 10.77 & 10.82 & 10.79 & 10.81 \\
& Diameter $(\mu \mathrm{m})$ & 593.5 & 593.2 & 594.0 & 608.1 & 593.4 & 591.4 \\
& Impurity $(\mathrm{ppm})$ & 1.13 & 0.95 & 0.90 & 0.92 & 0.88 & 0.88 \\
\hline \multirow{2}{*}{$1^{\text {st }}$ layer } & Density $(\mathrm{g} / \mathrm{cm} 3)$ & 1.122 & 1.121 & 1.147 & 1.143 & 1.170 & 1.152 \\
& Thickness $(\mu \mathrm{m})$ & 60.4 & 60.8 & 64.9 & 58.7 & 61.1 & 59.3 \\
\hline \multirow{2}{*}{$2^{\text {nd }}$ layer } & Density $(\mathrm{g} / \mathrm{cm} 3)$ & 1.909 & 1.902 & 1.894 & 1.878 & 1.902 & 1.873 \\
& Thickness $(\mu \mathrm{m})$ & 31.1 & 31.0 & 31.0 & 29.2 & 31.9 & 30.5 \\
\hline \multirow{2}{*}{$3^{\text {rd }}$ layer } & Density $(\mathrm{g} / \mathrm{cm} 3)$ & 3.205 & 3.208 & 3.202 & 3.201 & 3.207 & 3.202 \\
& Thickness $(\mu \mathrm{m})$ & 28.7 & 28.7 & 28.6 & 28.7 & 28.2 & 26.7 \\
\hline \multirow{2}{*}{$4^{\text {th }}$ layer } & Density $(\mathrm{g} / \mathrm{cm} 3)$ & 1.870 & 1.86 & 1.867 & 1.869 & 1.848 & 1.853 \\
& Thickness $(\mu \mathrm{m})$ & 45.0 & 46.1 & 46.2 & 45.6 & 46.0 & 46.3 \\
\hline
\end{tabular}

\subsection{Materials Data of Reflector, Control Rods Guide and Dummy Blocks}

The material of the permanent reflector blocks is PGX graphite that has a density of $1.732 \mathrm{~g} / \mathrm{cm}^{3}$ and an impurity content of $1.91 \mathrm{ppm}$. [4] The material data of the replaceable reflector, control rods guide, and dummy blocks are provided in Table 3.3. The densities of these blocks are similar to those for the fuel graphite block, but the impurity of the dummy block is much higher than that of the fuel graphite blocks.

The material of the control rod sleeve is Alloy $800 \mathrm{H}$ with density of $7.95 \mathrm{~g} / \mathrm{cm}^{3}$. The neutron absorber is $\mathrm{B}_{4} \mathrm{C}$ and carbon composite: its total weight of neutron absorber is $2351.2 \mathrm{~g}$ and the absorber (B-10) mass is $135.8 \mathrm{~g}$. 
Table 3.3. Materials Data of Fuel Compacts [4]

\begin{tabular}{|c|c|c|c|c|c|}
\hline & Type & ID & Material & Density $\left(\mathrm{g} / \mathrm{cm}^{3}\right)$ & Impurity (ppm) \\
\hline $\begin{array}{l}\text { Replaceable } \\
\text { reflector block }\end{array}$ & $\begin{array}{c}\text { A } 11 / 3 \\
\text { A } 12 / 3 \\
\text { A } 13 / 3 \\
\text { A } 21 / 3 \\
\text { A } 22 / 3 \\
\text { A } 23 / 3 \\
\text { B } 1 / 2 \\
\text { B } 2 / 2 \\
\text { C } 1 / 2 \\
\text { C } 2 / 2 \\
\text { D } 1 / 4 \\
\text { D } 2 / 4 \\
\text { D } 3 / 4 \\
\text { D } 4 / 4\end{array}$ & $\begin{array}{l}\text { RB-1 } \\
\text { RB-3 } \\
\text { RB-5 } \\
\text { RB-2 } \\
\text { RB-4 } \\
\text { RB-6 } \\
\text { RB-7 } \\
\text { RB-11 } \\
\text { RB-10 } \\
\text { IB-4 } \\
\text { RB-8 } \\
\text { IB-1 } \\
\text { IB-2 } \\
\text { RB-9 }\end{array}$ & IG-110 graphite & $\begin{array}{l}1.766 \\
1.760 \\
1.765 \\
1.769 \\
1.751 \\
1.761 \\
1.755 \\
1.756 \\
1.763 \\
1.788 \\
1.761 \\
1.759 \\
1.762 \\
1.763\end{array}$ & 0.37 \\
\hline $\begin{array}{l}\text { Control rods } \\
\text { guide block }\end{array}$ & $\begin{array}{c}\text { A } 1 / 2 \\
\text { A } 2 / 2 \\
\text { B } \\
\text { C } \\
\text { D } \\
\text { E } 1 / 2 \\
\text { E } 2 / 2\end{array}$ & $\begin{array}{l}\text { CB-1 } \\
\text { CB-0 } \\
\text { CB-2 } \\
\text { CB-3 } \\
\text { CB-4 } \\
\text { CB-5 } \\
\text { CB-6 }\end{array}$ & IG-110 graphite & $\begin{array}{l}1.776 \\
1.768 \\
1.757 \\
1.772 \\
1.762 \\
1.756 \\
1.761\end{array}$ & 0.37 \\
\hline Dummy block & $\begin{array}{c}0 \\
\text { A } \\
\text { B-1 } \\
\text { B-2 } \\
\text { Simple }\end{array}$ & $\begin{array}{l}\text { DB-1 } \\
\text { DB-2 } \\
\text { DB-3 } \\
\text { DB-4 } \\
\text { DB-5 }\end{array}$ & IG-11 graphite & $\begin{array}{l}1.767 \\
1.764 \\
1.764 \\
1.765 \\
1.767\end{array}$ & $\begin{array}{c}2.5(3.1)^{\mathrm{a})} \\
3.1 \\
3.1 \\
3.1 \\
2.5(3.1)^{\mathrm{a})}\end{array}$ \\
\hline
\end{tabular}

a) The impurity of the dummy block was increased to $3.1 \mathrm{ppm}$ from $2.5 \mathrm{ppm}$ by re-measurement [6] 


\section{EXPERIMENTAL MEASUREMENTS}

Experimental measurements performed in the HTTR start-up core are described below and the measured values are summarized in Table 4.1. [1,5] The notation in the parenthesis denotes the experiment ID specified by JAERI.

- Initial Criticality (HTTR-FC): In this experiment, the number of fuel columns is measured for the first criticality. The fuel are loaded into the core clockwise, from outer ring, one-by-one (fuel loading order is described in Figure 2.2). A small excess reactivity at the first criticality was also measured. In the experiment, the first criticality was obtained with 19 fuel columns.

- Control Rod Position at Criticality (HTTR-CR): The control rod insertion depths were measured at the critical condition for the thick annular core with 24 fuel columns and for the fully-loaded core with 30 fuel columns. Here, the control rod depth is defined by the distance from the control rod boundary to the bottom reflector. All control rod insertion levels are adjusted on the same level except for the three pairs at E01, E09, and E17. These three pairs were fully withdrawn at the operating condition.

- Excess Reactivity (HTTR-EX): The excess reactivity was measured using the inverse kinetic method. The approach to the criticality was observed by monitoring the inverse of neutron multiplication factor. The core was regarded as critical when the neutron density is maintained constant after removing the temporary neutron source. After the first criticality, the increment in reactivity was measured. The excess reactivity of the core was obtained by the addition of all increments of the reactivity from the first criticality to the fully-loaded core. A significantly high uncertainty was reported for the measured excess reactivity of the fully-loaded core (greater than $3.6 \% \Delta \mathrm{k})$. 
Table 4.1. Measured Data in HTTR Start-up Core [1,5]

\begin{tabular}{|l|c|}
\hline \multicolumn{1}{|c|}{ Measurement } & Measured value \\
\hline Number of fuel columns for first criticality & 19 \\
\hline Control rod depth for thick annular core $(\mathrm{cm})^{\text {a) }}$ & $221.5 \pm 0.5$ \\
\hline Control rod depth for fully-loaded core $(\mathrm{cm})^{\text {a) }}$ & $177.5 \pm 0.5$ \\
\hline Excess reactivity of fully-loaded core & $12 \% \Delta \mathrm{k} / \mathrm{k}$ \\
\hline K-effective of thick annular core & $1.1363 \pm>3.6 \%$ \\
\hline
\end{tabular}

a) Control rod depth is defined by the distance from the control rod boundary to the bottom reflector 


\section{BENCHMARK SPECIFICATION}

\subsection{Description of Model}

A benchmark model was established utilizing the real geometry and material data of the HTTR start-up core. However, since the HTTR core is too complicated to be a practical problem, minor simplifications were assumed in this work. It is possible to eliminate some complexity and obtain a benchmark model without losing the essential physics of the experiment.

As shown in Figure 2.2, the core boundary of the HTTR is formed by the permanent reflector blocks, which are 12-polygonal blocks. This geometry cannot be made by assembling right hexagonal prisms. Thus, the core boundary is changed in the benchmark model as shown in Figure 5.1. In this figure, the permanent reflector blocks are modeled as hexagonal prisms whose external shape is identical to the fuel (or replaceable reflector) blocks. The material of the hexagonal permanent reflector blocks is the same as that specified for the actual permanent reflector blocks and the total volume of the permanent reflector blocks is conserved in this model. The layer-by-layer configurations of the fully-loaded core are provided in Figures 5.2 - 5.9.

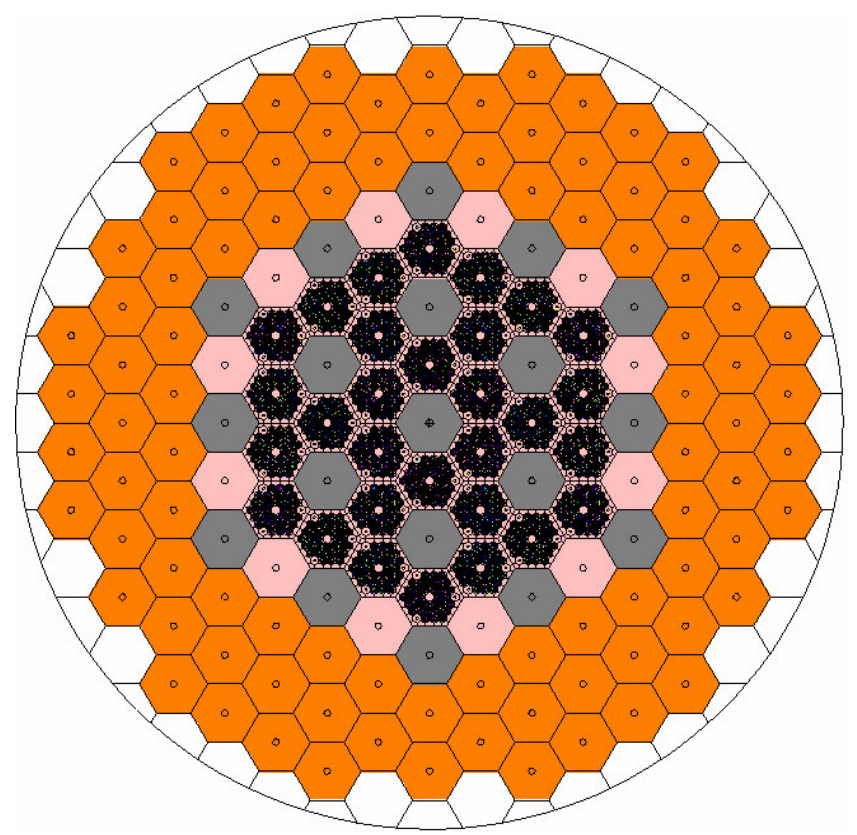

Figure 5.1. Core Layout for HTTR Benchmark Model 


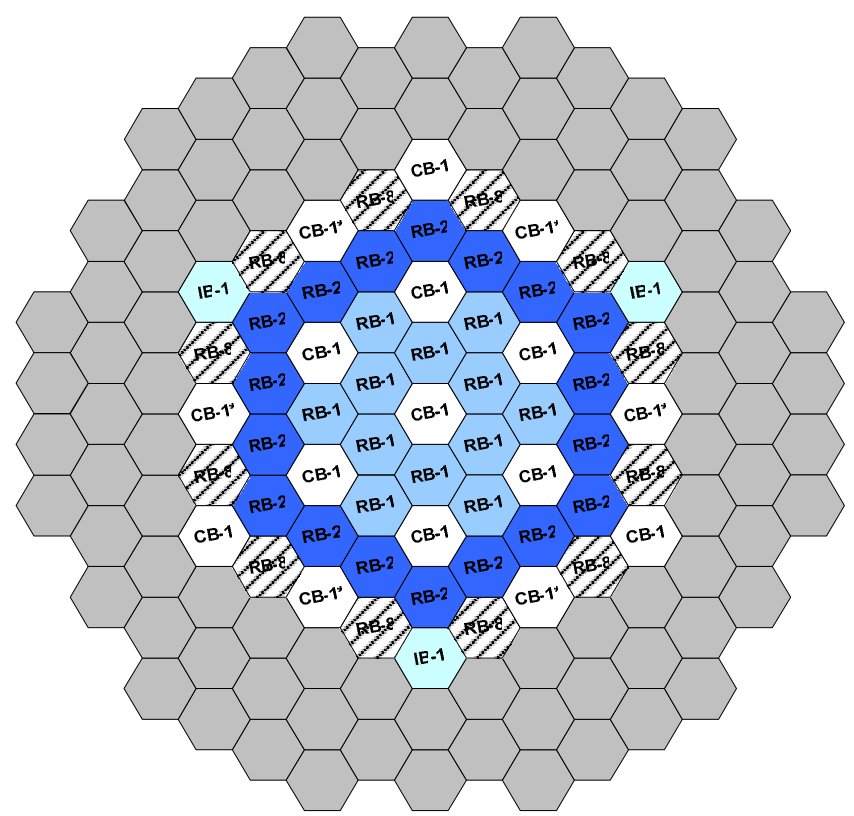

Figure 5.2. Horizontal View of Layers 1 and 2

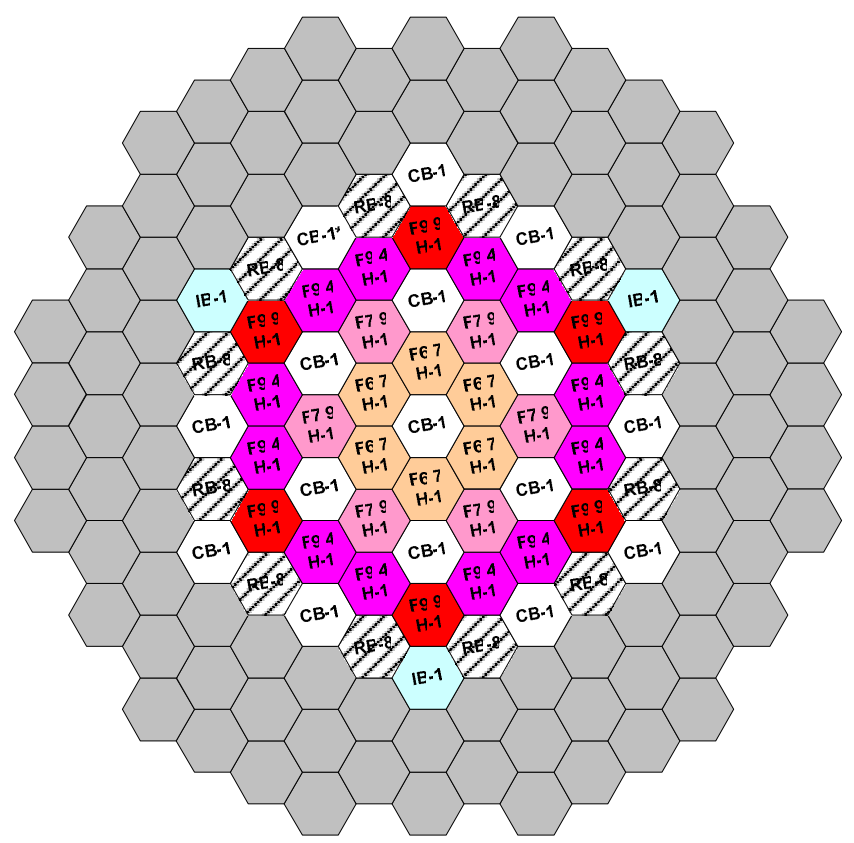

Figure 5.3. Horizontal View at $3^{\text {rd }}$ Layer 


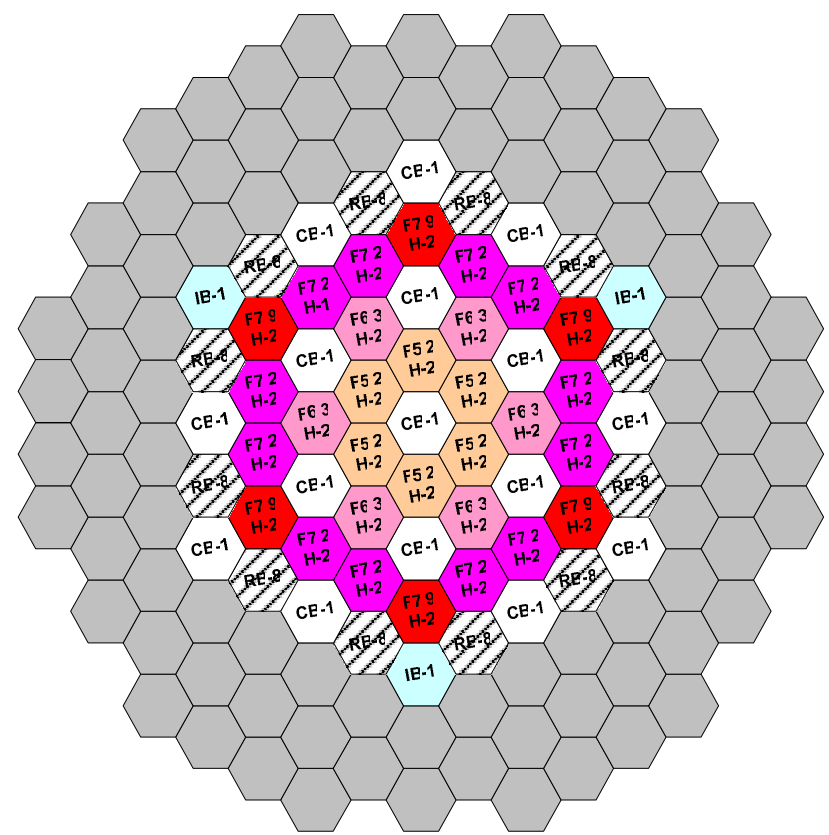

Figure 5.4. Horizontal View at $4^{\text {th }}$ Layer

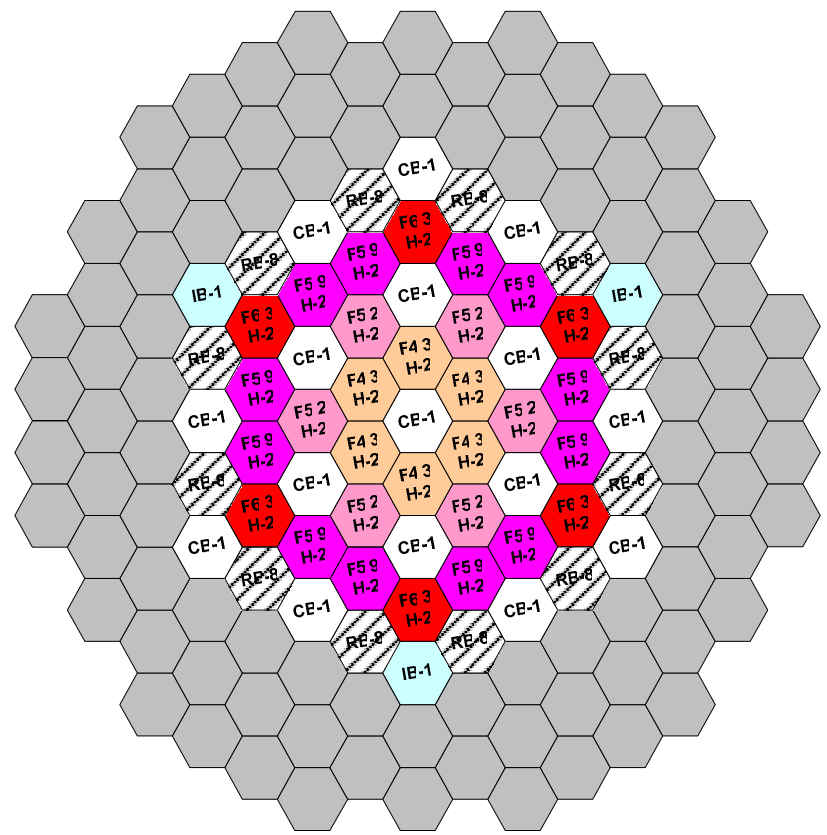

Figure 5.5. Horizontal View at $5^{\text {th }}$ Layer 


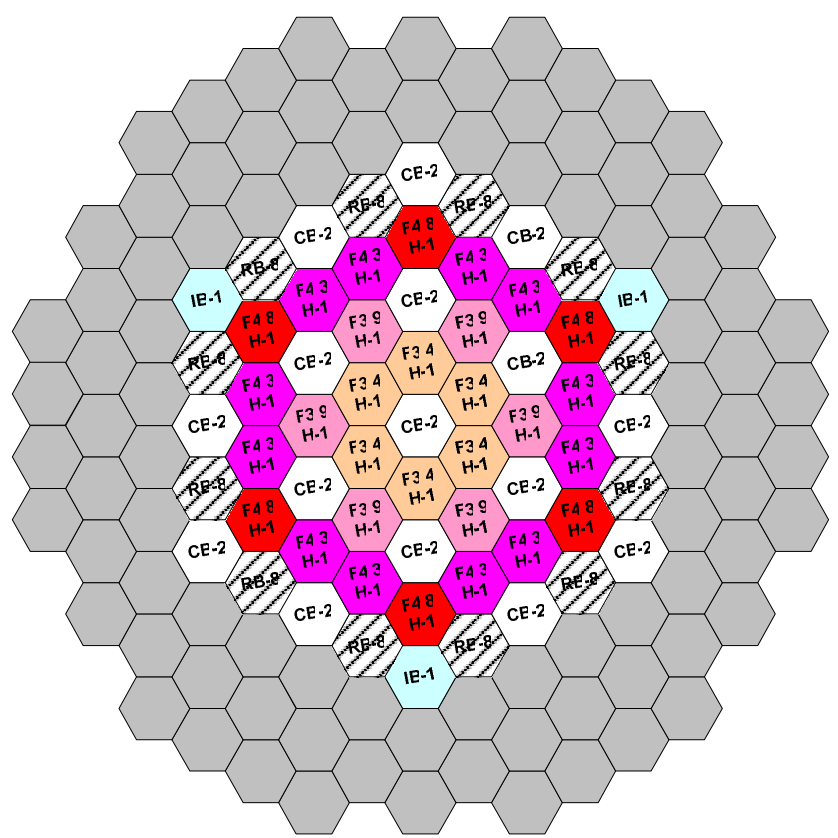

Figure 5.6. Horizontal View at $6^{\text {th }}$ Layer

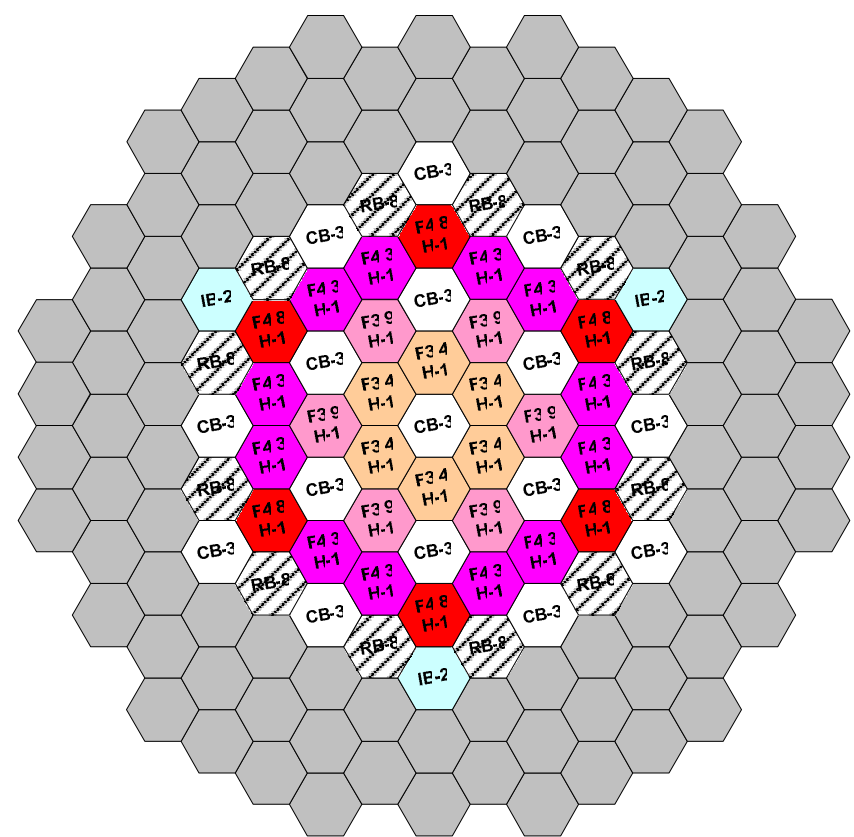

Figure 5.7. Horizontal View at $7^{\text {th }}$ Layer 


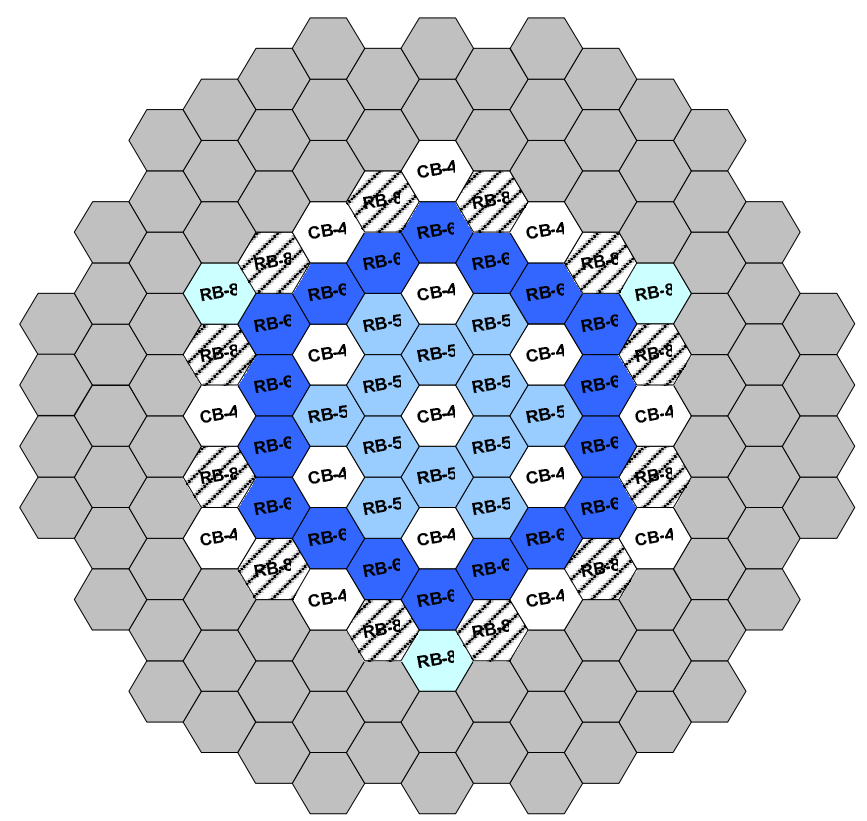

Figure 5.8. Horizontal View at $8^{\text {th }}$ Layer

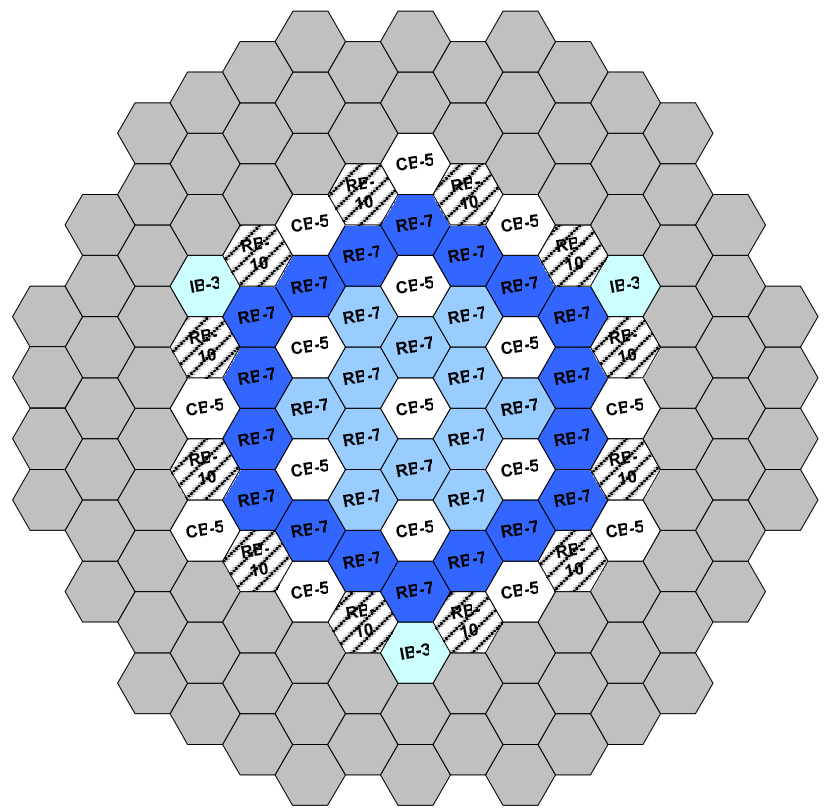

Figure 5.9. Horizontal View at $9^{\text {th }}$ Layer 
In the HTTR core, the outer boundary of the permanent blocks is coated with boroncarbide $\left(\mathrm{B}_{4} \mathrm{C}\right)$ and carbon composite for the purpose of neutron shielding. In addition, boron pins are installed into lower parts of the blocks in the $9^{\text {th }}$ layer for neutron shielding. Since References 4 and 5 recommended neglecting the neutron shielding in calculation models, the boron carbide coating and boron pins are ignored in the benchmark model.

Figure 2.4 shows the fuel graphite blocks. A fuel-handling hole is located at the center of each graphite block. The geometry of the fuel-handling hole is too complicated axially. In the benchmark model, the fuel-handling hole is smeared into the graphite axially. Thus, the graphite number density at the center of the graphite block is reduced as much as the volume fraction of the fuel-handling hole; the volume fraction is about $43 \%$.

Each fuel hole is filled by 14 fuel compacts and the top and bottom of the fuel holes are encapsulated by plugs. The plug diameter is the same as the fuel hole diameter and the length is $1.7 \mathrm{~cm}$ (note that the height of the fuel graphite block is $58 \mathrm{~cm}$ and the fuel compact length is 3.9 $\mathrm{cm})$. In addition, the top and bottom of the BP rods are encapsulated by the dowels. The dowel diameter is the same as for the BP hole and its length is $4.0 \mathrm{~cm}$. The material data of the plug and dowel are not provided in the HTTR references. Thus, the material data of the plug and dowel are assumed to be the same with the fuel graphite block.

\subsection{Materials Data}

In Section 3, the materials data of the HTTR core were given for the materials densities and impurities. However, these values may result in different number densities due to the use of different universal constants (such as Avogadro number, atomic weight number, etc). To minimize the uncertainty of the material data, the number densities are provided for this benchmark. Atom densities were calculated by JAERI utilizing the material data given in Section 3. [4] The materials for which such calculations have been done include fuel compacts, fuel rods, fuel graphite blocks, burnable poisons, all reflector blocks, control rod and control rods guide blocks, and dummy blocks (see Tables 5.1 to 5.5). In these calculations, the fuel compact was divided into six materials, such as a kernel, four coating layers of the CFPs, and graphite matrix of the fuel compact. 
Table 5.1. Number Densities of Fuel Compact (\#/cm-barn)

\begin{tabular}{|c|c|c|c|c|c|c|c|}
\hline \multicolumn{2}{|c|}{ Enrichment } & 3.40 & 3.9 & 4.3 & 4.8 & 5.2 & 5.9 \\
\hline \multirow{5}{*}{ Kernel } & U-235 & $8.0367 \mathrm{E}-4$ & $9.3638 \mathrm{E}-4$ & $1.0429 \mathrm{E}-3$ & $1.1627 \mathrm{E}-3$ & $1.2522 \mathrm{E}-3$ & $1.4357 \mathrm{E}-3$ \\
\hline & U-238 & $2.3280 \mathrm{E}-2$ & $2.3038 \mathrm{E}-2$ & $2.3008 \mathrm{E}-2$ & $2.2834 \mathrm{E}-2$ & $2.2750 \mathrm{E}-2$ & $2.2586 \mathrm{E}-2$ \\
\hline & $\mathrm{O}$ & $4.8188 \mathrm{E}-2$ & $4.7948 \mathrm{E}-2$ & $4.8102 \mathrm{E}-2$ & 4.7993E-2 & $4.8004 \mathrm{E}-2$ & 4.8044E-2 \\
\hline & B-10 & $1.1010 \mathrm{E}-7$ & $1.0602 \mathrm{E}-7$ & $1.0994 \mathrm{E}-7$ & $1.1207 \mathrm{E}-7$ & $1.4783 \mathrm{E}-7$ & $1.1456 \mathrm{E}-7$ \\
\hline & B-11 & $4.4317 \mathrm{E}-7$ & $4.2673 \mathrm{E}-7$ & $4.4251 \mathrm{E}-7$ & $4.5108 \mathrm{E}-7$ & $5.9515 \mathrm{E}-7$ & $4.6111 \mathrm{E}-7$ \\
\hline Buffer & $\mathrm{C}$ & $5.8060 \mathrm{E}-2$ & $5.4701 \mathrm{E}-2$ & $5.5754 \mathrm{E}-2$ & $5.5654 \mathrm{E}-2$ & $5.6055 \mathrm{E}-2$ & $5.5754 \mathrm{E}-2$ \\
\hline IPYC & $\mathrm{C}$ & $9.3909 \mathrm{E}-2$ & $9.4210 \mathrm{E}-2$ & $9.5514 \mathrm{E}-2$ & $9.5614 \mathrm{E}-2$ & $9.4912 \mathrm{E}-2$ & $9.5714 \mathrm{E}-2$ \\
\hline \multirow{2}{*}{$\mathrm{SiC}$} & $\mathrm{Si}$ & $4.8151 \mathrm{E}-2$ & $4.8166 \mathrm{E}-2$ & $4.8151 \mathrm{E}-2$ & $4.8136 \mathrm{E}-2$ & $4.8136 \mathrm{E}-2$ & $4.8121 \mathrm{E}-2$ \\
\hline & $\mathrm{C}$ & $4.8151 \mathrm{E}-2$ & $4.8166 \mathrm{E}-2$ & $4.8151 \mathrm{E}-2$ & $4.8136 \mathrm{E}-2$ & $4.8136 \mathrm{E}-2$ & $4.8121 \mathrm{E}-2$ \\
\hline $\mathrm{OPyC}$ & $\mathrm{C}$ & $9.3007 \mathrm{E}-2$ & $9.3157 \mathrm{E}-2$ & $9.3709 \mathrm{E}-2$ & $9.5514 \mathrm{E}-2$ & $9.2556 \mathrm{E}-2$ & $9.4762 \mathrm{E}-2$ \\
\hline \multirow{3}{*}{ Matrix } & $\mathrm{C}$ & $8.5085 \mathrm{E}-2$ & $8.4534 \mathrm{E}-2$ & $8.4534 \mathrm{E}-2$ & $8.4383 \mathrm{E}-2$ & $8.4734 \mathrm{E}-2$ & $8.4483 \mathrm{E}-2$ \\
\hline & B-10 & $2.4543 \mathrm{E}-8$ & $2.3506 \mathrm{E}-8$ & $2.2830 \mathrm{E}-8$ & $2.1702 \mathrm{E}-8$ & $1.8432 \mathrm{E}-8$ & $6.9024 \mathrm{E}-9$ \\
\hline & B-11 & $9.8790 \mathrm{E}-8$ & $9.4614 \mathrm{E}-8$ & $9.1893 \mathrm{E}-8$ & $8.7353 \mathrm{E}-8$ & 7.4189E-8 & $2.7783 \mathrm{E}-8$ \\
\hline \multirow{7}{*}{$\begin{array}{l}\text { Homogeneous } \\
\text { fuel compact }\end{array}$} & U-235 & $6.4509 \mathrm{E}-5$ & $7.4887 \mathrm{E}-5$ & $8.3358 \mathrm{E}-5$ & $9.3663 \mathrm{E}-5$ & $1.0049 \mathrm{E}-4$ & $1.1448 \mathrm{E}-4$ \\
\hline & U-238 & $1.8659 \mathrm{E}-3$ & $1.8396 \mathrm{E}-3$ & $1.8362 \mathrm{E}-3$ & $1.8366 \mathrm{E}-3$ & $1.8229 \mathrm{E}-3$ & $1.7983 \mathrm{E}-3$ \\
\hline & B-10 & $2.6099 \mathrm{E}-8$ & $2.4835 \mathrm{E}-8$ & $2.4642 \mathrm{E}-8$ & $2.4133 \mathrm{E}-8$ & $2.4651 \mathrm{E}-8$ & $1.3937 \mathrm{E}-8$ \\
\hline & B-11 & $1.0505 \mathrm{E}-7$ & $9.9963 \mathrm{E}-8$ & $9.9189 \mathrm{E}-8$ & $9.7138 \mathrm{E}-8$ & $9.9222 \mathrm{E}-8$ & $5.6098 \mathrm{E}-8$ \\
\hline & $\mathrm{C}$ & $7.6139 \mathrm{E}-2$ & $7.5473 \mathrm{E}-2$ & $7.5649 \mathrm{E}-2$ & $7.5631 \mathrm{E}-2$ & $7.5665 \mathrm{E}-2$ & $7.5751 \mathrm{E}-2$ \\
\hline & $\mathrm{O}$ & $3.8607 \mathrm{E}-3$ & $3.8291 \mathrm{E}-3$ & $3.8392 \mathrm{E}-3$ & $3.8605 \mathrm{E}-3$ & $3.8468 \mathrm{E}-3$ & $3.8255 \mathrm{E}-3$ \\
\hline & $\mathrm{Si}$ & $2.0505 \mathrm{E}-3$ & $2.0718 \mathrm{E}-3$ & $2.0943 \mathrm{E}-3$ & $2.0890 \mathrm{E}-3$ & $2.1200 \mathrm{E}-3$ & $2.0902 \mathrm{E}-3$ \\
\hline
\end{tabular}

\begin{tabular}{|c|c|c|c|c|c|c|c|}
\hline \multicolumn{2}{|c|}{ Enrichment } & 6.3 & 6.7 & 7.2 & 7.9 & 9.4 & 9.9 \\
\hline \multirow{5}{*}{ Kernel } & U-235 & $1.5149 \mathrm{E}-3$ & $1.6163 \mathrm{E}-3$ & $1.7460 \mathrm{E}-3$ & $1.9085 \mathrm{E}-3$ & $2.2773 \mathrm{E}-3$ & $2.3912 \mathrm{E}-3$ \\
& U-238 & $2.2455 \mathrm{E}-2$ & $2.2325 \mathrm{E}-2$ & $2.2291 \mathrm{E}-2$ & $2.2246 \mathrm{E}-2$ & $2.1812 \mathrm{E}-2$ & $2.1740 \mathrm{E}-2$ \\
& O & $4.7939 \mathrm{E}-2$ & $4.7883 \mathrm{E}-2$ & $4.8073 \mathrm{E}-2$ & $4.8309 \mathrm{E}-2$ & $4.8179 \mathrm{E}-2$ & $4.8262 \mathrm{E}-2$ \\
& $\mathrm{~B}-10$ & $1.3454 \mathrm{E}-7$ & $1.1297 \mathrm{E}-7$ & $1.0745 \mathrm{E}-7$ & $1.1037 \mathrm{E}-7$ & $1.0526 \mathrm{E}-7$ & $1.0544 \mathrm{E}-7$ \\
& $\mathrm{~B}-11$ & $5.4155 \mathrm{E}-7$ & $4.5474 \mathrm{E}-7$ & $4.3249 \mathrm{E}-7$ & $4.4423 \mathrm{E}-7$ & $4.2370 \mathrm{E}-7$ & $4.2441 \mathrm{E}-7$ \\
\hline Buffer & $\mathrm{C}$ & $5.6255 \mathrm{E}-2$ & $5.6205 \mathrm{E}-2$ & $5.7509 \mathrm{E}-2$ & $5.7308 \mathrm{E}-2$ & $5.8662 \mathrm{E}-2$ & $5.7760 \mathrm{E}-2$ \\
\hline IPYC & $\mathrm{C}$ & $9.5714 \mathrm{E}-2$ & $9.5363 \mathrm{E}-2$ & $9.4962 \mathrm{E}-2$ & $9.4160 \mathrm{E}-2$ & $9.5363 \mathrm{E}-2$ & $9.4210 \mathrm{E}-2$ \\
\hline \multirow{2}{*}{$\mathrm{SiC}$} & $\mathrm{Si}$ & $4.8136 \mathrm{E}-2$ & $4.8181 \mathrm{E}-2$ & $4.8091 \mathrm{E}-2$ & $4.8076 \mathrm{E}-2$ & $4.8166 \mathrm{E}-2$ & $4.8091 \mathrm{E}-2$ \\
& $\mathrm{C}$ & $4.8136 \mathrm{E}-2$ & $4.8181 \mathrm{E}-2$ & $4.8091 \mathrm{E}-2$ & $4.8076 \mathrm{E}-2$ & $4.8166 \mathrm{E}-2$ & $4.8091 \mathrm{E}-2$ \\
\hline OPyC & $\mathrm{C}$ & $9.3759 \mathrm{E}-2$ & $9.3258 \mathrm{E}-2$ & $9.3609 \mathrm{E}-2$ & $9.7371 \mathrm{E}-2$ & $9.2656 \mathrm{E}-2$ & $9.2907 \mathrm{E}-2$ \\
\hline \multirow{4}{*}{ Matrix } & $\mathrm{C}$ & $8.4383 \mathrm{E}-2$ & $8.4584 \mathrm{E}-2$ & $8.4333 \mathrm{E}-2$ & $8.5386 \mathrm{E}-2$ & $8.4534 \mathrm{E}-2$ & $8.5135 \mathrm{E}-2$ \\
& $\mathrm{~B}-10$ & $5.7948 \mathrm{E}-9$ & $6.6972 \mathrm{E}-9$ & $2.1174 \mathrm{E}-8$ & $2.1236 \mathrm{E}-8$ & $2.2699 \mathrm{E}-8$ & $2.3061 \mathrm{E}-8$ \\
& $\mathrm{~B}-11$ & $2.3325 \mathrm{E}-8$ & $2.6957 \mathrm{E}-8$ & $8.5228 \mathrm{E}-8$ & $8.5478 \mathrm{E}-8$ & $9.1367 \mathrm{E}-8$ & $9.2824 \mathrm{E}-8$ \\
\hline \multirow{5}{*}{ Homogeneous } & U-235 & $1.2041 \mathrm{E}-4$ & $1.2899 \mathrm{E}-4$ & $1.3793 \mathrm{E}-4$ & $1.5269 \mathrm{E}-4$ & $1.7780 \mathrm{E}-4$ & $1.8843 \mathrm{E}-4$ \\
fuel compact & $\mathrm{U}-238$ & $1.7822 \mathrm{E}-3$ & $1.7790 \mathrm{E}-3$ & $1.7583 \mathrm{E}-3$ & $1.7771 \mathrm{E}-3$ & $1.7004 \mathrm{E}-3$ & $1.7105 \mathrm{E}-3$ \\
& $\mathrm{~B}-10$ & $1.4730 \mathrm{E}-8$ & $1.3658 \mathrm{E}-8$ & $2.3131 \mathrm{E}-8$ & $2.3934 \mathrm{E}-8$ & $2.4146 \mathrm{E}-8$ & $2.4594 \mathrm{E}-8$ \\
& $\mathrm{~B}-11$ & $5.9288 \mathrm{E}-8$ & $5.4973 \mathrm{E}-8$ & $9.3106 \mathrm{E}-8$ & $9.6338 \mathrm{E}-8$ & $9.7191 \mathrm{E}-8$ & $9.8995 \mathrm{E}-8$ \\
& $\mathrm{C}$ & $7.5690 \mathrm{E}-2$ & $7.5746 \mathrm{E}-2$ & $7.5606 \mathrm{E}-2$ & $7.6443 \mathrm{E}-2$ & $7.6005 \mathrm{E}-2$ & $7.6407 \mathrm{E}-2$ \\
& $\mathrm{O}$ & $3.8052 \mathrm{E}-3$ & $3.8159 \mathrm{E}-3$ & $3.7924 \mathrm{E}-3$ & $3.8596 \mathrm{E}-3$ & $3.7564 \mathrm{E}-3$ & $3.7979 \mathrm{E}-3$ \\
& $\mathrm{Si}$ & $2.0372 \mathrm{E}-3$ & $2.0533 \mathrm{E}-3$ & $2.0566 \mathrm{E}-3$ & $1.9428 \mathrm{E}-3$ & $1.9802 \mathrm{E}-3$ & $1.8622 \mathrm{E}-3$ \\
\hline
\end{tabular}

To evaluate the double heterogeneous effect, the number densities of the homogeneous fuel compacts were also included in this benchmark model. The neutron detector insertion holes (about $0.7 \%$ volume fraction) are smeared into the permanent reflector blocks. The impurity 
content of the dummy block that was initially specified as $2.5 \mathrm{ppm}$ has been increased to $3.1 \mathrm{ppm}$ due to results from re-measurement in which the number of samples was increased from 1 to 18. [5] In this benchmark, the original impurity content was used in calculating the number density (the effect of impurity increment will be discussed in Section 6).

Table 5.2. Number Densities of Graphite Block and Control Rods (\#/cm-barn)

\begin{tabular}{|c|c|c|c|c|c|c|c|c|}
\hline \multicolumn{2}{|c|}{} & $\begin{array}{c}\text { Graphite } \\
\text { sleeve }\end{array}$ & $\begin{array}{c}\text { Graphite } \\
\text { block }\end{array}$ & H-1 of BP & H-II of BP & Disk of BP & $\begin{array}{c}\text { Permanent } \\
\text { block }\end{array}$ & $\begin{array}{c}\text { Control } \\
\text { absorber }\end{array}$ \\
\hline \multirow{3}{*}{ Kernel } & B-10 & $7.1811 \mathrm{E}-9$ & $7.8482 \mathrm{E}-9$ & $4.4613 \mathrm{E}-4$ & $5.6049 \mathrm{E}-4$ & $7.1771 \mathrm{E}-9$ & $3.6414 \mathrm{E}-8$ & $7.2842 \mathrm{E}-9$ \\
& B-11 & $2.8905 \mathrm{E}-8$ & $3.1590 \mathrm{E}-8$ & $1.7640 \mathrm{E}-3$ & $2.2162 \mathrm{E}-3$ & $2.8889 \mathrm{E}-8$ & $1.4657 \mathrm{E}-7$ & $2.9320 \mathrm{E}-8$ \\
& C & $8.8745 \mathrm{E}-2$ & $8.8745 \mathrm{E}-2$ & $8.7599 \mathrm{E}-2$ & $8.8693 \mathrm{E}-2$ & $8.8695 \mathrm{E}-2$ & $8.6232 \mathrm{E}-2$ & $8.9046 \mathrm{E}-2$ \\
\hline
\end{tabular}

Table 5.3. Number Densities in Replaceable Reflector Blocks (\#/cm-barn)

\begin{tabular}{|c|c|c|c|c|c|c|c|c|}
\hline \multicolumn{2}{|c|}{ Type } & A 1 1/3 & A 1 2/3 & A 1 3/3 & A 2 1/3 & A 2 2/3 & A 2 3/3 & B 1/2 \\
\hline \multicolumn{2}{|c|}{ ID } & RB-1 & RB-3 & RB-5 & RB-2 & RB-4 & RB-6 & RB-7 \\
\hline \multirow{3}{*}{ Kernel } & C & $8.8545 E-2$ & $8.8244 \mathrm{E}-2$ & $8.8494 \mathrm{E}-2$ & $8.8695 \mathrm{E}-2$ & $8.3779 \mathrm{E}-2$ & $8.8294 \mathrm{E}-2$ & $8.7993 \mathrm{E}-2$ \\
& B-10 & $7.2432 \mathrm{E}-9$ & $7.2186 \mathrm{E}-9$ & $7.2391 \mathrm{E}-9$ & $7.2555 \mathrm{E}-9$ & $7.1817 \mathrm{E}-9$ & $7.2227 \mathrm{E}-9$ & $7.1981 \mathrm{E}-9$ \\
& B-10 & $2.9155 \mathrm{E}-8$ & $2.9056 \mathrm{E}-8$ & $2.9138 \mathrm{E}-8$ & $2.9204 \mathrm{E}-8$ & $2.8907 \mathrm{E}-8$ & $2.9072 \mathrm{E}-8$ & $2.8973 \mathrm{E}-8$ \\
\hline \multicolumn{2}{|c|}{ Type } & B 2 2/2 & C 1/2 & C 2/2 & D 1/4 & D 2/4 & D 3/4 & D 4/4 \\
\hline \multicolumn{2}{|c|}{ ID } & RB-11 & RB-10 & IB-3 & RB-8 & IB-1 & IB-2 & RB-9 \\
\hline \multirow{3}{*}{ Kernel } & C & $8.8043 \mathrm{E}-2$ & $8.8394 \mathrm{E}-2$ & $8.8394 \mathrm{E}-2$ & $8.8294 \mathrm{E}-2$ & $8.8194 \mathrm{E}-2$ & $8.8344 \mathrm{E}-2$ & $8.8394 \mathrm{E}-2$ \\
& B-10 & $7.2022 \mathrm{E}-9$ & $7.2309 \mathrm{E}-9$ & $7.3334 \mathrm{E}-9$ & $7.2227 \mathrm{E}-9$ & $7.2145 \mathrm{E}-9$ & $7.2268 \mathrm{E}-9$ & $7.2309 \mathrm{E}-9$ \\
& B-11 & $2.8990 \mathrm{E}-8$ & $2.9105 \mathrm{E}-8$ & $2.9518 \mathrm{E}-8$ & $2.9072 \mathrm{E}-8$ & $2.9039 \mathrm{E}-8$ & $2.9089 \mathrm{E}-8$ & $2.9105 \mathrm{E}-8$ \\
\hline
\end{tabular}

Table 5.4. Number Densities of Control Rods Guide Blocks (\#/cm-barn)

\begin{tabular}{|c|c|c|c|c|c|c|c|c|}
\hline \multicolumn{2}{|c|}{ Type } & A 1/2 & A 2/2 & B & C & D & E 1/2 & E 2/2 \\
\hline \multicolumn{2}{|c|}{ ID } & CB-1 & CB-0 & CB-2 & CB-3 & CB-4 & CB-5 & CB-6 \\
\hline \multirow{3}{*}{ Kernel } & C & $8.9046 \mathrm{E}-2$ & $8.8645 \mathrm{E}-2$ & $8.8093 \mathrm{E}-2$ & $8.8845 \mathrm{E}-2$ & $8.8344 \mathrm{E}-2$ & $8.8043 \mathrm{E}-2$ & $8.8294 \mathrm{E}-2$ \\
& B-10 & $7.2842 \mathrm{E}-9$ & $7.2514 \mathrm{E}-9$ & $7.2063 \mathrm{E}-9$ & $7.2678 \mathrm{E}-9$ & $7.2268 \mathrm{E}-9$ & $7.2022 \mathrm{E}-9$ & $7.2227 \mathrm{E}-9$ \\
& B-11 & $2.9320 \mathrm{E}-8$ & $2.9188 \mathrm{E}-8$ & $2.9006 \mathrm{E}-8$ & $2.9254 \mathrm{E}-8$ & $2.9089 \mathrm{E}-8$ & $2.899 \mathrm{E}-8$ & $2.9072 \mathrm{E}-8$ \\
\hline
\end{tabular}

Table 5.5. Number Densities of Dummy Blocks (\#/cm-barn)

\begin{tabular}{|c|c|c|c|c|c|c|}
\hline \multicolumn{2}{|c|}{ Type } & & A & B-1 & B-2 & Simple \\
\hline \multicolumn{2}{|c|}{ ID } & DB-1 & DB-2 & DB-3 & DB-4 & DB-5 \\
\hline \multirow{3}{*}{ Kernel } & B-10 & $4.9164 \mathrm{E}-8$ & $6.0618 \mathrm{E}-8$ & $6.0618 \mathrm{E}-8$ & $6.0652 \mathrm{E}-8$ & $4.8772 \mathrm{E}-8$ \\
& B-11 & $1.9787 \mathrm{E}-7$ & $2.4399 \mathrm{E}-7$ & $2.4399 \mathrm{E}-7$ & $2.4413 \mathrm{E}-7$ & $1.9631 \mathrm{E}-7$ \\
& C & $8.8595 \mathrm{E}-2$ & $8.8444 \mathrm{E}-2$ & $8.8444 \mathrm{E}-2$ & $8.8484 \mathrm{E}-2$ & $8.8595 \mathrm{E}-2$ \\
\hline
\end{tabular}




\subsection{Temperature and Nitrogen Issue}

Since the HTTR start-up core experiments were performed at room temperature $[1,4,5]$, the room temperature value $(293 \mathrm{~K})$ is used in the benchmark model.

The thin annular core consists of 18 fuel columns. In the experiment, the first criticality of the HTTR was obtained with 19 fuel columns.[1] Thus, the thin annular HTTR core should be sub-critical. In the preliminary evaluation [6,7], which was performed by JAERI using the MVP continuous energy Monte Carlo code, the required fuel columns were estimated as $16 \pm 1$. To resolve the discrepancies between the experiment and MVP calculations (19 versus 16), a re-evaluation has been performed. [6] From this reevaluation, JAERI found that two factors were wrong in the preliminary evaluations: boron impurity in the dummy graphite blocks and the nitrogen in the porous graphite. The boron impurity of the dummy graphite block was assumed to be $2.5 \mathrm{ppm}$ originally, but it was found to be $3.1 \mathrm{ppm}$ in the re-measurement (the effect of the boron impurity will be discussed in Section 6). Nitrogen remains in the porous graphite at room temperature, but it is primarily released from the porous graphite when the core temperature increases. Nitrogen acts as a neutron absorber; however, it was ignored in the preliminary evaluations. The reevaluation using MVP code gave $18 \pm 1$ fuel columns to be critical and the eigenvalues of the annular core were 1.00593 and 1.00287 with JENDL 3.2 and JENDL 3.1 nuclear data libraries, respectively. The uncertainty level was $3 \sigma=0.15 \% \Delta \mathrm{k}$. Since the HTTR references do not discuss the detailed nitrogen mass in the porous graphite, the nitrogen content of the porous graphite is ignored in this benchmark model. 


\section{EVALUATION OF BENCHMARK SPECIFICATION}

\subsection{Reference Monte Carlo Calculations}

The whole-core geometry of the HTTR has been explicitly modeled in MCNP4C calculations, including explicit representation of fuel and reflector blocks, coolant channels, the gap between graphite blocks, plugs in fuel holes, dowels in BP holes, axial heterogeneity of the burnable poison rods, etc. Figure 6.1 shows two fuel compact models that have been employed in this study: in the first (homogeneous model), the coated fuel particles are smeared with the compact graphite matrix using volume weighting without accounting explicitly for the selfshielding effect of CFPs, while in the second (the heterogeneous model) the CFPs are explicitly modeled. The difference in the $\mathrm{k}_{\mathrm{eff}}$ values of these two models is defined as the double heterogeneous effect in this work (see Section 6.1.7). In MCNP4C calculations, the number of neutron histories per batch is 10,000 and the number of batches is 500 (i.e., total five million histories were traced). Before accumulating the tally, the first 5 batches were discarded. The ENDF/B-VI neutron library data was primarily used for these benchmark calculations, but JEF2.2 neutron library data was also used to evaluate neutron library effects (see Section 6.1.6).

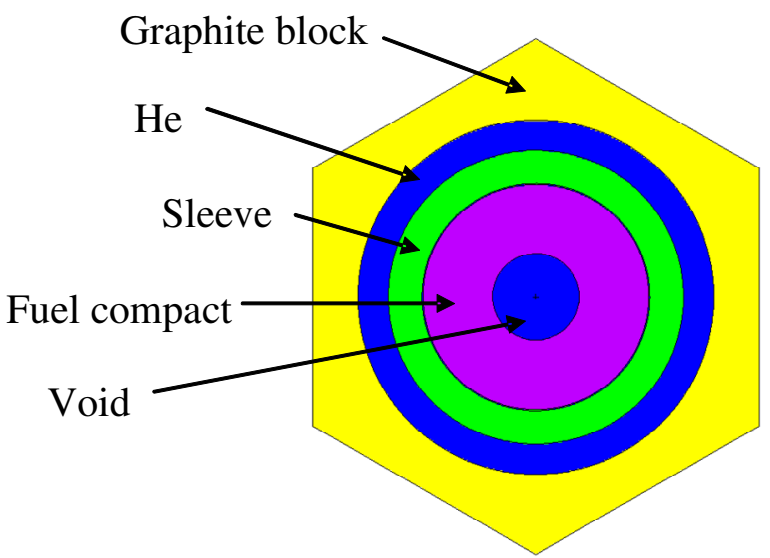

Homogeneous Model

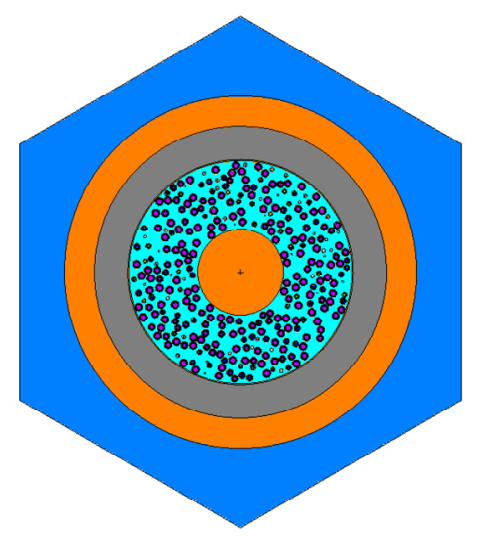

Heterogeneous Model

Figure 6.1. Fuel Compact Models 


\subsubsection{Number of Columns Required for First Criticality}

Corresponding to the experimental measurements, three major parameters (number of fuel columns for the first criticality (HTTR-FC), control rods position at criticality (HTTR-CR), and the excess reactivity (HTTR-EX)) of the benchmark model were evaluated. First, the required number of fuel columns for the first criticality was evaluated and the result is summarized in Table 6.1. The result obtained from the MCNP4C calculation is similar to the result of JAERI's preliminary calculation. As mentioned in the previous section, the benchmark model ignored the revised impurity content of the dummy blocks and the nitrogen content in the porous graphite. Thus, the specification of the benchmark model is similar to that used in JAERI's preliminary calculation. Finally, a review of literature [5] indicated that other MCNP4 calculations and analysis for this core (performed by other groups) observed such low values (ranging from 15-16) for the number of columns required for first criticality.

Table 6.1. Comparison of Number of Columns for First Criticality

\begin{tabular}{|l|l|c|c|}
\hline \multicolumn{1}{|c|}{ Organization } & \multicolumn{1}{c|}{ Code } & $\begin{array}{c}\text { Number of } \\
\text { columns }\end{array}$ & Eigenvalue \\
\hline JAERI -Japan & Experiment & 19 & Critical \\
\cline { 1 - 4 } JAERI - Japan & \multirow{2}{*}{ MVP } & $16 \pm 1^{\text {a) }}$ & $?$ \\
\cline { 1 - 4 } JAERI - Japan & $18 \pm 1^{\text {b) }}$ & $1.006 \pm ?$ \\
\cline { 1 - 4 } ANL (this study) & MCNP4C & 16 & $1.002 \pm 0.001$ \\
\hline
\end{tabular}

a) Preliminary results ( $2.5 \mathrm{ppm}$ impurity of dummy block and nitrogen in porous graphite is ignored).

b) Re-evaluated after adjustment of impurity of dummy block and nitrogen effect.

\subsubsection{Position of Control Rods for Critical Configurations}

The position (insertion depth) of the control rods have also been evaluated at the critical conditions for the cores with 24 and 30 fuel columns. The results are presented in Table 6.2. The MCNP4C calculation estimated lower positions for the control rods compared with the experimental measurements. Note that the depth of the control rod position is the distance between the boundary of the control rod and the bottom reflector. The reason for the lower calculated control rod positions compared to the experimental measurements is because MCNP4C over-estimated the excess reactivity, most likely because of inadequate information of 
impurities and the neglect of the nitrogen in the porous graphite. The ANL results are consistent with other MCNP4 results in open literature [5].

Table 6.2. Control Rods Positions at Critical Conditions

\begin{tabular}{|l|l|c|c|}
\hline \multirow{2}{*}{ Organization } & \multirow{2}{*}{ Code } & \multicolumn{2}{c|}{ Position $(\mathrm{cm})$} \\
\cline { 3 - 4 } & & 24 fuel columns & 30 fuel columns \\
\hline JAERI -Japan & Experiment & $221.5 \pm 0.5$ & $177.5 \pm 0.5$ \\
\hline JAERI - Japan & MVP & 208.0 & 180.0 \\
\hline ANL (this study) & MCNP4C & 203.0 & 167.0 \\
\hline
\end{tabular}

\subsubsection{Core Excess Reactivity}

The core $\mathrm{k}_{\text {eff }}$ values have been calculated for the thin annular (18 columns), thick annular (24 columns) and fully-loaded (30 columns) cores in order to determine the core excess reactivity. The results are summarized in Table 6.3. For the fully-loaded core, the $\mathrm{k}_{\text {eff }}$ value inferred from experimental measurement is 1.1363 ( $\pm>3.6 \%)$. The MCNP4C value obtained in this study is 1.15714 ( \pm 0.00037$)$. The uncertainty (experimental, etc) associated with the inferred measurement value is quite high, and the calculated value is within $1 \sigma$ of the "measured" value. The calculated $\mathrm{k}_{\text {eff }}$ value is however significantly higher $(1.8 \% \Delta \mathrm{k} / \mathrm{k})$ than the "measured" value.

Table 6.3. Eigenvalues of HTTR Core Calculations

\begin{tabular}{|c|c|c|}
\hline $\begin{array}{c}\text { Number of fuel } \\
\text { columns }\end{array}$ & Eigenvalue with ENDF/B-VI & Excess Reactivity $(\% \Delta \mathrm{k} / \mathrm{k})$ \\
\hline $\begin{array}{c}18 \\
\text { (Thin annular) }\end{array}$ & $1.02366 \pm 0.00056$ & 2.3 \\
\hline $\begin{array}{c}24 \\
\text { (Thick annular) }\end{array}$ & $1.11702 \pm 0.00047$ & 10.5 \\
\hline $\begin{array}{c}30^{\text {a) }} \\
\text { (Fully-loaded) }\end{array}$ & $1.15714 \pm 0.00037$ & 13.6 \\
\hline
\end{tabular}

a) Eigenvalue of experiment with inverse multiplication factor method is $1.13630 \pm>3.6 \%$.

\subsubsection{Comparison to Other Monte Carlo Results}

In Table 6.4, the results from this work are compared with other Monte Carlo results obtained under the IAEA Coordinated Research Program on Evaluation of High Temperature 
Gas Cooled Reactor [5]. The materials data used in the IAEA CRP are consistent with those used in this benchmark model (i.e., the original impurity content of the dummy block was used and nitrogen in the porous graphite was ignored).

Similar differences between calculation and measurement that are seen in this study were observed for the other evaluations. The excess reactivity evaluated from the KENO and MCNP Monte Carlo calculations is about $1.5-1.8 \%$ higher than that inferred from measurement, while the TRIPOLI-4 Monte Carlo calculation is $0.8 \%$ higher. In Reference 5, several causes of the differences between the Monte Carlo calculations and experiment are cited: (1) uncertainty of impurities in graphite block, (2) air or nitrogen content in graphite pores, (3) coated fuel particle modeling (regular and random distribution), and 4) choice of neutron library data.

Table 6.4. Comparison of Monte Carlo Calculations for Full-Core Case

\begin{tabular}{|l|l|l|l|c|}
\hline \multicolumn{1}{|c|}{ Organization } & \multicolumn{1}{|c|}{ Code } & Neutron Library & \multicolumn{1}{|c|}{ Eigenvalue } & $\begin{array}{c}\text { Excess reactivity } \\
(\% \Delta \mathrm{k} / \mathrm{k})\end{array}$ \\
\hline JAERI -Japan & Experiment & & $1.1363 \pm>3.6 \%$ & 12.0 \\
\hline CEA - France & TRIPOLI 4 ${ }^{\text {a) }}$ & JEF2.2 & $1.1463 \pm 0.0009$ & 12.8 \\
\hline IRI - Netherlands & KENO & JEF2.2 & $1.1584 \pm 0.0005$ & 13.7 \\
\hline IBRAE - Russia & MCNP4A & ENDF/B-VI & $1.1567 \pm ?$ & 13.6 \\
\hline Turkey & MCNP4B & ENDF/B-VI & $1.1564 \pm 0.0010$ & 13.5 \\
\hline \multirow{3}{*}{ ANL (this study) } & MCNP4C & ENDF/B-VI & $1.1571 \pm 0.0004$ & 13.6 \\
\cline { 2 - 5 } & MCNP4C & JEF2.2 & $1.1605 \pm 0.0006$ & 13.8 \\
\cline { 2 - 5 } & MCNP5 & ENDF/B-VI & $1.1579 \pm 0.0004$ & 13.6 \\
\hline
\end{tabular}

a) $1.13833 \pm 0.0009$ after adjusting the impurities and the air content in pores.

These result and the others presented above indicate significant differences between the code results and the measured core criticality. In our attempt to discern the reasons for the differences, sensitivity studies were performed. The results of those studies are summarized in the following sections.

\subsubsection{Impact of Regular Lattice versus Random CFP Modeling}

For modeling simplicity and computational efficiency, the random distribution of coated fuel particles in the graphite matrix has been approximated by regular lattice distributions using the lattice geometry option of MCNP4C. In previous studies, $[8,9]$ it was observed that the 
MCNP4C eigenvalues obtained with regular lattice distributions are consistently smaller than those obtained with random distributions. Although the regular lattice and random distribution models resulted in statistically meaningful eigenvalue differences, their magnitudes were generally small. Using a two-dimensional core problem (which was specified for the $5^{\text {th }}$ layer of the HTTR core), the difference in the $\mathrm{k}_{\mathrm{eff}}$ values from the regular lattice and random distribution models was evaluated. The difference was found to be about $150 \mathrm{pcm}$, with the regular lattice model giving a lower eigenvalue. Physics reasoning suggests that the impact will be smaller for the whole-core configuration (other core regions have lower spatial importance). Due to this small difference and because of the impracticality of using the random distribution model for whole-core Monte Carlo calculations (data storage requirements and significantly large computational tracking zones), the regular lattice distribution model was utilized to evaluate the HTTR cores.

\subsubsection{Impact of Nuclear Data Library}

The impact of nuclear data on the results has been evaluated using JEF2.2 data library in addition to the ENDF/B-VI library that was utilized for most of the current evaluation. The results of this study are summarized in Table 6.5. The eigenvalue difference between the calculations using the ENDF/B-VI and JEF2.2 libraries is about 250 - $270 \mathrm{pcm}$. So the data effect is not large, and would not account for the differences observed between the cases using ENDF/B-VI and JEF2.2 data in Table 6.4.

Table 6.5. Comparison of $\mathbf{k}_{\text {eff }}$ Obtained with Different Libraries

\begin{tabular}{|c|c|c|}
\hline $\begin{array}{c}\text { Number of fuel } \\
\text { columns }\end{array}$ & $\begin{array}{c}\text { Eigenvalue with } \\
\text { ENDF/B-VI }\end{array}$ & Eigenvalue with JEF2.2 \\
\hline $\begin{array}{c}18 \\
\text { (Thin annular) }\end{array}$ & $1.02366 \pm 0.00056$ & $1.02652 \pm 0.00059$ \\
\hline $\begin{array}{c}24 \\
\text { (Thick annular) }\end{array}$ & $1.11702 \pm 0.00047$ & $1.12041 \pm 0.00045$ \\
\hline $\begin{array}{c}30 \\
\text { (Fully-loaded) }\end{array}$ & $1.15714 \pm 0.00037$ & $1.16048 \pm 0.00059$ \\
\hline
\end{tabular}




\subsubsection{Impact of Homogeneous versus Heterogeneous Compact Modeling}

In the MCNP4C model used in this work, the CFPs have been modeled explicitly (using primarily the regular lattice model). It was however unclear what some of the other results used; explicit (heterogeneous) or smeared CFP-graphite-matrix compact (homogeneous) model, difference between which is termed "double heterogeneity". Additionally, we wanted an estimate of the double heterogeneity effect in order to determine the relevance of the HTTR to the VHTR. The results of the calculations for the three cores are summarized in Table 6.6. The double heterogeneity effect is seen to increase with the number of fuel columns (535 versus $743 \mathrm{pcm}$ ). The magnitude of the double heterogeneity effect for the HTTR is about a factor of $4-5$ lower than that observed for the prismatic block-type VHTR [9]. Note that the homogeneous model predicts a lower value of the core $\mathrm{k}_{\text {eff. }}$.

Table 6.6. Eigenvalues of HTTR Core Calculations

\begin{tabular}{|c|c|c|c|}
\hline $\begin{array}{c}\text { Number of fuel } \\
\text { columns }\end{array}$ & Homogeneous & Heterogeneous & $\begin{array}{c}\text { Double Heterogeneity } \\
\text { Effect }(\mathrm{pcm} \Delta \rho)\end{array}$ \\
\hline $\begin{array}{c}18 \\
\text { (Thin annular) }\end{array}$ & $1.01808 \pm 0.00058$ & $1.02366 \pm 0.00056$ & 535 \\
\hline $\begin{array}{c}24 \\
\text { (Thick annular) }\end{array}$ & $1.10945 \pm 0.00058$ & $1.11702 \pm 0.00047$ & 611 \\
\hline $\begin{array}{c}30 \\
\text { (Fully-loaded) }\end{array}$ & $1.14727 \pm 0.00058$ & $1.15714 \pm 0.00037$ & 743 \\
\hline
\end{tabular}

\subsubsection{Impact of Impurity on Core Criticality}

To assess the effect of the uncertainty in the impurity content of the dummy graphite block, the thin-annular core was re-evaluated using the updated information (i.e., increase in the impurity content). (Note that the uncertainty in the impurity content of the dummy blocks does not affect the $\mathrm{k}_{\text {eff }}$ of the fully-loaded core because all dummy blocks are replaced by the fuel blocks in this core configuration.) By increasing the impurity content of the dummy block (3.1 ppm versus $2.5 \mathrm{ppm}[6]$ ), the k-effective value of the thin annular core was decreased from 1.02366 to $1.01732( \pm 0.0006)$. This result indicates that the k-effective value is very sensitive to 
the impurity content of the graphite blocks. It is therefore necessary that in addition to specification of core constituents an accurate indication of the impurity content be specified.

\subsection{Whole-Core Deterministic Calculations}

Whole-core deterministic models have been developed for analyzing the HTTR core. Descriptions of the models and results are presented in this section.

\subsubsection{Descriptions of the DRAGON and DIF3D codes}

Currently, only a few lattice codes allow the detailed treatment of the double heterogeneity effect inherent in the HTGR design at the assembly level. Two modern tools that contain models for representing coated fuel particles are the WIMS8 [10] and DRAGON [11] codes. A distinction between the WIMS8 and DRAGON models for the HTGR assembly is that the WIMS8 code does not provide the particulate-fuel double heterogeneity treatment at the assembly level like DRAGON (but at the pin level). A two-step scheme is therefore necessary in the WIMS8 calculation for the assembly. [9] Thus, the DRAGON code was selected as the lattice code in this study.

The DRAGON code has a collection of models for simulating the neutronics behavior of a unit cell or a fuel lattice in a nuclear reactor. The typical functionalities found in most modern lattice codes are contained in DRAGON code. These include interpolation of microscopic cross sections supplied by means of standard libraries; resonance self-shielding calculations in multidimensional geometries; multi-group and multi-dimensional neutron flux calculations which can take into account neutron leakage; transport-transport or transport-diffusion equivalence calculations; and modules for editing condensed and homogenized nuclear properties for reactor calculations. The code also performs isotopic depletion calculations. The code user must however supply cross sections in one of the following standard formats: DRAGON, MATXS (TRANSX-CTR), WIMSD4, WIMS-AECL, and APOLLO. Macroscopic cross sections can also be read by DRAGON via the input data stream. At ANL, the 69- and 172group cross section libraries created in WIMSD4-format by the Reduced Enrichment for Research and Test Reactors (RERTR) project are used with the DRAGON code. 
It is noted that in the DRAGON full-assembly model for HTGR hexagonal block, the block is formed by a collection of pin-cell sized hexagons. Each pin-cell contains the fuel compact and its surrounding block graphite. When all the fuel and coolant-hole pin-cells are represented, the block graphite content is not totally accounted for and therefore an extra ring of pin-cell sized hexagons is used to represent the remaining graphite. The number density of the graphite in these peripheral cells is modified to preserve the graphite content of the assembly block. Due to the use of the pin-cell sized hexagons, the DRAGON assembly model has jagged boundaries, not the flat boundaries of the hexagonal block.

An assessment of the accuracy of the DRAGON code when used for analyzing the Very High Temperature Reactor (VHTR) fuel element has been done by comparing results from the code to those from the high fidelity MCNP4C code. [12] Results show that eigenvalues, neutron spectra, and magnitude of the double heterogeneity effect predicted by DRAGON generally agree well with the reference values obtained from MCNP4C calculations. [8,9]

There are a number of well-established deterministic tools for whole-core calculations. In this study, the DIF3D code [13], which was developed at ANL, was used for the whole-core calculations. The DIF3D code has several flux solvers such as finite-difference and nodal diffusion theory solvers, and the VARIANT nodal transport solver. The applicability of the DIF3D code for high temperature gas-cooled reactor whole-core calculations was assessed in a VHTR optimization study [14] and in a recent feasibility study of deep-burn transmutation [15]. The code model was found to provide sufficient accuracy.

\subsubsection{Lattice and Core Modeling}

The HTTR core has been evaluated using the DRAGON and DIF3D coupled calculations. The microscopic multigroup cross sections needed by the DIF3D code were generated by DRAGON calculations. For the standard fuel assembly, the DRAGON code solves the 172-group transport equations using a two-dimensional hexagon geometry and a reflective boundary condition. The code uses the multigroup flux obtained for the given problem to condense the microscopic cross sections (averaged over the assembly) into 6 neutron group data. However, for the control rods guide and reflector blocks, the DRAGON code cannot solve the 
transport equations directly because there is no fission source in the non-fueled graphite blocks. For this reason, the cross sections of the control rods guide and reflector blocks were generated from an approximate two-dimensional model (see Figure 6.2). In this model, in order to provide the appropriate neutron spectra to the non-fueled blocks, one fuel assembly is connected to the control rods guide and reflector blocks and a reflective boundary condition is imposed.

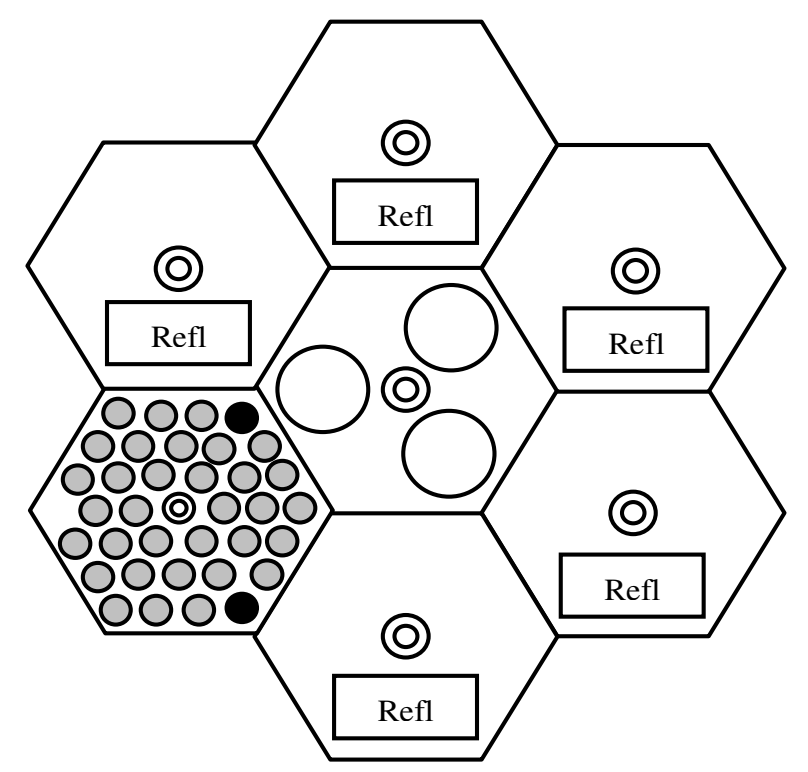

Figure 6.2. An Approximation Model for Generating Cross Sections of Control Rod Guide and Reflector Blocks

For the whole-core calculations, the Hexagonal-Z (Hex-Z) geometry option of DIF3D was utilized. The HTTR core has complicated radial and axial heterogeneities: 12 different fuel types, some in assemblies with 33 pins and some with 31 pins, two types of BP rods, fuel rods and BP rods encapsulated by plugs and dowels, axial and radial reflector blocks, etc. In the Hex$\mathrm{Z}$ core model, the radial heterogeneity in each hexagonal block is not explicitly modeled in the DIF3D code since cross sections have been rigorously homogenized by smearing all materials in the DRAGON lattice calculations. Axially, the regions of fuel plugs and dowels are modeled explicitly. However, due to the axial heterogeneity of the BP rods, two fuel block models were developed according to the BP homogenization approach (see Figure 6.3). The axial heterogeneity of the BP rod is shown in Figure 2.6; graphite disks are sandwiched between two BP pellets. In Figure 6.3, the BP rods (neutron absorber and graphite disks) are smeared with 
fuel rods and graphite block in the homogeneous BP model (left figure), while the neutron absorbers and graphite disks are separately smeared with fuel and graphite in the explicit BP model (right figure). Thus, there are three material layers axially defined in the simple BP model and five material layers in the standard BP model.
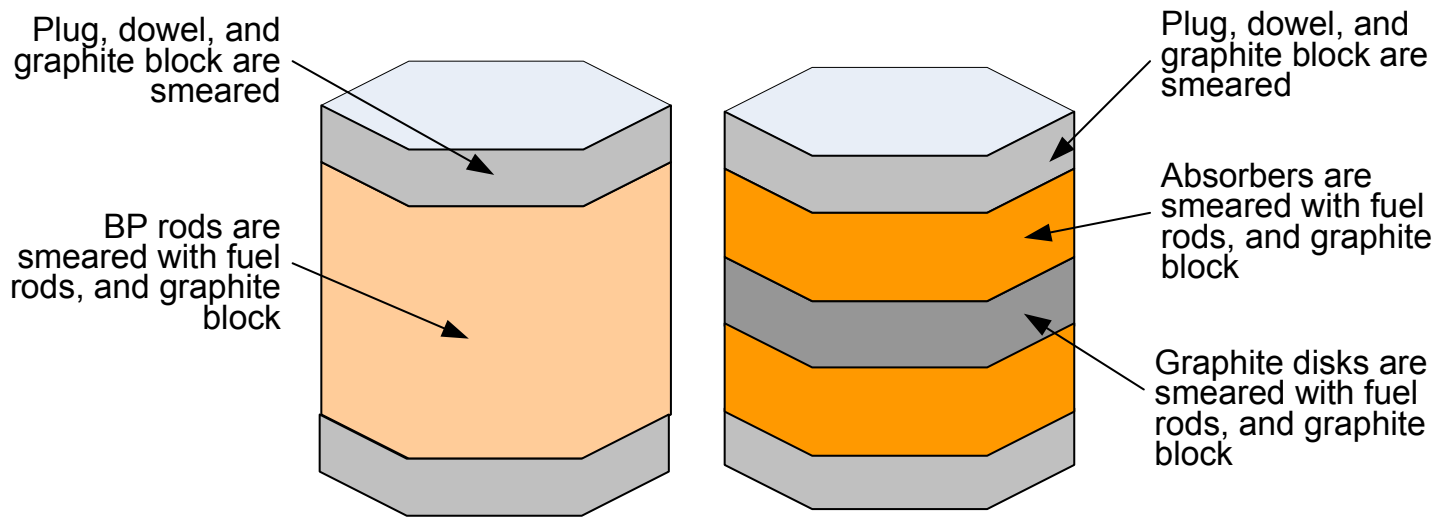

Figure 6.3. Fuel Block Models According to Axial BP Homogenization Approach

\subsubsection{Results of Deterministic Calculations}

\section{Comparison of Spectra}

As indication of the relevance of the HTTR to the VHTR [14], the fuel parameters and assembly-wise spectrum of the two systems have been compared and are summarized in Table 6.7 and Figure 6.4.

Table 6.7. Comparison of HTTR and VHTR Fuel Parameters

\begin{tabular}{|c|c|c|}
\hline Parameter & HTTR Model & VHTR Model \\
\hline Kernel diameter $(\mu \mathrm{m})$ & $\sim 600$ & 425 \\
\hline Particle diameter $(\mu \mathrm{m})$ & $\sim 930$ & 845 \\
\hline Packing fraction $(\%)$ & $\sim 30$ & 25 \\
\hline U enrichment (\%) & $3.4-9.9$ & 14.0 \\
\hline Number of BP rods & 2 with $\mathrm{B}_{4} \mathrm{C}$ & 0 \\
\hline Impurity of graphite block & $\sim 1.0 \mathrm{ppm}$ & Not modeled \\
\hline $\mathrm{C} / \mathrm{U}-235$ & $2570-1780$ & $\sim 2400$ \\
\hline Fast-to-thermal flux ratio ${ }^{\text {a) }}$ & $3.5-7.5$ & 2.61 \\
\hline
\end{tabular}

a) Cut-off energy is $0.4 \mathrm{eV}$ 
The uranium enrichment of the HTTR fuel is lower than that of the VHTR fuel, but the graphite-to-fissile (C/U-235) ratios of the HTTR fuel assemblies are similar or lower than that of the VHTR assembly because the packing fraction and kernel diameter are bigger. Due to the burnable poisons and impurity of the graphite, the thermal fluxes of the HTTR fuel assemblies are lower than that of the VHTR (see the spectrum and fast-to-thermal flux ratio). Note that the burnable poison and impurity of the graphite block were not modeled in the VHTR assembly model used in this comparison. In addition, due to the difference in the operating temperatures, the thermal flux of the VHTR is shifted to higher energy; HTTR tests were done at the cold state.

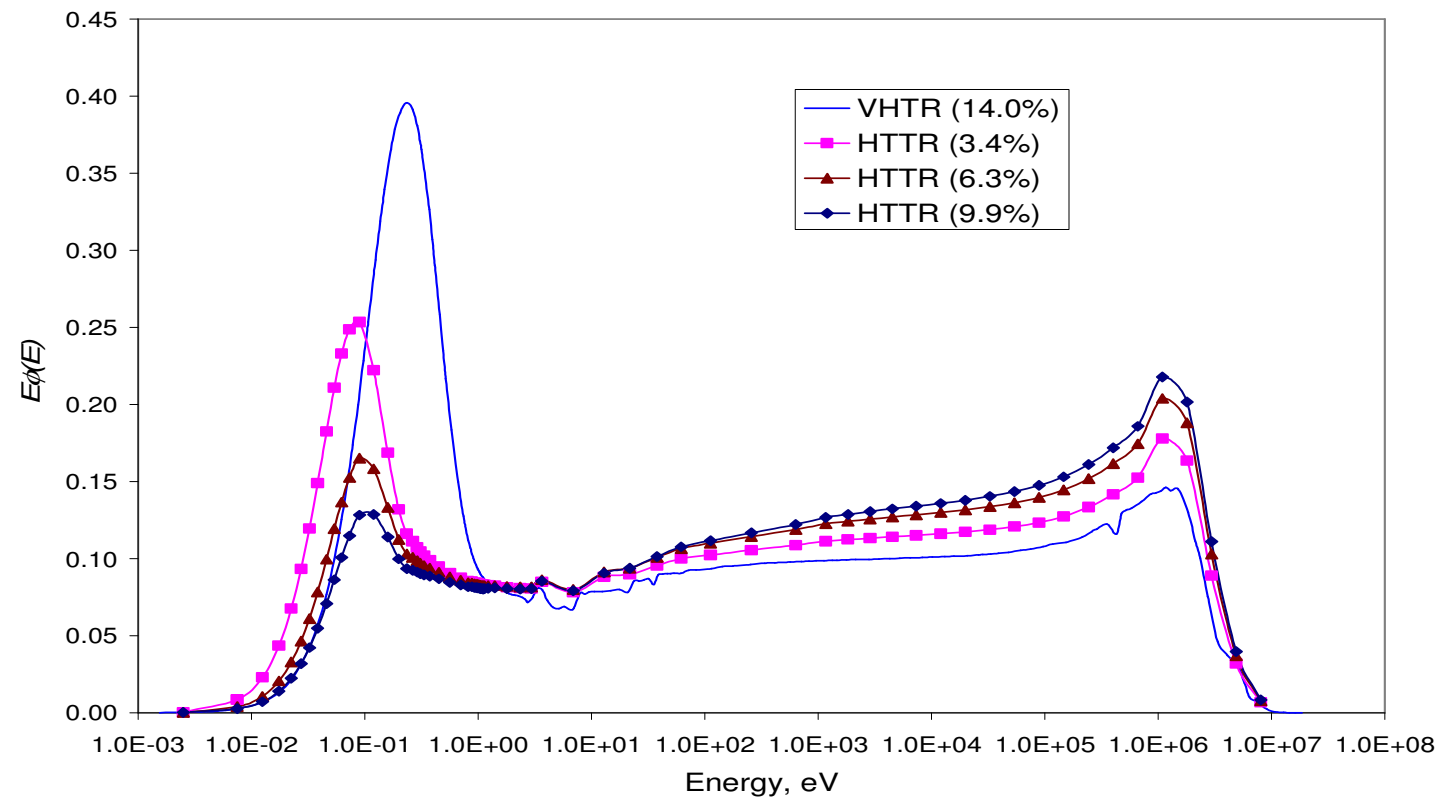

Figure 6.4. Spectra of HTTR Assemblies

\section{Comparison of Criticality for the Fully-Loaded Core}

The k-effective values of the fully-loaded core have been calculated and the results compared with other deterministic calculations [16]. Table 6.8 is a summary of the results. In these calculations, the high order variational nodal option $\left(5^{\text {th }}\right.$-order flux approximation, quadratic source approximation, and $\mathrm{P}_{3}$ angular flux expansion) of the DIF3D code was utilized with one hexagon per node and about $2.0 \mathrm{~cm}$ in height. Generally, the deterministic calculations gave an overestimation of the $\mathrm{k}_{\mathrm{eff}}$ of the fully-loaded HTTR core and the overestimation increases with increase in the number of neutron energy groups. 
The result of the DRAGON/DIF3D calculation with explicit BP model is about 3.4\% $\Delta \mathrm{k} / \mathrm{k}$ higher compared to the value inferred from measurement and about $1.6 \% \Delta \mathrm{k} / \mathrm{k}$ higher than the result of the MCNP4C calculation. Two possibilities are suspected for these large differences between the measurement and the deterministic calculations. The first possibility is the composition uncertainty (such as impurity and nitrogen in graphite), which was already observed in the Monte Carlo calculations. In Table 6.8, this effect is about $1.8 \% \Delta \mathrm{k} / \mathrm{k}$ (see the difference between the measurement and MCNP4C calculation).

Table 6.8. Eigenvalue Comparison for Deterministic HTTR Core Calculations

\begin{tabular}{|c|c|c|c|}
\hline Code & Equation & Spatial refinement & k-effective \\
\hline Experiment & & & $1.1363 \pm 3.6 \%$ \\
\hline MCNP4C(this study) & & Explicit Hexagonal-Z & $1.1571 \pm 0.0004$ \\
\hline BOLD VENTURE & 13 group diffusion & Cylindrical-Z, 6 rings, Finite difference & 1.1885 \\
\hline CRONOS & 8 group diffusion & Hexagonal-Z & 1.1698 \\
\hline CITATION & 4 group diffusion & Triangle-Z, Finite difference & 1.1607 \\
\hline PANTHER & 2 group diffusion & Triangle-Z, Finite element & 1.1595 \\
\hline \multirow{2}{*}{ DIF3D (this study) } & 6 group diffusion & $\begin{array}{l}\text { Hexagonal-Z, variational nodal option } \\
\text { with explicit BP model }\end{array}$ & 1.1750 \\
\hline & 6 group diffusion & $\begin{array}{l}\text { Hexagonal-Z, variational nodal option } \\
\text { with homogeneous BP model }\end{array}$ & 1.1619 \\
\hline
\end{tabular}

The second possibility is the approximation made in the flux solvers used for the deterministic calculations and the cross sections for the reflectors. There is significant streaming through the large holes of the control rods guide blocks and irradiation blocks (there are 19 control rods guide and irradiation columns among total 61 columns). However, the streaming effect was significantly underestimated in the DIF3D calculations. Similarly, the method introduced in this study to obtain the control block and reflector cross sections (see Figure 6.2) is not adequate to capture the streaming effect. In addition, the flux solvers of the deterministic codes are not accurate to estimate the reaction rates of the highly heterogeneous HTTR core: the evidence of this is observed from the results of the two axial BP models. In Table 6.6, the impact of homogenizing the BP rods (i.e., the k-effective difference between the homogeneous and explicit BP models) is about $1.1 \% \Delta \mathrm{k} / \mathrm{k}$ : similar results have been observed in the European benchmarking study [16]. 


\section{CONCLUSIONS}

A preliminary evaluation of the High Temperature Engineering Test Reactor (HTTR) start-up experiments has been performed. Monte Carlo and deterministic models were developed and used for the analysis of the four critical configurations of the HTTR, which were attained along the path to full-core loading. Data in open literature was used as basis for these evaluations. The results obtained show a significant difference $(1.8 \% \Delta \mathrm{k} / \mathrm{k})$ in the core criticality calculated by the MCNP code and the experimental measurement; larger differences of about $2.3-3.4 \% \Delta \mathrm{k} / \mathrm{k}$ were found for the deterministic codes. These are consistent with some of the values reported for an HTTR experiment evaluation previously arranged by the IAEA.

The lack of more detailed data was a major limitation to the effort because it was not possible to discern the major sources of the differences observed between calculation and measurement data for the experiments. Due to the potential relevance of the HTTR data in future licensing of the VHTR, it is recommended that avenues be pursued to obtain more detailed data from JAERI (Japan). This could be done under the bilateral or multilateral platform provided by the Generation IV International Forum or under the activities of international organizations. 


\section{REFERENCES}

1. "Status of the HTTR Project," Japan Atomic Energy Research Institute, Home page of HTTR, http://www2.tokai.jaeri.go.jp/httr/eng/index_main_eng.html, (2004).

2. S. Saito, et al, "Design of High Temperature Engineering Test Reactor (HTTR)," JAERI-1332, Japan Atomic Energy Research Institute (1994).

3. K. Yamashita, et al, "Nuclear Design of the High-Temperature Engineering Test Reactor (HTTR)," Nuclear Science and Engineering 122, 212 (1996).

4. N. Nojiri, et al, “Benchmark Problem's Data for HTTR's Start-up Core Physics Experiment IAEA Benchmark," JAERI-memo 10-1005, Japan (1998).

5. “Evaluation of High Temperature Gas Cooled Reactor Performance: Benchmark analysis related to initial testing of the HTTR and HTR-10," IAEA-TECDOC-1382, IAEA (2003).

6. N. Fujimoto, K. Yamashita, H. Nojiri, M. Takeuchi, S. Fujisaki, “Annular Core Experiments in HTTR's Start-up Core Physics Tests," Nuclear Science and Engineering, 150, 310 (2005).

7. N. Nojiri, et al, "Preliminary Analyses of HTTR's Start-up Physics Tests by Monte Carlo Code MVP," JAERI-Tech 98-032, Japan Atomic Energy Research Institute (1998).

8. T. K. Kim, W. S. Yang, T. A. Taiwo, and M. A. Smith, "Preliminary Assessment of Lattice Physics Capabilities for VHTR Analysis," Trans. Am. Nucl. Soc., 91 (2004).

9. T. K. Kim, W. S. Yang, M. A. Smith, T. A. Taiwo, and H. S. Khalil, “Assessment of Monte Carlo and Deterministic Codes for Next Generation Nuclear Plant (NGNP) Core Modeling," Gen-IV report, Argonne National Laboratory, April 15, 2004.

10. "WIMS - A Modular Scheme for Neutronics Calculations," User's Guide for Version 8, ANSWER/WIMS(99)9, The ANSWERS Software Package, AEA Technology. 
11. G. Marleau, et al, “A User Guide for DRAGON," Technical report IGE-174 Rev. 4, Ecole Polytechnique de Montréal, September 1998 (1998).

12. “MCNP - A General Monte Carlo N-Particle Transport Code," Version 4C, Los Alamos National Laboratory, LA-13709-M.

13. K. L. Derstine, "DIF3D: A Code to Solve One-, Two-, and Three-Dimensional Finite-Difference Diffusion Theory Problems," ANL-82-64, Argonne National Laboratory, 1984.

14. T. K. Kim, W. S. Yang, T. A. Taiwo and H. S. Khalil. "Equilibrium Cycle Analysis in Support of Fuel Specification for Next Generation Nuclear Power Plant," ICAPP-05, Seoul, Korea, May 15-19, 2005.

15. T. K. Kim, T. A. Taiwo, R. N. Hill, W. S. Kim and F. Venneri, “A Feasibility Study of Reactor-Based Deep-Burn Concepts," ANL-AFCI-155, Argonne National Laboratory, August, 2005.

16. X. Raepsaet et al. "Analysis of the European Results on the HTTR's Core Physics Benchmarks," Nuclear Engineering and Design, 222, 173 (2003). 


\author{
Evaluator \\ William K. Terry \\ Idaho National Laboratory \\ Internal Reviewers \\ Soon-Sam Kim \\ J. Blair Briggs
}

\author{
Independent Reviewers \\ Yuliang Sun \\ Institute of Nuclear Energy Technology \\ Tsinghua University
}

Temitope Taiwo

Argonne Laboratory 
Status of Compilation / Evaluation / Peer Review

\begin{tabular}{|c|c|c|c|c|c|}
\hline Chapter & Page & Compiled & $\begin{array}{l}\text { Independent } \\
\text { Review }\end{array}$ & $\begin{array}{l}\text { Working } \\
\text { Group Review }\end{array}$ & Approved \\
\hline 1.0 DETAILED DESCRIPTION & 4 & & & & \\
\hline $\begin{array}{l}\text { 1.1 Description of the Critical and / or } \\
\text { Subcritical Configuration }\end{array}$ & 6 & & & & \\
\hline $\begin{array}{l}\text { 1.2 Description of Buckling and } \\
\text { Extrapolation Length Measurements }\end{array}$ & 16 & & & & \\
\hline $\begin{array}{l}\text { 1.3 Description of Spectral Characteristics } \\
\text { Measurements }\end{array}$ & 16 & & & & \\
\hline $\begin{array}{l}\text { 1.4 Description of Reactivity Effects } \\
\text { Measurements }\end{array}$ & 16 & & & & \\
\hline $\begin{array}{l}\text { 1.5 Description of Reactivity Coefficient } \\
\text { Measurements }\end{array}$ & 16 & & & & \\
\hline 1.6 Description of Kinetics Measurements & 16 & & & & \\
\hline $\begin{array}{l}1.7 \quad \text { Description of Reaction-Rate } \\
\begin{array}{l}\text { Distribution } \\
\text { Measurements }\end{array} \\
\end{array}$ & 16 & & & & \\
\hline $\begin{array}{l}1.8 \text { Description of Power Distribution } \\
\text { Measurements }\end{array}$ & 16 & & & & \\
\hline 1.9 Description of Isotopic Measurements & 16 & & & & \\
\hline $\begin{array}{l}1.10 \text { Description of Other Miscellaneous } \\
\text { Types of Measurements }\end{array}$ & 16 & & & & \\
\hline Chapter & Page & Evaluated & $\begin{array}{l}\text { Independent } \\
\text { Review }\end{array}$ & $\begin{array}{c}\text { Working } \\
\text { Group Review }\end{array}$ & Approved \\
\hline $\begin{array}{l}2.0 \text { EVALUATION OF EXPERIMENTAL } \\
\text { DATA }\end{array}$ & 17 & & & & \\
\hline $\begin{array}{l}2.1 \text { Evaluation of Critical and / or } \\
\text { Subcritical Configuration Data }\end{array}$ & 19 & & & & \\
\hline $\begin{array}{l}2.2 \text { Evaluation of Buckling and } \\
\text { Extrapolation Length Data }\end{array}$ & 38 & & & & \\
\hline $\begin{array}{l}\text { 2.3 Evaluation of Spectral Characteristics } \\
\text { Data }\end{array}$ & 38 & & & & \\
\hline 2.4 Evaluation of Reactivity Effects Data & 38 & & & & \\
\hline $\begin{array}{ll}2.5 & \text { Evaluation of Reactivity Coefficient } \\
\text { Data } & \\
\end{array}$ & 38 & & & & \\
\hline $\begin{array}{l}\text { 2.6 Evaluation of Kinetics Measurements } \\
\text { Data }\end{array}$ & 38 & & & & \\
\hline $\begin{array}{l}2.7 \quad \text { Evaluation of Reaction Rate } \\
\text { Distributions }\end{array}$ & 38 & & & & \\
\hline 2.8 Evaluation of Power Distribution Data & 38 & & & & \\
\hline 2.9 Evaluation of Isotopic Measurements & 38 & & & & \\
\hline $\begin{array}{l}2.10 \text { Evaluation of Other Miscellaneous } \\
\text { Types of Measurements }\end{array}$ & 38 & & & & \\
\hline
\end{tabular}

\begin{tabular}{|ll|l|l|l|l|l|}
\hline \multicolumn{1}{|c|}{ Chapter } & Page & Compiled & $\begin{array}{c}\text { Independent } \\
\text { Review }\end{array}$ & $\begin{array}{c}\text { Working } \\
\text { Group } \\
\text { Review }\end{array}$ & Approved \\
\hline 3.0 & BENCHMARK SPECIFICATIONS & 39 & & & & \\
\hline $3.1 \quad \begin{array}{l}\text { Benchmark-Model Specifications for } \\
\text { Critical and / or Subcritical } \\
\text { Measurements }\end{array}$ & 39 & & & & \\
\hline
\end{tabular}


CRIT

\begin{tabular}{|c|c|c|c|c|c|}
\hline $\begin{array}{l}\text { 3.2 Benchmark-Model Specifications for } \\
\text { Buckling and Extrapolation Length } \\
\text { Measurements }\end{array}$ & 50 & & & & \\
\hline $\begin{array}{ll}\text { 3.3 } & \text { Benchmark-Model Specifications for } \\
\text { Spectral Characteristics Measurements }\end{array}$ & 50 & & & & \\
\hline $\begin{array}{ll}3.4 & \text { Benchmark-Model Specifications for } \\
\text { Reactivity Effects Measurements }\end{array}$ & 50 & & & & \\
\hline $\begin{array}{ll}3.5 & \text { Benchmark-Model Specifications for } \\
& \text { Reactivity Coefficient Measurements }\end{array}$ & 51 & & & & \\
\hline $\begin{array}{ll}3.6 & \text { Benchmark-Model Specifications for } \\
\text { Kinetics Measurements }\end{array}$ & 51 & & & & \\
\hline $\begin{array}{l}\text { 3.7 Benchmark-Model Specifications for } \\
\text { Reaction-Rate Distribution Measurements }\end{array}$ & 51 & & & & \\
\hline $\begin{array}{l}3.8 \text { Benchmark-Model Specifications for } \\
\text { Power Distribution Measurements }\end{array}$ & 51 & & & & \\
\hline $\begin{array}{l}\text { 3.9 Benchmark-Model Specifications for } \\
\text { Isotopic Measurements }\end{array}$ & 51 & & & & \\
\hline $\begin{array}{l}3.10 \text { Benchmark-Model Specifications of } \\
\text { Other } \\
\text { Measurements } \\
\end{array}$ & 51 & & & & \\
\hline Chapter & Page & Compiled & $\begin{array}{l}\text { Independent } \\
\text { Review }\end{array}$ & $\begin{array}{l}\text { Working } \\
\text { Group } \\
\text { Review }\end{array}$ & Approved \\
\hline $\begin{array}{l}\text { 4.0 RESULTS OF SAMPLE } \\
\text { CALCULATIONS }\end{array}$ & 52 & & & & \\
\hline $\begin{array}{l}\text { 4.1 Results of Calculations of the Critical or } \\
\text { Subcritical Configurations }\end{array}$ & 52 & & & & \\
\hline $\begin{array}{l}\text { 4.2 Results of Buckling and Extrapolation } \\
\text { Length Calculations }\end{array}$ & 52 & & & & \\
\hline $\begin{array}{ll}4.3 & \text { Results of Spectral Characteristics } \\
\text { Calculations }\end{array}$ & 52 & & & & \\
\hline 4.4 Results of Reactivity Effect Calculations & 52 & & & & \\
\hline $\begin{array}{l}\text { 4.5 Results of Reactivity Coefficient } \\
\text { Calculations }\end{array}$ & 52 & & & & \\
\hline 4.6 Results of Kinetics Parameter Calculations & 53 & & & & \\
\hline $\begin{array}{l}\text { 4.7 Results of Reaction-Rate Distribution } \\
\text { Calculations }\end{array}$ & 53 & & & & \\
\hline 4.8 Results of Power Distribution Calculations & 53 & & & & \\
\hline 4.9 Results of Isotopic Calculations & 53 & & & & \\
\hline $\begin{array}{l}\text { 4.10 Results of Calculations of Other } \\
\text { Miscellaneous Types of Measurements }\end{array}$ & 53 & & & & \\
\hline Chapter & Page & Compiled & $\begin{array}{l}\text { Independent } \\
\text { Review }\end{array}$ & $\begin{array}{l}\text { Working } \\
\text { Group } \\
\text { Review }\end{array}$ & Approved \\
\hline 5.0 REFERENCES & 53 & & & & \\
\hline $\begin{array}{l}\text { Appendix A: Computer Codes, Cross Sections, } \\
\text { and Typical Input Listings }\end{array}$ & 54 & & & & \\
\hline $\begin{array}{l}\text { Appendix B: Calculation of Base-case } \\
\text { Atomic Number Densities in the Core } \\
\text { Region }\end{array}$ & 79 & & & & \\
\hline Appendix C: Nuclear Constants & 85 & & & & \\
\hline
\end{tabular}


EVALUATION OF THE INITIAL CRITICAL CONFIGURATION OF THE HTR10 PEBBLE-BED REACTOR

IDENTIFICATION NUMBER: HTR10-GCR-RESR-001

CRIT

KEY WORDS: Pebble-bed reactor, criticality, research reactor, benchmark evaluation, Chinese Reactors, HTR-10, graphite-moderated reactors, HTGRs

\subsection{DETAILED DESCRIPTION}

The HTR-10 is a small (10 MWt) pebble-bed research reactor intended to develop pebble-bed reactor (PBR) technology in China. It will be used to test and develop fuel, verify PBR safety features, demonstrate combined electricity production and cogeneration of heat, and provide experience in PBR design, operation, and construction.

Table 1 gives major design features of the reactor, and Figure 1 illustrates the reactor layout. The reactor was not at power during the subject experiment, and some key features, such as the composition of the gas in the void spaces, were different from the specifications in Table 1, as explained in detail below. However, the data in Table 1 serve to characterize the reactor, and they are therefore included here.

Table 1. Reactor design features (from Reference 1)

\begin{tabular}{|l|l|l|}
\hline Reactor thermal power & $\mathrm{MW}$ & 10 \\
\hline Primary helium pressure & $\mathrm{MPa}$ & 3.0 \\
\hline Reactor core diameter & $\mathrm{cm}$. & 180 \\
\hline Average core height & $\mathrm{cm}$. & 197 \\
\hline Average helium temperature at reactor outlet & ${ }^{\circ} \mathrm{C}$ & 700 \\
\hline Average helium temperature at reactor inlet & ${ }^{\circ} \mathrm{C}$ & 250 \\
\hline Helium mass flow rate at full power & $\mathrm{kg} / \mathrm{s}$ & 4.3 \\
\hline Main steam pressure at steam generator outlet & $\mathrm{MPa}$ & 4.0 \\
\hline Main steam temperature at steam generator outlet & ${ }^{\circ} \mathrm{C}$ & 440 \\
\hline Feed water temperature & ${ }^{\circ} \mathrm{C}$ & 104 \\
\hline Main steam flow rate & $\mathrm{t} / \mathrm{hr}$ & 12.5 \\
\hline Number of control rods in side reflector & & 10 \\
\hline Number of absorber ball units in side reflector & & 7 \\
\hline Nuclear fuel & & $\mathrm{UO} 2$ \\
\hline Heavy metal loading per fuel element & $\mathrm{g}$ & 5 \\
\hline Enrichment of fresh fuel element & $\%$ & 17 \\
\hline Number of fuel elements in equilibrium core & & 27,000 \\
\hline Fuel loading mode & & multi-pass \\
\hline
\end{tabular}




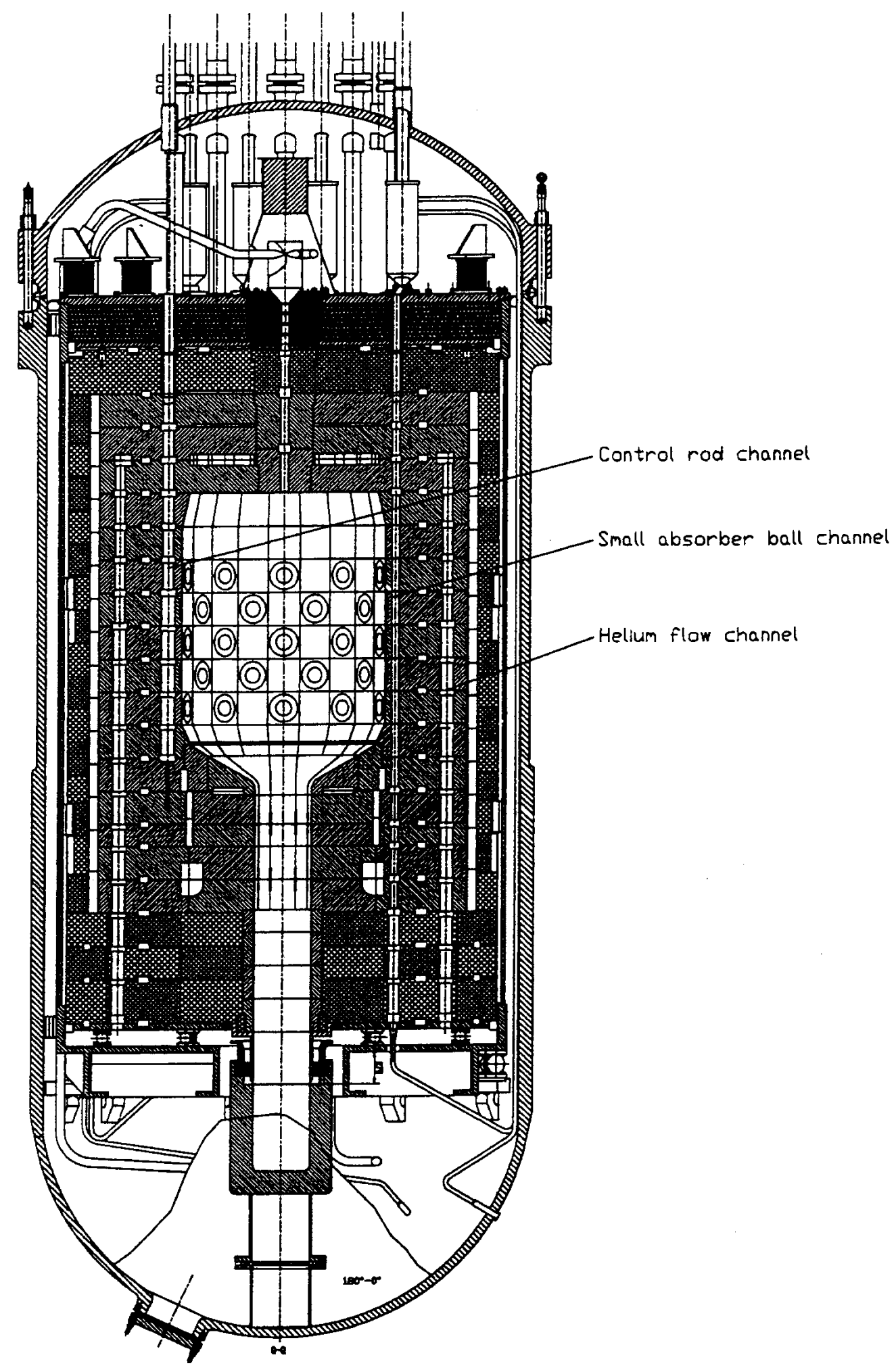

Figure 1. Layout of HTR-10 (from Reference 1) 
As a test reactor intended to demonstrate all the technologies associated with PBRs, the HTR-10 contains a complete cooling system that supplies hot helium to a steam generator for generation of electricity and supply of district heating. In a later experimental phase, the HTR-10 will supply heat to both a steam cycle and a gas-turbine cycle. The primary coolant loop contains three pressure vessels: the reactor vessel, the steam generator vessel, and the hot gas duct. In the initial criticality experiment, only the core and the reflector are modeled.

The HTR-10 first became critical on 1 December 2000. This evaluation assesses the usefulness of the data obtained in the initial criticality experiment as a benchmark for reactor physics codes. It is concluded that the experiment is an acceptable benchmark.

In the initial critical condition, all control rods were withdrawn. Measurements of control rod worth were also made on the cold clean core. The control rod worth experiments have not yet been evaluated.

\subsection{Description of the Critical Configuration}

Like any PBR, the HTR-10 is fueled by billiard-ball-size spheres containing fuel particles embedded in a matrix. During reactor operation, the fuel spheres are introduced at the top and slowly flow downwards through the core region. As shown in Figure 1, the HTR-10 core is a cylindrical cavity above a conical zone (the "conus") that funnels pebbles into a discharge tube. The core, conus, and discharge tube are surrounded by graphite blocks (the reflector), most of which contain boron and some of which are penetrated by various borings for coolant flow, control rods, emergency shutdown absorber balls, and other purposes. In the initial critical experiment, the voids in the core and reflector were filled by moist air rather than the helium with which the reactor is cooled while in operation, and the conus was filled with "dummy" balls - spheres the same size as fuel spheres but made only of graphite. In the cylindrical core, a mixture of fuel balls and dummy balls in the ratio of 57:43 was added until the core became critical. During this initial fuel loading, pebbles were not removed at the bottom, so the pebbles remained stationary after they settled into position in the core. A small Am-Be source $\left(4.4 \times 10^{7}\right.$ neutrons/s) was provided to assist startup, and the neutron flux was tracked by neutron counters. Criticality was achieved when 16,890 balls (fuel and dummy) had been loaded. This is equivalent to a level core height of $123.06 \mathrm{~cm}$.

\subsubsection{Overview of Experiment}

The HTR-10 is located at the Institute of Nuclear Energy Technology (INET), a unit of Tsinghua University, near Beijing. The HTR-10 project was approved by the Chinese State Council in March 1992, ground was broken in 1994, and construction was 
completed in 2000. Initial criticality was achieved on 1 December 2000 . The experiment was performed by the INET.

In advance of the actual experiment, data were distributed worldwide for interested groups to use in benchmarking calculations with various computer codes. The benchmark problem specifications differed in several respects from the experiment as it was run. Some compositions provided in the benchmark specifications were different from the as-built compositions, the benchmark and as-run temperatures were different, and the void spaces in the actual experiment were filled with air instead of helium. The results of the benchmark efforts are reported in Reference 1.

The initial criticality experiment has a total uncertainty in $\mathrm{k}_{\mathrm{eff}}$ of slightly more than 0.005 . It is judged acceptable as a benchmark.

\subsubsection{Description of Experimental Configuration}

Dimensions and material data describing the initial critical experiment were provided by the HTR-10 research group in Reference 1. Dimensional data are presented in this subsection, and material data are provided in the next one. Figure 2 shows the construction of the fuel pebble and the TRISO fuel particles embedded in the fuel zone matrix of the fuel pebble. Table 2 shows the dimensions of the various components of the fuel pebble and fuel particle illustrated in Figure 2. Table 3 shows the nominal dimensions of all components in the core and reflector, together with tolerance limits, observed ranges, and standard deviations where they are known. The nominal compositions are taken from Reference 1, and the uncertainties are taken from Reference 2. Reference 2 presents data obtained by 1997, so it might not reflect tolerances or observations in the year of the experiment, but it contains the only information found on the tolerance specifications for the HTR-10.

\section{Table 2. Dimensions of Pebbles and Fuel Particles}

\begin{tabular}{|l|l|}
\hline Diameter of ball & $6.0 \mathrm{~cm}$ \\
\hline Diameter of fuel zone & $5.0 \mathrm{~cm}$ \\
\hline Volumetric filling fraction of balls in the core & 0.61 \\
\hline Radius of the kernel(mm) & 0.25 \\
\hline Coating layer materials (starting from kernel) & Buffer $/ \mathrm{PyC} / \mathrm{SiC} / \mathrm{PyC}$ \\
\hline Coating layer thickness(mm) & $0.09 / 0.04 / 0.035 / 0.04$ \\
\hline Diameter of dummy (no fuel) elements & $6.0 \mathrm{~cm}$ \\
\hline
\end{tabular}

As noted above, the reflector region comprises numerous graphite blocks of different compositions. The variations in the volume-averaged compositions of the blocks arise both from different boron concentrations and from different sizes and placements of borings. Reference 1 contains a mapping of the various blocks into model regions, with average material densities provided. This mapping, with dimensions shown, is presented 
in Figure 3; this figure differs slightly from the analogous figure in Reference 1, as explained in Section 3.

\section{Fuel Spheres}

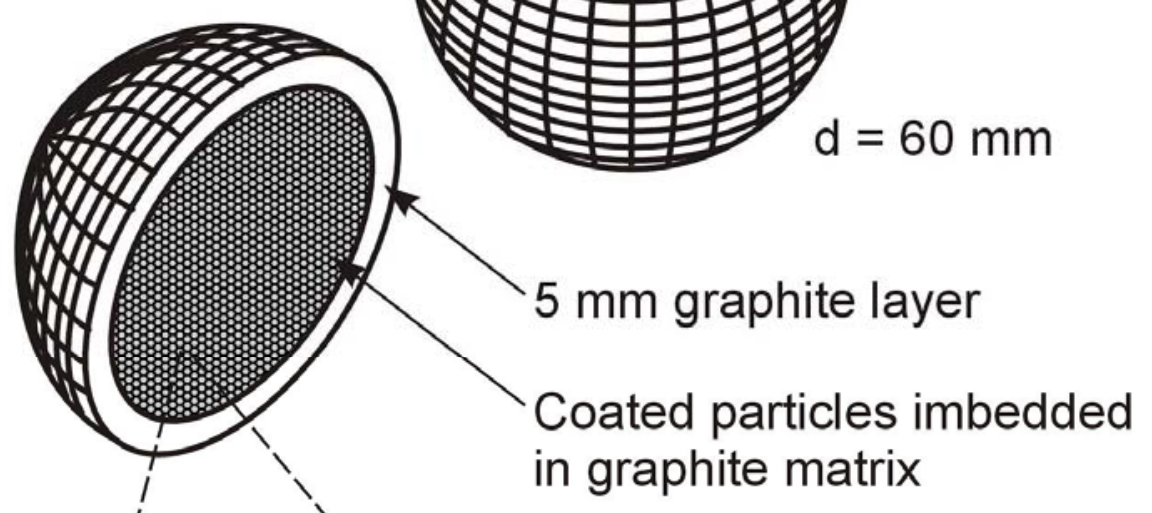

\section{Coated Particles}

$\mathrm{PyC}, 0.04 \mathrm{~mm}$ thick

$\mathrm{SiC}, 0.035 \mathrm{~mm}$ thick

$\mathrm{PyC}, 0.04 \mathrm{~mm}$ thick

Buffer C, $0.09 \mathrm{~mm}$ thick

$\mathrm{d}=0.91 \mathrm{~mm}$

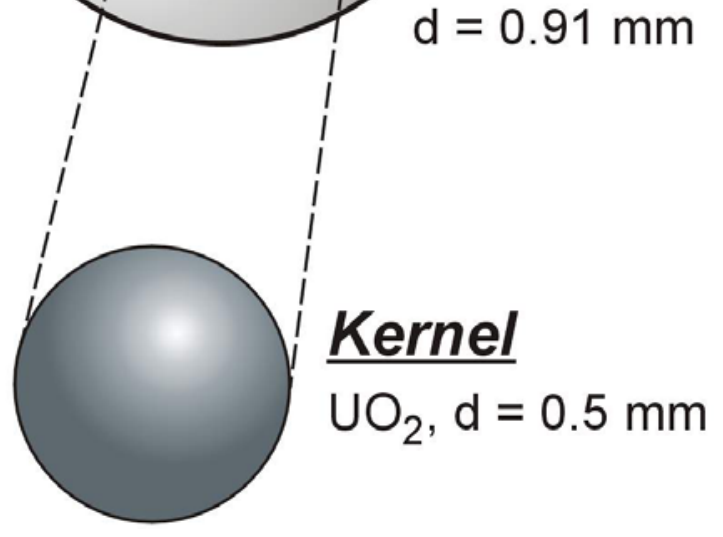

05-GA50001-222

Figure 2. Illustration of Fuel Spheres and TRISO Coated Particles 
Table 3. Nominal values and variations in dimensions

Item

Core height

Diameter of core cavity

Height of core cavity

Height of conus

Dimensions of graphite blocks

Outer diameter of graphite reflector

Overall height of graphite reflector

Diameter of cold helium flow channels

Radial location of cold helium flow channels

Height of cold helium flow channels

Diameter of control rod and irradiation channels

Height of control rod and irradiation channels

Radial location of control rod and irradiation channels

Diameter of round part of KLAK channels

Width of oval part of KLAK channels

Length (in plane of cross section) of oval part of KLAK channels

Diameter of hot gas duct

Elevation of hot gas duct axis

Length of hot gas duct

Radius of fuel discharge tube

Length of fuel discharge tube

Diameter of fuel pebble

Diameter of kernel

Thickness of buffer layer

Thickness of IPyC layer

Thickness of SiC layer

Thickness of OPyC layer

Packing fraction

$\begin{array}{lc}\text { Nominal } & \text { Design } \\ \text { Value } & \text { Tolerances } \\ & \\ 123 \mathrm{~cm} & \mathrm{n} / \mathrm{a} \\ 180 \mathrm{~cm} & \mathrm{n} / \mathrm{a} \\ 221.818 \mathrm{~cm} & \mathrm{n} / \mathrm{a} \\ 36.946 \mathrm{~cm} & \mathrm{n} / \mathrm{a} \\ \text { Various } & \text { n/a } \\ 380.0 \mathrm{~cm} & \mathrm{n} / \mathrm{a} \\ 610.0 \mathrm{~cm} & \mathrm{n} / \mathrm{a} \\ 8.0 \mathrm{~cm} & \mathrm{n} / \mathrm{a} \\ 144.6 \mathrm{~cm} & \mathrm{n} / \mathrm{a} \\ 505.0 \mathrm{~cm} & \mathrm{n} / \mathrm{a} \\ 13.0 \mathrm{~cm} & \mathrm{n} / \mathrm{a} \\ 450.0 \mathrm{~cm} & \mathrm{n} / \mathrm{a} \\ 102.1 \mathrm{~cm} & \mathrm{n} / \mathrm{a} \\ 6.0 \mathrm{~cm} & \mathrm{n} / \mathrm{a} \\ 6.0 \mathrm{~cm} & \mathrm{n} / \mathrm{a} \\ 16.0 \mathrm{~cm} & \mathrm{n} / \mathrm{a} \\ 30.0 \mathrm{~cm} & \mathrm{n} / \mathrm{a} \\ 480.0 \mathrm{~cm} & \mathrm{n} / \mathrm{a} \\ 100.0 \mathrm{~cm} & \mathrm{n} / \mathrm{a} \\ 25.0 \mathrm{~cm} & \mathrm{n} / \mathrm{a} \\ 221.236 \mathrm{~cm} & \mathrm{n} / \mathrm{a} \\ 6.0 \mathrm{~cm} & 5.98-6.0 \\ 0.5 \mathrm{~mm} & 0.5 \\ 0.09 \mathrm{~mm} & 0.09 \\ 0.04 \mathrm{~mm} & 0.03-0.05 \\ 0.035 \mathrm{~mm} & 0.031-0.039 \\ 0.04 \mathrm{~mm} & 0.03-0.05 \\ 0.61 & \mathrm{n} / \mathrm{a} \\ & \end{array}$

Observed

Standard

Range

Deviation

$\begin{array}{cc}\mathrm{n} / \mathrm{a} & \mathrm{n} / \mathrm{a} \\ \mathrm{n} / \mathrm{a} & \mathrm{n} / \mathrm{a} \\ \mathrm{n} / \mathrm{a} & \mathrm{n} / \mathrm{a} \\ \mathrm{n} / \mathrm{a} & \mathrm{n} / \mathrm{a} \\ \mathrm{n} / \mathrm{a} & \mathrm{n} / \mathrm{a} \\ \mathrm{n} / \mathrm{a} & \mathrm{n} / \mathrm{a} \\ \mathrm{n} / \mathrm{a} & \mathrm{n} / \mathrm{a} \\ \mathrm{n} / \mathrm{a} & \mathrm{n} / \mathrm{a} \\ \mathrm{n} / \mathrm{a} & \mathrm{n} / \mathrm{a} \\ \mathrm{n} / \mathrm{a} & \mathrm{n} / \mathrm{a} \\ \mathrm{n} / \mathrm{a} & \mathrm{n} / \mathrm{a} \\ \mathrm{n} / \mathrm{a} & \mathrm{n} / \mathrm{a} \\ \mathrm{n} / \mathrm{a} & \mathrm{n} / \mathrm{a} \\ \mathrm{n} / \mathrm{a} & \mathrm{n} / \mathrm{a} \\ \mathrm{n} / \mathrm{a} & \mathrm{n} / \mathrm{a} \\ \mathrm{n} / \mathrm{a} & \mathrm{n} / \mathrm{a} \\ \mathrm{n} / \mathrm{a} & \mathrm{n} / \mathrm{a} \\ \mathrm{n} / \mathrm{a} & \mathrm{n} / \mathrm{a} \\ \mathrm{n} / \mathrm{a} & \mathrm{n} / \mathrm{a} \\ \mathrm{n} / \mathrm{a} & \mathrm{n} / \mathrm{a} \\ \mathrm{n} / \mathrm{a} & \mathrm{n} / \mathrm{a} \\ 5.98-6.0 & \mathrm{n} / \mathrm{a} \\ 0.501 & \mathrm{~s}\end{array}$

0.501

0.0902

0.025 des, $0.0102 \exp$

$0.0368-0.0424$

$0.0324-0.0376$

0.018 des, 0.0044 exp

0.039-0.045

$\mathrm{n} / \mathrm{a}$

$\mathrm{n} / \mathrm{a}$
$\mathrm{n} / \mathrm{a}$
$\mathrm{n} / \mathrm{a}$
$\mathrm{n} / \mathrm{a}$




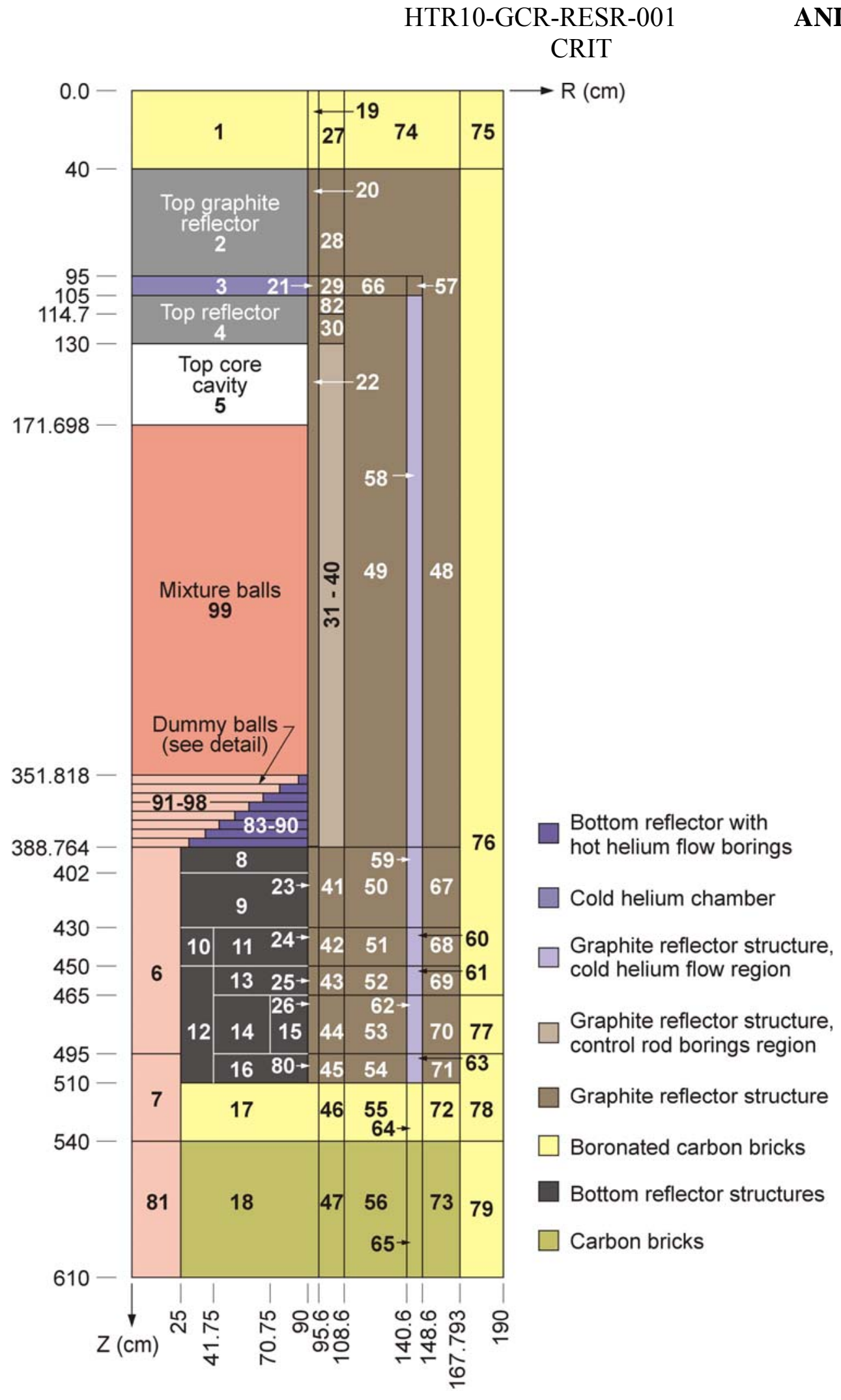

Figure 3(a). Zones of HTR-10 for modeling (dimensions are in cm) 
CRIT

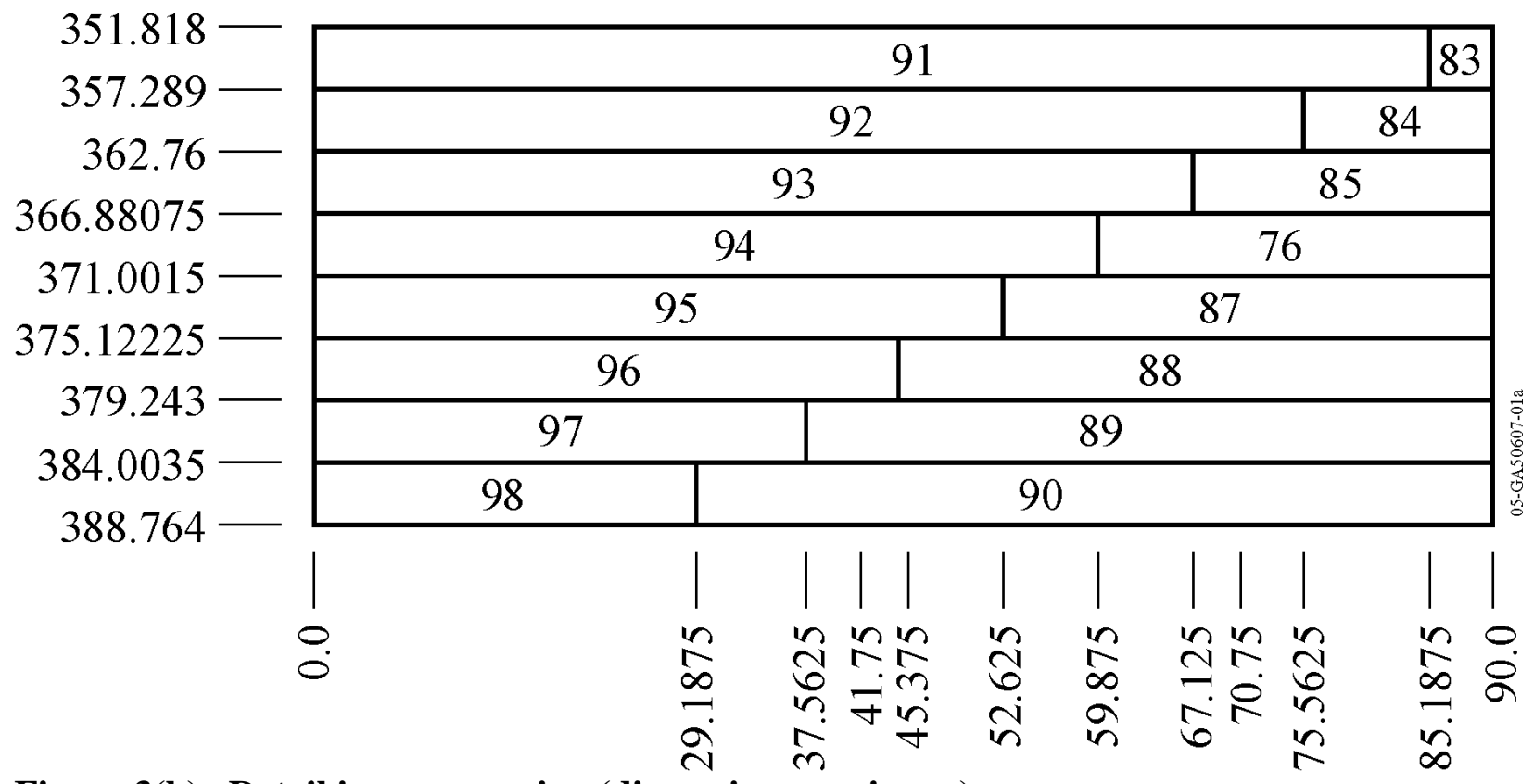

Figure 3(b). Detail in conus region (dimensions are in $\mathbf{c m}$ )

Figure 4 shows a horizontal cross section at an elevation within the core, displaying the borings for coolant flow channels, control rod and experiment channels, and emergency shutdown absorber ball channels. Figure 4 also shows the cross section of the emergency shutdown absorber ball channels in the section next to the core (above and below the core region, these channels are circular in cross section).

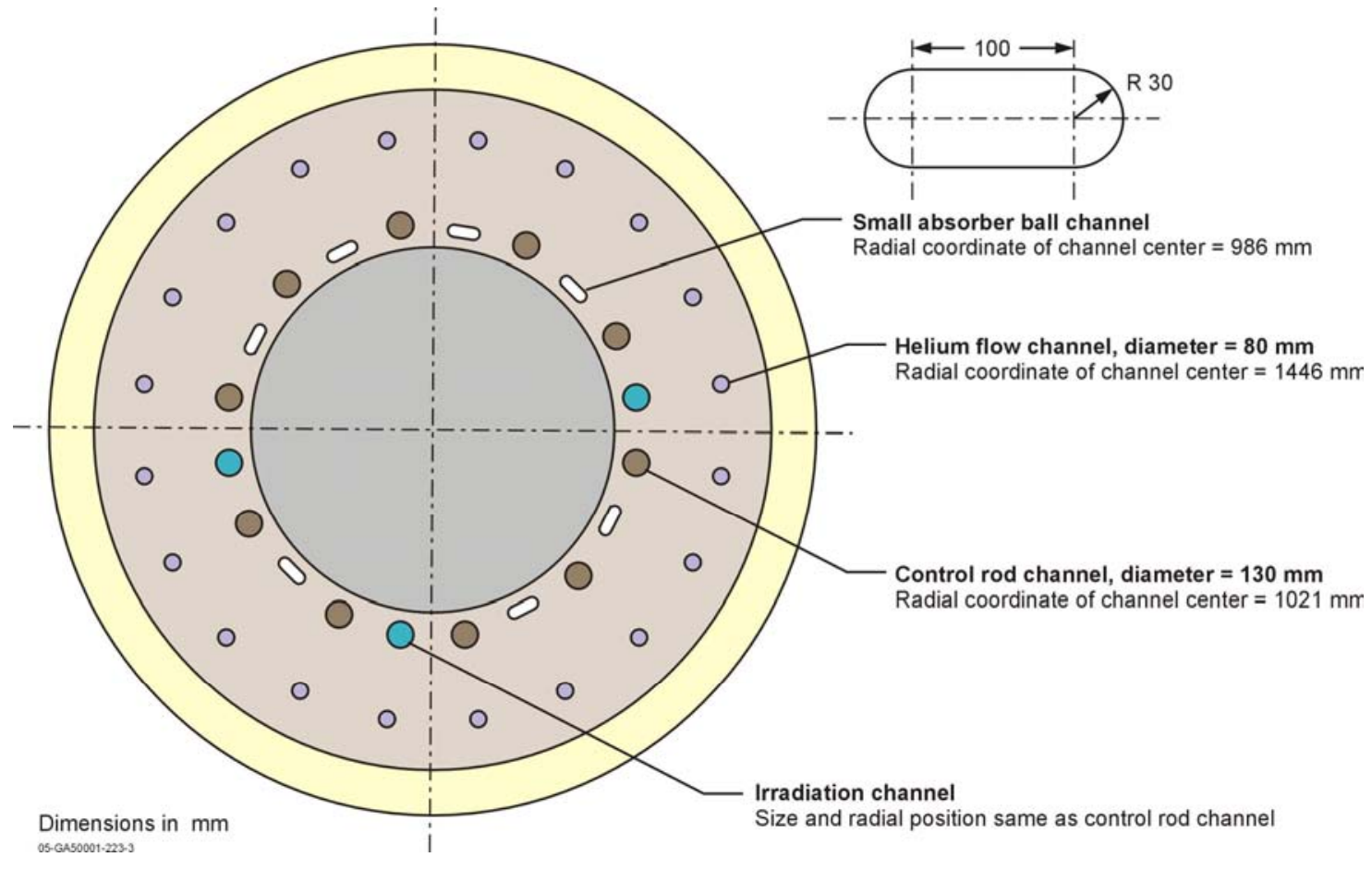

Figure 4. Cross section of reactor in core region 


\subsubsection{Description of Material Data}

The nominal data for the fuel and dummy ball materials, in the actual as-built configuration, are given in Table 4. The material data for the reflector region are given in Table 5 for the zones shown in Figure 3.

The only materials specified in Table 5 are carbon and natural boron. The relative boron fraction varies among reflector zones, especially where highly boronated graphite is used to absorb neutrons near the periphery of the reflector. The graphite density also varies, because many of the zones have voids for various purposes. Since the control rods were withdrawn in the initial criticality experiment, and since no emergency neutron absorber balls had been introduced into the reflector, all the voids were assumed to be filled with air.

Although the HTR-10 is cooled by helium in operation, in the initial criticality experiment the voids in the reactor were filled with "moist" air at a total pressure of $0.1013 \mathrm{MPa}$ and a temperature of $15^{\circ} \mathrm{C}$. The word "moist," which was used by the HTR-10 modeling group, is taken to mean saturated, as the water vapor density specified at the nominal temperature of $27^{\circ} \mathrm{C}$ (see Section 1.1.4) is in fact the saturation density.

Table 4. Nominal material properties of fuel and dummy pebbles as built (from Reference 1)

\begin{tabular}{|l|l|}
\hline Density of graphite in matrix and outer shell & $1.73 \mathrm{~g} / \mathrm{cm} 3$ \\
\hline Heavy metal (uranium) loading (weight) per ball & $5.0 \mathrm{~g}$ \\
\hline Enrichment of 235U (weight) & $17 \%$ \\
\hline Equivalent natural boron content of impurities in uranium & $4 \mathrm{ppm}$ \\
\hline Equivalent natural boron content of impurities in graphite & $1.3 \mathrm{ppm}$ \\
\hline Volumetric filling fraction of balls in the core & 0.61 \\
\hline UO2 density(g/cm3) & 10.4 \\
\hline Coating layer materials (starting from kernel) & $\mathrm{Buffer} / \mathrm{PyC} / \mathrm{SiC} / \mathrm{PyC}$ \\
\hline Coating layer density(g/cm3) & $1.1 / 1.9 / 3.18 / 1.9$ \\
\hline Density of graphite in dummy balls & $1.84 \mathrm{~g} / \mathrm{cm} 3$ \\
\hline $\begin{array}{l}\text { Equivalent natural boron content of impurities in graphite } \\
\text { in dummy balls }\end{array}$ & $0.125 \mathrm{ppm}$ \\
\hline
\end{tabular}

Table 6 specifies the compositions of all the components in the reactor. Tolerance limits and observed ranges are shown where they are known. The nominal compositions are taken from Reference 1, and the uncertainties are taken from Reference 2. As noted above for the dimensions, Reference 2 presents data obtained by 1997, so it might not reflect tolerances or observations in the year of the experiment, but it contains the only information found on the tolerance specifications for the HTR-10. 
CRIT

\subsubsection{Temperature Information}

The initial criticality experiment was run with a clean cold core. In the benchmark specifications provided in advance of the experiment, the temperature was given as 20 ${ }^{\circ} \mathrm{C}$, and the composition of the air actually occupying the void spaces in the reactor was specified at $27{ }^{\circ} \mathrm{C}$, but the actual temperature on the day of the experiment was $15{ }^{\circ} \mathrm{C}$. The actual temperature, $15^{\circ} \mathrm{C}$, is used in this evaluation.

\subsubsection{Additional Information Relevant to Critical and Subcritical Measurements}

No additional information is applicable. 
Table 5. Compositions of zones shown in Figure 3 (from Reference 1, with revisions)

\begin{tabular}{|c|c|c|c|}
\hline $\begin{array}{l}\text { No. of } \\
\text { zone }\end{array}$ & $\begin{array}{l}\text { Carbon density } \\
(\mathrm{a} / \mathrm{b}-\mathrm{cm})\end{array}$ & $\begin{array}{l}\text { Natural boron density } \\
(\mathrm{a} / \mathrm{b}-\mathrm{cm})\end{array}$ & Remarks \\
\hline $83-90$ & $0.851047 \mathrm{E}-01$ & $0.456926 \mathrm{E}-06$ & Bottom reflector with hot helium flow borings \\
\hline 1 & $0.729410 \mathrm{E}-01$ & $0.329811 \mathrm{E}-02$ & Boronated carbon bricks \\
\hline 2 & $0.851462 \mathrm{E}-01$ & $0.457148 \mathrm{E}-06$ & Top graphite reflector \\
\hline 3 & $0.145350 \mathrm{E}-01$ & $0.780384 \mathrm{E}-07$ & Cold helium chamber \\
\hline 4 & $0.802916 \mathrm{E}-01$ & $0.431084 \mathrm{E}-06$ & Top reflector \\
\hline 5 & & & Top core cavity \\
\hline $6,7,91-97$ & $0.572501 \mathrm{E}-01$ & $0.277884 \mathrm{E}-08$ & Dummy balls, simplified as graphite of lower density \\
\hline 8 & $0.781408 \mathrm{E}-01$ & $0.419537 \mathrm{E}-06$ & Bottom reflector structures \\
\hline 9 & $0.823751 \mathrm{E}-01$ & $0.442271 \mathrm{E}-06$ & Bottom reflector structures \\
\hline 10 & $0.843647 \mathrm{E}-01$ & $0.298504 \mathrm{E}-03$ & Bottom reflector structures \\
\hline 11 & $0.817101 \mathrm{E}-01$ & $0.156416 \mathrm{E}-03$ & Bottom reflector structures \\
\hline 12 & $0.850790 \mathrm{E}-01$ & $0.209092 \mathrm{E}-03$ & Bottom reflector structures \\
\hline 13 & $0.819167 \mathrm{E}-01$ & $0.358529 \mathrm{E}-04$ & Bottom reflector structures \\
\hline 14 & $0.541118 \mathrm{E}-01$ & $0.577456 \mathrm{E}-04$ & Bottom reflector structures \\
\hline 15 & $0.332110 \mathrm{E}-01$ & $0.178309 \mathrm{E}-06$ & Bottom reflector structures \\
\hline 16 & $0.881811 \mathrm{E}-01$ & $0.358866 \mathrm{E}-04$ & Bottom reflector structures \\
\hline $\begin{array}{l}17,55,72, \\
74,75,76, \\
78,79\end{array}$ & $0.765984 \mathrm{E}-01$ & $0.346349 \mathrm{E}-02$ & Boronated carbon bricks \\
\hline $18,56,73$ & $0.797184 \mathrm{E}-01$ & $0.000000 \mathrm{E}+00$ & Carbon bricks \\
\hline 19 & $0.761157 \mathrm{E}-01$ & $0.344166 \mathrm{E}-02$ & Boronated carbon bricks \\
\hline 20 & $0.878374 \mathrm{E}-01$ & $0.471597 \mathrm{E}-06$ & Graphite reflector structure \\
\hline 21 & $0.579696 \mathrm{E}-01$ & $0.311238 \mathrm{E}-06$ & Graphite reflector structure \\
\hline $\begin{array}{l}22,23,25, \\
49, \\
50,52,54, \\
66, \\
67,69,71, \\
80\end{array}$ & $0.882418 \mathrm{E}-01$ & $0.473769 \mathrm{E}-06$ & Graphite reflector structure \\
\hline $24,51,68$ & $0.879541 \mathrm{E}-01$ & $0.168369 \mathrm{E}-03$ & Graphite reflector structure \\
\hline 26 & $0.846754 \mathrm{E}-01$ & $0.454621 \mathrm{E}-06$ & Graphite reflector structure \\
\hline 27 & $0.589319 \mathrm{E}-01$ & $0.266468 \mathrm{E}-02$ & Boronated carbon bricks \\
\hline 28,82 & $0.678899 \mathrm{E}-01$ & $1.400000 \mathrm{E}-05$ & Graphite reflector structure \\
\hline 29 & $0.403794 \mathrm{E}-01$ & $1.400000 \mathrm{E}-05$ & Graphite reflector structure \\
\hline 30,41 & $0.678899 \mathrm{E}-01$ & $0.364500 \mathrm{E}-06$ & Graphite reflector structure \\
\hline $31-40$ & $0.634459 \mathrm{E}-01$ & $0.340640 \mathrm{E}-06$ & Graphite reflector, control rod borings region \\
\hline 42 & $0.676758 \mathrm{E}-01$ & $0.125331 \mathrm{E}-03$ & Graphite reflector structure \\
\hline 43,45 & $0.861476 \mathrm{E}-01$ & $0.462525 \mathrm{E}-06$ & Graphite reflector structure \\
\hline 44 & $0.829066 \mathrm{E}-01$ & $0.445124 \mathrm{E}-06$ & Graphite reflector structure \\
\hline 46 & $0.747805 \mathrm{E}-01$ & $0.338129 \mathrm{E}-02$ & Boronated carbon bricks \\
\hline 47 & $0.778265 \mathrm{E}-01$ & $0.000000 \mathrm{E}+00$ & Carbon bricks \\
\hline 48 & $0.582699 \mathrm{E}-01$ & $0.312850 \mathrm{E}-06$ & Graphite reflector structure \\
\hline 53 & $0.855860 \mathrm{E}-01$ & $0.459510 \mathrm{E}-06$ & Graphite reflector structure \\
\hline 57 & $0.728262 \mathrm{E}-01$ & $0.391003 \mathrm{E}-06$ & Graphite reflector structure \\
\hline $\begin{array}{l}58,59,61, \\
63\end{array}$ & $0.760368 \mathrm{E}-01$ & $0.408240 \mathrm{E}-06$ & Graphite reflector, cold helium flow region \\
\hline 60 & $0.757889 \mathrm{E}-01$ & $0.145082 \mathrm{E}-03$ & Graphite reflector, cold helium flow region \\
\hline 62 & $0.737484 \mathrm{E}-01$ & $0.395954 \mathrm{E}-06$ & Graphite reflector, cold helium flow region \\
\hline 64 & $0.660039 \mathrm{E}-01$ & $0.298444 \mathrm{E}-02$ & Boronated carbon bricks \\
\hline 65 & $0.686924 \mathrm{E}-01$ & $0.000000 \mathrm{E}+00$ & Carbon bricks \\
\hline 70 & $0.861500 \mathrm{E}-01$ & $0.462538 \mathrm{E}-06$ & Graphite reflector structure \\
\hline 77 & $0.749927 \mathrm{E}-01$ & $0.339088 \mathrm{E}-02$ & Boronated carbon bricks \\
\hline 81 & $0.847872 \mathrm{E}-01$ & $0.000000 \mathrm{E}+00$ & Dummy balls, but artificially taken as carbon bricks \\
\hline
\end{tabular}


Table 6. Nominal values and variations in compositions

Item

Uranium fuel loading (g/fuel pebble)

Density of graphite matrix in fuel pebble

Total ash in fuel element

Lithium in fuel element

Boron in fuel element

Density of graphite matrix in reflector

Density of boron in natural graphite reflector elements

Ratio of oxygen to uranium in kernel

Density of kernel

Density of buffer layer

Density of IPyC layer

Density of SiC layer

Density of OPyC layer

Composition of coolant

Moisture content of coolant

$\begin{array}{lc}\begin{array}{l}\text { Nominal } \\ \text { Value }\end{array} & \begin{array}{l}\text { Design } \\ \text { Tolerances }\end{array} \\ 5.0 \mathrm{~g} & 4.9-5.1 \\ 1.73 \mathrm{~g} / \mathrm{cm} 3 & 1.73-1.77 \\ 0 & \leq 300.0 \mathrm{ppm} \\ 0 & \leq 0.3 \mathrm{ppm} \\ 1.3 \mathrm{ppm} & \leq 3.0 \mathrm{ppm} \\ 1.76 \mathrm{~g} / \mathrm{cm} 3 & \mathrm{n} / \mathrm{a} \\ 4.8366 \mathrm{ppm} & \mathrm{n} / \mathrm{a} \\ 2 & <2.01 \\ 10.4 \mathrm{~g} / \mathrm{cm} 3 & >10.4 \\ 1.1 \mathrm{~g} / \mathrm{cm} 3 & \leq 1.1 \\ 1.9 \mathrm{~g} / \mathrm{cm} 3 & 1.8-2.0 \\ 3.18 \mathrm{~g} / \mathrm{cm} 3 & \geq 3.18 \\ 1.9 \mathrm{~g} / \mathrm{cm} 3 & 1.8-2.0 \\ 1.149 \mathrm{e}-3 & \mathrm{n} / \mathrm{a} \\ \mathrm{g} / \mathrm{cm} 3 & \mathrm{n} / \mathrm{a} \\ 2.57 \mathrm{E}-5 & \mathrm{~g} / \mathrm{cm} 3\end{array}$

Observed

Range

Standard Deviation

$4.95-5.05$
1.73
$130-190$
$0.007-0.023$
0.15
$\mathrm{n} / \mathrm{a}$
$\mathrm{n} / \mathrm{a}$
$\mathrm{n} / \mathrm{a}$
10.83
1.02
$1.80-1.92$
$3.19-3.23$
$1.85-1.89$
$\mathrm{n} / \mathrm{a}$
$\mathrm{n} / \mathrm{a}$

$\mathrm{n} / \mathrm{a}$

$\mathrm{n} / \mathrm{a}$

$\mathrm{n} / \mathrm{a}$

n/a

$\mathrm{n} / \mathrm{a}$

n/a

$\mathrm{n} / \mathrm{a}$

$\mathrm{n} / \mathrm{a}$

n/a

$0.03 \exp$

$\mathrm{n} / \mathrm{a}$

$\mathrm{n} / \mathrm{a}$

$\mathrm{n} / \mathrm{a}$

$\mathrm{n} / \mathrm{a}$

$\mathrm{n} / \mathrm{a}$ 


\subsection{Description of Buckling and Extrapolation Length Measurements}

No buckling or extrapolation length measurements were reported.

\subsection{Description of Spectral Characteristics Measurements}

No spectral characteristics were measured.

\subsection{Description of Reactivity Effects Measurements}

With a slight excess reactivity (i.e., at a total loading of 17,000 pebbles, or 110 more than the critical count), a control rod worth calibration experiment was carried out. One "typical" control rod was inserted a distance of $223 \mathrm{~cm}$ from its withdrawn position. The integral worth of the control rod was measured to be $1.4693 \%$.

\subsection{Description of Reactivity Coefficient Measurements}

No reactivity coefficient measurements were made.

\subsection{Description of Kinetics Measurements}

No kinetics parameters were measured.

\subsection{Description of Reaction-Rate Distribution Measurements}

No reaction-rate distribution measurements were made.

\subsection{Description of Power Distribution Measurements}

No power distribution measurements were made.

\subsection{Description of Isotopic Measurements}

No isotopic measurements were made.

\subsection{Description of Other Miscellaneous Types of Measurements}

No other measurements have been reported. 


\subsection{EVALUATION OF EXPERIMENTAL DATA}

The overall uncertainty in a calculated parameter that is a function of multiple input parameters is given by ${ }^{(1)}$

$$
u_{c}^{2}\left(k_{e f f}\right)=\sum_{i=1}^{N}\left(\Delta k_{i}\right)^{2}+2 \sum_{i=1}^{N-1} \sum_{j=i+1}^{N}\left(\Delta k_{i}\right)\left(\Delta k_{j}\right) r_{i, j}
$$

In Equation $1, \Delta k_{i}$ is the change in $\mathrm{k}_{\mathrm{eff}}$ when parameter $i$ is changed by the increment $u_{i}$, the standard uncertainty in the parameter, and $r_{i, j}$ is the correlation coefficient for parameters $i$ and $j$.

Data on dimensions and materials are given in Table 4 (Section 1.1.2). Most of the data are given only as nominal values, with no information provided about tolerances, observed variations, or standard deviations. Where standard deviations are available, they are used for calculating the $u_{i}$. Where observed ranges are given, but not standard deviations, the limiting values of the observed ranges are usually applied, and plausible distribution functions are assumed for finding the $u_{i}$. Where only tolerances are given, their limiting values are used, along with plausible distribution functions. Where no guidance is given on the variability of a parameter, conservative engineering judgment is used. All uncertainties are adjusted to values of $1 \sigma$.

One category of unknown dimensional uncertainties includes the dimensions of the graphite blocks from which the reflector is constructed. In typical milling operations, tolerances on the order of tenths of millimeters are common. Cumulative uncertainties from stacking a set of ten or so blocks milled with such tolerances would be on the order of millimeters or less. For conservatism, a tolerance of $\pm 1 \mathrm{~cm}$ is usually assumed for dimensions specifying the positioning of graphite reflector elements. Because borings have to line up much more precisely than that, a tolerance of $0.25 \mathrm{~cm}$ is usually assumed for the locations and radii of the various channels in the core.

Usually, no information is given about the distribution function of the deviation of a parameter from its nominal value. In most cases, it is assumed for convenience that the most relevant quantity is uniformly distributed. For example, if the change in $\mathrm{k}_{\mathrm{eff}}$ from its nominal value is proportional to the change in the volume of a spatial region, then it is assumed that the deviation of the volume of that region from its nominal value is uniformly distributed.

The following subsections discuss the calculation of the uncertainties in the parameters listed in Table 4. The values of $k_{\text {eff }}$ are computed in the as-run critical configuration and in the configuration with each parameter assigned its maximum variation (or its standard deviation

(1) "ICSBEP Guide to the Expression of Uncertainties," Larry G. Blackwood, Independent Reviewer, Revision 1, September 30, 2004, p. 29. This guide has not been published, but it is available to anyone involved in the IRPhEP. 
when available), one parameter at a time. The bases for the choices of the parameter values are discussed. Only a few parameters are important enough that reasonable variations in them produce relatively large variations in $\mathrm{k}_{\mathrm{eff}}$; these parameters are discussed at greater length.

The value of $\mathrm{k}_{\mathrm{eff}}$ computed for a given configuration depends on the microscopic cross sections used in the calculation. The calculated microscopic cross sections are somewhat sensitive to the fast and thermal buckling values used in the input to COMBINE, the cross section processing code $^{(1)}$ used in this evaluation. The buckling values were found by a buckling search, as explained in subsection 3.1.1. In most cases, variations in the problem specifications were small enough that the same cross sections were used for both the critical baseline configuration and the perturbed configuration. However, in some cases, new cross sections were calculated for a perturbed case. The baseline value of $\mathrm{k}_{\mathrm{eff}}$ is 1.03257 .

The baseline value of $\mathrm{k}_{\mathrm{eff}}$ computed for this evaluation is farther from 1.0 than one would like to see. PEBBED, ${ }^{(2)}$ the code used to calculate $\mathrm{k}_{\mathrm{eff}}$, has been validated extensively, ${ }^{(3)}$ but its results are naturally dependent on the quality of the cross sections supplied to it. Calculation of cross sections in graphite systems presents problems that have not yet been resolved. Another possible source of inaccuracy is the shape of the upper surface of the core. Pebbles fall onto the upper surface at discrete drop points, where mounds build up, and they roll down a mound until they lodge more or less randomly on the surface. PEBBED assumes a planar upper core surface, like all the benchmark models reported in Reference 1. The error introduced by this assumption is not known. However, it introduces a constant bias in the results, and the uncertainty analysis should be unaffected by this bias.

Another possible source of inaccuracy in the PEBBED results is the use of only two spectral zones in the model - one in the core, and the other in the reflector. This might be inadequate, even in the HTR-10 initial startup core, which is uniform in composition. Again, however, this representation introduces in the results a constant bias that will not affect the uncertainties calculated when dimensional or compositional parameters are varied.

(1) Robert A. Grimesey, David W. Nigg, and Richard L. Curtis, COMBINE/PC - A Portable ENDF/B Version 5 Neutron Spectrum and Cross-Section Generation Program, EGG-2589, Rev. 1, Idaho National Engineering Laboratory, February 1991.

(2) W. K. Terry, H. D. Gougar, and A. M. Ougouag, "Direct Deterministic Method for Neutronics Analysis and Computation of Asymptotic Burnup Distribution in a Recirculating Pebble-Bed Reactor,” Annals of Nuclear Energy 29 (2002), pp. 1345-1364.

(3) Hans D. Gougar, Abderrafi M. Ougouag, and William K. Terry, "Validation of the Neutronic Solver within the PEBBED Code for Pebble Bed Reactor Design," proc. Mathematics and Computation, Supercomputing, Reactor Physics and Nuclear and Biological Applications, Palais des Papes, Avignon, France, September 12-15, 2005, American Nuclear Society, LaGrange Park, IL (2005) 
Another minor source of inaccuracy in the PEBBED results is the assumption that the core density is uniform. Of course, the pebble packing fraction is only about $61 \%$, so on the scale of a pebble diameter the density is highly nonuniform, but on the scale of the core dimensions, this nonuniformity is not expected to make much difference. However, spheres in a container are not distributed uniformly throughout. It has been observed experimentally ${ }^{(1)}$ that the packing fraction varies from zero at the edges through several damped oscillations to approach an asymptotic value of about $61 \%$ over a distance of about five sphere diameters. The effects of these inhomogeneities have been studied for a simple hypothetical PBR reactor configuration.(2) It was found that the difference in the calculated value of $\mathrm{k}_{\mathrm{eff}}$ was about $5 \times 10^{-4}$ for that reactor. The packing fraction itself is uncertain, but the uncertainty in this parameter is addressed in the analysis.

For perspective, the results of the international benchmark collaboration are noted, as given in Reference 1. The objective of the initial criticality benchmark was to predict the initial critical core height. The measured height was $123.06 \mathrm{~cm}$, and the assumed temperature for the predictions was $20{ }^{\circ} \mathrm{C}$. Predictions by various groups ranged from $107 \mathrm{~cm}$ to $137.3 \mathrm{~cm}$. These values range from $-13 \%$ to $+12 \%$ of the core height. It is reported in subsection 2.1 .1 below that a difference of $0.1 \%$ in the core height produces a difference of $3.7 \times 10^{-4}$ in $\mathrm{k}_{\text {eff. }}$ If the relationship between the difference in $\mathrm{k}_{\mathrm{eff}}$ and the difference in core height were linear over the entire range of core heights, the errors in $\mathrm{k}_{\mathrm{eff}}$ would vary from -0.048 to +0.044 , corresponding to a range in $\mathrm{k}_{\mathrm{eff}}$ of 0.952 to 1.044 . Computation of $\mathrm{k}_{\mathrm{eff}}$ in PBRs is evidently not straightforward, and considerable research seems needed before accuracy is routinely obtained comparable to that in computations for light water reactors.

\subsection{Evaluation of Critical Configuration Data}

The following subsections contain evaluations of the critical configuration measurements described in Section 1.1. In many cases, the assumptions on the uncertainties in experimental parameters are very crude. However, the only important parameters are those whose uncertainties lead to uncertainties of more than $10^{-3}$ in $\mathrm{k}_{\text {eff. }}$. When reasonable and conservative assumptions lead to smaller uncertainties than that in $\mathrm{k}_{\mathrm{eff}}$, little is to be gained by trying to be more precise.

In all cases where tolerances or observed variations apply to large numbers of objects (pebbles and fuel particles or portions thereof), both systematic errors (applying to all the objects equally)

(1) R. F. Benenati and C. B. Brosilow, "Void Fraction Distribution in Beds of Spheres," A. I. Ch. E. Journal 8, No. 3, pp. 359-361 (1962).

(2) W. K. Terry, A. M. Ougouag, Farzad Rahnema, and Michael Scott McKinley, "Effects of spatial variations in packing fraction on reactor physics parameters in pebble-bed reactors," American Nuclear Society Mathematics \& Computation Division Conference, Gatlinburg, Tennessee, April 6-11, 2003. 
and random errors (different from one pebble to the next) will occur. For the fuel particles and their subregions especially, the uncertainties from the random errors are extremely small (the tolerance limit for the random error divided by the square root of the number of fuel particles, $\sqrt{ }(4751 \times 16,890)=8957.9$ (see Appendix B)). For errors in properties of pebbles, the uncertainty in the random component is equal to the tolerance limit for the random component divided by the square root of the number of pebbles, or 129.96. In all cases, division by such large numbers would make the random component of the uncertainty negligible. However, since nothing is known about how the errors are divided between the systematic and random components, it is assumed throughout that the errors are all systematic. This assumption provides the analysis with a large degree of conservatism.

When a variable $x$ is judged to be distributed uniformly between the bounding values $\mu$ and $\mu+a$, the standard deviation in $x$ can be shown to be $a / \sqrt{ } 3 .^{(1)}$ (The reference actually proves the claim for a uniform distribution from $\mu-a$ to $\mu+a$, but the extension of the proof to the half-interval is trivial.) Then the standard deviation of a linear function $f(x)$ is $f(a / \sqrt{3})$. This observation is used repeatedly in the following analysis.

\subsubsection{Core Height and Core Diameter}

The core height is a calculated parameter, based on the number of balls contained in the core. As discussed above, the upper core surface is actually a mound, but it is modeled as a plane at an elevation consistent with the core volume and a cylindrical core shape. The total number of balls (fuel and dummy) in the cylindrical core region at criticality was given as 16,890, and no information was given on the accuracy of the count. The core height was computed from the number of balls and the nominal core diameter at an assumed packing fraction of 0.61 .

The number of pebbles in the core is

$$
N_{p}=\frac{\pi f_{p} R_{c}^{2} H_{c}}{V_{p}}
$$

where $f_{p}=$ packing fraction,

$R_{C}=$ core radius,

$H_{c}=$ core height,

and $\quad V_{p}=$ pebble volume.

Then, in part, $\mathrm{k}_{\mathrm{eff}}$ is a function of the packing fraction, core radius, core height, and pebble volume. The dependencies of $\mathrm{k}_{\mathrm{eff}}$ on pebble volume and packing fraction are treated in subsequent subsections. In this subsection, pebble volume and packing fraction are held

(1) "ICSBEP Guide to the Expression of Uncertainties," Larry G. Blackwood, Independent Reviewer, Revision 1, September 30, 2004, p. 29. This guide has not been published, but it is available to anyone involved in the IRPhEP. 
constant. It is convenient to treat core radius and core height together; it is reasonable to treat them as independent (uncorrelated) variables.

No estimate is given on the uncertainty in the number of balls in the core, but engineering judgment suggests that a counting accuracy of less than $1 \%$ would be very poor, while an accuracy of $0.1 \%$ (at one standard deviation) might be acceptable. The latter figure corresponds to a miscount of about 17 balls in the core. PEBBED calculations (based on changes of $1 \mathrm{~cm}$ in radius and height) show that a change in the core radius leads to a change in $\mathrm{k}_{\text {eff }}$ of $1.10643 \times 10^{-5}$ per ball, while a change in core height leads to a change in $\mathrm{k}_{\mathrm{eff}}$ of $2.16393 \times 10^{-5}$ per ball. (This difference in sensitivity is due to the relatively short and wide configuration of the core at initial criticality). Then for a miscount of 17 balls,

$u_{\text {core radius }}=1.9 \times 10^{-4}$

and

$u_{\text {core height }}=3.7 \times 10^{-4}$.

\subsubsection{Height of Core Cavity}

This parameter is the height of the cavity in which the core resides, which includes the void space above the core, not the height of the core itself. The effect on $\mathrm{k}_{\mathrm{eff}}$ of variations in this parameter is assessed by raising the datum plane at the top of the core cavity. No other computational cells are affected by this change. No guidance is given on the possible variation in core cavity height, but this parameter depends on the precision with which the graphite components of the reflector are milled. As noted above, a very conservative value of $1 \mathrm{~cm}$ is assumed for most graphite dimensional uncertainties. If the top of the core cavity is raised by 1 $\mathrm{cm}, \mathrm{k}_{\mathrm{eff}}$ changes by $-4.2 \times 10^{-4}$. For lack of specific knowledge about how errors in core cavity height might be distributed, it is conservatively assumed that the distribution is uniform. Then the standard deviation in core height errors and the resulting change in $k_{\text {eff }}$ are the limiting value divided by $\sqrt{ } 3$ (cf. Footnote (a)):

$u_{\text {core cavity }}=-2.4 \times 10^{-4}$.

\subsubsection{Height of Conus}

An uncertainty in the height of the conus is represented by moving the datum plane at the top of the conus upwards by $2.7355 \mathrm{~cm}$, an increment that fits conveniently with the PEBBED nodalization, and by moving the datum plane at the top of the core by an equal amount. Thus, the active core height does not change. The shift roughly amounts to one pebble radius, which corresponds to a miscount of about 375 pebbles, an unlikely amount. For this assumed uncertainty, the change in $\mathrm{k}_{\mathrm{eff}}$ is found to be $1.05 \times 10^{-3}$. Conservatively assuming a uniform distribution function for errors in conus height, one divides this number by $\sqrt{3}$ to find (to the nearest significant figure) 
$u_{\text {conus }}=6.1 \times 10^{-4}$

\subsubsection{Dimensions of Graphite Blocks}

As discussed in Section 2.0, tolerances of about $0.1 \mathrm{~mm}$ are assumed for milling the graphite blocks. Such tolerances appear reasonable in view of the necessity of coolant, control rod, and emergency absorber ball channels to line up. Except in the outer periphery of the reflector, where boronated carbon bricks are used to reduce neutron leakage into the surroundings, the only differences among adjacent blocks are in their void fraction; uncertainties in void fraction are accounted for below where the sizes and locations of the different borings are varied. Uncertainties in the inner and outer reflector diameters and the inner and outer reflector axial dimensions are also treated in other subsections. The importance of neutrons is low in the outer periphery. Therefore, it is not necessary to analyze the effects of uncertainties in the internal boundaries between reflector blocks.

\subsubsection{Outer Diameter of Graphite Reflector}

The outer diameter of the reflector could differ from the nominal value by an accumulation of off-nominal radial dimensions in graphite blocks at several radial locations or by off-nominal radial dimensions at a single radial location. Two cases of the latter possibility were explored. First, the outermost zone was increased $1 \mathrm{~cm}$ in radius; this led to an increase in $\mathrm{k}_{\mathrm{eff}}$ of $1.8 \times 10^{-4}$. Second, with the outermost zone again at its nominal thickness, the next-to-outermost zone was increased $1 \mathrm{~cm}$ in radius; this led to a decrease in $\mathrm{k}_{\mathrm{eff}}$ of $1.4 \times 10^{-4}$.

The outermost zone consists of boronated carbon bricks, installed for the purpose of capturing neutrons that would otherwise escape into the surrounding pressure vessel (which was not represented in the model provided in Reference 1 by the Chinese research group). Even though boron has a high absorption cross section for thermal neutrons, increasing the thickness of the boronated carbon bricks provides more scattering sites from which neutrons can be scattered back towards the core. In other words, nothing is as good an absorber as a vacuum boundary condition, so replacing vacuum with anything increases $\mathrm{k}_{\mathrm{eff}}$. However, increasing the thickness of the region inside the boronated graphite layer is found to decrease $\mathrm{k}_{\text {eff. }}$. It is surmised that this additional layer of low-boron graphite softens the neutron energy spectrum slightly, which increases the absorption of neutrons in the boronated carbon bricks and decreases the number of neutrons that can be reflected back into the core.

The larger effect is taken as the uncertainty in $\mathrm{k}_{\mathrm{eff}}$ resulting from differences in the reflector outer diameter from the nominal value. The change in $\mathrm{k}_{\mathrm{eff}}$ is proportional to the change in the crosssectional area of the outermost zone. If the error in the cross-sectional area is uniformly distributed, a reasonable assumption, then the uncertainty in $\mathrm{k}_{\text {eff }}$ associated with uncertainty in reflector outside diameter is $1.8 \times 10^{-4} / \sqrt{ } 3$, or (to the nearest significant figure) 
$u_{\text {refl O.D. }}=1.0 \times 10^{-4}$

\subsubsection{Height of Graphite Reflector}

In this case, because of the large height of the reflector, a greater uncertainty was assumed in the height: $\pm 1 \%$, which is a dimensional uncertainty of $\pm 6.1 \mathrm{~cm}$. Increasing the axial thickness of the first axial region increases $\mathrm{k}_{\mathrm{eff}}$ by $1.0 \times 10^{-5}$. Increasing the axial thickness of the last region by $6.1 \mathrm{~cm}$ causes no change in $\mathrm{k}_{\text {eff. }}$. Whatever distribution function applies, the error at the standard deviation is smaller, but when it is rounded to the nearest significant figure the value returns to $1 \times 10^{-5}$.

$u_{\text {refl ht }}=1 \times 10^{-5}$.

\subsubsection{Diameter of Cold Helium Flow Channels}

The nominal diameter of the helium flow channels is $8.0 \mathrm{~cm}$; tolerance information is not given. A very conservative tolerance of $\pm 0.5 \mathrm{~cm}$ is assumed; more realistic tolerances would be of the order of a fraction of a millimeter.

The helium flow channels occupy portions of Regions 58-65 in Figure 3. From Table 2, one can infer the void fraction in each region (Regions 22 , etc., have no voids) and the part of the void space taken by the flow channels in each region. Then a reduction in the flow channel diameter can be used to find the new void fraction and the new nuclide number densities in each region. It is found that a simultaneous reduction of $0.5 \mathrm{~cm}$ in all the flow channel diameters produces an increase in $\mathrm{k}_{\mathrm{eff}}$ of $2 \times 10^{-5}$. If the error in cross-sectional area is assumed to be distributed uniformly, then the uncertainty in $\mathrm{k}_{\mathrm{eff}}$ is $2 \times 10^{-5} / \sqrt{3}$, or, to the nearest significant figure,

$u_{\text {He flow dia }}=1 \times 10^{-5}$.

\subsubsection{Radial Location of Cold Helium Flow Channels}

The helium flow channels occupy the entire radial span of Regions 58-65; i.e., $r=140.6-148.6$ $\mathrm{cm}$. (No tolerance information is given.) Therefore, the radial location of the channels can be adjusted by moving the inner and outer boundaries of these regions by equal amounts. The flow channels must line up well in axially adjacent blocks in order for the coolant to flow smoothly, so the tolerances in radial location must be quite small. For conservatism, it is assumed that the tolerance is $0.25 \mathrm{~cm}$. An outward shift in the radial location of the flow channels produces a reduction of $4.0 \times 10^{-5}$ in $\mathrm{k}_{\text {eff. }}$ If the error in radial location is distributed uniformly, then the uncertainty in $\mathrm{k}_{\mathrm{eff}}$ is $4.0 \times 10^{-5} / \sqrt{3}$, or, to the nearest significant figure,

$u_{\text {He rad loc }}=-2 \times 10^{-5}$. 


\subsubsection{Height of Cold Helium Flow Channels}

The cold helium flow channels extend to the bottom of the model in Figure 3. To change their height, one must extend them or contract them at the top. It was assumed for modeling convenience that the cold helium flow channels were extended through the entire axial span of region 57 of Figure 3, an increase of $10 \mathrm{~cm}$. This is a very conservative assumption. This adjustment caused no change at all in $\mathrm{k}_{\mathrm{eff}}$.

$u_{\text {He chan } h t}=0.0$

\subsubsection{Diameter of Control Rod and Irradiation Channels}

The control rod and irradiation channels are located at the same radial position and have the same diameter and axial extent. They occupy the entire radial span of Regions 27-31, 41, 42, and 82 , or $r=95.6-108.6 \mathrm{~cm}$. No tolerance range is given. The diameter is conservatively assumed to be $0.5 \mathrm{~cm}$ smaller than nominal. The same approach is applied as to the helium flow channels, discussed in Section 2.1.7 above. The change in $\mathrm{k}_{\mathrm{eff}}$ is $6.1 \times 10^{-4}$, and the uncertainty is $6.1 \times 10^{-4} / \sqrt{ } 3$ :

$u_{C R \text { dia }}=3.5 \times 10^{-4}$.

\subsubsection{Height of Control Rod and Irradiation Channels}

The control rod and irradiation channels extend from the top of the core through Region 42 of Figure 3. The region below Region 31 is Region 43, which is $15 \mathrm{~cm}$ in height. Because neutrons are more important near the core than in the helium flow channel regions, it is excessively coarse to assume a perturbation in the height of the control rod and irradiation channels that extends the entire length of Region 43. It is assumed instead, still conservatively, that the perturbed channels extend $2 \mathrm{~cm}$ into Region 43. This perturbation does not change $\mathrm{k}_{\mathrm{eff}}$.

$u_{C R h t .}=0.0$

\subsubsection{Radial Location of Control Rod and Irradiation Channels}

No tolerances are given on the location of the control rod and irradiation channels. If the inner and outer boundaries of the annulus containing these channels are moved outwards by $0.25 \mathrm{~cm}$, the change in $\mathrm{k}_{\mathrm{eff}}$ is $1.1 \times 10^{-4}$. Assuming a uniform error distribution in the radial location of the channels, one finds the uncertainty in $\mathrm{k}_{\mathrm{eff}}$ to be

$u_{C R ~ l o c}=6 \times 10^{-5}$ 


\subsubsection{Dimensions of KLAK Channels}

The HTR-10 has two independent shutdown systems: the normal control rods and a supply of small spherical absorbers, often called "KLAK" from the German acronym for small absorber balls ("kleine aufsauger Kugeln"), that can be dropped into seven channels located in the same radial regions of the model as the control rod and irradiation channels. The KLAK channels run the entire length of the model. In the core and conus axial range, the channel cross sections are ovals $6 \mathrm{~cm}$ wide and $16 \mathrm{~cm}$ long, with the long sides oriented in the circumferential direction of the reactor. Above and below that axial range, the KLAK channels are cylindrical, with a diameter of $6 \mathrm{~cm}$. No tolerance ranges are given.

The channels occupy a $6 \mathrm{~cm}$ radial zone in model regions $13 \mathrm{~cm}$ in radial extent. The KLAK channels can move in a range of $7 \mathrm{~cm}$ radially in these regions without changing the region densities. Such large perturbations in the KLAK channel locations are implausible. Therefore, the effects of radial mislocations of the KLAK channels are not modeled. However, the effects of perturbations in the size of the channels indicate that the effects of such mislocations are probably very small.

For the KLAK channels, an uncertainty of 10\% (in standard deviation) was assumed in the crosssectional area for all regions. This corresponds to about $5 \%$ in linear dimensions $(\sqrt{ } 1.1=$ 1.04881 ), or about $1.5 \mathrm{~mm}$ in radius in the cylindrical sections and $8 \mathrm{~mm}$ in the long direction in the oval section. The uncertainties in $\mathrm{k}_{\mathrm{eff}}$ were computed from such increases in the sizes of the three sections of the KLAK channels.

Upper cylindrical section: $u_{K L A K ~ u p p e r}=0.0$

Oval section : $u_{K L A K ~ m i d d l e}=-2.8 \times 10^{-4}$.

Lower cylindrical section: $u_{K L A K}$ lower $=0.0$.

\subsubsection{Dimensions of Hot Gas Duct}

The hot gas duct extends from $r=90 \mathrm{~cm}$ to the outer edge of the reflector, in regions $26,44,53$, 62,70 , and 77 in an axial zone from $z=465 \mathrm{~cm}$ to $z=495 \mathrm{~cm}$. The nominal diameter of the duct, $30 \mathrm{~cm}$, spans this axial range. No tolerance ranges are given.

Because the duct is large, a large perturbation of $1 \mathrm{~cm}$ was assumed in the diameter. The same approach described above for the cold helium flow channels was applied to the duct diameter. The changed duct diameter had no effect on $\mathrm{k}_{\mathrm{eff}}$.

The effect of a perturbation in the length of the duct was examined by assuming the duct to extend through the radial extent of Region 15, which is adjacent to Region 26. This assumption extends the length of the duct by $19.25 \mathrm{~cm}$, which is completely unrealistic. However, the 
perturbation caused no change in $\mathrm{k}_{\mathrm{eff}}$, so more realistic perturbations would also have no effect.

A shift in the axial location of the duct could be accomplished by changing the locations of the datum planes at $z=465 \mathrm{~cm}$ and $z=495 \mathrm{~cm}$, but this change would affect the nuclide number densities in other regions besides those containing the duct. An axial shift could also be represented by calculating perturbed nuclide number densities in regions adjacent to the nominal location of the duct, into which the duct would move in the perturbation, but this approach would alter the nuclide number densities throughout the adjacent regions, which would give distorted neutron flux distributions. Because of the lack of influence the other changes in duct dimensions have on $\mathrm{k}_{\mathrm{eff}}$, it is simply assumed that realistic shifts in hot gas duct axial position also have no effect.

$u_{\text {hot gas duct }}=0.0$

\subsubsection{Radius of Fuel Discharge Tube}

The fuel discharge tube occupies regions 6,7 , and 81 in Figure 3. Its nominal radius is $25 \mathrm{~cm}$; no tolerance range is given. The uncertainty in discharge tube radius is modeled by moving the radial boundary of Regions 6,7 , and 81 outwards by $0.25 \mathrm{~cm}$. There is no effect on $\mathrm{k}_{\mathrm{eff}}$.

$u_{\text {discharge radius }}=0.0$.

\subsubsection{Height of Fuel Discharge Tube}

The fuel discharge tube extends to the bottom of the model. The effect of increasing the height of the model has already been examined. A perturbation in the fuel discharge tube height is redundant.

$u_{\text {discharge height }}=0.0$

\subsubsection{Diameter of Fuel Pebble}

The HTR-10 fuel pebble is a sphere $6 \mathrm{~cm}$ in diameter, consisting of an inner fuel zone $5 \mathrm{~cm}$ in diameter and an outer unfueled layer. The inner fuel zone consists of a graphite matrix containing an average of 8335 TRISO coated fuel particles. The outer layer contains only graphite. The core also contains dummy graphite balls, which are also $6 \mathrm{~cm}$ in diameter; the ratio of fuel balls to dummy balls is 57:43.

The tolerance range on fuel pebble diameter is $5.98-6.0 \mathrm{~cm}$; this is also the observed range. The uncertainty in $\mathrm{k}_{\mathrm{eff}}$ resulting from uncertainty in fuel pebble diameter is evaluated by reducing the pebble diameter to $5.98 \mathrm{~cm}$. 
There are several ways to do this, but the greatest changes in average nuclide densities in the core region are produced by keeping the diameter of the fuel zone constant and reducing the thickness of the outer graphite layer. For example, reducing the diameter of the fuel zone and keeping the outer graphite layer thickness constant would shrink the fuel zone volume almost in proportion to the shrinkage in total pebble volume; then the average nuclide densities in the core would be almost unaffected and $\mathrm{k}_{\mathrm{eff}}$ would hardly change at all. The average densities are further changed by assuming that the dummy balls are also reduced to $5.98 \mathrm{~cm}$ in diameter. The result of making those changes is to decrease $\mathrm{k}_{\mathrm{eff}}$ by $2.12 \times 10^{-3}$.

As noted in Section 2.1, the error within the tolerance range presumably comprises a systematic component and a random component. However, no information is available on how the error is apportioned between the systematic and random components. The most conservative approach is to assume that the error is all systematic. The uncertainty in the systematic component is equal to the tolerance limit for the systematic component divided by $\sqrt{3}$, assuming that the systematic error in volume is uniformly distributed (the change in $\mathrm{k}_{\mathrm{eff}}$ is proportional to the volume change, not the linear change). Then the uncertainty in $\mathrm{k}_{\text {eff }}$ is $-2.12 \times 10^{-3} / \sqrt{3}$, or

$u_{\text {FPdia }}=-1.22 \times 10^{-3}$

It merits comment that $\mathrm{k}_{\mathrm{eff}}$ is reduced by packing more fuel balls, which each contain the same amount of fuel as the nominal pebbles, into the same volume of core. Evidently the HTR-10 is undermoderated, so that the loss of moderation caused by reducing the amount of graphite in the core overshadows the increase in the macroscopic fission cross section obtained by increasing the amount of fuel. A study of the effect of changing the relative amounts of fuel and moderator in PBRs has found that the usual formula of $5 \mathrm{~cm}$ for the fuel zone diameter and $6 \mathrm{~cm}$ for the fuel pebble diameter does not provide optimal moderation, at least for some fuel particle packing fractions. ${ }^{(1)}$

\subsubsection{Diameter of Kernel}

The nominal kernel diameter is $0.5 \mathrm{~mm}$, and the measured standard deviation is $0.0102 \mathrm{~mm}$. The $1-\sigma$ kernel is $6.2457 \%$ larger in volume than the nominal kernel. However, there is a tolerance in pebble fuel loading of $5.0 \pm 0.1 \mathrm{~g} /$ pebble. This is only a variation of $\pm 2 \%$. Therefore, if all of the kernels were allowed to reach their $1 \sigma$ diameter, the limit on fuel loading would be exceeded. Hence, the limit on fuel loading (see Section 2.1.23) bounds the effects of uncertainties in the fuel kernel diameter, and the fuel kernel diameter is not used in the uncertainty analysis.

(1) Abderrafi M. Ougouag, Hans D. Gougar, William K. Terry, Ramatsemela Mphahlele, and Kostadin N. Ivanov, "Optimal Moderation in the Pebble-Bed Reactor for Enhanced Passive Safety and Improved Fuel Utilization," proc. PHYSOR 2004, The Physics of Fuel Cycles and Advanced Nuclear Systems: Global Developments, American Nuclear Society, Chicago, IL, April 25-29, 2004. 


\subsubsection{Thickness of Buffer Layer}

The buffer layer is a relatively porous layer of carbon immediately surrounding the kernel. Its porosity is intended to provide room for fission product gases without excessive pressure buildup. In the HTR-10 fuel, the buffer layer thickness is nominally $0.09 \mathrm{~mm}$, and the experimentally observed standard deviation is $0.0044 \mathrm{~mm}$. In the uncertainty analysis, it was assumed that all the buffer layers in the core were increased by one standard deviation from the nominal value, and that all the other layers in the fuel particles kept their original volumes. The new core average nuclide densities were computed, and $\mathrm{k}_{\text {eff }}$ was found to decline by $-3.0 \times 10^{-5}$. It is assumed that the error in buffer volume is uniformly distributed; then the uncertainty in $\mathrm{k}_{\mathrm{eff}}$ is $3.0 \times 10^{-5} / \sqrt{ } 3$, or, to the nearest significant figure,

$u_{\text {buffer thickness }}=-2 \times 10^{-5}$.

The reason for the decrease in $\mathrm{k}_{\mathrm{eff}}$ is that the expanded buffer layer displaces matrix material, since the diameter of the fuel zone is held constant. Then there is a decrease in carbon density in the core, which reduces moderation.

\subsubsection{Thickness of IPyC Layer}

Outside the buffer layer, the TRISO particle consists of three hard and dense layers that provide a miniature containment vessel for fission products. The first of these is the inner pyrolytic carbon (IPyC) layer. Its nominal thickness is $0.04 \mathrm{~mm}$, its tolerance range is $0.03-0.05 \mathrm{~mm}$, and its observed range of variation is $0.0368-0.0424 \mathrm{~mm}$. For conservatism, it was assumed that all of the IPyC layers in the core were expanded to their maximum allowable thickness, while all the other layers retained their nominal volumes. The density of the pyrolytic carbon layers is greater than that of the matrix material, so expansion of the layers increases the carbon density in the

core and enhances moderation. Therefore, $\mathrm{k}_{\mathrm{eff}}$ increases slightly; the change is $3 \times 10^{-5}$. If the volume error is uniformly distributed, then to the nearest significant figure,

$u_{\text {IPyC thickness }}=2 \times 10^{-5}$.

\subsubsection{Thickness of SiC Layer}

The second hard and dense layer outside of the buffer zone is the silicon carbide layer. This is the strongest layer in the fuel particle and the principal containment shell. It has a nominal thickness of $0.035 \mathrm{~mm}$, a tolerance range of 0.031-0.039 mm, and an observed range of 0.0324$0.0376 \mathrm{~mm}$. Standard deviations are not given. First, it was assumed that all of the SiC layers in the core were expanded to their maximum allowable thickness, while all the other layers retained their nominal volumes. This perturbation produced a decrease in $\mathrm{k}_{\mathrm{eff}}$ of $-3.4 \times 10^{-4}$. 
In cases like the IPyC layer, where even perturbations up to the maximum tolerance value produce only very small changes in $\mathrm{k}_{\text {eff, }}$ it is both conservative and inconsequential to use the maximum allowable perturbation to compute the uncertainty in $\mathrm{k}_{\mathrm{eff}}$. However, when such a perturbation produces a larger change in $\mathrm{k}_{\mathrm{eff}}$, it is more reasonable to assume the maximum observed perturbation. The computed change in $\mathrm{k}_{\mathrm{eff}}$ and the fractional volume change were applied were used to calculate

$$
\frac{d k_{e f f}}{d \bar{V}}=-2.70499 \times 10^{-3}
$$

Then an increase of the $\mathrm{SiC}$ thickness to its maximum observed value gives a change in $\mathrm{k}_{\text {eff }}$ of $-2.2 \times 10^{-4}$. If the change in $\mathrm{SiC}$ volume is assumed to be distributed uniformly, then

$u_{\text {SiC thickness }}=-1.3 \times 10^{-4}$.

\subsubsection{Thickness of OPyC Layer}

The final hard and dense layer in the TRISO particle, and its outermost shell, is the outer pyrolytic carbon (OPyC) layer. This shell has a nominal thickness of $0.04 \mathrm{~mm}$, a tolerance range of $0.03-0.05 \mathrm{~mm}$, and an observed range of $0.039-0.045 \mathrm{~mm}$. It was assumed that all the OPyC layers in the core were increased to their maximum allowable values while all the other layers retained their nominal volumes. This assumption led to an increase of $5 \times 10^{-5}$ in $\mathrm{k}_{\text {eff. If the }}$ change in the OPyC volume is distributed uniformly,

$u_{O P y C}$ thickness $=3 \times 10^{-5}$.

\subsubsection{Uranium Fuel Loading}

The nominal uranium loading in the HTR-10 fuel is $5 \mathrm{~g}$ per pebble. The tolerance range is 4.9$5.1 \mathrm{~g}$, and the observed range is $4.95-5.05 \mathrm{~g}$. The tolerance range was used to estimate the derivative

$$
\frac{d k_{e f f}}{d \bar{m}_{U}}=0.179
$$

where $\bar{m}_{U}$ is the normalized uranium mass in the pebble.

The observed variation in $\bar{m}_{U}$ is $\pm 1 \%$, so the associated variation in $\mathrm{k}_{\text {eff }}$ is $1.79 \times 10^{-3}$. If the deviation of the uranium loading from the nominal value is distributed uniformly within the observed range, the uncertainty in $\mathrm{k}_{\mathrm{eff}}$ is

$1.79 \times 10^{-3} / \sqrt{ } 3$, or 
$u_{U}$ loading $=1.03 \times 10^{-3}$.

\subsubsection{Density of Graphite Matrix in Fuel Pebble}

The density of the graphite matrix in the fuel pebble is nominally $1.73 \mathrm{~g} / \mathrm{cm}^{3}$. The tolerance range is $1.73-1.77 \mathrm{~g} / \mathrm{cm}^{3}$, and only the nominal value was observed. It is not plausible to assume that there is no uncertainty in the graphite density, but the observation of only one value suggests that a uniform distribution is not appropriate. For this case, a triangular distribution was assumed, with the mode (i.e., the most frequently observed value) equal to the nominal value and the distribution function declining to zero at the maximum tolerance value.

The variance in the triangular distribution is given by ${ }^{(1)}$

$$
\sigma^{2}=\frac{a^{2}+b^{2}+c^{2}-a b-a c-b c}{18},
$$

where $a$ and $b$ are the limits of the interval on which the distribution function is defined, and $c$ is the mode.

This formula was applied to the deviation of the graphite density from $1.73 \mathrm{~g} / \mathrm{cm}^{3}$, so that $a=0$, $b=0.04$, and $c=0$. Then $\sigma^{2}=8.88889 \times 10^{-5}$ and $\sigma=0.009428$. The uncertainty is found by computing $\mathrm{k}_{\text {eff }}$ at one standard deviation away from the nominal value. Thus, the value of the graphite matrix density at which $\mathrm{k}_{\mathrm{eff}}$ is to be evaluated is $1.739428 \mathrm{~g} / \mathrm{cm}^{3}$. The boron content of the graphite matrix is assumed to remain at $1.3 \mathrm{ppm}$. The fuel matrix graphite is only one component of the carbon in the core region. All the other carbon components are assumed to be unaffected. When the new graphite and boron densities are used in PEBBED, the associated uncertainty in $\mathrm{k}_{\mathrm{eff}}$ is found to be

$u_{\text {fuel graphite density }}=1.13 \times 10^{-3}$.

\subsubsection{Total Ash in Fuel Element}

The fuel specifications permit small amounts of unspecified impurities. Without knowing what they are, it is impossible to assess their effects quantitatively. However, it is not necessary to do so. The tolerance limits on the boron content of the fuel and reflector are actually limits on equivalent boron content, which includes the unspecified impurities.

\subsubsection{Lithium in Fuel Element}

(1) M. Evans, Nicholas Hastings, and Brian Peacock, Statistical Distributions, 3rd Edition, John Wiley and Sons, New York, 2000, pp. 187-188. 
The nominal fuel element contains no lithium, but a trace amount of up to $0.3 \mathrm{ppm}$ is permitted, and concentrations of 0.007-0.023 ppm are observed.

The maximum allowable amount of lithium was assumed, not only in the fuel elements but also in the dummy balls. A new cross section set was generated, and the revised multiplication constant was computed. The change in $\mathrm{k}_{\mathrm{eff}}$ is $1.7 \times 10^{-5}$. The deviation of the lithium concentration from zero to the maximum allowable value is assumed to be uniform. Then the uncertainty in $\mathrm{k}_{\text {eff }}$ is $1.7 \times 10^{-5} / \sqrt{ } 3$, or

$u_{L i}=1 \times 10^{-5}$

\subsubsection{Boron in Fuel Element}

The nominal boron concentration in the fuel graphite is $1.3 \mathrm{ppm}$, while the tolerance limit is 3.0 ppm. The only observed value reported in Reference 2 for the boron in the fuel element graphite matrix is $0.15 \mathrm{ppm}$. As in the case of the fuel matrix graphite density, it requires judgment to choose a distribution function for the boron concentration. When, in contrast, the boron content in the dummy balls was found to differ substantially from the nominal value (the nominal value was $1.3 \mathrm{ppm}$, while the as-built value is reported as $0.125 \mathrm{ppm}$ ), the deviation was noted in the experiment report (Reference 1). One would expect that a deviation almost as great in the fuel element matrix boron would also have been reported. The nominal value is almost in the middle of the tolerance range. It is very conservative to assume a uniform distribution between the minimum and maximum values of 0 and $3.0 \mathrm{ppm}$, respectively, and to find $\mathrm{k}_{\mathrm{eff}}$ at the maximum of $3.0 \mathrm{ppm}$.

When this value is used to adjust the boron concentration in all components of the fuel element except the kernels, for which a value of $4 \mathrm{ppm}$ was used as reported in Reference 1, the change in $\mathrm{k}_{\mathrm{eff}}$ from the baseline value is $-7.43 \times 10^{-3}$. The uncertainty for a uniform distribution is $-7.43 \times 10^{-3} / \sqrt{ } 3$, or

$u_{\text {fuel boron }}=-4.29 \times 10^{-3}$.

\subsubsection{Density of Graphite Matrix in Reflector}

The nominal graphite density in the reflector material is $1.76 \mathrm{~g} / \mathrm{cm}^{3}$; no information is given on tolerances, observed ranges, or standard deviations. It is assumed that the total tolerance range is the same as for the graphite matrix in the fuel pebbles, i.e., $0.04 \mathrm{~g} / \mathrm{cm}^{3}$, but that the nominal value is centered in the range. So the assumed tolerance range becomes $1.76 \pm 0.02 \mathrm{~g} / \mathrm{cm}^{3}$. Furthermore, it is assumed that the deviation from the nominal value is distributed uniformly within this range. The boron content is assumed to vary in proportion to the carbon density.

With these assumptions, when $\mathrm{k}_{\text {eff }}$ is evaluated at a density of $1.78 \mathrm{~g} / \mathrm{cm}^{3}$, the change in $\mathrm{k}_{\text {eff }}$ becomes $1.09 \times 10^{-3}$, and the uncertainty is found to be $1.09 \times 10^{-3} \sqrt{3}$, or 
$u_{\text {reflector graphite }}=6.3 \times 10^{-4}$.

\subsubsection{Density of Boron in Reflector Natural Graphite}

Here, the boron is assumed to vary independently from the carbon density. The nominal boron concentration is $4.8366 \mathrm{ppm}$ by weight; no information is given on tolerances, observed ranges, or standard deviations. This value applies to the natural graphite in the reflector, and not to boronated carbon bricks or other structures in which the boron concentration is elevated above the natural level.

The change in $\mathrm{k}_{\text {eff }}$ was calculated for a $10 \%$ deviation in boron density from the nominal value. The result was $-5.00 \times 10^{-3}$. This is a very large effect, showing that $\mathrm{k}_{\mathrm{eff}}$ is quite sensitive to the boron concentration, as one would expect. Accordingly, it is unlikely that a tolerance of $\pm 10 \%$ would be considered acceptable. It is likely to be still conservative to assume a tolerance range of $\pm 5 \%$, which would approximately halve the change in $\mathrm{k}_{\text {eff. }}$ If the distribution function is uniform, the uncertainty is $-5.00 \times 10^{-3} / 2 \sqrt{3}$, or

$u_{\text {reflector boron }}=-1.44 \times 10^{-3}$.

\subsubsection{Ratio of Oxygen to Uranium in Kernel}

The nominal value is the stoichiometric ratio of 2.0; the tolerance limit is 2.01 . It is assumed that the distribution is uniform from the nominal value to the limit. The multiplication factor is found to change by $1 \times 10^{-5}$, so that the uncertainty is $1 \times 10^{-5} / \sqrt{ } 3$, or, to the nearest significant figure,

$u_{O / U}=1 \times 10^{-5}$

\subsubsection{Density of Kernel}

The nominal kernel density is $10.4 \mathrm{~g} / \mathrm{cm}^{3}$, which is also the lower tolerance limit. The observed value is given in Reference 2 as $10.83 \mathrm{~g} / \mathrm{cm}^{3}$. The observed value is considerably higher than the nominal value, so new cross sections were computed for this uncertainty calculation. Then $\mathrm{k}_{\mathrm{eff}}$ was found for a kernel density of $10.83 \mathrm{~g} / \mathrm{cm}^{3}$. The change in $\mathrm{k}_{\mathrm{eff}}$ was found to be $5.48 \times 10^{-3}$.

This is a very large change in $\mathrm{k}_{\text {eff }}$, but the difference in kernel density from the nominal value is also quite large, namely $4.13 \%$. There is a tolerance range on fuel loading per pebble, as discussed in subsection 2.1.24 above, of 4.9-5.1 g, or $\pm 2 \%$. Therefore, if all kernel densities were equal to the value reported in Reference 2, and if the number of kernels were unchanged, the pebble would exceed its tolerance on fuel loading. The fuel loading tolerance limit is 
CRIT

bounding on the average kernel density, and the effects of variations in kernel density within the fuel loading tolerance limit are included in the uncertainty reported in subsection 2.1.23.

\subsubsection{Density of Buffer Layer}

The nominal value of the density of the buffer layer is $1.1 \mathrm{~g} / \mathrm{cm}^{3}$, the tolerance range is $0-1.1$ $\mathrm{g} / \mathrm{cm}^{3}$, the observed value given in Reference 2 is $1.02 \mathrm{~g} / \mathrm{cm}^{3}$, and the standard deviation is 0.03 $\mathrm{g} / \mathrm{cm}^{3}$. The boron concentration is assumed to remain at $1.3 \mathrm{ppm}$. A deviation of $0.1 \mathrm{~g} / \mathrm{cm}^{3}$ was used to calculate $d k_{e f f} / d \rho_{\text {buffer }}$, but the uncertainty was evaluated at the standard deviation; to the nearest significant figure, this is

$u_{\text {buffer density }}=-3 \times 10^{-5}$.

\subsubsection{Density of IPyC Layer}

The nominal IPyC density is $1.9 \mathrm{~g} / \mathrm{cm}^{3}$, the tolerance range is $1.8-2.0 \mathrm{~g} / \mathrm{cm}^{3}$, and the observed range is $1.8-1.92 \mathrm{~g} / \mathrm{cm}^{3}$. No standard deviation is given. The change in $\mathrm{k}_{\text {eff }}$ from the nominal value was computed from the tolerance limit of $2.0 \mathrm{~g} / \mathrm{cm}^{3}$, with the boron concentration unchanged at $1.3 \mathrm{ppm}$. The change in $\mathrm{k}_{\text {eff }}$ was found to be $6 \times 10^{-5}$; if the probability distribution is uniform, then to the nearest significant figure,

$u_{I P y C}$ density $=3 \times 10^{-5}$.

\subsubsection{Density of SiC Layer}

The nominal $\mathrm{SiC}$ density is $3.18 \mathrm{~g} / \mathrm{cm}^{3}$, the tolerance range is $\geq 3.18 \mathrm{~g} / \mathrm{cm}^{3}$, the observed range is $3.19-3.23 \mathrm{~g} / \mathrm{cm}^{3}$, and no standard deviation is given. For conservatism, the change in $\mathrm{k}_{\mathrm{eff}}$ was computed for the upper tolerance limit and found to be $-2 \times 10^{-5}$. If the distribution in the range from $3.18-3.23 \mathrm{~g} / \mathrm{cm}^{3}$ is uniform, then to the nearest significant figure,

$u_{\text {SiC density }}=1 \times 10^{-5}$

\subsubsection{Density of OPyC Layer}

The nominal OPyC density is $1.9 \mathrm{~g} / \mathrm{cm}^{3}$, the tolerance range is $1.8-2.0 \mathrm{~g} / \mathrm{cm}^{3}$, and the observed range is $1.85-1.89 \mathrm{~g} / \mathrm{cm}^{3}$. The derivative $d k_{\text {eff }} / d \rho_{\text {OP } y C}$ was calculated at the tolerance limit of 2.0 $\mathrm{g} / \mathrm{cm}^{3}$, but the distribution was assumed uniform between $1.85 \mathrm{~g} / \mathrm{cm}^{3}$ and $1.9 \mathrm{~g} / \mathrm{cm}^{3}$ for simplicity and conservatism; then the change in $\mathrm{k}_{\mathrm{eff}}$ is $-4.5 \times 10^{-5}$ and the uncertainty is that value divided by $\sqrt{3}$; to the nearest significant figure, this is

$u_{O P y C}$ density $=3 \times 10^{-5}$. 


\subsubsection{Composition of Coolant}

The coolant in actual reactor operation is helium, but in the initial criticality experiment the voids in the reactor were occupied by ambient air, which was specified as "moist" air at a total pressure of $0.1013 \mathrm{MPa}$ and a temperature of $15{ }^{\circ} \mathrm{C}$. The specified pressure of $0.1013 \mathrm{MPa}$ is standard sea level atmospheric pressure, 29.92 in $\mathrm{Hg}$. As mentioned in subsection 1.1.3, the term "moist" is taken to mean saturated. Therefore, the baseline composition is saturated air at $15{ }^{\circ} \mathrm{C}$ and $0.1013 \mathrm{MPa}$.

There are two potential causes of uncertainty in the specification of the coolant. First, the air was probably not fully saturated. Second, the air pressure was probably not standard sea level pressure. The second possibility is treated in the next subsection. A check of weather data in Beijing on the Internet shows a wide variability in the relative humidity, from low humidity (e.g., around $20 \%$ ) to nearly saturated. The lowest possible value of relative humidity is zero. The change in $k_{\text {eff }}$ from saturated air to totally dry air was found to be $-3 \times 10^{-5}$. Assuming a uniform distribution between the extremes of humidity, one finds, to the nearest significant figure,

$u_{\text {water vapor }}=2 \times 10^{-5}$

\subsubsection{Air Pressure}

Standard sea level pressure is 29.92 in. $\mathrm{Hg}(0.1013 \mathrm{MPa})$. Sea level pressure typically varies about \pm 1 in. $\mathrm{Hg}$. While larger variations are not uncommon, they represent more extreme weather than normal. Atmospheric pressure also varies with elevation above sea level; the elevation at Beijing is given on the Internet variously from 35 to $55 \mathrm{~m}$. This is sufficiently close to sea level not to affect the standard atmospheric pressure significantly. A cursory search of the Internet failed to reveal a standard deviation for atmospheric pressure, so $1 \mathrm{in}$. $\mathrm{Hg}$ was taken as a conservative estimate. With the components of dry air made denser by a factor of 30.92/29.92, the change in $\mathrm{k}_{\mathrm{eff}}$ was found to be $-3.0 \times 10^{-4}$. This is a small change compared to some of the other uncertainties, and not worth trying to refine further.

$u_{\text {air pressure }}=-3.0 \times 10^{-4}$.

\subsubsection{Boron in Kernels and Dummy Balls}

Reference 1 gives the boron concentration in the kernels as 4 ppm and the boron concentration in the dummy balls as $0.125 \mathrm{ppm}$. No information is given on tolerances, observed ranges, or standard deviations. No information was given on these boron concentrations in Reference 2.

It is implied that these concentrations are confidently known values. In the specifications for the 
international benchmark that was performed before the initial criticality experiment, the boron concentration in the dummy balls was given as $1.3 \mathrm{ppm}$, but Reference 1 states that the actual value was $0.125 \mathrm{ppm}$ instead of the previously stated value of $1.3 \mathrm{ppm}$. This implies that the corrected value is known accurately. It seems unlikely that whatever tolerance range applies to this parameter is as large as those that apply to the reflector and fuel ball matrix graphite compositions. It is customary in such circumstances to assume an uncertainty of one-half the last digit, i.e, $\pm 0.5 \times 0.001= \pm 0.0005$, or $\pm 0.4 \%$. This is too small to merit analysis.

The argument to support confidence in the value of $4 \mathrm{ppm}$ for the kernel boron concentration is less compelling, but in the absence of specific data on the variability of this parameter, the given value is taken as a measurement with the customary uncertainty of one-half the last digit: $\pm 0.5 \times 1= \pm 0.5$. This tolerance was applied to the kernel graphite, with a resulting change in $\mathrm{k}_{\mathrm{eff}}$ of $-7 \times 10^{-5}$. Assuming a uniform error distribution, one finds

$u_{\text {kernel boron }}=-4 \times 10^{-5}$.

\subsubsection{Packing Fraction}

The average packing fraction is assumed to be 0.61 , as has been observed experimentally. ${ }^{(5)}$ But other packing fractions are theoretically possible, and a numerical study has shown that shifts in packing fraction, as might happen in an earthquake, can induce substantial changes (of the order of $1 \%$ ) in k-effective. ${ }^{(1)}$ Evidently an increase in packing fraction causes a reduction in leakage even though the total mass of the core remains constant.

The statistical variation in packing fraction in a bed of spheres is not known. It is unlikely that the packing fraction will exceed 0.64 , which corresponds to the maximally random jammed state $^{\text {(2) }}$ This is the condition where the pebbles are as closely packed as possible while remaining randomly arranged. Closer packing requires organized lattice structure.

In this analysis, it is assumed that the packing fraction varies uniformly in the range from 0.60 0.62. This assumption is believed to be conservative. When the inventory of core constituents remains constant, a change in packing fraction entails a change in core height. This change is uncorrelated with the change analyzed in subsection 2.1.1, because there the change in core height was assumed to result from an inaccurate pebble count. The change in $\mathrm{k}_{\mathrm{eff}}$ from an increase in packing fraction to 0.62 is found to be $3.3 \times 10^{-3}$, when the core height changes as

(1) A. M. Ougouag and W. K. Terry, "A Preliminary Study of the Effect of Shifts in Packing Fraction on k-effective in Pebble-Bed Reactors," American Nuclear Society Mathematics \& Computation Division Conference, Salt Lake City, Utah, September 9-13, 2001.

(2) S. Torquato, T. M. Truskett, and P. G. Debenedetti, "Is Random Close Packing of Spheres Well Defined?” Phys. Rev. Lett. $\underline{84}$, p. 2064, 6 March 2000. 
CRIT

needed to keep the core material inventories constant. For a uniform distribution, the corresponding uncertainty in $\mathrm{k}_{\mathrm{eff}}$ is

$u_{\text {packing fraction }}=1.90 \times 10^{-3}$.

\subsubsection{Overall Uncertainty in $\mathbf{k}_{\mathrm{eff}}$}

When Eq. 1 is applied to all the uncertainties calculated in subsections 2.1.1-2.1.39, assuming that all the uncertainties are uncorrelated (a reasonable and pragmatically necessary assumption), the result is

$u_{\text {overall }}=5.41 \times 10^{-3}$, or about $0.5 \%$.

This number was obtained by making consistently conservative assumptions on the variability of parameters on which $\mathrm{k}_{\mathrm{eff}}$ may depend. The parameters that could have the largest effect are the various boron densities, the graphite matrix density, the fuel loading, and the pebble diameter. It is unlikely that any of the boron densities, on average, are as far from the nominal value as the tolerance range permits. Therefore, the initial criticality measurement in HTR-10 is judged to be an acceptable benchmark.

Table 7 summarizes the results of the uncertainty calculations. 
Table 7. Individual and total uncertainties

\begin{tabular}{|c|c|}
\hline Item & Uncertainty $\left(u_{i}\right)$ (NA means not applicable - see text) \\
\hline Core radius & $1.9 \mathrm{e}-4$ \\
\hline Core height & $3.7 \mathrm{e}-4$ \\
\hline Height of core cavity & $2.4 \mathrm{e}-4$ \\
\hline Height of conus & $6.1 \mathrm{e}-4$ \\
\hline Dimensions of graphite blocks & NA \\
\hline Outer diameter of graphite reflector & $1.0 \mathrm{e}-4$ \\
\hline Height of graphite reflector & $1 e-5$ \\
\hline Diameter of cold helium flow channels & $1 e-5$ \\
\hline Radial location of cold helium flow channels & $-2 \mathrm{e}-5$ \\
\hline Height of cold helium flow channels & 0 \\
\hline Diameter of control rod and irradiation channels & $3.5 \mathrm{e}-4$ \\
\hline Height of control rod and irradiation channels & 0 \\
\hline Radial location of control rod and irradiation channels & $6 e-5$ \\
\hline Diameter of KLAK channels (upper) & 0 \\
\hline Dimensions of KLAK channels (middle) & $-2.8 \mathrm{e}-4$ \\
\hline Diameter of KLAK channels (lower) & 0 \\
\hline Dimensions of hot gas duct & 0 \\
\hline Radius of fuel discharge tube & 0 \\
\hline Height of fuel discharge tube & 0 \\
\hline Diameter of fuel pebble & $1.22 \mathrm{e}-3$ \\
\hline Diameter of kernel & NA \\
\hline Thickness of buffer layer & $-2 \mathrm{e}-5$ \\
\hline Thickness of IPyC layer & $2 \mathrm{e}-5$ \\
\hline Thickness of SiC layer & $-1.3 \mathrm{e}-4$ \\
\hline Thickness of OPyC layer & $3 e-5$ \\
\hline Uranium fuel loading & $1.03 \mathrm{e}-3$ \\
\hline Density of graphite matrix in fuel pebble & $1.13 \mathrm{e}-3$ \\
\hline Total ash in fuel element & NA \\
\hline Lithium in fuel element & $1 \mathrm{e}-5$ \\
\hline Boron in fuel element & $-4.29 \mathrm{e}-3$ \\
\hline Density of graphite matrix in reflector & $6.3 \mathrm{e}-4$ \\
\hline Density of boron in reflector graphite & $-1.44 \mathrm{e}-3$ \\
\hline Ratio of $\mathrm{O}$ to $\mathrm{U}$ in kernel & $1 \mathrm{e}-5$ \\
\hline Density of kernel & NA \\
\hline Density of buffer & $-3 e-5$ \\
\hline Density of IPyC layer & $3 e-5$ \\
\hline Density of SiC layer & $1 \mathrm{e}-5$ \\
\hline Density of OPyC layer & $3 e-5$ \\
\hline Composition of coolant (saturated vs. dry air) & $2 \mathrm{e}-5$ \\
\hline Air pressure & $-3 e-4$ \\
\hline Boron in kernels & $-4 \mathrm{e}-5$ \\
\hline Boron in dummy balls & NA \\
\hline Packing fraction & $1.9 \mathrm{e}-3$ \\
\hline Total (root mean square) & $5.41 \mathrm{e}-3$ \\
\hline
\end{tabular}


CRIT

\subsection{Evaluation of Buckling and Extrapolation Length Data}

No buckling or extrapolation length measurements were made.

\subsection{Evaluation of Spectral Characteristics Data}

No spectral characteristics were measured.

\subsection{Evaluation of Reactivity Effects Data}

The control rod worth measurements have not yet been evaluated.

\subsection{Evaluation of Reactivity Coefficient Data}

No reactivity coefficients were measured.

\subsection{Evaluation of Kinetics Measurements Data}

No kinetics measurements were made.

\subsection{Evaluation of Reaction-Rate Distributions}

No reaction-rate measurements were made.

\subsection{Evaluation of Power Distribution Data}

No power distribution measurements were made.

\subsection{Evaluation of Isotopic Measurements}

No isotopic measurements were made.

\subsection{Evaluation of Other Miscellaneous Types of Measurements}

No other measurements were made. 
CRIT

\subsection{BENCHMARK SPECIFICATIONS}

\subsection{Benchmark-Model Specifications for Critical and / or Subcritical Measurements}

This section contains benchmark specifications for the critical configuration described in Section 1.1 .

\subsubsection{Description of the Calculational Model and Methodology}

The geometry of the HTR-10 was divided into axisymmetric regions as shown in Figures 5 and 6. The definition of regions in Figure 5 is mostly as specified by the HTR-10 research group in its invitation to participants in its international benchmark project. The graphite and boron densities for the regions in Figure 5 were also supplied by the HTR-10 team in Reference 1; these are given in Table 8 . The dimensions of components in the fuel and dummy pebbles are given in Table 9. The HTR-10 research group has access to the detailed design drawings and documents for their reactor; the data in these figures and tables are surely better than anything one could derive from publicly available documents. Thus, these data were used as the basis for the calculational model in this evaluation. For this evaluation, the INL code PEBBED ${ }^{(1),(2)}$ was used to calculate $\mathrm{k}_{\mathrm{eff}}$ for the nominal and perturbed configurations. PEBBED is a reactor physics and fuel management code developed by the Idaho National Laboratory (INL) specifically for PBRs. For compatibility with PEBBED, the numbering of some zones in the reflector, the conus, and the bottom reflector section with hot helium flow borings was changed slightly from the numbering assigned by the HTR-10 modeling group. Figure 5 shows the numbering used in this evaluation report. The only change that affects the fidelity of the model is the approximation of the straight, slanted surface of the conus by a series of stair-steps. This is a necessary approximation for the use of any code in cylindrical geometry; some participants in the preexperiment benchmark program applied the same approach. The stair-steps are small, so that the effects of the approximation should be negligible; in any case, the approximation introduces a uniform bias in the results and will not corrupt the uncertainty calculation.

The PEBBED input deck for the nominal configuration is presented in Appendix A.

1 W. K. Terry, H. D. Gougar, and A. M. Ougouag, "Direct Deterministic Method for Neutronics Analysis and Computation of Asymptotic Burnup Distribution in a Recirculating Pebble-Bed Reactor," Annals of Nuclear Energy 29 (2002), pp. 1345-1364.

(2) H. D. Gougar, W. K. Terry, and A. M. Ougouag, PEBBED V.4.3 Manual (DRAFT), Idaho National Engineering and Environmental Laboratory. This manual has not been published, but it will be provided to officially designated reviewers. 
HTR10-GCR-RESR-001

ANL-GenIV-059

CRIT

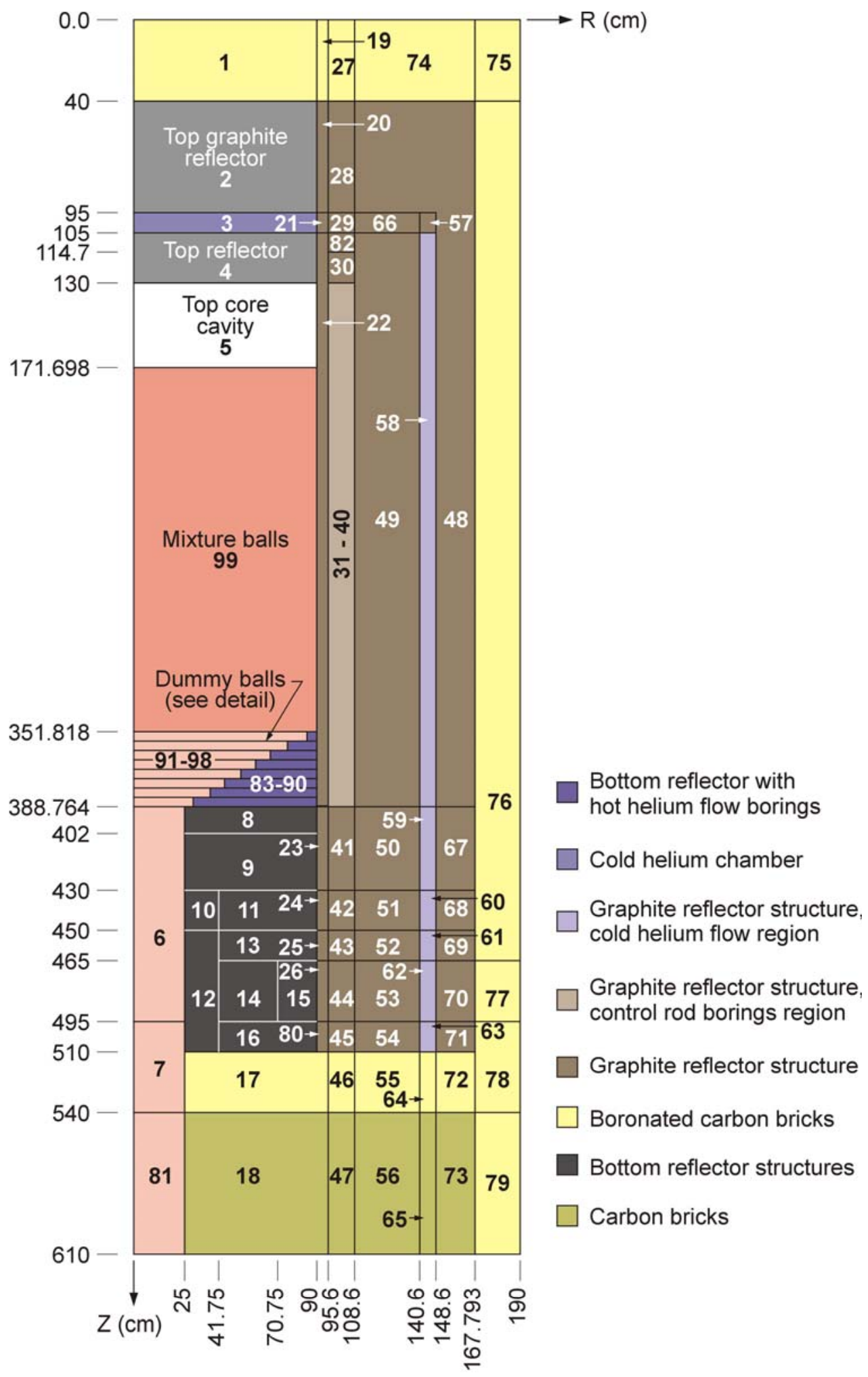

Figure 5(a). Zones of HTR-10 for modeling (dimensions are in cm) 
CRIT

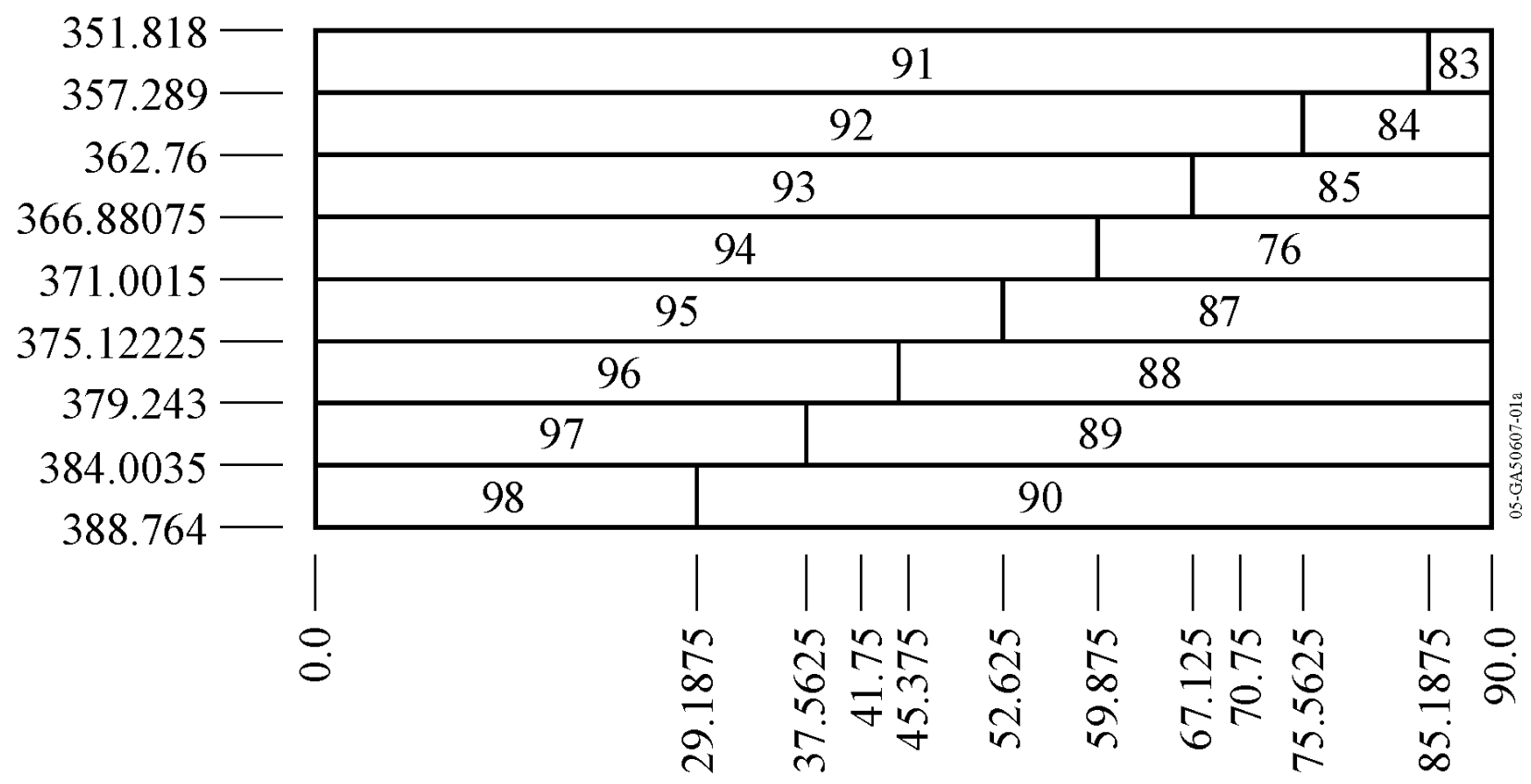

Figure 5(b). Detail in conus region (dimensions are in $\mathbf{c m}$ )

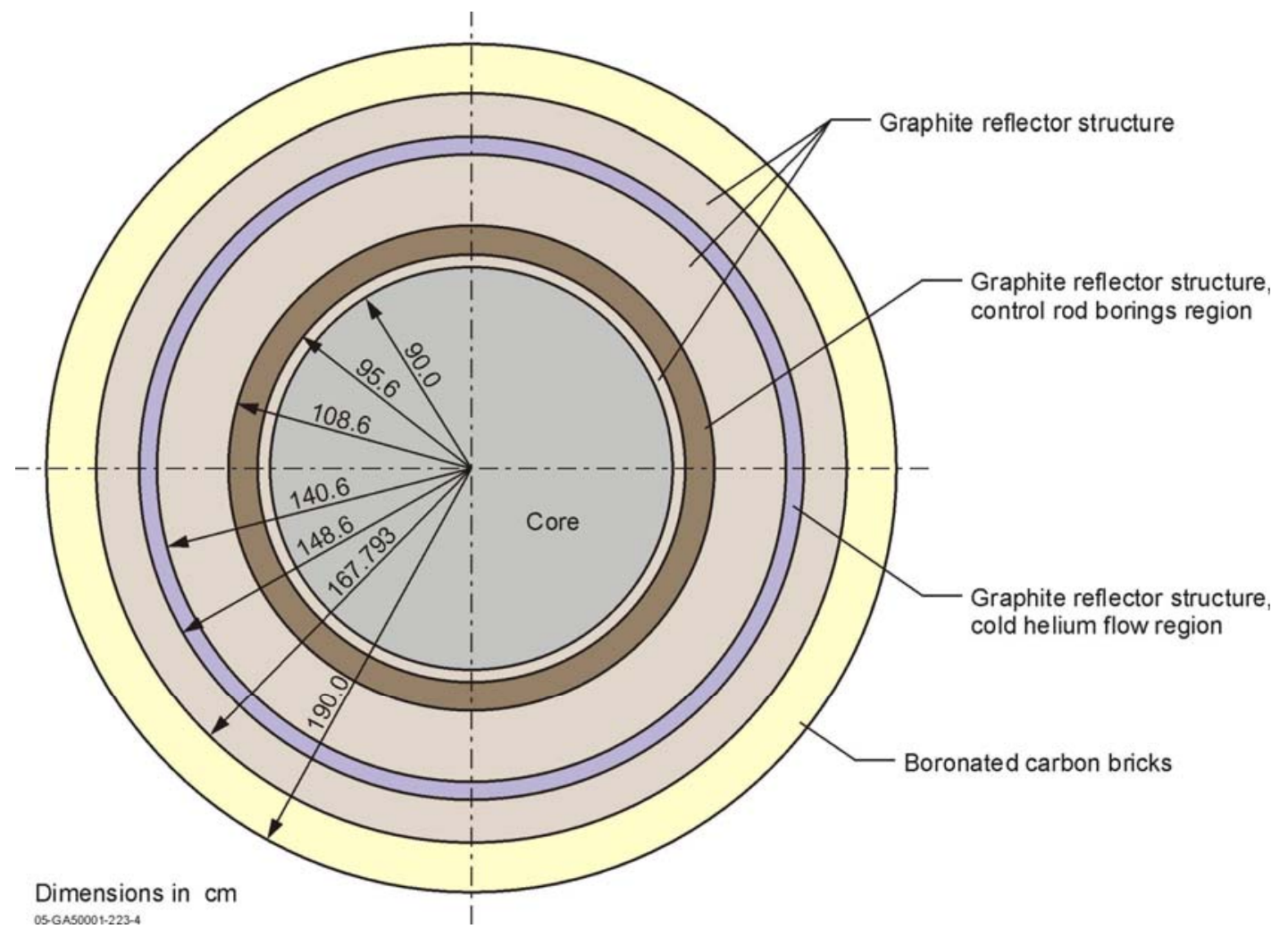

Figure 6. Cross section of reactor in core region 
CRIT

Table 8. Compositions of zones shown in Figure 3 (from Reference 1, with revisions)

\begin{tabular}{|c|c|c|c|}
\hline $\begin{array}{l}\text { No. of } \\
\text { zone }\end{array}$ & $\begin{array}{l}\text { Carbon density } \\
(\mathrm{a} / \mathrm{b}-\mathrm{cm})\end{array}$ & $\begin{array}{l}\text { Natural boron density } \\
(\mathrm{a} / \mathrm{b}-\mathrm{cm})\end{array}$ & Remarks \\
\hline $83-90$ & $0.851047 \mathrm{E}-01$ & $0.456926 \mathrm{E}-06$ & Bottom reflector with hot helium flow borings \\
\hline 1 & $0.729410 \mathrm{E}-01$ & $0.329811 \mathrm{E}-02$ & Boronated carbon bricks \\
\hline 2 & $0.851462 \mathrm{E}-01$ & $0.457148 \mathrm{E}-06$ & Top graphite reflector \\
\hline 3 & $0.145350 \mathrm{E}-01$ & $0.780384 \mathrm{E}-07$ & Cold helium chamber \\
\hline 4 & $0.802916 \mathrm{E}-01$ & $0.431084 \mathrm{E}-06$ & Top reflector \\
\hline 5 & & & Top core cavity \\
\hline $6,7,91-97$ & $0.572501 \mathrm{E}-01$ & $0.277884 \mathrm{E}-08$ & Dummy balls, simplified as graphite of lower density \\
\hline 8 & $0.781408 \mathrm{E}-01$ & $0.419537 \mathrm{E}-06$ & Bottom reflector structures \\
\hline 9 & $0.823751 \mathrm{E}-01$ & $0.442271 \mathrm{E}-06$ & Bottom reflector structures \\
\hline 10 & $0.843647 \mathrm{E}-01$ & $0.298504 \mathrm{E}-03$ & Bottom reflector structures \\
\hline 11 & $0.817101 \mathrm{E}-01$ & $0.156416 \mathrm{E}-03$ & Bottom reflector structures \\
\hline 12 & $0.850790 \mathrm{E}-01$ & $0.209092 \mathrm{E}-03$ & Bottom reflector structures \\
\hline 13 & $0.819167 \mathrm{E}-01$ & $0.358529 \mathrm{E}-04$ & Bottom reflector structures \\
\hline 14 & $0.541118 \mathrm{E}-01$ & $0.577456 \mathrm{E}-04$ & Bottom reflector structures \\
\hline 15 & $0.332110 \mathrm{E}-01$ & $0.178309 \mathrm{E}-06$ & Bottom reflector structures \\
\hline 16 & $0.881811 \mathrm{E}-01$ & $0.358866 \mathrm{E}-04$ & Bottom reflector structures \\
\hline $\begin{array}{l}17,55,72, \\
74,75,76, \\
78,79\end{array}$ & $0.765984 \mathrm{E}-01$ & $0.346349 \mathrm{E}-02$ & Boronated carbon bricks \\
\hline $18,56,73$ & $0.797184 \mathrm{E}-01$ & $0.000000 \mathrm{E}+00$ & Carbon bricks \\
\hline 19 & $0.761157 \mathrm{E}-01$ & $0.344166 \mathrm{E}-02$ & Boronated carbon bricks \\
\hline 20 & $0.878374 \mathrm{E}-01$ & $0.471597 \mathrm{E}-06$ & Graphite reflector structure \\
\hline 21 & $0.579696 \mathrm{E}-01$ & $0.311238 \mathrm{E}-06$ & Graphite reflector structure \\
\hline $\begin{array}{l}22,23,25, \\
49, \\
50,52,54, \\
66, \\
67,69,71, \\
80\end{array}$ & $0.882418 \mathrm{E}-01$ & $0.473769 \mathrm{E}-06$ & Graphite reflector structure \\
\hline $24,51,68$ & $0.879541 \mathrm{E}-01$ & $0.168369 \mathrm{E}-03$ & Graphite reflector structure \\
\hline 26 & $0.846754 \mathrm{E}-01$ & $0.454621 \mathrm{E}-06$ & Graphite reflector structure \\
\hline 27 & $0.589319 \mathrm{E}-01$ & $0.266468 \mathrm{E}-02$ & Boronated carbon bricks \\
\hline 28,82 & $0.678899 \mathrm{E}-01$ & $1.400000 \mathrm{E}-05$ & Graphite reflector structure \\
\hline 29 & $0.403794 \mathrm{E}-01$ & $1.400000 \mathrm{E}-05$ & Graphite reflector structure \\
\hline 30,41 & $0.678899 \mathrm{E}-01$ & $0.364500 \mathrm{E}-06$ & Graphite reflector structure \\
\hline $31-40$ & $0.634459 \mathrm{E}-01$ & $0.340640 \mathrm{E}-06$ & Graphite reflector, control rod borings region \\
\hline 42 & $0.676758 \mathrm{E}-01$ & $0.125331 \mathrm{E}-03$ & Graphite reflector structure \\
\hline 43,45 & $0.861476 \mathrm{E}-01$ & $0.462525 \mathrm{E}-06$ & Graphite reflector structure \\
\hline 44 & $0.829066 \mathrm{E}-01$ & $0.445124 \mathrm{E}-06$ & Graphite reflector structure \\
\hline 46 & $0.747805 \mathrm{E}-01$ & $0.338129 \mathrm{E}-02$ & Boronated carbon bricks \\
\hline 47 & $0.778265 \mathrm{E}-01$ & $0.000000 \mathrm{E}+00$ & Carbon bricks \\
\hline 48 & $0.582699 \mathrm{E}-01$ & $0.312850 \mathrm{E}-06$ & Graphite reflector structure \\
\hline 53 & $0.855860 \mathrm{E}-01$ & $0.459510 \mathrm{E}-06$ & Graphite reflector structure \\
\hline 57 & $0.728262 \mathrm{E}-01$ & $0.391003 \mathrm{E}-06$ & Graphite reflector structure \\
\hline $\begin{array}{l}58,59,61, \\
63\end{array}$ & $0.760368 \mathrm{E}-01$ & $0.408240 \mathrm{E}-06$ & Graphite reflector, cold helium flow region \\
\hline 60 & $0.757889 \mathrm{E}-01$ & $0.145082 \mathrm{E}-03$ & Graphite reflector, cold helium flow region \\
\hline 62 & $0.737484 \mathrm{E}-01$ & $0.395954 \mathrm{E}-06$ & Graphite reflector, cold helium flow region \\
\hline 64 & $0.660039 \mathrm{E}-01$ & $0.298444 \mathrm{E}-02$ & Boronated carbon bricks \\
\hline 65 & $0.686924 \mathrm{E}-01$ & $0.000000 \mathrm{E}+00$ & Carbon bricks \\
\hline 70 & $0.861500 \mathrm{E}-01$ & $0.462538 \mathrm{E}-06$ & Graphite reflector structure \\
\hline 77 & $0.749927 \mathrm{E}-01$ & $0.339088 \mathrm{E}-02$ & Boronated carbon bricks \\
\hline 81 & $0.847872 \mathrm{E}-01$ & $0.000000 \mathrm{E}+00$ & Dummy balls, but artificially taken as carbon bricks \\
\hline
\end{tabular}


Table 9. Dimensions of Pebbles and Fuel Particles

\begin{tabular}{|l|l|}
\hline Diameter of ball & $6.0 \mathrm{~cm}$ \\
\hline Diameter of fuel zone & $5.0 \mathrm{~cm}$ \\
\hline Volumetric filling fraction of balls in the core & 0.61 \\
\hline Radius of the kernel(mm) & 0.25 \\
\hline Coating layer materials (starting from kernel) & Buffer/PyC/SiC/PyC \\
\hline Coating layer thickness(mm) & $0.09 / 0.04 / 0.035 / 0.04$ \\
\hline Diameter of dummy (no fuel) elements & $6.0 \mathrm{~cm}$ \\
\hline
\end{tabular}

PEBBED is a core design and fuel management tool written to obtain simultaneous solutions of the neutron diffusion equation and the nuclide depletion/production equations in the equilibrium core directly, without following the evolution of the nuclide number densities and the neutron flux in time. PEBBED accounts explicitly for the motion of the fuel and treats arbitrarily specified pebble recirculation patterns. In the HTR-10 startup core, the fuel was not moving; PEBBED also treats this special case.

PEBBED now offers an analytical nodal option for solving the diffusion equation. However, this option had not been fully implemented in $r$ - $z$ cylindrical geometry when this uncertainty analysis was begun. Therefore, the uncertainty analysis was performed with the older finite-difference option in PEBBED. PEBBED has the capability to perform full $r-\theta-z$ analysis with the finitedifference option, but this uncertainty analysis was done in $r-z$ geometry. PEBBED will soon have full three-dimensional analytical nodal capability in cylindrical geometry.

Most of the regions in Figure 5 were subdivided into several computational mesh cells in the PEBBED model. The computational mesh can be inferred from the input file in Appendix A. The meshing was selected on the basis of prior experience with spatial convergence in verification and validation studies of PEBBED.

Cross sections for PEBBED were computed by the INL's COMBINE code, ${ }^{(1)}$ so named because it combines the PHROG ${ }^{(2)}$ and INCITE $^{(1)}$ fast and thermal spectrum codes. COMBINE uses a

1 Robert A. Grimesey, David W. Nigg, and Richard L. Curtis, COMBINE/PC - A Portable ENDF/B Version 5 Neutron Spectrum and Cross-Section Generation Program, EGG-2589, Rev. 1, Idaho National Engineering Laboratory, February 1991.

(2) R.L. Curtis, et al., PHROG - A FORTRAN-IV Program to Generate Fast Neutron Spectra and Average Multigroup Constants, Idaho Nuclear Corp., IN-1435, April 1971. 
166-group cross section data base derived from the Evaluated Nuclear Data Files (ENDF/B), Version $6^{(2)}$ over the energy range from $0.001 \mathrm{eV}$ to $16.905 \mathrm{MeV}$. COMBINE solves the B-1 or B-3 approximations to the neutron transport equation, at the user's choice. The P-1 approximation may be chosen as a special case of the B-1 solution. For this evaluation, the B-1 option was chosen.

COMBINE has been improved numerous times since it was first written. The version used for this evaluation is COMBINE-6.02. ${ }^{(3)}$ Footnote (5) is an abbreviated report, mostly containing revised material library labels and revised input instructions. Footnote (1) is still the proper source for detailed theoretical elucidation of COMBINE.

In the HTR-10 startup core, $57 \%$ of the pebbles are fuel spheres and $43 \%$ are dummy balls. The COMBINE model in the core consists of a fuel sphere surrounded by the corresponding quantities of coolant and dummy-pebble graphite in a homogeneous mixture. The fuel sphere consists of a homogenized fuel zone and a pure graphite zone. A separate COMBINE model was developed for the reflector; the COMBINE calculations in the core and the reflector produce cross sections in the two spectral zones defined in the PEBBED model - i.e., the core spectral zone and the reflector spectral zone. In the reflector, the only materials present are carbon, boron, and coolant. The proportions of carbon and boron are similar except in the boronated carbon bricks used in the outer region where the neutron importance is low. Therefore, the atomic number densities used in the COMBINE reflector model were based on only two of the regions shown in Figure 5, regions 22 and 31. The COMBINE input file for the as-run critical configuration is also contained in Appendix A.

For heterogeneous systems such as PBRs, shadowing effects are accounted for in COMBINE by Dancoff factors. The PBR is doubly heterogeneous, so both interpebble and intrapebble Dancoff factors are required. For this evaluation, the Dancoff factors were computed by the new code PEBDAN, developed at the INL specifically for PBRs by Kloosterman and Ougouag. ${ }^{(4)}$ The

(1) R. L. Curtis and R. A. Grimesey, INCITE: A FORTRAN-IV Program to Generate Thermal Neutron Spectra and Multigroup Constants Using Arbitrary Scattering Kernels, Idaho Nuclear Corporation, IN-1062, 1967.

(2) R. Kinsey, Data Formats and Procedures for the Evaluated Nuclear Data File ENDF, Brookhaven National Laboratory, BNL-NCS-50496, 1979.

(3) W. Y. Yoon letter to D. W. Nigg, “COMBINE-6 CYCLE 1,” WYY-01-94, January 17, 1994.

(4) J. Kloosterman and A. M. Ougouag, "Computation of Dancoff Factors for Fuel Elements Incorporating Randomly Packed TRISO Particles,” INEEL/EXT-05-02593, Idaho National Engineering and Environmental Laboratory, January 2005. 
input file for PEBDAN is also included in Appendix A.

COMBINE not only predicts $\mathrm{k}_{\infty}$ for the unit cell, it also predicts $\mathrm{k}_{\mathrm{eff}}$ for specified values of fast and thermal buckling. Since the actual reactor is critical, the appropriate values of buckling are those for which COMBINE gives $k_{\text {eff }}=1.0$. A search was performed to determine these appropriate values; the result was $\mathrm{B}^{2}=4.958 \times 10^{-4}$ for both the fast and thermal cases.

\subsubsection{Dimensions}

The dimensions of the model regions are shown in Figure 5. The pebble dimensions are given in Table 9. The dimensions of other regions involved in the uncertainty analysis are given in Table 10. Figure 7 shows the dimensions of the KLAK channels in the core region.

Table 10. Dimensions of regions in HTR-10 not defined elsewhere

\begin{tabular}{|l|l|l|l|}
\hline Region & Diameter $(\mathrm{cm})$ & Coordinate of center $(\mathrm{cm})$ & Channel length range $(\mathrm{cm})$ \\
\hline Twenty helium flow channels & 8.0 & 144.6 radius & $105.0 \leq \mathrm{Z} \leq 610.0$ \\
\hline $\begin{array}{l}\text { Ten control rod channels \& } 3 \\
\text { irradiation channels }\end{array}$ & 13.0 & 102.1 radius & $0 \leq \mathrm{Z} \leq-450.0$ \\
\hline $\begin{array}{l}\text { Seven KLAK channels, sections } \\
\text { with circular cross section }\end{array}$ & 6.0 & 98.6 radius & $\begin{array}{l}0 \leq \mathrm{Z}<-130.0 \\
388.764<\mathrm{Z} \leq-610.0\end{array}$ \\
\hline $\begin{array}{l}\text { Seven KLAK channels, sections } \\
\text { with oval cross section }\end{array}$ & See Figure 6. & $\begin{array}{l}98.6 \text { radius (the long axis of the } \\
\text { cross section is in the } \\
\text { circumferential direction) }\end{array}$ & $130.0 \leq \mathrm{Z} \leq-388.764$ \\
\hline Hot gas duct & 30.0 & $\mathrm{z}=480.0$ & $90.0 \leq r \leq 190.0$ \\
\hline Fuel discharge tube & 25.0 & $r=0$ & $388.764 \leq \mathrm{z} \leq 610.0$ \\
\hline
\end{tabular}

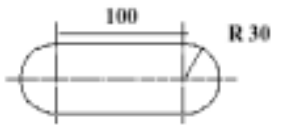

Figure 7. Cross section of KLAK channel in axial zone of the core (dimensions in mm)

\subsubsection{Material Data}

As shown in Figure 5, the model regions are numbered from 1 to 99. In the model of the initial critical configuration, the control rod regions in Figure 5, labeled 31-40, were consolidated into region 31, leaving a gap from 32-40. (Dividing the control rod region into several model regions allowed partial insertion of control rods, which would be required to evaluate the control rod worth experiment.) 
Because the cross sections of the same nuclides will be different in the core and the reflector, which are treated as different spectral zones in the model, nuclides that appear in both zones are treated separately in the two zones, with different material numbers.

The only materials present in the model are graphite (with varying boron concentrations), fuel, and coolant. The reactor vessel and other structural components are omitted. These components are all located in regions of very small neutron importance, so their omission is reasonable. (Perusal of the PEBBED flux output file shows that the thermal neutron flux in the boronated carbon bricks is between four and eleven orders of magnitude lower than that in the core, as depicted in Figure 8; the other neutron energy groups show similar disparities.) The channels for coolant flow, control rods, and KLAK are merely borings in the reflector, so there are no structural materials associated with them.

For the reflector components, the carbon and boron atomic number densities were provided by the HTR-10 group (Reference 1); these densities are presented in Table 8. Only the total boron densities were specified; these were converted to B-10 and B-11 densities by multiplying by the natural abundance $\left(0.199\right.$ for B-10 and 0.801 for B-11; cf. the Chart of the Nuclides $\left.{ }^{(1)}\right)$. The atomic number densities of the gaseous constituents were calculated from the stated temperature and total pressure, $15^{\circ} \mathrm{C}$ and $0.1013 \mathrm{MPa}$, and the assumption that the air is saturated. The proportions of the constituents of dry air are listed below by volume ${ }^{(2)}$ :

Nitrogen $78.084 \%$

Oxygen $20.9476 \%$

Argon $0.934 \%$.

The remaining constituents of dry air are ignored.

The graphite density in regions $22,23,25,48,49,50,52,54,67,69,71$, and 80 is solid density (at 1.76 $\mathrm{g} / \mathrm{cm}^{3}$, the specified density of the reflector graphite); the coolant volumes are determined in the other regions as the fractions of the solid density that the graphite in them occupies.

The carbon and boron atomic number densities are also tabulated in Reference 1 for the dummy balls, but the tabulated densities had to be corrected for the as-built composition $\left(1.84 \mathrm{~g} / \mathrm{cm}^{3}\right.$ instead of $1.73 \mathrm{~g} / \mathrm{cm}^{3}$ for carbon and $0.125 \mathrm{ppm}$ instead of $1.3 \mathrm{ppm}$ for boron).

The number densities in the core were calculated from the specifications given in Reference 1. First, a typical cell was defined consisting of $57 \%$ of a fuel ball, $43 \%$ of a dummy ball, and the

(1) Chart of the Nuclides, Thirteenth Edition, General Electric Company, 1984.

(2) http://www.physlink.com/Reference/AirComposition.cfm, citing the CRC Handbook of Chemistry and Physics, David R. Lide, Editor-in-Chief, 1997 Edition. 
CRIT

PEBBED Flux (n/cm²/s) for Group 6

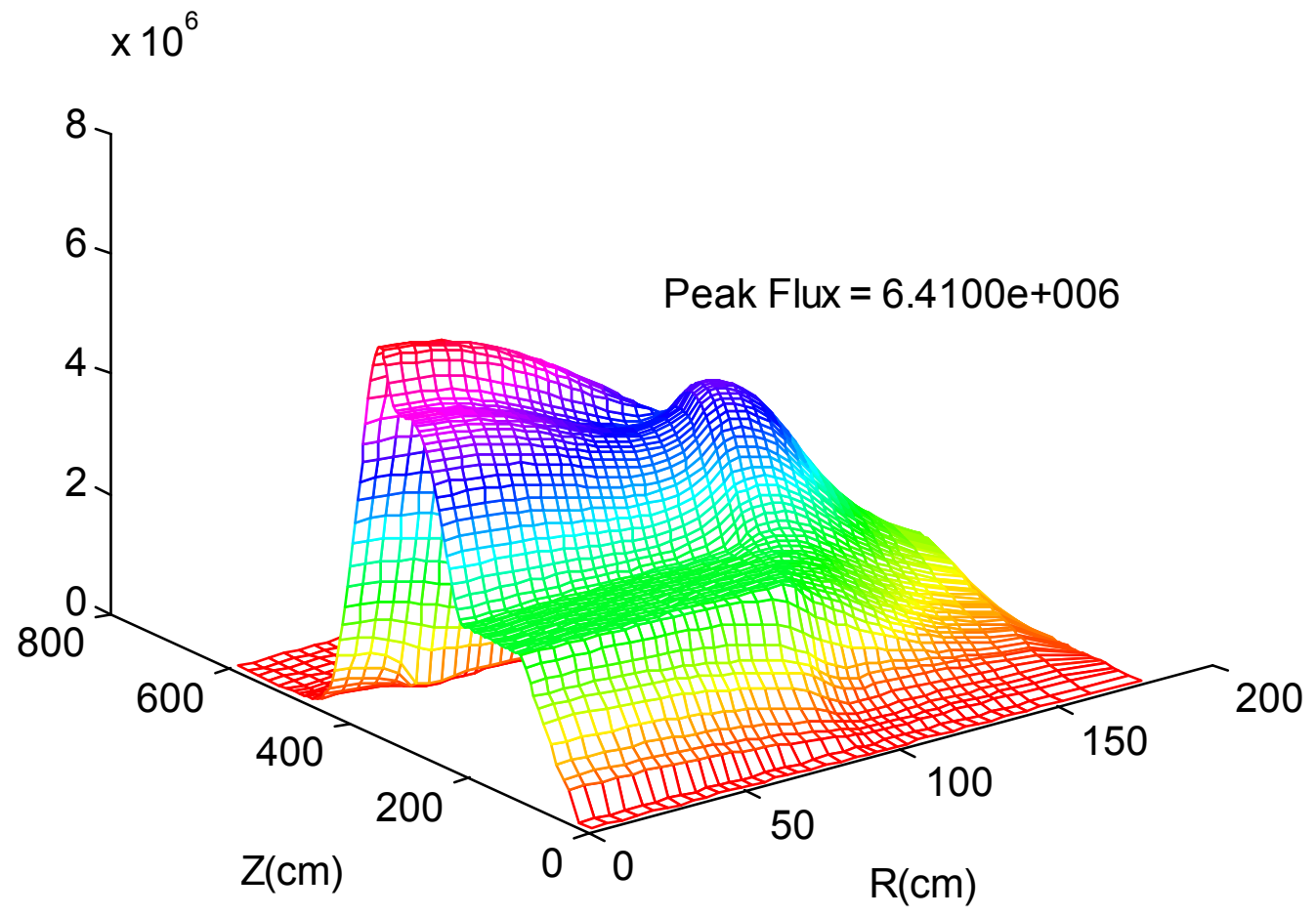

Figure 8. Thermal neutron flux in HTR-10 nominal case (the origin is at the top center of the model)

coolant volume associated with one ball, based on a packing fraction of $61 \%$ as stated in Reference 1. The volume of the cell was found to be $185.405 \mathrm{~cm}^{3}$. Table 11 specifies the dimensions and compositions of all the components in the core region. From these data, one can calculate the average number densities of all the nuclides in the core. Because this calculation is tedious, it is sketched in Appendix B. Table 12 specifies the nominal compositions of the reflector graphite and boronated carbon bricks.

The zone-averaged atomic number densities of all nuclides in all zones in the model are given in the base-case PEBBED input in Appendix A. Tables 13-16 also give the calculated atomic number densities. Table 13 presents the homogenized number densities used in the model. Table 14 gives the number densities in the core components. The values in Table 14 are given for the reader's convenience; they were not used in this uncertainty analysis. Table 15 gives the number densities of the raw materials in the reflector - the solid reflector graphite and boronated carbon materials. Table 16 gives the number densities in air at the experiment conditions. 
Table 11. Nominal material properties of fuel and dummy pebbles as built (from Reference 1)

\begin{tabular}{|l|l|}
\hline Density of graphite in matrix and outer shell & $1.73 \mathrm{~g} / \mathrm{cm}^{3}$ \\
\hline Heavy metal (uranium) loading (weight) per ball & $5.0 \mathrm{~g}$ \\
\hline Enrichment of $\mathrm{U}_{235}$ (weight) & $17 \%$ \\
\hline Equivalent natural boron content of impurities in uranium & $4 \mathrm{ppm}$ \\
\hline Equivalent natural boron content of impurities in graphite & $1.3 \mathrm{ppm}$ \\
\hline Volumetric filling fraction of balls in the core & 0.61 \\
\hline UO2 density $\left(\mathrm{g} / \mathrm{cm}^{3}\right.$ ) & 10.4 \\
\hline Coating layer materials (starting from kernel) & Buffer/PyC/SiC/PyC \\
\hline Coating layer density $\left(\mathrm{g} / \mathrm{cm}^{3}\right)$ & $1.1 / 1.9 / 3.18 / 1.9$ \\
\hline Density of graphite in dummy balls & $1.84 \mathrm{~g} / \mathrm{cm}^{3}$ \\
\hline $\begin{array}{l}\text { Equivalent natural boron content of impurities in graphite } \\
\text { in dummy balls }\end{array}$ & $0.125 \mathrm{ppm}$ \\
\hline
\end{tabular}

Table 12. Nominal material properties of reflector materials (from Reference 1)

\begin{tabular}{|l|l|}
\hline Density of reflector graphite & $1.76 \mathrm{~g} / \mathrm{cm}^{3}$ \\
\hline Equivalent natural boron impurity in reflector graphite & $4.8366 \mathrm{ppm}$ \\
\hline Density of boronated carbon bricks including $\mathrm{B}_{4} \mathrm{C}$ & $1.59 \mathrm{~g} / \mathrm{cm}^{3}$ \\
\hline Weight ratio of $\mathrm{B}_{4} \mathrm{C}$ in boronated carbon bricks & $5 \%$ \\
\hline
\end{tabular}

Table 13. Homogenized atomic number densities in the model

\begin{tabular}{|l|l|}
\hline Nuclide & $\begin{array}{l}\text { Atomic number density } \\
(\mathrm{a} / \mathrm{b}-\mathrm{cm})\end{array}$ \\
\hline U-235, averaged over core & $6.69520 \mathrm{E}-6$ \\
\hline U-238, averaged over core & $3.22755 \mathrm{E}-5$ \\
\hline O-16 in kernels, averaged over core & $7.79414 \mathrm{E}-5$ \\
\hline Natural Si, averaged over core & $8.51054 \mathrm{E}-5$ \\
\hline Graphite averaged over core & $5.40964 \mathrm{E}-2$ \\
\hline B-10 averaged over core & $9.92089 \mathrm{E}-9$ \\
\hline B-11 averaged over core & $3.99328 \mathrm{E}-8$ \\
\hline Nitrogen averaged over core & $1.55875 \mathrm{E}-5$ \\
\hline O-16 in dry air, averaged over core & $4.09021 \mathrm{E}-6$ \\
\hline Argon averaged over core & $9.11929 \mathrm{E}-8$ \\
\hline Hydrogen averaged over core & $3.34631 \mathrm{E}-7$ \\
\hline O-16 from water vapor, averaged over core & $1.67316 \mathrm{E}-7$ \\
\hline Graphite at 1.76 g/cm & $8.82418 \mathrm{E}-2$ \\
\hline B-10 at 4.8366 ppm total boron concentration & $9.42800 \mathrm{E}-8$ \\
\hline B-11 at 4.8366 ppm total boron concentration & $3.79489 \mathrm{E}-7$ \\
\hline
\end{tabular}


Table 14. Number densities in core components (not homogenized)

\begin{tabular}{|l|l|}
\hline Nuclide & $\begin{array}{l}\text { Atomic number density } \\
(\mathrm{a} / \mathrm{b}-\mathrm{cm})\end{array}$ \\
\hline U-235 in kernel & $3.99198 \mathrm{E}-3$ \\
\hline U-238 in kernel & $1.92441 \mathrm{E}-2$ \\
\hline O-16 in kernel & $4.64720 \mathrm{E}-2$ \\
\hline B-10 in kernel & $4.06384 \mathrm{E}-7$ \\
\hline B-11 in kernel & $1.63575 \mathrm{E}-6$ \\
\hline Carbon in buffer & $5.51511 \mathrm{E}-2$ \\
\hline B-10 in buffer & $1.58513 \mathrm{E}-8$ \\
\hline B-11 in buffer & $6.38035 \mathrm{E}-8$ \\
\hline Carbon in IPyC and OPyC & $9.52610 \mathrm{E}-2$ \\
\hline B-10 in IPyC and OPyC & $2.73795 \mathrm{E}-8$ \\
\hline B-11 in IPyC and OPyC & $1.10206 \mathrm{E}-7$ \\
\hline Carbon in SiC & $4.77597 \mathrm{E}-2$ \\
\hline Si (nat) in SiC & $4.77597 \mathrm{E}-2$ \\
\hline Carbon in fuel matrix & $8.67377 \mathrm{E}-2$ \\
\hline B-10 in fuel matrix & $2.49298 \mathrm{E}-8$ \\
\hline B-11 in fuel matrix & $1.00345 \mathrm{E}-7$ \\
\hline Carbon in dummy balls & $9.22528 \mathrm{E}-2$ \\
\hline B-10 in dummy balls & $2.54951 \mathrm{E}-9$ \\
\hline B-11 in dummy balls & $1.02621 \mathrm{E}-8$ \\
\hline
\end{tabular}

Table 15. Number densities in solid reflector components

\begin{tabular}{|l|l|}
\hline Nuclide & $\begin{array}{l}\text { Atomic number density } \\
(\mathrm{a} / \mathrm{b}-\mathrm{cm})\end{array}$ \\
\hline Graphite at $1.76 \mathrm{~g} / \mathrm{cm}^{3}$ & $8.82418 \mathrm{E}-2$ \\
\hline B-10 at $4.8366 \mathrm{ppm}$ total boron concentration & $9.42800 \mathrm{E}-8$ \\
\hline B-11 at $4.8366 \mathrm{ppm}$ total boron concentration & $3.79489 \mathrm{E}-7$ \\
\hline Carbon in boronated carbon bricks & $7.65984 \mathrm{E}-2$ \\
\hline B-10 in boronated carbon bricks & $6.89235 \mathrm{E}-4$ \\
\hline B-11 in boronated carbon bricks & $2.77426 \mathrm{E}-2$ \\
\hline
\end{tabular}


Table 16. Number densities in air at experiment conditions

\begin{tabular}{|l|l|}
\hline Nuclide & $\begin{array}{l}\text { Atomic number density } \\
(\mathrm{a} / \mathrm{b}-\mathrm{cm})\end{array}$ \\
\hline Nitrogen in dry air & $3.95901 \mathrm{E}-5$ \\
\hline O-16 in dry air & $1.06209 \mathrm{E}-5$ \\
\hline Ar in dry air & $2.36778 \mathrm{E}-7$ \\
\hline Hydrogen in vapor at saturation & $8.58028 \mathrm{E}-7$ \\
\hline O-16 in vapor at saturation & $4.29014 \mathrm{E}-7$ \\
\hline
\end{tabular}

\subsubsection{Temperature Data}

The temperature of the entire system was a uniform $15^{\circ} \mathrm{C}$.

\subsubsection{Experimental and Benchmark-Model $\mathbf{k}_{\text {eff }}$ and / or Subcritical Parameters}

The value of $k_{\text {eff }}$ is not explicitly given in Reference 1 . Instead, the core height at criticality is given. It is implied that $\mathrm{k}_{\mathrm{eff}}$ is exactly equal to 1 at the measured critical core height of 123.06 $\mathrm{cm}$. The effects of uncertainty in the core height specification, which is equivalent to an uncertainty in the number of pebbles in the core, are discussed in subsection 2.1.1. The approach to criticality was tracked by neutron counters, and a small Am-Be neutron source was used to provide a neutron flux for the counters to track.

\subsection{Benchmark-Model Specifications for Buckling and Extrapolation-Length} Measurements

No buckling or extrapolation length measurements were made.

\subsection{Benchmark-Model Specifications for Spectral Characteristics Measurements}

No spectral characteristics were measured.

\subsection{Benchmark-Model Specifications for Reactivity Effects Measurements}

The control rod worth measurements are not evaluated in this report. 


\subsection{Benchmark-Model Specifications for Reactivity Coefficient Measurements}

No reactivity coefficient measurements were made.

\subsection{Benchmark-Model Specifications for Kinetics Measurements}

No kinetics parameters were measured.

3.7 Benchmark-Model Specifications for Reaction-Rate Distribution Measurements

No reaction-rate distribution measurements were made.

3.8 Benchmark-Model Specifications for Power Distribution Measurements

No power distribution measurements were made.

\subsection{Benchmark-Model Specifications for Isotopic Measurements}

No isotopic measurements were made.

\subsection{Benchmark-Model Specifications for Other Miscellaneous Types of Measurements}

No other measurements have been reported. 


\subsection{RESULTS OF SAMPLE CALCULATIONS}

This section presents the principal results of the calculations described in Section 2. The expected value of $\mathrm{k}_{\mathrm{eff}}$ is 1.0 , but the calculational model gives a value of 1.03257 . The uncertainty is given as a percentage deviation from the model result.

\subsection{Results of Calculations of the Critical or Subcritical Configurations}

As noted above, the baseline value of keff is 1.03257. The deviation from 1.0 is believed to be due to inaccuracies in the cross sections. Whatever the reason, the bias of 0.03257 is carried through the analysis.

Table 7. Principal results of calculations

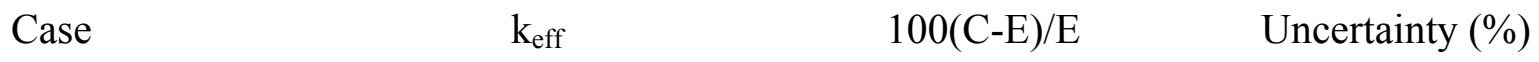

$\begin{array}{llll}\text { Expected value } & 1.00000 & 0.00000 & \mathrm{~N} / \mathrm{A}\end{array}$

$\begin{array}{llll}\text { Base case } & 1.03257 & 3.25700 & \text { N/A }\end{array}$

$\begin{array}{llll}\text { Overall uncertainty } & 1.03798^{*} & 3.79800 & 0.52394\end{array}$

$*$ This is the value of $\mathrm{k}_{\mathrm{eff}}$ at $+1 \sigma$. The value at $-1 \sigma, 1.02716$, is equally valid.

\subsection{Results of Buckling and Extrapolation Length Calculations}

No buckling or extrapolation length measurements were made.

\subsection{Results of Spectral-Characteristics Calculations}

No spectral characteristics were measured.

\subsection{Results of Reactivity-Effects Calculations}

No reactivity effects were calculated.

\subsection{Results of Reactivity Coefficient Calculations}

No reactivity coefficients were measured. 


\subsection{Results of Kinetics Parameter Calculations}

No kinetics parameters were measured.

\subsection{Results of Reaction-Rate Distribution Calculations}

No reaction-rate distributions were measured.

\subsection{Results of Power Distribution Calculations}

No power distributions were measured.

\subsection{Results of Isotopic Calculations}

Isotopic concentrations were not measured.

\subsection{Results of Calculations for Other Miscellaneous Types of Measurements}

No other measurements were reported.

\subsection{REFERENCES}

1. "Evaluation of high temperature gas cooled reactor performance: Benchmark analysis related to initial testing of the HTTR and HTR-10," IAEA-TECDOC-1382, International Atomic Energy Agency, Vienna, November 2003.

2. "Fuel performance and fission product behavior in gas cooled reactors," IAEA-TECDOC978, International Atomic Energy Agency, Vienna, November, 1927, pp. 11-13. 


\title{
APPENDICES
}

\section{APPENDIX A: COMPUTER CODES, CROSS SECTIONS, AND TYPICAL INPUT LISTINGS}

The codes used in this evaluation are PEBBED4, COMBINE-6, and PEBDAN. Detailed information on these codes is given in this appendix.

\author{
A.1.1 Name(s) of code system(s) used \\ PEBBED4 \\ COMBINE-6 version 2 \\ COMBDAN
}

\section{A.1.2 Bibliographic references for the codes used.}

H. D. Gougar, W. K. Terry, and A. M. Ougouag, PEBBED V.4.3 Manual (DRAFT), Idaho National Engineering and Environmental Laboratory. This manual has not been published, but it will be provided to officially designated reviewers.

Robert A. Grimesey, David W. Nigg, and Richard L. Curtis, COMBINE/PC - A Portable ENDF/B Version 5 Neutron Spectrum and Cross-Section Generation Program, EGG-2589, Rev. 1, Idaho National Engineering Laboratory, February 1991.

W. Y. Yoon letter to D. W. Nigg, “COMBINE-6 CYCLE 1,” WYY-01-94, January 17, 1994.

.J. Kloosterman and A. M. Ougouag, "Computation of Dancoff Factors for Fuel Elements Incorporating Randomly Packed TRISO Particles," INEEL/EXT-05-02593, Idaho National Engineering and Environmental Laboratory, January 2005.

R. Kinsey, Data Formats and Procedures for the Evaluated Nuclear Data File ENDF, Brookhaven National Laboratory, BNL-NCS-50496, 1979.

\section{A.1.3 Origin of cross-section data}

COMBINE uses cross sections from ENDF/B-VI.

\section{A.1.4 Calculational methods used}


PEBBED solves the neutron diffusion equation in one-, two-, or three-dimensional cylindrical or Cartesian geometry by finite-difference methods or in one- or two-dimensional cylindrical geometry by nodal methods. In PEBBED, the neutron diffusion equation is solved simultaneously with the nuclide depletion/production equations in a flowing core for a user-specified number of nuclides in the steady-state configuration of neutron flux and composition distribution. It does this by an iterative scheme without following the development of the state of the reactor in time. PEBBED also contains thermohydraulics modules for computing temperatures in normal operation and accident scenarios. However, in this evaluation, only the diffusion-theory component was needed since the fuel was all fresh and the core was stationary. Because the two-dimensional nodal option was not yet working when this evaluation was initiated, the finite-difference option was applied.

COMBINE solves the B-1 or B-3 approximation to the neutron transport equation, or the P-1 approximation as a special case of the B-1 approximation. At the user's option, it can perform an $\mathrm{ABH}$ thermal calculation and Nordheim, GAM-1, or Bondarenko treatment of the resolved resonance region. It uses the Wigner Rational Approximation in the unresolved resonance region. In this evaluation, the B-1 approximation was used, and the Nordheim treatment of the unresolved resonance region was chosen. The ABH option was not used. The only fissile nuclide present in the fresh HTR-10 core is $\mathrm{u}-235$, so a U-235 fission spectrum was used. Self-shielding factors were not specified.

COMBINE contains an internal module for computing Dancoff factors to account for shadowing effects in doubly heterogeneous systems like PBRs. However, recent advances in treating such double heterogeneities have led to an improved method of calculating the Dancoff factors. This method is implemented in the PEBDAN code. PEBDAN results were provided as input data to the COMBINE input file.

\section{A.1.5 Energy group structure}

COMBINE begins with a 166-group energy structure from ENDF/B-6; in this evaluation, the fine group structure was collapsed to six groups in the following energy ranges:

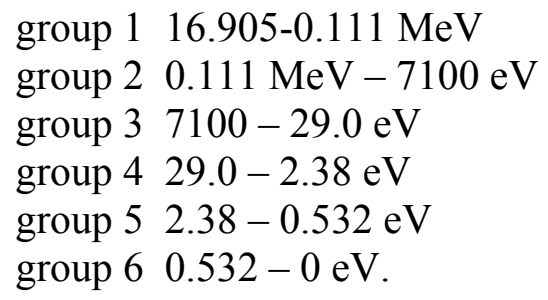

The two groups of lowest energy are the thermal groups. 


\section{A.1.6 Component calculations}

\section{A.1.6.1 COMBINE core spectrum and cross section calculation}

Type of calculation: Unit cell

Geometry: spherical

Theory used: transport

Method used: B-1 approximation, Nordheim numerical method, Wigner rational approximation

Calculation characteristics: spectrum calculation in mixture-ball region of core, cross section calculation for each nuclide in the core (with separate nuclide labels assigned to oxygen in fuel, dry air, and water vapor), resonance materials are U-235 and U-238

\section{A.1.6.2 COMBINE reflector cross section calculation}

Type of calculation: coarse-group cross section calculation Geometry: NA

Theory used: transport Method used: $B_{1}$ approximation Calculation characteristics: given U-235 fission spectrum, thermal and fast buckling values, compute group microscopic cross sections in reflector materials; no resonance materials are present

\section{A.1.6.3 PEBDAN calculation of Dancoff factors}

Type of calculation: computation of Dancoff factors

Geometry: spheres in finite media

Theory used: transport

Method used: Monte Carlo ray tracing

Calculation characteristics: given the fuel particle characteristics and packing fraction, find the intrapebble Dancoff factor; given the pebble characteristics and packing distribution, find the interpebble Dancoff factor

\section{A.1.6.4 PEBBED calculation of $\mathbf{k}_{\text {eff }}$}

Type of calculation: full reactor

Geometry: cylindrical

Theory used: diffusion

Method used: finite-difference

Calculation characteristics: given detailed description of core and reflector regions, compute k-effective; six energy groups, two thermal groups, homogenized core region, reflector regions defined by HTR-10 group, two spectral zones 
A.1.7 Other assumptions and characteristics - see detailed description in Section 3.1

\section{A.1.8 Typical Input Listings for each code system type}

\section{A.1.8.1 COMBINE Input Listing}

The input listing presented below is the COMBINE input for the configuration experimentally measured to be critical. It includes sections for both the core and reflector regions.

$=$ HTR-10 Spectral Zone Computation with $25 \mathrm{~mm}$ (o.r.) fuel region $17 \%$ enrichment by wt WKT 9 Sept 05

$=$ Two Spectral Zones

$=$ Spectrum calculation and core zone

$=$ COMBINE V5.23 Conversion (DWN) back to v6.02 (wkt)

$=$ As run with moist air coolant, $15 \operatorname{deg} \mathrm{C}, \mathrm{p}$ tot $=0.1013 \mathrm{MPa}$

$101010100111261-110000543100$

$1010102 \quad 00000$

101020116614413311110154

$1020101 \quad 1100000000000$

1030101440000000

$103020121 \quad * \mathrm{U}-235$

$103020222 \quad * \mathrm{U}-238$

$103020323 *$ O-16 in UO2 at $296 \mathrm{~K}$

$103020424 \quad *$ Silicon

$103020525 \quad *$ Graphite in core at $296 \mathrm{~K}$

$103020626 *$ *Core Boron-10

$103020727 \quad *$ Core Boron-11

$103020828 \quad *$ Core Nitrogen

103020929 *Oxygen in dry air in core

$1030210210 \quad *$ Argon in core

$1030211211 * \mathrm{H}$ in $\mathrm{H} 2 \mathrm{O}$ vapor in core at $296 \mathrm{~K}$

1030212212 *Oxygen in water vapor in core

1041001 4.958E-4 4.958E-4 288.15 *SPECT AT 15 deg C

$10420019228.092 .23501 \quad 6.69520 \mathrm{E}-060.03 .3333 \mathrm{E}-020.2318 * \mathrm{U}-235$

10420029237.092 .23801 3.22755E-05 0.0 3.3333E-02 $0.2318 * \mathrm{U}-238$

$1042003825.08 .01601 \quad 7.79414 \mathrm{E}-050.03 .3333 \mathrm{E}-020.2318 * \mathrm{O}-16$ in UO2 at $296 \mathrm{~K}$

$1042004 \quad 1400.014 .00001 \quad 8.51054 \mathrm{E}-050.03 .3333 \mathrm{E}-020.2318 *$ Silicon

$1042005 \quad 600.06 .01201 \quad 5.40718 \mathrm{E}-020.03 .3333 \mathrm{E}-020.2318 *$ Graphite in core at $296 \mathrm{~K}$

$1042006525.05 .01001 \quad 9.92089 \mathrm{E}-090.03 .3333 \mathrm{E}-020.2318 *$ Boron-10 in core

$1042007 \quad 528.05 .01101 \quad 3.99328 \mathrm{E}-08$ 0.0 3.3333E-02 0.2318 *Boron-11 in core

$1042008 \quad 725.07 .01401 \quad 1.51624 \mathrm{E}-050.03 .3333 \mathrm{E}-020.2318 *$ Nitrogen in core

$1042009825.08 .01601 \quad 4.06762 \mathrm{E}-060.03 .3333 \mathrm{E}-020.2318 * \mathrm{O}-16$ in dry air in core at $296 \mathrm{~K}$

$10420101837.018 .04001 \quad 9.06821 \mathrm{E}-080.03 .3333 \mathrm{E}-020.2318 *$ Argon in core

$1042011 \quad 125.01 .01801 \quad 3.34631 \mathrm{E}-070.03 .3333 \mathrm{E}-020.2318 * \mathrm{H}$ in $\mathrm{H} 2 \mathrm{O}$ vapor in core at $296 \mathrm{~K}$

$1042012825.08 .01601 \quad 1.67316 \mathrm{E}-070.03 .3333 \mathrm{E}-02 \quad 0.2318 * \mathrm{O}-16$ in $\mathrm{H} 2 \mathrm{O}$ vapor in core at $296 \mathrm{~K}$

$1043011293.0 \quad 3.03 .29243 \mathrm{E}-052.50 \quad 0.2634-1.0 \quad 8.54441 \mathrm{E}-02 * \mathrm{U}-235$

$1043012 \quad 4.22952 \mathrm{E}-04$ 3.87344E-04 $600.01400 .0 \quad 825.00 .00 .0$

$1043021293.0 \quad 3.01 .60748 \mathrm{E}-042.50 \quad 0.2634-1.0 \quad 8.54441 \mathrm{E}-02 * \mathrm{U}-238$ 
$=$ HTR-10 6-Group Cross Sections $17 \%$ enriched, thermal $<0.876 \mathrm{eV}$, fast $>0.10 \mathrm{eV}$

$=$ Reflector Spectral Zone

$=$ Updated with moist air coolant

$=1010101 \quad 0011861110000541100$

$101010100011961-110000541100$

101020116614413311110154

10301014000000

$1030201213 *$ Reflector Graphite at $296 \mathrm{~K}$

$1030202214 *$ Reflector Boron-10

$1030203215 *$ Reflector Boron-11

$1030204216 *$ Nitrogen in reflector

$1030205217 *$ O-16 in dry air in reflector at $296 \mathrm{~K}$

$1030206218 *$ Argon in reflector

$1030207219 * \mathrm{H}$ in $\mathrm{H} 2 \mathrm{O}$ vapor in reflector at $296 \mathrm{~K}$

$1030208220 * \mathrm{O}-16$ in $\mathrm{H} 2 \mathrm{O}$ vapor in reflector at $296 \mathrm{k}$

$1030209 \quad 021 * \mathrm{U}-235$ for spectrum

1041001 4.965E-4 4.965E-4 288.15 *SPECT AT 15 deg C

$1042001600.06 .01201 \quad 7.04227 \mathrm{E}-02 \quad 0.0 *$ Reflector Graphite at $296 \mathrm{~K}$

$1042002525.05 .01001 \quad 7.52415 \mathrm{E}-080.0 *$ Reflector Boron-10

$1042003528.05 .01101 \quad 3.02857 \mathrm{E}-070.0 *$ Reflector Boron-11

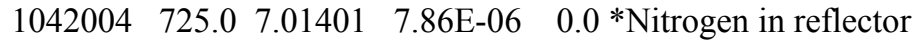

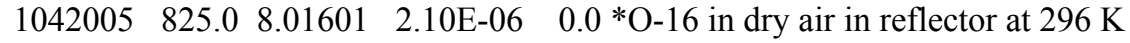

$1042006 \quad 1837.018 .04001 \quad 4.70 \mathrm{E}-08 \quad 0.0 *$ Argon in reflector

$1042007 \quad 125.0 \quad 1.01801 \quad 1.73 \mathrm{E}-07 \quad 0.0 * \mathrm{H}$ in $\mathrm{H} 2 \mathrm{O}$ vapor in reflector at $296 \mathrm{~K}$

$1042008825.0 \quad 8.01601 \quad 8.64 \mathrm{E}-08 \quad 0.0 * \mathrm{O}-16$ in $\mathrm{H} 2 \mathrm{O}$ vapor in reflector at $296 \mathrm{~K}$

$10420099228.092 .23501 \quad 1.0 \mathrm{E}-15 \quad 0.0 * \mathrm{U}-235$ to generate spectrum

\section{A.1.8.2 PEBDAN Input Listing}

The input listing presented below is the PEBDAN input.

MODULE Constants

IMPLICIT NONE

\footnotetext{
! Input on fuel and core design

! $=====================$

! HTR-10

INTEGER, PARAMETER::npart = 8335 ! number of particles per standard pebble

REAL, PARAMETER::radgrn1 $=0.025$ ! fuel kernel radis $(\mathrm{cm})$

REAL, PARAMETER::radpeb1 $=2.5 \quad$ ! inner zone radius $(\mathrm{cm})$

REAL, PARAMETER::radpeb2 $=3.0 \quad$ ! outer pebble radius $(\mathrm{cm})$

REAL, PARAMETER::radref $=0.0 \quad$ ! radius of cylindrical inner reflector $(\mathrm{cm})$

REAL, PARAMETER::radcore $=90.0 \quad$ ! radius of the core $(\mathrm{cm})$

REAL, PARAMETER::hgtcore $=180.118 \quad$ ! height of the core $(\mathrm{cm})$

$!=======================$
Input for generation pebble coordinates

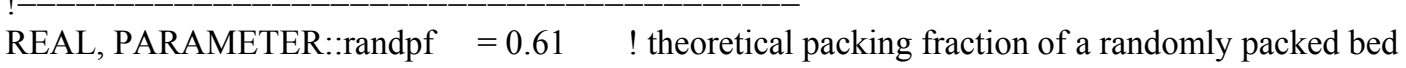

INTEGER, PARAMETER::nranpeb $=200000 \quad$ ! number of random points per pebble generated
} 
! then only a part of the file need to be read

! The actual number of pebbles read always becomes "np"

INTEGER, PARAMETER::npeb = INT(randpf*(radcore2-radref2)*hgtcore/radpeb23)

END MODULE Constants

\section{A.1.8.3 PEBBED Input Listing}

The following listing is the PEBBED input for the configuration that was measured as critical by the HTR10 group.

00001 HTR-10 R-Z 6-Group Critical As Run - Final corrected compositions, 17 wt \%

$=$ ptyp ndim geo sdim NR NQ NZ

00002121240199

$=\mathrm{R} \mathrm{Q} \mathrm{Z}$

00003101100

00004521001000201210

00005 1.E-4 1.0-8 1.0E-4 1.0E-4 0.2 0.1 1.0E-4

00006100

$=$ ngr ntg infuel inpres

$\begin{array}{lllll}00007 & 6 & 2 & 2 & 0\end{array}$

$00008 \quad 0.950510 .047997$ 1.4854E-03 5.0481E-06 0.00 .0

00009 1.6905E7 1.1109E5 7102. 29.0232 2.38237 0.532

$=$

00010219930

000111.61 .0

000154000000

$=$

000400

$\begin{array}{lll}00060 & 0.000001 & 0.0\end{array}$

$=$ No pebble flow

$\begin{array}{lll}00070 & 0.0 & 0.0\end{array}$

$=$

$=\quad$ Radial mesh

00101555.044 .187583 .62544 .812522 .8

00102543.2584 .024 .029 .5965122 .207

$=$

$=$ Azimuthal mesh

0020111360 .

$=$

$=$ Axial mesh

003014220.0511 .0110 .024 .85

00302427.65185 .48656304 .10242 .7355

00303444.1207524 .760543 .30974 .0

00304445.027 .547 .527 .5

003052215.0417 .5

$=$

$\begin{array}{lllll}00500 & 1 & 1 & 21 & 61\end{array}$

0050122

$=$

$=$ Pebble Specifications

0070021

$00701 \quad 100.0100 .0$

00702 FUEL DUMMY 


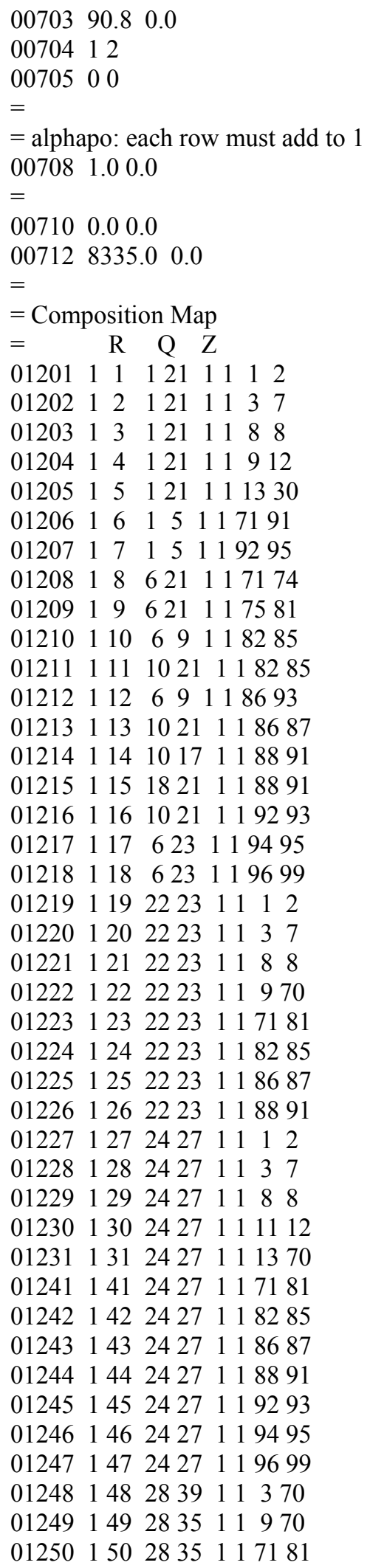


$\begin{array}{lllllll}01251 & 151 & 2835 & 1 & 18285\end{array}$

$\begin{array}{llllll}01252 & 152 & 2835 & 1 & 18687\end{array}$

$\begin{array}{llllllll}01253 & 153 & 28 & 35 & 1 & 18891\end{array}$

012541542835119293

012551552835119495

012561562835119699

$\begin{array}{llllllll}01257 & 157 & 36 & 37 & 1 & 1 & 8 & 8\end{array}$

$\begin{array}{lllllll}01258 & 158 & 36 & 37 & 1 & 1 & 970\end{array}$

$012591593637 \quad 117181$

012601603637118285

$012611613637 \quad 118687$

012621623637118891

012631633637119293

012641643637119495

012651653637119699

$\begin{array}{llllllll}01266 & 166 & 28 & 35 & 1 & 1 & 8 & 8\end{array}$

$\begin{array}{llllllll}01267 & 167 & 38 & 39 & 1 & 17181\end{array}$

0126816838391118285

$\begin{array}{lllllll}01269 & 169 & 38 & 39 & 1 & 18687\end{array}$

$\begin{array}{llllllll}01270 & 170 & 38 & 39 & 1 & 18891\end{array}$

012711713839119293

012721723839119495

012731733839119699

01274174283911112

$\begin{array}{lllllllll}01275 & 175 & 40 & 40 & 1 & 1 & 1 & 2\end{array}$

$\begin{array}{llllllll}01276 & 1764040 & 1 & 1 & 387\end{array}$

$01277 \quad 1774040118891$

012781784040119295

012791794040119699

012801802223119293

$\begin{array}{lllllll}01281 & 181 & 1 & 5 & 1 & 19699\end{array}$

$\begin{array}{llllllll}01282 & 182 & 24 & 27 & 1 & 1 & 9 & 10\end{array}$

012831832121116162

012841841921116364

012851851721116565

012861861521116666

$01287 \quad 1871321 \quad 116767$

012881881121116868

$01289189 \quad 921116969$

$\begin{array}{lllllll}01290 & 190 & 721 & 117070\end{array}$

$01291 \quad 191 \quad 120116162$

$01292 \quad 192 \quad 118 \quad 116364$

$01293 \quad 193 \quad 116116565$

$01294194 \quad 114116666$

$\begin{array}{llllll}01295 & 195 & 1 & 12 & 1 & 16767\end{array}$

$01296196 \quad 110116868$

$\begin{array}{llllllll}01297 & 197 & 1 & 8 & 1 & 16969\end{array}$

$01298198 \quad 161617070$

$01299199 \quad 1211113160$

$=$

$=$ Spectral Zone Assignment

$01401112 \quad 140111199$

01402133121112160 
$=$

$=$ Zone Temperatures $($ deg. $\mathrm{C})$

0150020.0

$\begin{array}{llllll}01501 & 2 & 2 & 20.0 & 3 & 20.0\end{array}$

$=$

$=$ Combine Cross-Sections for HTR-10 6-Group

$=$

$=$ Generated on $09 / 09 / 2005$

$=$

$21100 \mathrm{H}$ in $\mathrm{H}$

$21110 \quad 1.010 .0000 \mathrm{E}+00 \quad 0.0000 \mathrm{E}+000.0000 \mathrm{E}+000.0000 \mathrm{E}+00$

$211012.6165 \mathrm{E}+004.2799 \mathrm{E}-050.0000 \mathrm{E}+000.0000 \mathrm{E}+00$

$211025.6099 \mathrm{E}+002.7738 \mathrm{E}-040.0000 \mathrm{E}+00 \quad 0.0000 \mathrm{E}+00$

$21103 \quad 6.7492 \mathrm{E}+003.2373 \mathrm{E}-03 \quad 0.0000 \mathrm{E}+00 \quad 0.0000 \mathrm{E}+00$

$21104 \quad 6.8306 \mathrm{E}+001.9218 \mathrm{E}-02 \quad 0.0000 \mathrm{E}+00 \quad 0.0000 \mathrm{E}+00$

$211059.3640 \mathrm{E}+005.1221 \mathrm{E}-020.0000 \mathrm{E}+000.0000 \mathrm{E}+00$

$21106 \quad 2.9322 \mathrm{E}+012.1686 \mathrm{E}-010.0000 \mathrm{E}+000.0000 \mathrm{E}+00$

$211113.6327 \mathrm{E}+002.0689 \mathrm{E}+00$ 1.4079E-01 5.3227E-04 3.5440E-05 9.0480E-06

$211210.0000 \mathrm{E}+001.0715 \mathrm{E}+016.0162 \mathrm{E}+002.2662 \mathrm{E}-02$ 1.5747E-03 4.4902E-04

$211310.0000 \mathrm{E}+00 \quad 0.0000 \mathrm{E}+001.6754 \mathrm{E}+013.2268 \mathrm{E}+002.2411 \mathrm{E}-016.4455 \mathrm{E}-02$

$211410.0000 \mathrm{E}+00 \quad 0.0000 \mathrm{E}+00 \quad 0.0000 \mathrm{E}+001.3179 \mathrm{E}+015.6608 \mathrm{E}+001.6281 \mathrm{E}+00$

$211510.0000 \mathrm{E}+000.0000 \mathrm{E}+00 \quad 0.0000 \mathrm{E}+00 \quad 0.0000 \mathrm{E}+001.1938 \mathrm{E}+019.4635 \mathrm{E}+00$

$211610.0000 \mathrm{E}+00 \quad 0.0000 \mathrm{E}+00 \quad 0.0000 \mathrm{E}+00 \quad 0.0000 \mathrm{E}+001.2365 \mathrm{E}-023.9377 \mathrm{E}+01$

$=$

20600 B-10 i

$20610 \quad 10.010 .0000 \mathrm{E}+00 \quad 0.0000 \mathrm{E}+000.0000 \mathrm{E}+000.0000 \mathrm{E}+00$

$206013.1081 \mathrm{E}+00$ 7.3837E-01 $0.0000 \mathrm{E}+000.0000 \mathrm{E}+00$

$206025.9186 \mathrm{E}+003.7928 \mathrm{E}+00 \quad 0.0000 \mathrm{E}+000.0000 \mathrm{E}+00$

$206033.9147 \mathrm{E}+013.7166 \mathrm{E}+010.0000 \mathrm{E}+000.0000 \mathrm{E}+00$

$206042.2395 \mathrm{E}+022.2196 \mathrm{E}+020.0000 \mathrm{E}+000.0000 \mathrm{E}+00$

$206055.9336 \mathrm{E}+025.9136 \mathrm{E}+020.0000 \mathrm{E}+000.0000 \mathrm{E}+00$

$206062.5054 \mathrm{E}+032.5034 \mathrm{E}+03 \quad 0.0000 \mathrm{E}+000.0000 \mathrm{E}+00$

$206112.5682 \mathrm{E}+001.3320 \mathrm{E}-01$ 5.9149E-07 4.2445E-10 0.0000E+00 0.0000E+00

$206210.0000 \mathrm{E}+002.1323 \mathrm{E}+001.3877 \mathrm{E}-010.0000 \mathrm{E}+00 \quad 0.0000 \mathrm{E}+00 \quad 0.0000 \mathrm{E}+00$

$206310.0000 \mathrm{E}+00 \quad 0.0000 \mathrm{E}+00 \quad 2.0567 \mathrm{E}+006.7179 \mathrm{E}-020.0000 \mathrm{E}+00 \quad 0.0000 \mathrm{E}+00$

$206410.0000 \mathrm{E}+00 \quad 0.0000 \mathrm{E}+00 \quad 0.0000 \mathrm{E}+001.9877 \mathrm{E}+001.5216 \mathrm{E}-010.0000 \mathrm{E}+00$

$206510.0000 \mathrm{E}+00 \quad 0.0000 \mathrm{E}+00 \quad 0.0000 \mathrm{E}+00 \quad 0.0000 \mathrm{E}+00 \quad 2.1420 \mathrm{E}+000.0000 \mathrm{E}+00$

$206610.0000 \mathrm{E}+00 \quad 0.0000 \mathrm{E}+00 \quad 0.0000 \mathrm{E}+00 \quad 0.0000 \mathrm{E}+00 \quad 0.0000 \mathrm{E}+002.1435 \mathrm{E}+00$

$=$

20700 B-11 i

$20710 \quad 11.010 .0000 \mathrm{E}+00 \quad 0.0000 \mathrm{E}+000.0000 \mathrm{E}+000.0000 \mathrm{E}+00$

$207012.6964 \mathrm{E}+002.2159 \mathrm{E}-050.0000 \mathrm{E}+00 \quad 0.0000 \mathrm{E}+00$

$20702 \quad 4.5932 \mathrm{E}+001.0174 \mathrm{E}-040.0000 \mathrm{E}+000.0000 \mathrm{E}+00$

$207034.5444 \mathrm{E}+005.2749 \mathrm{E}-050.0000 \mathrm{E}+000.0000 \mathrm{E}+00$

20704 4.5447E+00 3.1871E-04 0.0000E $+000.0000 \mathrm{E}+00$

$20705 \quad 4.5452 \mathrm{E}+00 \quad 8.4838 \mathrm{E}-040.0000 \mathrm{E}+00 \quad 0.0000 \mathrm{E}+00$

$20706 \quad 4.5480 \mathrm{E}+003.5894 \mathrm{E}-03 \quad 0.0000 \mathrm{E}+000.0000 \mathrm{E}+00$

$207112.8370 \mathrm{E}+001.8161 \mathrm{E}-016.0275 \mathrm{E}-07$ 9.5296E-11 $0.0000 \mathrm{E}+000.0000 \mathrm{E}+00$

$207210.0000 \mathrm{E}+004.5839 \mathrm{E}+002.9026 \mathrm{E}-010.0000 \mathrm{E}+00 \quad 0.0000 \mathrm{E}+000.0000 \mathrm{E}+00$

$207310.0000 \mathrm{E}+00 \quad 0.0000 \mathrm{E}+004.7010 \mathrm{E}+001.3901 \mathrm{E}-010.0000 \mathrm{E}+000.0000 \mathrm{E}+00$

$207410.0000 \mathrm{E}+00 \quad 0.0000 \mathrm{E}+00 \quad 0.0000 \mathrm{E}+004.5254 \mathrm{E}+003.1456 \mathrm{E}-010.0000 \mathrm{E}+00$

$207510.0000 \mathrm{E}+00 \quad 0.0000 \mathrm{E}+00 \quad 0.0000 \mathrm{E}+00 \quad 0.0000 \mathrm{E}+004.8400 \mathrm{E}+00 \quad 0.0000 \mathrm{E}+00$

$207610.0000 \mathrm{E}+00 \quad 0.0000 \mathrm{E}+00 \quad 0.0000 \mathrm{E}+00 \quad 0.0000 \mathrm{E}+00 \quad 0.0000 \mathrm{E}+004.8400 \mathrm{E}+00$ 
CRIT

\section{$=$}

20500 Graphi

$20510 \quad 12.00 \quad 0.0000 \mathrm{E}+00 \quad 0.0000 \mathrm{E}+00 \quad 0.0000 \mathrm{E}+000.0000 \mathrm{E}+00$

$205012.7220 \mathrm{E}+002.9868 \mathrm{E}-040.0000 \mathrm{E}+000.0000 \mathrm{E}+00$

$20502 \quad 4.3239 \mathrm{E}+00 \quad 1.9843 \mathrm{E}-06 \quad 0.0000 \mathrm{E}+000.0000 \mathrm{E}+00$

20503 4.4674E+00 3.4623E-05 0.0000E $+000.0000 \mathrm{E}+00$

$20504 \quad 4.4738 \mathrm{E}+001.9630 \mathrm{E}-040.0000 \mathrm{E}+000.0000 \mathrm{E}+00$

20505 4.4861E+00 5.2440E-04 0.0000E+00 0.0000E+00

$20506 \quad 4.8054 \mathrm{E}+002.2057 \mathrm{E}-03 \quad 0.0000 \mathrm{E}+000.0000 \mathrm{E}+00$

$205112.8240 \mathrm{E}+00$ 1.6487E-01 4.1034E-07 4.3954E-10 0.0000E+00 0.0000E +00

$205210.0000 \mathrm{E}+004.3450 \mathrm{E}+002.5981 \mathrm{E}-010.0000 \mathrm{E}+000.0000 \mathrm{E}+000.0000 \mathrm{E}+00$

$205310.0000 \mathrm{E}+00 \quad 0.0000 \mathrm{E}+00 \quad 4.6081 \mathrm{E}+001.2538 \mathrm{E}-010.0000 \mathrm{E}+00 \quad 0.0000 \mathrm{E}+00$

$205410.0000 \mathrm{E}+00 \quad 0.0000 \mathrm{E}+00 \quad 0.0000 \mathrm{E}+00 \quad 4.4552 \mathrm{E}+002.8390 \mathrm{E}-010.0000 \mathrm{E}+00$

$205510.0000 \mathrm{E}+00 \quad 0.0000 \mathrm{E}+00 \quad 0.0000 \mathrm{E}+00 \quad 0.0000 \mathrm{E}+00 \quad 4.2776 \mathrm{E}+004.6085 \mathrm{E}-01$

$205610.0000 \mathrm{E}+00 \quad 0.0000 \mathrm{E}+00 \quad 0.0000 \mathrm{E}+00 \quad 0.0000 \mathrm{E}+00 \quad 5.1482 \mathrm{E}-03 \quad 4.8199 \mathrm{E}+00$

$=$

20800 Nitrog

$20810 \quad 14.000 .0000 \mathrm{E}+000.0000 \mathrm{E}+000.0000 \mathrm{E}+000.0000 \mathrm{E}+00$

$208012.2369 \mathrm{E}+006.2977 \mathrm{E}-02 \quad 0.0000 \mathrm{E}+000.0000 \mathrm{E}+00$

$20802 \quad 6.0554 \mathrm{E}+00 \quad 1.9237 \mathrm{E}-03 \quad 0.0000 \mathrm{E}+000.0000 \mathrm{E}+00$

$20803 \quad 9.1713 \mathrm{E}+00 \quad 1.8428 \mathrm{E}-02 \quad 0.0000 \mathrm{E}+00 \quad 0.0000 \mathrm{E}+00$

$208049.5425 \mathrm{E}+001.1009 \mathrm{E}-010.0000 \mathrm{E}+000.0000 \mathrm{E}+00$

$20805 \quad 9.7369 \mathrm{E}+00 \quad 2.9322 \mathrm{E}-01 \quad 0.0000 \mathrm{E}+00 \quad 0.0000 \mathrm{E}+00$

$208061.0863 \mathrm{E}+011.2406 \mathrm{E}+000.0000 \mathrm{E}+000.0000 \mathrm{E}+00$

$208112.2659 \mathrm{E}+00 \quad 1.3331 \mathrm{E}-01 \quad 6.4639 \mathrm{E}-08$ 1.4682E-11 $0.0000 \mathrm{E}+000.0000 \mathrm{E}+00$

$208210.0000 \mathrm{E}+006.0358 \mathrm{E}+00 \quad 4.0103 \mathrm{E}-010.0000 \mathrm{E}+00 \quad 0.0000 \mathrm{E}+00 \quad 0.0000 \mathrm{E}+00$

$208310.0000 \mathrm{E}+00 \quad 0.0000 \mathrm{E}+00 \quad 9.3932 \mathrm{E}+00 \quad 2.2605 \mathrm{E}-010.0000 \mathrm{E}+00 \quad 0.0000 \mathrm{E}+00$

$208410.0000 \mathrm{E}+00 \quad 0.0000 \mathrm{E}+00 \quad 0.0000 \mathrm{E}+00 \quad 9.3955 \mathrm{E}+005.1269 \mathrm{E}-010.0000 \mathrm{E}+00$

$208510.0000 \mathrm{E}+00 \quad 0.0000 \mathrm{E}+000.0000 \mathrm{E}+000.0000 \mathrm{E}+009.9201 \mathrm{E}+000.0000 \mathrm{E}+00$

$208610.0000 \mathrm{E}+00 \quad 0.0000 \mathrm{E}+00 \quad 0.0000 \mathrm{E}+000.0000 \mathrm{E}+00 \quad 0.0000 \mathrm{E}+001.0109 \mathrm{E}+01$

$=$

$20300 \quad 0-16 \mathrm{i}$

$20310 \quad 15.990 .0000 \mathrm{E}+00 \quad 0.0000 \mathrm{E}+000.0000 \mathrm{E}+000.0000 \mathrm{E}+00$

$203013.1852 \mathrm{E}+003.8153 \mathrm{E}-03 \quad 0.0000 \mathrm{E}+000.0000 \mathrm{E}+00$

$203023.6967 \mathrm{E}+001.9010 \mathrm{E}-060.0000 \mathrm{E}+000.0000 \mathrm{E}+00$

$20303 \quad 3.7237 \mathrm{E}+003.2161 \mathrm{E}-060.0000 \mathrm{E}+000.0000 \mathrm{E}+00$

$203043.7248 \mathrm{E}+001.1422 \mathrm{E}-050.0000 \mathrm{E}+00 \quad 0.0000 \mathrm{E}+00$

$203052.1938 \mathrm{E}+002.9528 \mathrm{E}-050.0000 \mathrm{E}+00 \quad 0.0000 \mathrm{E}+00$

$203063.7890 \mathrm{E}+001.2418 \mathrm{E}-040.0000 \mathrm{E}+000.0000 \mathrm{E}+00$

$203113.4212 \mathrm{E}+001.1220 \mathrm{E}-01$ 9.6106E-08 1.3497E-11 0.0000E $+000.0000 \mathrm{E}+00$

$203210.0000 \mathrm{E}+003.6391 \mathrm{E}+001.6315 \mathrm{E}-010.0000 \mathrm{E}+000.0000 \mathrm{E}+000.0000 \mathrm{E}+00$

$203310.0000 \mathrm{E}+000.0000 \mathrm{E}+003.8070 \mathrm{E}+007.8163 \mathrm{E}-020.0000 \mathrm{E}+000.0000 \mathrm{E}+00$

$203410.0000 \mathrm{E}+00 \quad 0.0000 \mathrm{E}+00 \quad 0.0000 \mathrm{E}+003.7111 \mathrm{E}+001.7717 \mathrm{E}-010.0000 \mathrm{E}+00$

$203510.0000 \mathrm{E}+00 \quad 0.0000 \mathrm{E}+00 \quad 0.0000 \mathrm{E}+00 \quad 0.0000 \mathrm{E}+001.8844 \mathrm{E}+003.3018 \mathrm{E}-01$

$203610.0000 \mathrm{E}+00 \quad 0.0000 \mathrm{E}+00 \quad 0.0000 \mathrm{E}+00 \quad 0.0000 \mathrm{E}+00 \quad 4.6017 \mathrm{E}-03 \quad 3.9510 \mathrm{E}+00$

$=$

20900 O-16 i

$20910 \quad 15.990 .0000 \mathrm{E}+00 \quad 0.0000 \mathrm{E}+00 \quad 0.0000 \mathrm{E}+000.0000 \mathrm{E}+00$

$209013.1881 \mathrm{E}+003.8153 \mathrm{E}-03 \quad 0.0000 \mathrm{E}+00 \quad 0.0000 \mathrm{E}+00$

$209023.6967 \mathrm{E}+001.9010 \mathrm{E}-06 \quad 0.0000 \mathrm{E}+00 \quad 0.0000 \mathrm{E}+00$

$20903 \quad 3.7237 \mathrm{E}+003.2161 \mathrm{E}-06 \quad 0.0000 \mathrm{E}+00 \quad 0.0000 \mathrm{E}+00$

$209043.7248 \mathrm{E}+00 \quad 1.1422 \mathrm{E}-050.0000 \mathrm{E}+00 \quad 0.0000 \mathrm{E}+00$

$209052.1938 \mathrm{E}+002.9528 \mathrm{E}-050.0000 \mathrm{E}+000.0000 \mathrm{E}+00$ 
$209063.7890 \mathrm{E}+001.2418 \mathrm{E}-040.0000 \mathrm{E}+000.0000 \mathrm{E}+00$

$209113.4256 \mathrm{E}+001.1220 \mathrm{E}-01$ 9.6106E-08 1.3497E-11 0.0000E $+000.0000 \mathrm{E}+00$

$209210.0000 \mathrm{E}+003.6391 \mathrm{E}+001.6315 \mathrm{E}-010.0000 \mathrm{E}+000.0000 \mathrm{E}+000.0000 \mathrm{E}+00$

$209310.0000 \mathrm{E}+000.0000 \mathrm{E}+003.8070 \mathrm{E}+007.8163 \mathrm{E}-020.0000 \mathrm{E}+000.0000 \mathrm{E}+00$

$209410.0000 \mathrm{E}+00 \quad 0.0000 \mathrm{E}+00 \quad 0.0000 \mathrm{E}+003.7111 \mathrm{E}+001.7717 \mathrm{E}-010.0000 \mathrm{E}+00$

$209510.0000 \mathrm{E}+000.0000 \mathrm{E}+00 \quad 0.0000 \mathrm{E}+000.0000 \mathrm{E}+001.8844 \mathrm{E}+003.3018 \mathrm{E}-01$

$209610.0000 \mathrm{E}+00 \quad 0.0000 \mathrm{E}+00 \quad 0.0000 \mathrm{E}+00 \quad 0.0000 \mathrm{E}+00$ 4.6017E-03 3.9510E +00

$=$

$21200 \quad \mathrm{O}-16 \mathrm{i}$

$21210 \quad 15.990 .0000 \mathrm{E}+000.0000 \mathrm{E}+000.0000 \mathrm{E}+000.0000 \mathrm{E}+00$

$212013.1881 \mathrm{E}+003.8153 \mathrm{E}-03 \quad 0.0000 \mathrm{E}+000.0000 \mathrm{E}+00$

$212023.6967 \mathrm{E}+001.9010 \mathrm{E}-060.0000 \mathrm{E}+00 \quad 0.0000 \mathrm{E}+00$

$21203 \quad 3.7237 \mathrm{E}+003.2161 \mathrm{E}-060.0000 \mathrm{E}+00 \quad 0.0000 \mathrm{E}+00$

$212043.7248 \mathrm{E}+00 \quad 1.1422 \mathrm{E}-050.0000 \mathrm{E}+00 \quad 0.0000 \mathrm{E}+00$

$212052.1938 \mathrm{E}+002.9528 \mathrm{E}-050.0000 \mathrm{E}+00 \quad 0.0000 \mathrm{E}+00$

$212063.7890 \mathrm{E}+001.2418 \mathrm{E}-040.0000 \mathrm{E}+000.0000 \mathrm{E}+00$

$212113.4256 \mathrm{E}+001.1220 \mathrm{E}-019.6106 \mathrm{E}-08$ 1.3497E-11 $0.0000 \mathrm{E}+000.0000 \mathrm{E}+00$

$212210.0000 \mathrm{E}+003.6391 \mathrm{E}+001.6315 \mathrm{E}-010.0000 \mathrm{E}+000.0000 \mathrm{E}+00 \quad 0.0000 \mathrm{E}+00$

$212310.0000 \mathrm{E}+00 \quad 0.0000 \mathrm{E}+003.8070 \mathrm{E}+00 \quad 7.8163 \mathrm{E}-020.0000 \mathrm{E}+00 \quad 0.0000 \mathrm{E}+00$

$212410.0000 \mathrm{E}+00 \quad 0.0000 \mathrm{E}+00 \quad 0.0000 \mathrm{E}+00 \quad 3.7111 \mathrm{E}+00 \quad 1.7717 \mathrm{E}-010.0000 \mathrm{E}+00$

$212510.0000 \mathrm{E}+00 \quad 0.0000 \mathrm{E}+00 \quad 0.0000 \mathrm{E}+00 \quad 0.0000 \mathrm{E}+001.8844 \mathrm{E}+003.3018 \mathrm{E}-01$

$212610.0000 \mathrm{E}+00 \quad 0.0000 \mathrm{E}+00 \quad 0.0000 \mathrm{E}+00 \quad 0.0000 \mathrm{E}+004.6017 \mathrm{E}-03 \quad 3.9510 \mathrm{E}+00$

$=$

20400 Si-28

$20410 \quad 27.980 .0000 \mathrm{E}+00 \quad 0.0000 \mathrm{E}+000.0000 \mathrm{E}+000.0000 \mathrm{E}+00$

$204012.8985 \mathrm{E}+00 \quad 4.6662 \mathrm{E}-03 \quad 0.0000 \mathrm{E}+00 \quad 0.0000 \mathrm{E}+00$

$20402 \quad 1.9813 \mathrm{E}+00 \quad 3.0649 \mathrm{E}-03 \quad 0.0000 \mathrm{E}+00 \quad 0.0000 \mathrm{E}+00$

$20403 \quad 2.0349 \mathrm{E}+002.1954 \mathrm{E}-03 \quad 0.0000 \mathrm{E}+00 \quad 0.0000 \mathrm{E}+00$

$204042.0176 \mathrm{E}+009.3001 \mathrm{E}-030.0000 \mathrm{E}+000.0000 \mathrm{E}+00$

$204052.0179 \mathrm{E}+002.4785 \mathrm{E}-02 \quad 0.0000 \mathrm{E}+000.0000 \mathrm{E}+00$

$204062.0978 \mathrm{E}+001.0468 \mathrm{E}-010.0000 \mathrm{E}+000.0000 \mathrm{E}+00$

$204113.6411 \mathrm{E}+00$ 1.6969E-02 2.4295E-04 8.7372E-08 0.0000E+00 0.0000E+00

$204210.0000 \mathrm{E}+002.0192 \mathrm{E}+004.9657 \mathrm{E}-020.0000 \mathrm{E}+00 \quad 0.0000 \mathrm{E}+000.0000 \mathrm{E}+00$

$204310.0000 \mathrm{E}+00 \quad 0.0000 \mathrm{E}+002.0605 \mathrm{E}+002.4211 \mathrm{E}-020.0000 \mathrm{E}+00 \quad 0.0000 \mathrm{E}+00$

$204410.0000 \mathrm{E}+000.0000 \mathrm{E}+00 \quad 0.0000 \mathrm{E}+002.0037 \mathrm{E}+005.3928 \mathrm{E}-020.0000 \mathrm{E}+00$

$204510.0000 \mathrm{E}+000.0000 \mathrm{E}+000.0000 \mathrm{E}+00 \quad 0.0000 \mathrm{E}+002.0420 \mathrm{E}+000.0000 \mathrm{E}+00$

$204610.0000 \mathrm{E}+00 \quad 0.0000 \mathrm{E}+00 \quad 0.0000 \mathrm{E}+00 \quad 0.0000 \mathrm{E}+00 \quad 0.0000 \mathrm{E}+002.0420 \mathrm{E}+00$

$=$

21000 Argon

$2101039.950 .0000 \mathrm{E}+000.0000 \mathrm{E}+000.0000 \mathrm{E}+00 \quad 0.0000 \mathrm{E}+00$

$210010.0000 \mathrm{E}+00 \quad 0.0000 \mathrm{E}+000.0000 \mathrm{E}+000.0000 \mathrm{E}+00$

$210020.0000 \mathrm{E}+00 \quad 0.0000 \mathrm{E}+00 \quad 0.0000 \mathrm{E}+000.0000 \mathrm{E}+00$

$210030.0000 \mathrm{E}+000.0000 \mathrm{E}+000.0000 \mathrm{E}+000.0000 \mathrm{E}+00$

$210040.0000 \mathrm{E}+000.0000 \mathrm{E}+000.0000 \mathrm{E}+000.0000 \mathrm{E}+00$

21005 1.0181E-01 1.0181E-01 $0.0000 \mathrm{E}+000.0000 \mathrm{E}+00$

21006 4.3086E-01 4.3086E-01 0.0000E $+000.0000 \mathrm{E}+00$

$210110.0000 \mathrm{E}+00 \quad 0.0000 \mathrm{E}+00 \quad 0.0000 \mathrm{E}+00 \quad 0.0000 \mathrm{E}+000.0000 \mathrm{E}+000.0000 \mathrm{E}+00$

$210210.0000 \mathrm{E}+00 \quad 0.0000 \mathrm{E}+00 \quad 0.0000 \mathrm{E}+00 \quad 0.0000 \mathrm{E}+000.0000 \mathrm{E}+000.0000 \mathrm{E}+00$

$210310.0000 \mathrm{E}+00 \quad 0.0000 \mathrm{E}+00 \quad 0.0000 \mathrm{E}+00 \quad 0.0000 \mathrm{E}+000.0000 \mathrm{E}+000.0000 \mathrm{E}+00$

$210410.0000 \mathrm{E}+00 \quad 0.0000 \mathrm{E}+00 \quad 0.0000 \mathrm{E}+00 \quad 0.0000 \mathrm{E}+000.0000 \mathrm{E}+000.0000 \mathrm{E}+00$

$210510.0000 \mathrm{E}+00 \quad 0.0000 \mathrm{E}+00 \quad 0.0000 \mathrm{E}+00 \quad 0.0000 \mathrm{E}+000.0000 \mathrm{E}+000.0000 \mathrm{E}+00$

$210610.0000 \mathrm{E}+00 \quad 0.0000 \mathrm{E}+00 \quad 0.0000 \mathrm{E}+00 \quad 0.0000 \mathrm{E}+00 \quad 0.0000 \mathrm{E}+00 \quad 0.0000 \mathrm{E}+00$ 
$20100 \mathrm{U}-235$

$20110235.043 .1000 \mathrm{E}-17 \quad 0.0000 \mathrm{E}+00 \quad 0.0000 \mathrm{E}+001.9290 \mathrm{E}+02$

$201016.0607 \mathrm{E}+001.3910 \mathrm{E}+003.1496 \mathrm{E}+001.2355 \mathrm{E}+00$

$20102 \quad 1.3493 \mathrm{E}+012.9359 \mathrm{E}+00 \quad 5.3492 \mathrm{E}+002.2024 \mathrm{E}+00$

$201033.7485 \mathrm{E}+012.4670 \mathrm{E}+014.0773 \mathrm{E}+011.6753 \mathrm{E}+01$

20104 8.0454E+01 6.8163E+01 9.6498E+01 3.9649E+01

$201056.8804 \mathrm{E}+015.5305 \mathrm{E}+01 \quad 1.0974 \mathrm{E}+024.5089 \mathrm{E}+01$

20106 4.3674E+02 4.2200E+02 8.7811E+02 3.6080E+02

$201116.8027 \mathrm{E}+00 \quad 1.5930 \mathrm{E}-01 \quad 1.5906 \mathrm{E}-031.1697 \mathrm{E}-06 \quad 0.0000 \mathrm{E}+000.0000 \mathrm{E}+00$

$201210.0000 \mathrm{E}+00 \quad 1.1080 \mathrm{E}+013.7459 \mathrm{E}-02 \quad 7.6640 \mathrm{E}-08 \quad 0.0000 \mathrm{E}+00 \quad 0.0000 \mathrm{E}+00$

$201310.0000 \mathrm{E}+00 \quad 0.0000 \mathrm{E}+001.2855 \mathrm{E}+01 \quad 1.5603 \mathrm{E}-02 \quad 0.0000 \mathrm{E}+00 \quad 0.0000 \mathrm{E}+00$

$201410.0000 \mathrm{E}+00 \quad 0.0000 \mathrm{E}+00 \quad 0.0000 \mathrm{E}+00 \quad 1.2291 \mathrm{E}+013.5879 \mathrm{E}-02 \quad 0.0000 \mathrm{E}+00$

$201510.0000 \mathrm{E}+00 \quad 0.0000 \mathrm{E}+00 \quad 0.0000 \mathrm{E}+00 \quad 0.0000 \mathrm{E}+00 \quad 1.3538 \mathrm{E}+01 \quad 0.0000 \mathrm{E}+00$

$201610.0000 \mathrm{E}+00 \quad 0.0000 \mathrm{E}+00 \quad 0.0000 \mathrm{E}+00 \quad 0.0000 \mathrm{E}+00 \quad 0.0000 \mathrm{E}+00 \quad 1.4784 \mathrm{E}+01$

$=$

20200 U-238

$20210 \quad 238.05$ 4.9000E-17 0.0000E+00 0.0000E+00 1.9390E+02

$202016.1320 \mathrm{E}+002.3528 \mathrm{E}-013.8763 \mathrm{E}-01$ 1.4144E-01

$202021.3160 \mathrm{E}+01$ 4.4233E-01 4.3791E-04 1.7562E-04

$202033.5334 \mathrm{E}+018.0616 \mathrm{E}+006.8038 \mathrm{E}-042.7301 \mathrm{E}-04$

$202045.9006 \mathrm{E}+014.2350 \mathrm{E}+01$ 1.1417E-04 4.5814E-05

$202059.6559 \mathrm{E}+00$ 5.2035E-01 5.0755E-06 2.0366E-06

$202061.1115 \mathrm{E}+011.7866 \mathrm{E}+001.9225 \mathrm{E}-05$ 7.7145E-06

$202118.1526 \mathrm{E}+001.1641 \mathrm{E}-012.0523 \mathrm{E}-043.2338 \mathrm{E}-080.0000 \mathrm{E}+000.0000 \mathrm{E}+00$

$202210.0000 \mathrm{E}+00 \quad 1.3208 \mathrm{E}+013.8851 \mathrm{E}-02 \quad 1.8712 \mathrm{E}-08 \quad 0.0000 \mathrm{E}+00 \quad 0.0000 \mathrm{E}+00$

$202310.0000 \mathrm{E}+00 \quad 0.0000 \mathrm{E}+00 \quad 2.7338 \mathrm{E}+01 \quad 1.0862 \mathrm{E}-02 \quad 0.0000 \mathrm{E}+00 \quad 0.0000 \mathrm{E}+00$

$202410.0000 \mathrm{E}+00 \quad 0.0000 \mathrm{E}+00 \quad 0.0000 \mathrm{E}+00 \quad 1.6681 \mathrm{E}+012.1347 \mathrm{E}-02 \quad 0.0000 \mathrm{E}+00$

$202510.0000 \mathrm{E}+00 \quad 0.0000 \mathrm{E}+00 \quad 0.0000 \mathrm{E}+00 \quad 0.0000 \mathrm{E}+00 \quad 9.1615 \mathrm{E}+00 \quad 0.0000 \mathrm{E}+00$

$202610.0000 \mathrm{E}+00 \quad 0.0000 \mathrm{E}+00 \quad 0.0000 \mathrm{E}+00 \quad 0.0000 \mathrm{E}+00 \quad 0.0000 \mathrm{E}+00 \quad 9.3552 \mathrm{E}+00$

$=$

$21900 \mathrm{H}$ in $\mathrm{H}$

$21910 \quad 1.010 .0000 \mathrm{E}+00 \quad 0.0000 \mathrm{E}+00 \quad 0.0000 \mathrm{E}+00 \quad 0.0000 \mathrm{E}+00$

$219012.6279 \mathrm{E}+004.2847 \mathrm{E}-050.0000 \mathrm{E}+000.0000 \mathrm{E}+00$

$219025.6138 \mathrm{E}+002.7828 \mathrm{E}-040.0000 \mathrm{E}+000.0000 \mathrm{E}+00$

$219036.7504 \mathrm{E}+003.3008 \mathrm{E}-03 \quad 0.0000 \mathrm{E}+000.0000 \mathrm{E}+00$

$219046.8308 \mathrm{E}+001.9491 \mathrm{E}-020.0000 \mathrm{E}+000.0000 \mathrm{E}+00$

21905 9.3749E+00 5.1339E-02 0.0000E+00 0.0000E+00

$21906 \quad 3.5919 \mathrm{E}+012.7204 \mathrm{E}-010.0000 \mathrm{E}+000.0000 \mathrm{E}+00$

$219113.6350 \mathrm{E}+002.0805 \mathrm{E}+001.4158 \mathrm{E}-01$ 5.3523E-04 3.5653E-05 9.1040E-06

$219210.0000 \mathrm{E}+001.0699 \mathrm{E}+01 \quad 6.0448 \mathrm{E}+002.2770 \mathrm{E}-02 \quad 1.5822 \mathrm{E}-03$ 4.5117E-04

$219310.0000 \mathrm{E}+00 \quad 0.0000 \mathrm{E}+00 \quad 1.6641 \mathrm{E}+01 \quad 3.3346 \mathrm{E}+00 \quad 2.3160 \mathrm{E}-01 \quad 6.6608 \mathrm{E}-02$

$219410.0000 \mathrm{E}+00 \quad 0.0000 \mathrm{E}+00 \quad 0.0000 \mathrm{E}+001.2990 \mathrm{E}+015.8081 \mathrm{E}+001.6705 \mathrm{E}+00$

$219510.0000 \mathrm{E}+00 \quad 0.0000 \mathrm{E}+00 \quad 0.0000 \mathrm{E}+00 \quad 0.0000 \mathrm{E}+001.1901 \mathrm{E}+019.5076 \mathrm{E}+00$

$219610.0000 \mathrm{E}+00 \quad 0.0000 \mathrm{E}+00 \quad 0.0000 \mathrm{E}+00 \quad 0.0000 \mathrm{E}+00 \quad 2.6123 \mathrm{E}-03 \quad 4.5132 \mathrm{E}+01$

$=$

21400 B-10 i

$21410 \quad 10.010 .0000 \mathrm{E}+000.0000 \mathrm{E}+000.0000 \mathrm{E}+00 \quad 0.0000 \mathrm{E}+00$

$214013.1139 \mathrm{E}+007.4047 \mathrm{E}-010.0000 \mathrm{E}+000.0000 \mathrm{E}+00$

$214025.9263 \mathrm{E}+003.8014 \mathrm{E}+000.0000 \mathrm{E}+000.0000 \mathrm{E}+00$

$21403 \quad 3.9879 \mathrm{E}+013.7897 \mathrm{E}+010.0000 \mathrm{E}+000.0000 \mathrm{E}+00$

$214042.2711 \mathrm{E}+022.2512 \mathrm{E}+02 \quad 0.0000 \mathrm{E}+000.0000 \mathrm{E}+00$

$214055.9472 \mathrm{E}+025.9272 \mathrm{E}+02 \quad 0.0000 \mathrm{E}+00 \quad 0.0000 \mathrm{E}+00$

$214063.1425 \mathrm{E}+03 \quad 3.1405 \mathrm{E}+03 \quad 0.0000 \mathrm{E}+00 \quad 0.0000 \mathrm{E}+00$ 
$214112.5707 \mathrm{E}+001.3429 \mathrm{E}-01 \quad 5.8876 \mathrm{E}-07$ 4.2298E-10 0.0000E+00 0.0000E +00 $214210.0000 \mathrm{E}+002.1300 \mathrm{E}+001.4011 \mathrm{E}-010.0000 \mathrm{E}+00 \quad 0.0000 \mathrm{E}+00 \quad 0.0000 \mathrm{E}+00$ $214310.0000 \mathrm{E}+00 \quad 0.0000 \mathrm{E}+00 \quad 2.0528 \mathrm{E}+00 \quad 7.1324 \mathrm{E}-02 \quad 0.0000 \mathrm{E}+00 \quad 0.0000 \mathrm{E}+00$ $214410.0000 \mathrm{E}+000.0000 \mathrm{E}+00 \quad 0.0000 \mathrm{E}+001.9803 \mathrm{E}+001.5967 \mathrm{E}-010.0000 \mathrm{E}+00$ $214510.0000 \mathrm{E}+00 \quad 0.0000 \mathrm{E}+00 \quad 0.0000 \mathrm{E}+00 \quad 0.0000 \mathrm{E}+002.1420 \mathrm{E}+00 \quad 0.0000 \mathrm{E}+00$ $214610.0000 \mathrm{E}+00 \quad 0.0000 \mathrm{E}+00 \quad 0.0000 \mathrm{E}+00 \quad 0.0000 \mathrm{E}+00 \quad 0.0000 \mathrm{E}+002.1447 \mathrm{E}+00$ $=$

21500 B-11 i

$21510 \quad 11.010 .0000 \mathrm{E}+000.0000 \mathrm{E}+000.0000 \mathrm{E}+000.0000 \mathrm{E}+00$

$215012.7006 \mathrm{E}+002.1983 \mathrm{E}-050.0000 \mathrm{E}+000.0000 \mathrm{E}+00$

$21502 \quad 4.5939 \mathrm{E}+001.0195 \mathrm{E}-040.0000 \mathrm{E}+000.0000 \mathrm{E}+00$

$21503 \quad 4.5444 \mathrm{E}+005.3833 \mathrm{E}-050.0000 \mathrm{E}+000.0000 \mathrm{E}+00$

21504 4.5447E+00 3.2315E-04 0.0000E $+000.0000 \mathrm{E}+00$

$21505 \quad 4.5452 \mathrm{E}+00 \quad 8.5033 \mathrm{E}-040.0000 \mathrm{E}+00 \quad 0.0000 \mathrm{E}+00$

21506 4.5489E+00 4.5026E-03 0.0000E $+000.0000 \mathrm{E}+00$

$215112.8398 \mathrm{E}+001.8311 \mathrm{E}-01 \quad 6.0399 \mathrm{E}-07$ 9.5369E-11 $0.0000 \mathrm{E}+000.0000 \mathrm{E}+00$

$215210.0000 \mathrm{E}+004.5820 \mathrm{E}+002.9308 \mathrm{E}-010.0000 \mathrm{E}+000.0000 \mathrm{E}+00 \quad 0.0000 \mathrm{E}+00$

$215310.0000 \mathrm{E}+000.0000 \mathrm{E}+004.6923 \mathrm{E}+001.4771 \mathrm{E}-010.0000 \mathrm{E}+000.0000 \mathrm{E}+00$

$215410.0000 \mathrm{E}+00 \quad 0.0000 \mathrm{E}+00 \quad 0.0000 \mathrm{E}+00 \quad 4.5099 \mathrm{E}+003.3012 \mathrm{E}-010.0000 \mathrm{E}+00$

$215510.0000 \mathrm{E}+00 \quad 0.0000 \mathrm{E}+000.0000 \mathrm{E}+000.0000 \mathrm{E}+004.8400 \mathrm{E}+000.0000 \mathrm{E}+00$

$215610.0000 \mathrm{E}+00 \quad 0.0000 \mathrm{E}+00 \quad 0.0000 \mathrm{E}+00 \quad 0.0000 \mathrm{E}+00 \quad 0.0000 \mathrm{E}+004.8400 \mathrm{E}+00$

$=$

21300 Graphi

$21310 \quad 12.00 \quad 0.0000 \mathrm{E}+00 \quad 0.0000 \mathrm{E}+000.0000 \mathrm{E}+000.0000 \mathrm{E}+00$

$213012.7262 \mathrm{E}+002.9526 \mathrm{E}-040.0000 \mathrm{E}+000.0000 \mathrm{E}+00$

$21302 \quad 4.3245 \mathrm{E}+001.9895 \mathrm{E}-060.0000 \mathrm{E}+000.0000 \mathrm{E}+00$

$21303 \quad 4.4676 \mathrm{E}+003.5257 \mathrm{E}-050.0000 \mathrm{E}+00 \quad 0.0000 \mathrm{E}+00$

$21304 \quad 4.4738 \mathrm{E}+001.9912 \mathrm{E}-040.0000 \mathrm{E}+000.0000 \mathrm{E}+00$

$213054.4862 \mathrm{E}+005.2560 \mathrm{E}-040.0000 \mathrm{E}+000.0000 \mathrm{E}+00$

$21306 \quad 4.8971 \mathrm{E}+002.7628 \mathrm{E}-030.0000 \mathrm{E}+000.0000 \mathrm{E}+00$

$213112.8272 \mathrm{E}+001.6624 \mathrm{E}-01$ 4.1165E-07 4.4114E-10 0.0000E $+000.0000 \mathrm{E}+00$

$213210.0000 \mathrm{E}+004.3430 \mathrm{E}+002.6235 \mathrm{E}-010.0000 \mathrm{E}+000.0000 \mathrm{E}+000.0000 \mathrm{E}+00$

$213310.0000 \mathrm{E}+00 \quad 0.0000 \mathrm{E}+004.6003 \mathrm{E}+001.3331 \mathrm{E}-010.0000 \mathrm{E}+000.0000 \mathrm{E}+00$

$213410.0000 \mathrm{E}+00 \quad 0.0000 \mathrm{E}+00 \quad 0.0000 \mathrm{E}+00 \quad 4.4412 \mathrm{E}+002.9797 \mathrm{E}-010.0000 \mathrm{E}+00$

$213510.0000 \mathrm{E}+00 \quad 0.0000 \mathrm{E}+00 \quad 0.0000 \mathrm{E}+00 \quad 0.0000 \mathrm{E}+004.2713 \mathrm{E}+004.6719 \mathrm{E}-01$

$213610.0000 \mathrm{E}+000.0000 \mathrm{E}+00 \quad 0.0000 \mathrm{E}+00 \quad 0.0000 \mathrm{E}+001.0870 \mathrm{E}-034.8227 \mathrm{E}+00$

$=$

21600 Nitrog

$21610 \quad 14.000 .0000 \mathrm{E}+00 \quad 0.0000 \mathrm{E}+000.0000 \mathrm{E}+000.0000 \mathrm{E}+00$

$216012.2405 \mathrm{E}+00 \quad 6.2591 \mathrm{E}-02 \quad 0.0000 \mathrm{E}+00 \quad 0.0000 \mathrm{E}+00$

$216026.0629 \mathrm{E}+00 \quad 1.9272 \mathrm{E}-03 \quad 0.0000 \mathrm{E}+000.0000 \mathrm{E}+00$

$216039.1781 \mathrm{E}+001.8792 \mathrm{E}-020.0000 \mathrm{E}+000.0000 \mathrm{E}+00$

$216049.5441 \mathrm{E}+001.1165 \mathrm{E}-010.0000 \mathrm{E}+000.0000 \mathrm{E}+00$

$216059.7376 \mathrm{E}+002.9390 \mathrm{E}-010.0000 \mathrm{E}+000.0000 \mathrm{E}+00$

$216061.1280 \mathrm{E}+01 \quad 1.5562 \mathrm{E}+00 \quad 0.0000 \mathrm{E}+000.0000 \mathrm{E}+00$

$216112.2691 \mathrm{E}+00 \quad 1.3443 \mathrm{E}-01 \quad 6.4465 \mathrm{E}-08$ 1.4511E-11 $0.0000 \mathrm{E}+000.0000 \mathrm{E}+00$

$216210.0000 \mathrm{E}+006.0396 \mathrm{E}+004.0499 \mathrm{E}-010.0000 \mathrm{E}+000.0000 \mathrm{E}+000.0000 \mathrm{E}+00$

$216310.0000 \mathrm{E}+000.0000 \mathrm{E}+009.3853 \mathrm{E}+002.4057 \mathrm{E}-010.0000 \mathrm{E}+000.0000 \mathrm{E}+00$

$216410.0000 \mathrm{E}+000.0000 \mathrm{E}+000.0000 \mathrm{E}+00 \quad 9.3702 \mathrm{E}+005.3816 \mathrm{E}-010.0000 \mathrm{E}+00$

$216510.0000 \mathrm{E}+00 \quad 0.0000 \mathrm{E}+00 \quad 0.0000 \mathrm{E}+00 \quad 0.0000 \mathrm{E}+009.9201 \mathrm{E}+000.0000 \mathrm{E}+00$

$216610.0000 \mathrm{E}+00 \quad 0.0000 \mathrm{E}+00 \quad 0.0000 \mathrm{E}+00 \quad 0.0000 \mathrm{E}+00 \quad 0.0000 \mathrm{E}+001.0219 \mathrm{E}+01$

$=$

21700 O-16 i 
$21710 \quad 15.990 .0000 \mathrm{E}+000.0000 \mathrm{E}+000.0000 \mathrm{E}+000.0000 \mathrm{E}+00$

$217013.1936 \mathrm{E}+003.7994 \mathrm{E}-03 \quad 0.0000 \mathrm{E}+00 \quad 0.0000 \mathrm{E}+00$

$217023.6968 \mathrm{E}+001.8951 \mathrm{E}-060.0000 \mathrm{E}+000.0000 \mathrm{E}+00$

$21703 \quad 3.7237 \mathrm{E}+003.2499 \mathrm{E}-060.0000 \mathrm{E}+000.0000 \mathrm{E}+00$

$217043.7248 \mathrm{E}+001.1499 \mathrm{E}-050.0000 \mathrm{E}+000.0000 \mathrm{E}+00$

$21705 \quad 2.2125 \mathrm{E}+002.9595 \mathrm{E}-050.0000 \mathrm{E}+000.0000 \mathrm{E}+00$

$21706 \quad 3.8293 \mathrm{E}+00 \quad 1.5574 \mathrm{E}-040.0000 \mathrm{E}+00 \quad 0.0000 \mathrm{E}+00$

$217113.4298 \mathrm{E}+00$ 1.1314E-01 9.5813E-08 1.3458E-11 0.0000E+00 0.0000E+00

$217210.0000 \mathrm{E}+003.6379 \mathrm{E}+001.6476 \mathrm{E}-010.0000 \mathrm{E}+00 \quad 0.0000 \mathrm{E}+00 \quad 0.0000 \mathrm{E}+00$

$217310.0000 \mathrm{E}+00 \quad 0.0000 \mathrm{E}+003.8021 \mathrm{E}+00 \quad 8.3211 \mathrm{E}-020.0000 \mathrm{E}+000.0000 \mathrm{E}+00$

$217410.0000 \mathrm{E}+000.0000 \mathrm{E}+00 \quad 0.0000 \mathrm{E}+003.7023 \mathrm{E}+001.8598 \mathrm{E}-010.0000 \mathrm{E}+00$

$217510.0000 \mathrm{E}+00 \quad 0.0000 \mathrm{E}+00 \quad 0.0000 \mathrm{E}+00 \quad 0.0000 \mathrm{E}+001.8966 \mathrm{E}+003.3528 \mathrm{E}-01$

$217610.0000 \mathrm{E}+00 \quad 0.0000 \mathrm{E}+00 \quad 0.0000 \mathrm{E}+00 \quad 0.0000 \mathrm{E}+00 \quad 9.7212 \mathrm{E}-04 \quad 3.9922 \mathrm{E}+00$

$=$

22000 O-16 i

$22010 \quad 15.990 .0000 \mathrm{E}+00 \quad 0.0000 \mathrm{E}+000.0000 \mathrm{E}+000.0000 \mathrm{E}+00$

$220013.1936 \mathrm{E}+003.7994 \mathrm{E}-030.0000 \mathrm{E}+000.0000 \mathrm{E}+00$

$220023.6968 \mathrm{E}+001.8951 \mathrm{E}-060.0000 \mathrm{E}+000.0000 \mathrm{E}+00$

$22003 \quad 3.7237 \mathrm{E}+003.2499 \mathrm{E}-060.0000 \mathrm{E}+000.0000 \mathrm{E}+00$

$220043.7248 \mathrm{E}+001.1499 \mathrm{E}-050.0000 \mathrm{E}+000.0000 \mathrm{E}+00$

$220052.2125 \mathrm{E}+002.9595 \mathrm{E}-050.0000 \mathrm{E}+00 \quad 0.0000 \mathrm{E}+00$

$220063.8293 \mathrm{E}+001.5574 \mathrm{E}-040.0000 \mathrm{E}+000.0000 \mathrm{E}+00$

$220113.4298 \mathrm{E}+00$ 1.1314E-01 9.5813E-08 1.3458E-11 0.0000E+00 0.0000E +00

$220210.0000 \mathrm{E}+003.6379 \mathrm{E}+001.6476 \mathrm{E}-010.0000 \mathrm{E}+00 \quad 0.0000 \mathrm{E}+00 \quad 0.0000 \mathrm{E}+00$

$220310.0000 \mathrm{E}+00 \quad 0.0000 \mathrm{E}+003.8021 \mathrm{E}+00 \quad 8.3211 \mathrm{E}-020.0000 \mathrm{E}+000.0000 \mathrm{E}+00$

$220410.0000 \mathrm{E}+00 \quad 0.0000 \mathrm{E}+00 \quad 0.0000 \mathrm{E}+00 \quad 3.7023 \mathrm{E}+001.8598 \mathrm{E}-010.0000 \mathrm{E}+00$

$220510.0000 \mathrm{E}+00 \quad 0.0000 \mathrm{E}+00 \quad 0.0000 \mathrm{E}+00 \quad 0.0000 \mathrm{E}+001.8966 \mathrm{E}+003.3528 \mathrm{E}-01$

$220610.0000 \mathrm{E}+00 \quad 0.0000 \mathrm{E}+00 \quad 0.0000 \mathrm{E}+00 \quad 0.0000 \mathrm{E}+00 \quad 9.7212 \mathrm{E}-04 \quad 3.9922 \mathrm{E}+00$

$=$

21800 Argon

$21810 \quad 39.950 .0000 \mathrm{E}+00 \quad 0.0000 \mathrm{E}+000.0000 \mathrm{E}+000.0000 \mathrm{E}+00$

$218010.0000 \mathrm{E}+000.0000 \mathrm{E}+000.0000 \mathrm{E}+000.0000 \mathrm{E}+00$

$218020.0000 \mathrm{E}+000.0000 \mathrm{E}+000.0000 \mathrm{E}+000.0000 \mathrm{E}+00$

$21803 \quad 0.0000 \mathrm{E}+00 \quad 0.0000 \mathrm{E}+00 \quad 0.0000 \mathrm{E}+00 \quad 0.0000 \mathrm{E}+00$

$218040.0000 \mathrm{E}+000.0000 \mathrm{E}+000.0000 \mathrm{E}+000.0000 \mathrm{E}+00$

21805 1.0204E-01 1.0204E-01 0.0000E+00 0.0000E +00

$218065.4048 \mathrm{E}-015.4048 \mathrm{E}-010.0000 \mathrm{E}+000.0000 \mathrm{E}+00$

$218110.0000 \mathrm{E}+000.0000 \mathrm{E}+000.0000 \mathrm{E}+000.0000 \mathrm{E}+000.0000 \mathrm{E}+000.0000 \mathrm{E}+00$

$218210.0000 \mathrm{E}+00 \quad 0.0000 \mathrm{E}+00 \quad 0.0000 \mathrm{E}+00 \quad 0.0000 \mathrm{E}+00 \quad 0.0000 \mathrm{E}+00 \quad 0.0000 \mathrm{E}+00$

$218310.0000 \mathrm{E}+00 \quad 0.0000 \mathrm{E}+00 \quad 0.0000 \mathrm{E}+00 \quad 0.0000 \mathrm{E}+00 \quad 0.0000 \mathrm{E}+00 \quad 0.0000 \mathrm{E}+00$

$218410.0000 \mathrm{E}+000.0000 \mathrm{E}+000.0000 \mathrm{E}+000.0000 \mathrm{E}+000.0000 \mathrm{E}+000.0000 \mathrm{E}+00$

$218510.0000 \mathrm{E}+00 \quad 0.0000 \mathrm{E}+000.0000 \mathrm{E}+000.0000 \mathrm{E}+000.0000 \mathrm{E}+000.0000 \mathrm{E}+00$

$218610.0000 \mathrm{E}+00 \quad 0.0000 \mathrm{E}+00 \quad 0.0000 \mathrm{E}+00 \quad 0.0000 \mathrm{E}+00 \quad 0.0000 \mathrm{E}+00 \quad 0.0000 \mathrm{E}+00$

$=$

22100 Void

$221100.0000 \mathrm{E}+00 \quad 0.0000 \mathrm{E}+00 \quad 0.0000 \mathrm{E}+00 \quad 0.0000 \mathrm{E}+00 \quad 0.0000 \mathrm{E}+00$

$221017.1579 \mathrm{E}-030.0000 \mathrm{E}+000.0000 \mathrm{E}+000.0000 \mathrm{E}+00$

$221027.1579 \mathrm{E}-030.0000 \mathrm{E}+000.0000 \mathrm{E}+000.0000 \mathrm{E}+00$

$221037.1579 \mathrm{E}-030.0000 \mathrm{E}+000.0000 \mathrm{E}+000.0000 \mathrm{E}+00$

$221047.1579 \mathrm{E}-030.0000 \mathrm{E}+000.0000 \mathrm{E}+000.0000 \mathrm{E}+00$

22105 7.1579E-03 0.0000E $+000.0000 \mathrm{E}+000.0000 \mathrm{E}+00$

$221067.1579 \mathrm{E}-030.0000 \mathrm{E}+000.0000 \mathrm{E}+000.0000 \mathrm{E}+00$

$221110.0000 \mathrm{E}+00 \quad 0.0000 \mathrm{E}+00 \quad 0.0000 \mathrm{E}+00 \quad 0.0000 \mathrm{E}+00 \quad 0.0000 \mathrm{E}+00 \quad 0.0000 \mathrm{E}+00$ 
$221210.0000 \mathrm{E}+00 \quad 0.0000 \mathrm{E}+00 \quad 0.0000 \mathrm{E}+00 \quad 0.0000 \mathrm{E}+00 \quad 0.0000 \mathrm{E}+000.0000 \mathrm{E}+00$

$221310.0000 \mathrm{E}+00 \quad 0.0000 \mathrm{E}+00 \quad 0.0000 \mathrm{E}+00 \quad 0.0000 \mathrm{E}+00 \quad 0.0000 \mathrm{E}+00 \quad 0.0000 \mathrm{E}+00$

$221410.0000 \mathrm{E}+00 \quad 0.0000 \mathrm{E}+00 \quad 0.0000 \mathrm{E}+00 \quad 0.0000 \mathrm{E}+00 \quad 0.0000 \mathrm{E}+00 \quad 0.0000 \mathrm{E}+00$

$221510.0000 \mathrm{E}+00 \quad 0.0000 \mathrm{E}+00 \quad 0.0000 \mathrm{E}+00 \quad 0.0000 \mathrm{E}+00 \quad 0.0000 \mathrm{E}+00 \quad 0.0000 \mathrm{E}+00$

$221610.0000 \mathrm{E}+00 \quad 0.0000 \mathrm{E}+00 \quad 0.0000 \mathrm{E}+00 \quad 0.0000 \mathrm{E}+00 \quad 0.0000 \mathrm{E}+00 \quad 0.0000 \mathrm{E}+00$

$=$

$=$ Compositions

$=$

30100 Boronated carbon bricks (1)

301013

30111131415

$30121 \quad 7.29410 \mathrm{E}-2 \quad 6.56324 \mathrm{E}-4 \quad 2.64179 \mathrm{E}-3$

$=$

30200 Top graphite reflector

302018

302111314151617181920

$30221 \quad 8.51462 \mathrm{E}-2$ 9.09725E-8 3.66176E-7 1.36389E-6

30222 3.65893E-7 8.15710E-9 3.00997E-8 1.50498E-8

$=$

30300 Cold helium chamber

303018

303111314151617181920

30321 1.45350E-2 1.55296E-8 6.25088E-8 3.24753E-5

$30322 \quad 8.71219 \mathrm{E}-6$ 1.94227E-7 7.16697E-7 3.58349E-7

$=$

30400 Top reflector

304018

304111314151617181920

$30421 \quad 8.02916 \mathrm{E}-2$ 8.59362E-8 3.45298E-7 3.50289E-6

$30422 \quad 9.39723 \mathrm{E}-7$ 2.09498E-8 7.73051E-8 3.86526E-8

$=$

30500 Top core cavity

305016

$30511 \quad 161718192021$

$30521 \quad 3.88795 \mathrm{E}-5$ 1.04303E-5 2.32528E-7 8.58030E-7

30522 4.29015E-7 1.0! Moist air at $15 \mathrm{C}$

$=$

30600 Dummy balls simplified (1)

306018

$30611 \quad 1314151617181920$

$30621 \quad 5.72501 \mathrm{E}-2$ 6.14369E-9 2.47292E-8 1.51630E-5

30622 4.06779E-6 9.06859E-8 3.34631E-7 1.67316E-7

$=$

30700 Dummy balls simplified (2)

307018

$30711 \quad 1314151617181920$

$30721 \quad 5.72501 \mathrm{E}-2$ 6.14369E-9 2.47292E-8 1.51630E-5

$30722 \quad 4.06779 \mathrm{E}-6$ 9.06859E-8 3.34631E-7 1.67316E-7

$=$

30800 Bottom reflector structures (1)

308018

308111314151617181920

30821 7.81408E-2 8.34879E-8 3.36049E-7 4.45053E-6 
30822 1.19395E-6 2.66175E-8 9.82187E-8 4.91093E-8

$=$

30900 Bottom reflector structures (2)

309018

309111314151617181920

$30921 \quad 8.23751 \mathrm{E}-2$ 8.80119E-8 3.54259E-7 2.58488E-6

$309226.93448 \mathrm{E}-7$ 1.54595E-8 5.70456E-8 2.85228E-8

$=$

31000 Bottom reflector structures (3)

310018

$31011 \quad 1314151617181920$

31021 8.43647E-2 5.94023E-5 2.39102E-4 1.57694E-6

31022 4.23047E-7 9.43126E-9 3.48014E-8 1.74007E-8

$=$

31100 Bottom reflector structures (4)

311018

311111314151617181920

31121 8.17101E-2 3.11268E-5 1.25289E-4 2.80916E-6

31122 7.53616E-7 1.68008E-8 6.19952E-8 3.09976E-8

$=$

31200 Bottom reflector structures (5)

312018

312111314151617181920

$312218.50790 \mathrm{E}-2$ 4.16093E-5 1.67483E-4 1.30161E-6

$31222 \quad 3.49184 \mathrm{E}-7$ 7.78458E-9 2.87252E-8 1.43626E-8

$=$

31300 Bottom reflector structures (6)

313018

313111314151617181920

$313218.19167 \mathrm{E}-2$ 7.13473E-6 2.87182E-5 2.77125E-6

31322 7.43445E-7 1.65741E-8 6.11585E-8 3.05793E-8

$=$

31400 Bottom reflector structures (7)

314018

$31411 \quad 1314151617181920$

$314215.41118 \mathrm{E}-2$ 1.14914E-5 4.62542E-5 1.50124E-5

31422 4.02740E-6 8.97853E-8 3.31308E-7 1.65654E-7

$=$

31500 Bottom reflector structures (8)

315018

315111314151617181920

$31521 \quad 3.32110 \mathrm{E}-2$ 3.54835E-8 1.42826E-7 2.42467E-5

$315226.50468 \mathrm{E}-6$ 1.45013E-7 5.35099E-7 2.67549E-7

$=$

31600 Bottom reflector structures (9)

316013

$\begin{array}{llll}31611 & 13 & 14 & 15\end{array}$

$31621 \quad 8.81811 \mathrm{E}-2 \quad 7.14143 \mathrm{E}-6 \quad 2.87452 \mathrm{E}-5$

$=$

31700 Boronated carbon bricks (2)

317013

$\begin{array}{llll}31711 & 13 & 14 & 15\end{array}$

$31721 \quad 7.65984 \mathrm{E}-2 \quad 6.89235 \mathrm{E}-4 \quad 2.77426 \mathrm{E}-3$ 


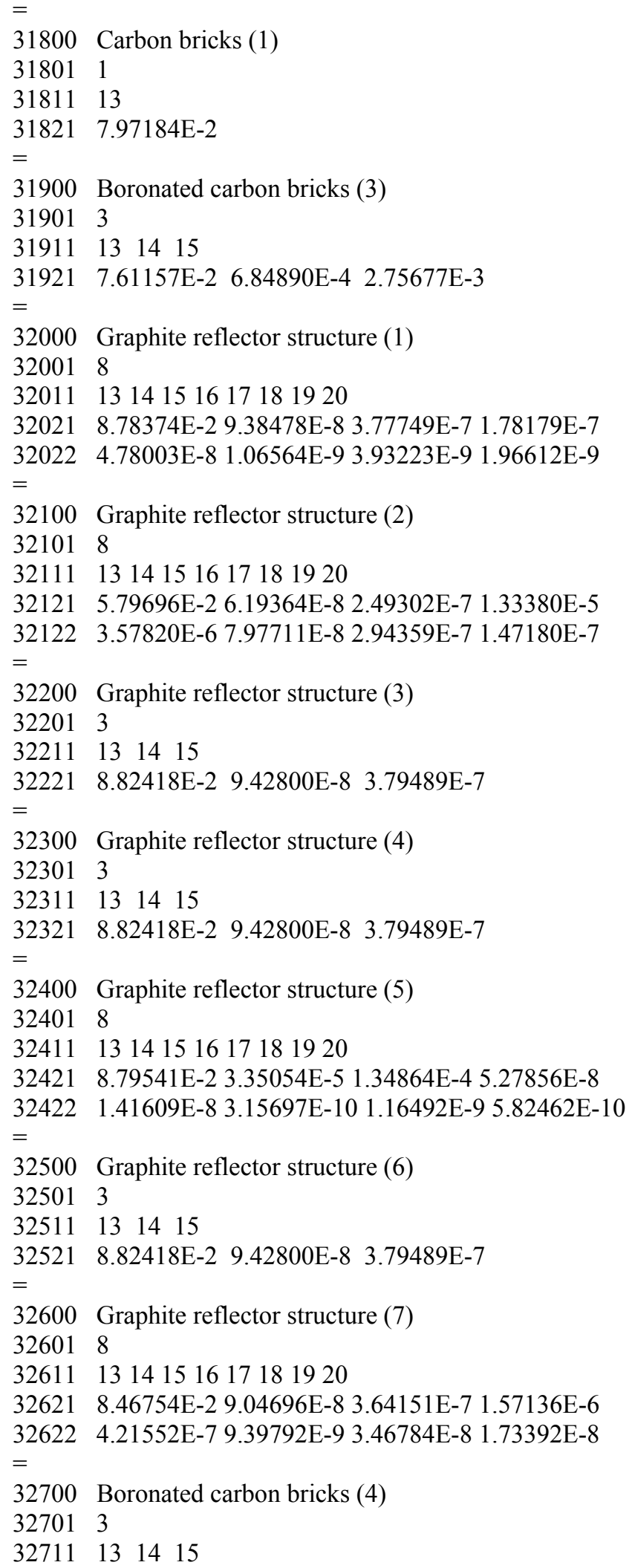


$=$

32800 Graphite reflector structure (8)

328018

328111314151617181920

$328216.78899 \mathrm{E}-2$ 2.78600E-6 1.12140E-5 8.96110E-6

$32822 \quad 2.40400 \mathrm{E}-6$ 5.35940E-8 1.97762E-7 9.88811E-8

$=$

32900 Graphite reflector structure (9)

329018

329111314151617181920

32921 4.03794E-2 2.78600E-6 1.12140E-5 2.10822E-5

32922 5.65574E-6 1.26087E-7 4.65262E-7 2.32631E-7

$=$

33000 Graphite reflector structure (10)

330018

330111314151617181920

$330216.78899 \mathrm{E}-2$ 7.25335E-8 2.91965E-7 8.52248E-6

33022 2.28634E-6 5.09708E-8 1.88082E-7 9.40412E-8

$=$

33100 Graphite reflector, control rod borings region

331018

331111314151617181920

$331216.34459 \mathrm{E}-2$ 6.76727E-8 2.72853E-7 1.09251E-5

33122 2.93090E-6 6.53404E-8 2.41106E-7 1.20553E-7

$=$

34100 Graphite reflector structure (11)

341018

$34111 \quad 1314151617181920$

$34121 \quad 6.78899 \mathrm{E}-2$ 7.25335E-8 2.91965E-7 8.52248E-6

$34122 \quad 2.28634 \mathrm{E}-6$ 5.09708E-8 1.88082E-7 9.40412E-8

$=$

34200 Graphite reflector structure (12)

342018

342111314151617181920

34221 6.76758E-2 2.49409E-5 1.00390E-4 9.00634E-6

$34222 \quad 2.41614 \mathrm{E}-6$ 5.38646E-8 1.98761E-7 9.93804E-8

$=$

34300 Graphite reflector structure (13)

343018

343111314151617181920

$34321 \quad 8.61476 \mathrm{E}-2$ 6.77874E-8 2.72853E-7 9.22759E-7

$34322 \quad 2.47550 \mathrm{E}-7$ 5.51879E-9 2.03643E-8 1.01822E-8

$=$

34400 Graphite reflector structure (14)

344018

$34411 \quad 1314151617181920$

$34421 \quad 8.29066 \mathrm{E}-2$ 8.85797E-8 3.56544E-7 2.35070E-6

$344226.30625 \mathrm{E}-7$ 1.40589E-8 5.18775E-8 2.59388E-8

$=$

34500 Graphite reflector structure (15)

345018

345111314151617181920 


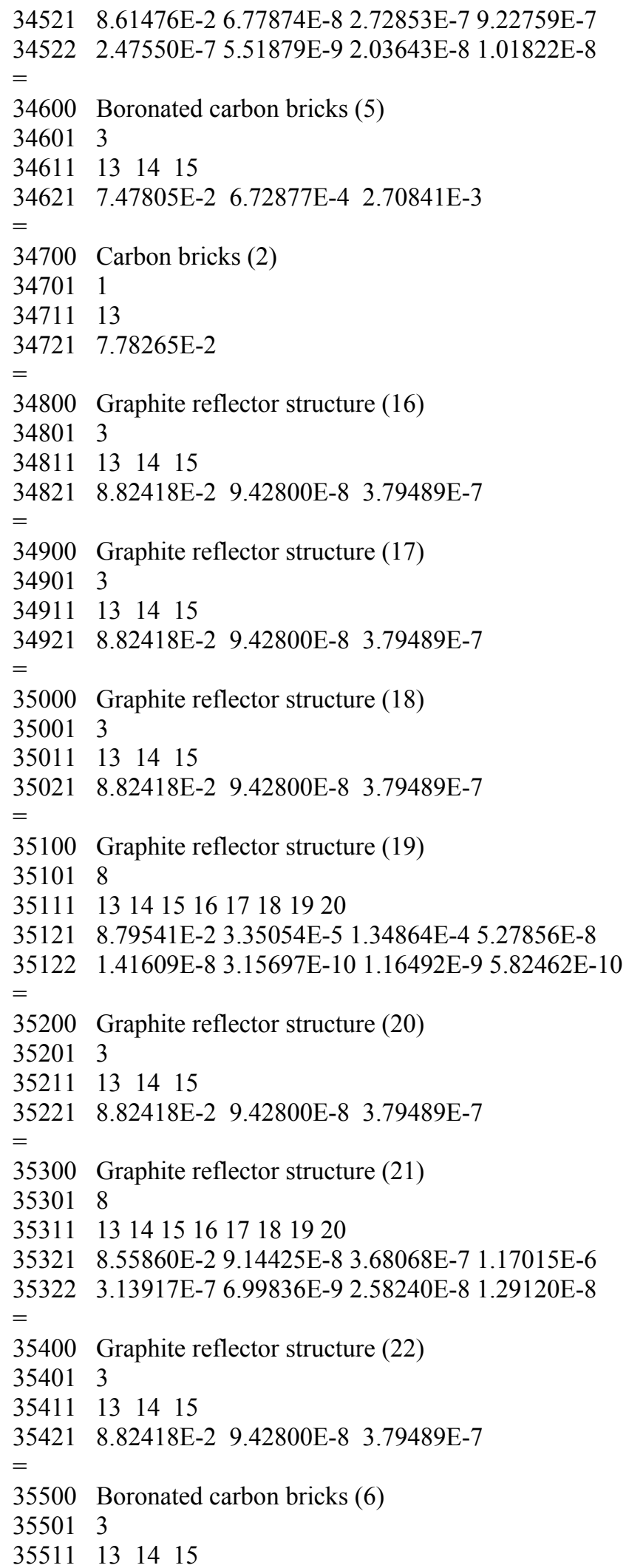




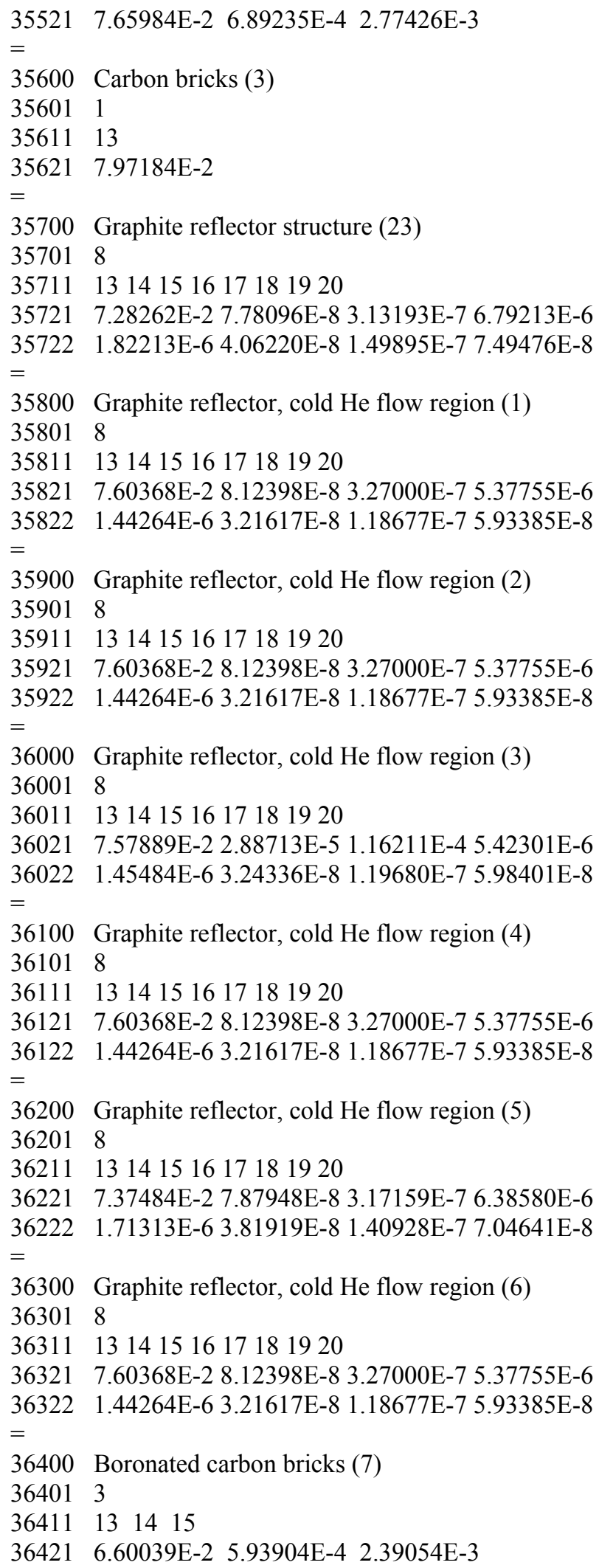




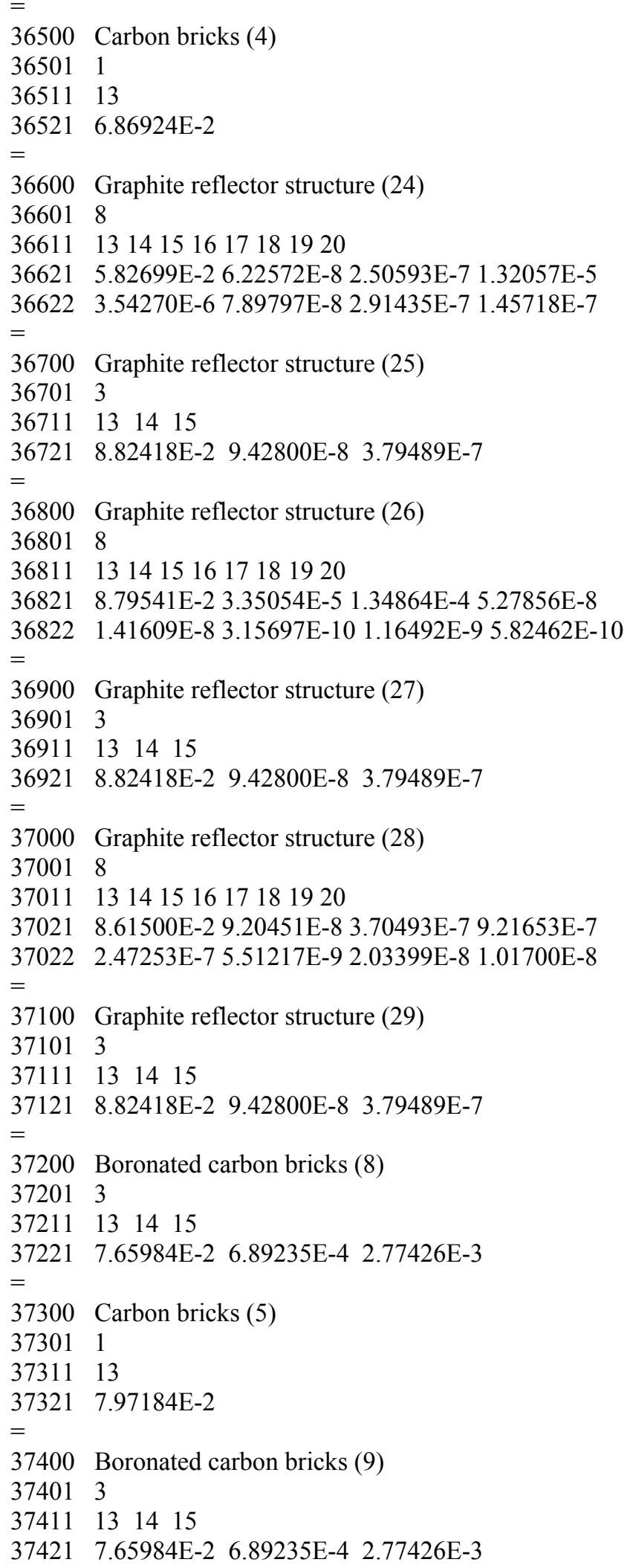




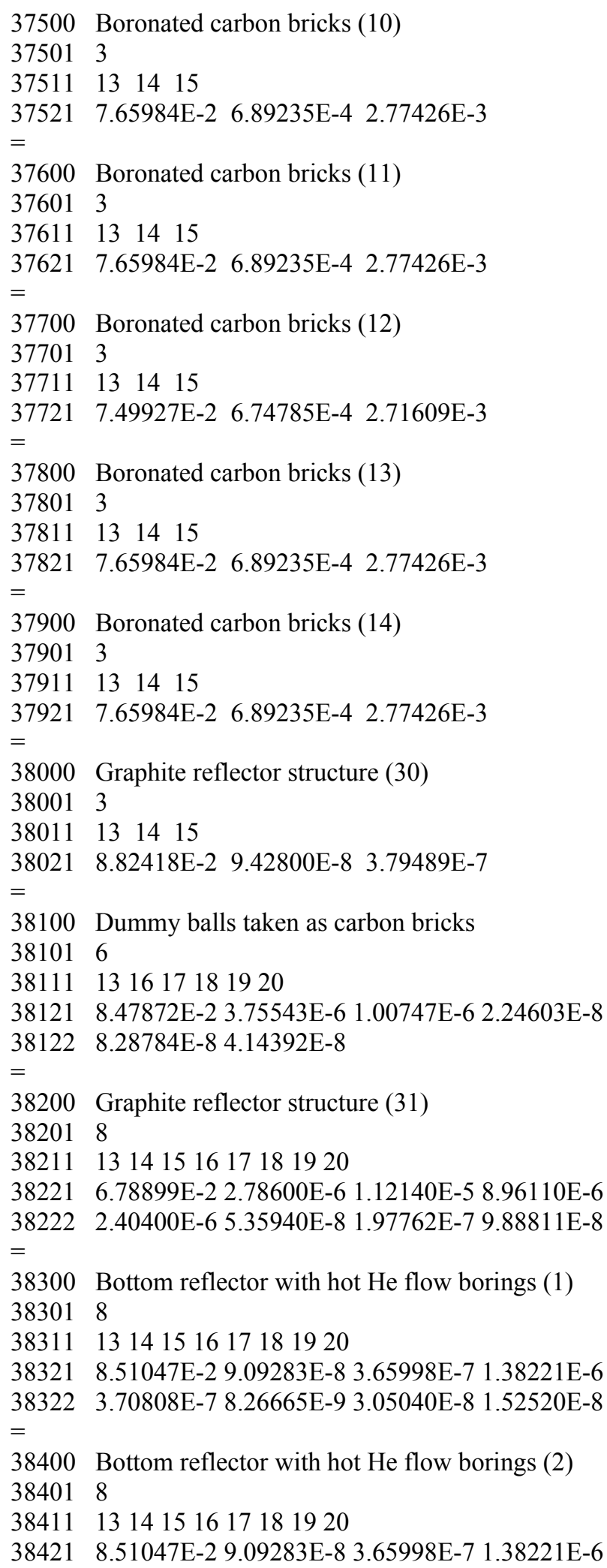


$38422 \quad 3.70808 \mathrm{E}-7$ 8.26665E-9 3.05040E-8 1.52520E-8

$=$

38500 Bottom reflector with hot He flow borings (3)

385018

385111314151617181920

$38521 \quad 8.51047 \mathrm{E}-2$ 9.09283E-8 3.65998E-7 1.38221E-6

38522 3.70808E-7 8.26665E-9 3.05040E-8 1.52520E-8

$=$

38600 Bottom reflector with hot He flow borings (4)

386018

386111314151617181920

38621 8.51047E-2 9.09283E-8 3.65998E-7 1.38221E-6

38622 3.70808E-7 8.26665E-9 3.05040E-8 1.52520E-8

$=$

38700 Bottom reflector with hot He flow borings (5)

387018

387111314151617181920

$38721 \quad 8.51047 \mathrm{E}-2$ 9.09283E-8 3.65998E-7 1.38221E-6

$38722 \quad 3.70808 \mathrm{E}-7$ 8.26665E-9 3.05040E-8 1.52520E-8

$=$

38800 Bottom reflector with hot He flow borings (6)

388018

388111314151617181920

$38821 \quad 8.51047 \mathrm{E}-2$ 9.09283E-8 3.65998E-7 1.38221E-6

$38822 \quad 3.70808 \mathrm{E}-7$ 8.26665E-9 3.05040E-8 1.52520E-8

$=$

38900 Bottom reflector with hot He flow borings (7)

389018

$38911 \quad 1314151617181920$

$38921 \quad 8.51047 \mathrm{E}-2$ 9.09283E-8 3.65998E-7 1.38221E-6

38922 3.70808E-7 8.26665E-9 3.05040E-8 1.52520E-8

$=$

39000 Bottom reflector with hot He flow borings (8)

390018

390111314151617181920

39021 8.51047E-2 9.09283E-8 3.65998E-7 1.38221E-6

$39022 \quad 3.70808 \mathrm{E}-7$ 8.26665E-9 3.05040E-8 1.52520E-8

$=$

39100 Dummy balls simplified (3)

391018

$39111 \quad 1314151617181920$

$39121 \quad 5.72501 \mathrm{E}-2$ 6.14369E-9 2.47292E-8 1.51630E-5

$391224.06779 \mathrm{E}-6$ 9.06859E-8 3.34631E-7 1.67316E-7

$=$

39200 Dummy balls simplified (4)

392018

$39211 \quad 1314151617181920$

$39221 \quad 5.72501 \mathrm{E}-2$ 6.14369E-9 2.47292E-8 1.51630E-5

39222 4.06779E-6 9.06859E-8 3.34631E-7 1.67316E-7

$=$

39300 Dummy balls simplified (5)

393018

393111314151617181920 
$39321 \quad 5.72501 \mathrm{E}-2$ 6.14369E-9 2.47292E-8 1.51630E-5

39322 4.06779E-6 9.06859E-8 3.34631E-7 1.67316E-7

$=$

39400 Dummy balls simplified (6)

394018

394111314151617181920

$39421 \quad 5.72501 \mathrm{E}-2$ 6.14369E-9 2.47292E-8 1.51630E-5

39422 4.06779E-6 9.06859E-8 3.34631E-7 1.67316E-7

$=$

39500 Dummy balls simplified (7)

395018

$39511 \quad 1314151617181920$

$39521 \quad 5.72501 \mathrm{E}-2$ 6.14369E-9 2.47292E-8 1.51630E-5

39522 4.06779E-6 9.06859E-8 3.34631E-7 1.67316E-7

$=$

39600 Dummy balls simplified (8)

396018

396111314151617181920

$39621 \quad 5.72501 \mathrm{E}-2$ 6.14369E-9 2.47292E-8 1.51630E-5

39622 4.06779E-6 9.06859E-8 3.34631E-7 1.67316E-7

$=$

39700 Dummy balls simplified (9)

397018

397111314151617181920

$39721 \quad 5.72501 \mathrm{E}-2$ 6.14369E-9 2.47292E-8 1.51630E-5

39722 4.06779E-6 9.06859E-8 3.34631E-7 1.67316E-7

$=$

39800 Dummy balls simplified (10)

398018

398111314151617181920

$39821 \quad 5.72501 \mathrm{E}-2$ 6.14369E-9 2.47292E-8 1.51630E-5

39822 4.06779E-6 9.06859E-8 3.34631E-7 1.67316E-7

$=$

39900 Mixture balls

3990112

$\begin{array}{lllllllll}39911 & 1 & 2 & 3 & 4 & 5 & 6 & 7 & 8\end{array}$

399129101112

$399216.69520 \mathrm{E}-6$ 3.22755E-5 7.79414E-5 8.51054E-5

$39922 \quad 5.40964 \mathrm{E}-2$ 9.92089E-9 3.99328E-8 1.55875E-5

39923 4.09021E-6 9.11929E-8 3.34631E-7 1.67316E-7 


\section{APPENDIX B \\ CALCULATION OF BASE-CASE ATOMIC NUMBER DENSITIES IN THE CORE REGION}

This appendix presents the calculation of the atomic number densities for Region 99 in the PEBBED model, which is the core region, where the mixture of fuel and dummy balls is located.

First, some data from Table 3 are repeated:

Fuel enrichment $=17 \%$ by weight

Core unit cell volume $=185.405 \mathrm{~cm}^{3}$

Kernel density $=10.4 \mathrm{~g} / \mathrm{cm}^{3}$

Buffer layer density $=1.1 \mathrm{~g} / \mathrm{cm}^{3}$

IPyC density $=1.9 \mathrm{~g} / \mathrm{cm}^{3}$

$\mathrm{SiC}$ density $=3.18 \mathrm{~g} / \mathrm{cm}^{3}$

OPyC density $=1.9 \mathrm{~g} / \mathrm{cm}^{3}$

Fuel matrix density $=1.73 \mathrm{~g} / \mathrm{cm}^{3}$

Dummy matrix density $=1.84 \mathrm{~g} / \mathrm{cm}^{3}$

Pebble packing fraction $=61 \%$

Fuel loading per fuel pebble $=5 \mathrm{~g} \mathrm{U}$

Number of kernels in a fuel pebble $=8335$

Ratio of fuel pebbles to dummy pebbles: 57:43

Boron concentration in kernel (by weight) $=4 \mathrm{ppm}$

Boron concentration in fuel matrix (by weight) $=1.3 \mathrm{ppm}$

Boron concentration in dummy-ball matrix (by weight) $=0.125 \mathrm{ppm}$

Kernel radius $=0.025 \mathrm{~cm}$

Buffer layer thickness $=0.009 \mathrm{~cm}$

IPyC layer thickness $=0.004 \mathrm{~cm}$

$\mathrm{SiC}$ layer thickness $=0.0035 \mathrm{~cm}$

OPyC layer thickness $=0.004 \mathrm{~cm}$

The weights of one gram-mole of the nuclides and elements used in the calculations are taken from the Chart of the Nuclides. ${ }^{\text {B1 }}$

\section{B.1 Nuclides in kernel}

The uranium is $17 \% \mathrm{U}-235$ by weight. Ignore all isotopes except U-235 and U-238. Let $\tilde{N}_{235}$ and $\tilde{N}_{238}$ be the atom fractions of U-235 and U-238, respectively, $A_{235}$ and $A_{238}$ be the 
molecular weights of U-235 and U-238, respectively, and $\bar{A}$ be the average molecular weight of the mixture of the two isotopes. Then

$0.17 \bar{A}=\tilde{N}_{235} A_{235}$

and $0.83 \bar{A}=\tilde{N}_{238} A_{238}$,

so that $\frac{0.17 \bar{A}}{0.83 \bar{A}}=\frac{\tilde{N}_{235} A_{235}}{\tilde{N}_{238} A_{238}}=\frac{\tilde{N}_{235} \times 235.043928}{\tilde{N}_{238} \times 238.050788}$,

or $\frac{\tilde{N}_{235}}{\tilde{N}_{238}}=0.207439$.

But $\tilde{N}_{235}+\tilde{N}_{238}=1$. This and the previous equation are solved simultaneously to yield

$\tilde{N}_{235}=0.171801$

and $\tilde{N}_{238}=0.828199$.

The mass of uranium in an average $\mathrm{UO}_{2}$ molecule is

$(0.171801 \times 235.043928+0.828199 \times 238.050788)(\mathrm{g} / \mathrm{mole}) \times 1$ mole $/ 6.022 \times 10^{23}$ molecules $=$ $3.94444 \times 10^{-22} \mathrm{~g}$.

The ratio of fuel balls to dummy balls is 57:43. Thus, the computational cell is defined to contain $57 \%$ of a fuel ball and $43 \%$ of a dummy ball, plus the volume of coolant associated with one ball in the core. The number of $\mathrm{U}$ atoms, or $\mathrm{UO}_{2}$ molecules, in a computational cell is thus

$\left(N_{U}\right)_{\text {cell }}=0.57 \times 5 \mathrm{~g} / 3.94444 \times 10^{-22} \mathrm{~g} /$ molecule $=7.22536 \times 10^{21}$ molecules.

Then the atomic number densities are

$\left(n_{U-235}\right)_{\text {cell }}=0.171801 \times 7.22536 \times 10^{21} \times 10^{-24} / 185.405 \mathrm{a} / \mathrm{b}-\mathrm{cm}=6.69520 \times 10^{-6} \mathrm{a} / \mathrm{b}-\mathrm{cm}$

and, analogously, $\left(n_{U-238}\right)_{\text {cell }}=3.22755 \times 10^{-5} \mathrm{a} / \mathrm{b}-\mathrm{cm}$

and $\left(\bar{n}_{O}\right)_{\text {cell }}^{\text {kernels }}=7.79414 \times 10^{-5} \mathrm{a} / \mathrm{b}-\mathrm{cm}$.

The oxygen in the kernel is given a different material label from the oxygen in the water vapor in the PEBBED and COMBINE inputs because the cross sections are different in different 
materials. Similarly, identical nuclides in the core and reflector are given different labels because their cross sections will be different in the two spectral zones.

The boron concentration in the kernel is $4 \mathrm{ppm}$ by weight of uranium. The mass of the average boron atom is $(10.811 \mathrm{~g} / \mathrm{mole}) / 6.022 \times 10^{23}$ atoms $\left./ \mathrm{mole}\right)=1.79525 \times 10^{-23} \mathrm{~g} /$ atom. Then the ratio of the number of boron atoms to the number of $\mathrm{UO}_{2}$ molecules is

$$
\frac{4 \times 10^{-6} \times 3.94444 \times 10^{-22}}{1.79525 \times 10^{-23}}=8.78861 \times 10^{-5}
$$

and the number of atoms of boron in the computational cell from kernels is

$$
\left(N_{B}\right)_{\text {cell }}^{\text {kernels }}=8.78861 \times 10^{-5}\left(N_{U}\right)_{\text {cell }}=6.35009 \times 10^{17} \text { atoms }
$$

\section{B.2 Nuclides in fuel particle layers}

The number of TRISO particles in the cell is $0.57 \times 8335=4751$. The volume of the buffer layer is $4 \pi\left[(0.025+0.009)^{3}-0.025^{3}\right] / 3 \mathrm{~cm}^{3}=9.91864 \times 10^{-5} \mathrm{~cm}^{3}$, so the total volume of buffer zone in the cell is $4751 \times 9.91864 \times 10^{-5} \mathrm{~cm}^{3}=0.471235 \mathrm{~cm}^{3}$. The density of the buffer zone is $1.1 \mathrm{~g} / \mathrm{cm}^{3}$, and the boron content is $1.3 \mathrm{ppm}$ (by weight).

The masses of the average carbon and boron atoms are $12.011 / 6.022 \times 10^{23} \mathrm{~g}=1.99452 \times 10^{-23} \mathrm{~g}$ and $10.811 / 6.022 \times 10^{23} \mathrm{~g}=1.79525 \times 10^{-23} \mathrm{~g}$, respectively; by number, a boron content of $1.3 \mathrm{ppm}$ by mass is

$$
1.3 \times 10^{-6} \times 12.011 / 10.811=1.44430 \times 10^{-6} \text {. }
$$

Then $\left(n_{C}\right)_{\text {buffer }}=1.1 \mathrm{~g} / \mathrm{cm}^{3} /\left(1.99452 \times 10^{-23}+1.4443 \times 10^{-6} \times 1.79525 \times 10^{-23}\right) \mathrm{g}=5.51510 \times 10^{22}$ atoms $/ \mathrm{cm}^{3}$

and the total number of $\mathrm{C}$ atoms in the cell from buffer zones is

$$
\left(N_{C}\right)_{\text {cell }}^{\text {buffer }}=5.51510 \times 10^{22} \text { atoms } / \mathrm{cm}^{3} \times 0.471235 \mathrm{~cm}^{3}=2.59891 \times 10^{22} \text { atoms } .
$$

It is assumed that the graphite in the carbon layers of the TRISO particle have the same boron concentration as the graphite fuel matrix. This assumption can only affect the boron content of the computational cell slightly. The number of boron atoms in the cell from buffer zones is

$$
\left(N_{B}\right)_{\text {cell }}^{\text {buffer }}=1.4443 \times 10^{-6} \times 2.59891 \times 10^{22} \text { atoms }=3.75361 \times 10^{16} \text { atoms }
$$

In similar fashion, the carbon, silicon, and boron contents of the remaining zones are found. The 
silicon carbide layer is assumed to contain no boron.

$$
\begin{aligned}
& \left(N_{C}\right)_{\text {cell }}^{I P y C}=2.95135 \times 10^{22} \text { atoms } \\
& \left(N_{B}\right)_{\text {cell }}^{I P y C}=4.26264 \times 10^{16} \text { atoms } \\
& \left(N_{C}\right)_{\text {cell }}^{S i C}=1.57790 \times 10^{22} \text { atoms } \\
& \left(N_{S i}\right)_{\text {cell }}^{S i C}=1.57790 \times 10^{22} \text { atoms } \\
& \left(N_{C}\right)_{\text {cell }}^{\text {OPyC }}=4.30778 \times 10^{22} \text { atoms } \\
& \left(N_{B}\right)_{\text {cell }}^{\text {OPyC }}=6.22173 \times 10^{16} \text { atoms }
\end{aligned}
$$

\section{B.3 Nuclides in fuel matrix and dummy-ball matrix}

The total volume of TRISO particles in the cell is $4751 \times 4 \pi(0.0455 \mathrm{~cm})^{3} / 3=1.87460 \mathrm{~cm}^{3}$. The volume of one pebble is $4 \pi(3 \mathrm{~cm})^{3} / 3=113.097 \mathrm{~cm}^{3}$, of which in the computational cell $57 \%$ is fuel pebble and $43 \%$ is dummy pebble. Then the volume of fuel matrix in the cell is $0.57 \times 113.097 \mathrm{~cm}^{3}-1.87460 \mathrm{~cm}^{3}=62.5907 \mathrm{~cm}^{3}$, and the volume of dummy matrix in the cell is $0.43 \times 113.097 \mathrm{~cm}^{3}=48.6317 \mathrm{~cm}^{3}$. From the given densities of the graphite matrix in the fuel and dummy balls, $1.73 \mathrm{~g} / \mathrm{cm}^{3}$ and $1.84 \mathrm{~g} / \mathrm{cm}^{3}$, respectively, and the mass of the average carbon atom, it is found that the atomic number densities of carbon in the fuel and dummy matrix materials are $8.67377 \times 10^{22}$ atoms $/ \mathrm{cm}^{3}$ and $9.22528 \times 10^{22}$ atoms $/ \mathrm{cm}^{3}$, respectively. Then the carbon atomic number densities are

$$
\left(N_{C}\right)_{\text {cell }}^{\text {fuel matrix }}=5.42897 \times 10^{24} \text { atoms }
$$

and

$$
\left(N_{C}\right)_{\text {cell }}^{\text {dummymatrix }}=4.48641 \times 10^{24} \text { atoms } .
$$

In the fuel matrix the boron concentration is $1.3 \mathrm{ppm}$, but in the dummy matrix it is $0.125 \mathrm{ppm}$ by weight, which is equivalent to $0.138875 \mathrm{ppm}$ by number. These proportions give the boron content of the matrix materials:

$$
\left(N_{B}\right)_{\text {cell }}^{\text {fuel matrix }}=7.84269 \times 10^{18} \text { atoms }
$$

and 
$\left(N_{B}\right)_{\text {cell }}^{\text {dummymatrix }}=6.23050 \times 10^{17}$ atoms .

\section{B.4 Total carbon and boron number densities}

When all the contributions to the carbon and boron contents of the cell are summed and divided by the cell volume, and the result is converted to $\mathrm{a} / \mathrm{b}-\mathrm{cm}$, the resulting densities are

$\left(\bar{n}_{C}\right)_{\text {cell }}=5.40964 \times 10^{-2} \mathrm{a} / \mathrm{b}-\mathrm{cm}$

$\left(\bar{n}_{B-10}\right)_{\text {cell }}=9.92089 \times 10^{-9} \mathrm{a} / \mathrm{b}-\mathrm{cm}$

and

$\left(\bar{n}_{B-11}\right)_{\text {cell }}=3.99328 \times 10^{-8} \mathrm{a} / \mathrm{b}-\mathrm{cm}$.

\section{B.5 Nuclides in air}

The densities of the gaseous constituents are found from the specified conditions and the assumption that the air is saturated with water vapor. At $15^{\circ} \mathrm{C}(288.15 \mathrm{~K})$, at a relative humidity of $100 \%$ the water vapor density is ${ }^{\mathrm{B} 2} 1.28343 \times 10^{-5} \mathrm{~g} / \mathrm{cm}^{3}$ and the vapor pressure is $1.70507 \times 10^{-3}$ $\mathrm{MPa}$. (Reference B2 gives data in British units; $15^{\circ} \mathrm{C}=59{ }^{\circ} \mathrm{F}$, at which the saturation pressure is $0.2473 \mathrm{lbf} / \mathrm{in}^{2}$ (psi) and the saturated vapor specific volume is $1248.1 \mathrm{ft}^{3} / \mathrm{lbm}$. The conversion factors used to obtain metric units are ${ }^{\mathrm{B} 3} 6894.7572 \mathrm{~N} / \mathrm{m}^{2}-$ psi and $16.018463 \mathrm{~kg}-\mathrm{ft}^{3} / \mathrm{lbm}-\mathrm{m}^{3}$ ) At this mass density, the number density of water vapor molecules is found to be $4.29014 \times 10^{17}$ molecules $/ \mathrm{cm}^{3}$, and the average number densities of hydrogen and oxygen from vapor in the cell are

$\left(\bar{n}_{H}\right)_{\text {cell }}=3.34631 \times 10^{-7} \mathrm{a} / \mathrm{b}-\mathrm{cm}$

and

$\left(\bar{n}_{O}\right)_{\text {cell }}^{\text {vapor }}=1.67316 \times 10^{-7} \mathrm{a} / \mathrm{b}-\mathrm{cm}$.

The pressure of the dry air is then $0.1013 \mathrm{MPa}-1.70507 \times 10^{-3} \mathrm{MPa}=9.95949 \times 10^{-2} \mathrm{MPa}$. The ideal gas law (with $\mathrm{R}=8.314 \mathrm{~Pa}-\mathrm{m}^{3} / \mathrm{mole}^{\mathrm{K}} \mathrm{K}$ ) ${ }^{\mathrm{B} 4}$ then gives a molecular density of $2.50351 \times 10^{19}$ molecules $/ \mathrm{cm}^{3}$. The proportions given in subsection 3.1.3 lead to the following atomic densities:

$\left(\bar{n}_{N}\right)_{\text {cell }}=1.55875 \times 10^{-5} \mathrm{a} / \mathrm{b}-\mathrm{cm}$ 
CRIT

$$
\begin{aligned}
& \left(\bar{n}_{O}\right)_{\text {cell }}^{\text {air }}=4.09021 \times 10^{-6} \mathrm{a} / \mathrm{b}-\mathrm{cm} \\
& \left(\bar{n}_{A r}\right)_{\text {cell }}=9.11929 \times 10^{-8} \mathrm{a} / \mathrm{b}-\mathrm{cm}
\end{aligned}
$$

\section{REFERENCES FOR APPENDIX B}

B1. Chart of the Nuclides, Thirteenth Edition, General Electric Company, 1984.

B2. Joseph H. Keenan and Frederick G. Keyes, Thermodynamic Properties of Steam, Wiley, New York, Thirty-fifth Printing, 1963.

B3. Donald R. Pitts and Leighton E. Sissom, Heat Transfer, Schaum's Outline Series in Engineering, McGraw-Hill, New York, 1977.

B4. Samuel Glasstone and Alexander Sesonske, Nuclear Reactor Engineering, Third Edition, Van Nostrand Reinhold, New York, 1981. 
CRIT

\section{APPENDIX C}

\section{NUCLEAR CONSTANTS}

atoms

Avogadro's Number $6.022 \times 10^{23} \overline{\text { gram }- \text { mole }}$

TABLE C1. Atomic Weights.

H 1.00794

Nuclide or Isotope

Atomic Weight

Li 6.941

B 10.811

B 10.0129

${ }^{11} \mathrm{~B} 11.0093$

C 12.011

O 15.9994

Si 28.0855

${ }^{235} \mathrm{U} 235.043928$

U 238.050788

2 "Chart of the Nuclides," Thirteenth Edition, General Electric Company, 1984. 